\title{
ATILA CSOBI
}

\section{AMORTECIMENTO SUPERFICIAL NOS SISTEMAS DE MICRO- DRENAGEM EM REGIÕES DE BAIXA DECLIVIDADE}

\author{
Dissertação apresentada à Escola Politécnica da \\ Universidade de São Paulo como pré-requisito \\ para obtenção do título de Mestre em Engenharia
}

São Paulo 


\title{
ATILA CSOBI
}

\section{AMORTECIMENTO SUPERFICIAL NOS SISTEMAS DE MICRO- DRENAGEM EM REGIÕES DE BAIXA DECLIVIDADE}

\author{
Dissertação apresentada à Escola Politécnica da \\ Universidade de São Paulo como pré-requisito \\ para obtenção do título de Mestre em Engenharia
}

Área de Concentração:

Engenharia Hidráulica e Sanitária

Orientador: Prof. Dr. José Rodolfo Scarati Martins

\section{São Paulo}





\section{Este exemplar foi revisado e alterado em relação à versão original, sob responsabilidade única do autor e com a anuência de seu orientador.}

São Paulo, de maio de 2011.

Assinatura do autor

Assinatura do orientador

\section{FICHA CATALOGRÁFICA}

\section{Csobi, Atila}

Amortecimento superficial nos sistemas de micro-drenagem / A. Csobi. -- ed.rev. -- São Paulo, 2011.

$154 \mathrm{p}$.

Dissertação (Mestrado) - Escola Politécnica da Universidade de São Paulo. Departamento de Engenharia Hidráulica e Sanitária.

1. Micro-drenagem 2. Escoamento superficial 3. Drenagem urbana I. Universidade de São Paulo. Escola Politécnica. Departamento de Engenharia Hidráulica e Sanitária II. t. 
A meu pai que me ensinou que conhecimento não tem preço. A minha que mãe que sempre me incentivou em todos os objetivos de minha vida. 


\section{AGRADECIMENTOS}

Ao Prof. Rodolfo por todos os conhecimentos transmitidos antes e durante a elaboração desta dissertação.

A Secretaria de Obras Públicas da Prefeitura da Estância Balneária de Praia Grande que possibilitou a mim a oportunidade de elaborar este estudo.

A todos os amigos que me incentivaram nesta etapa de minha vida.

A todos os que de certa forma colaboraram com a elaboração deste trabalho. 
"A mente que se abre a uma nova idéia jamais voltará ao seu tamanho original"

Albert Einstein 


\section{RESUMO}

O presente trabalho desenvolve uma proposta para a avaliação da redução da vazão de pico do hidrograma do método racional, no contexto de bacias hidrográficas topograficamente planas. Entendem-se como planas aquelas localidades, cujas declividades médias características e/ou projetadas são inferiores a 0,5\%. Pretende-se também neste trabalho apresentar metodologias e práticas de projeto de drenagem usualmente adotadas em regiões de características topográficas semelhantes.

No desenvolvimento do estudo, foram discutidas as bases teóricas do Método Racional e outros métodos de avaliação hidrológica que procuram levar em conta o amortecimento da vazão durante o seu escoamento sobre o leito das vias. Apresentamse também as bases científicas para a criação de um modelo hidrodinâmico a ser usado no estudo para a determinação do fator de redução da vazão de pico do hidrograma racional. A capacidade de escoamento em vias urbanas é então discutida, de forma a se justificar as relações criadas como conclusão do trabalho.

O resultado final apresentado é o estabelecimento de uma relação entre a variação do pico da vazão do Método Racional, com a capacidade de armazenamento ou amortecimento de cheias existente nessas vias. Relações estas que, para fins práticos, significam tanto o incremento positivo no período de retorno do projeto, quanto a redução da vazão para efeito de dimensionamento de galerias. Tais resultados são demonstrados de forma prática por meio do estudo de caso no município de Praia Grande, o litoral sul paulista.

Palavras-chave: drenagem urbana, redução de pico de vazão, escoamento superficial, declividade longitudinal, regiões planas. 


\begin{abstract}
This work presents a proposal for estimating the reduction of the Peak Flow Rate determined by the Rational Method, considering flat basins as a main characteristic. It is considered flat, all of those basins in which the average slope on the streets are smaller than $0,5 \%$. It is also intentions of this work discuss methods and practices adopted to flat areas as urban drainage solutions and best management practices.

Within this work, we also present all the theoretical basis of the Rational Method, among others, that try to fuse the street storm water storage capacity whit the conveyance capacity of a usual street. It is also presented theoretical basis of hydrodynamic models to be used as the main tool to determine de peak flow reduction factor of the Rational Method Hydrogram. Conveyance capacity of a usual street is discussed, street storm water conveyance capacity is also discussed in order to justify the relations proposed as a conclusion of this work.
\end{abstract}

As a result of this work it is established a relationship between the Peak flow rate determined by the Rational Method and the street storm water storage capacity. In addition, this peak reduction can be used as a positive increment on the Recurrence Interval or as flow rate reduction when designing the sewerage system, which means implementation costs reduction. An application to the city of Praia Grande, located the Sao Paulo State, is presented and used as a case of study.

Key-words: urban drainage, peak flow rate reduction, run-off flow, longitudinal slope, flat areas. 


\section{SUMÁRIO}

1 INTRODUÇÃO.

1

2 OBJETIVO GERAL 4

2.1 OBJETIVOS ESPECÍFICOS 4

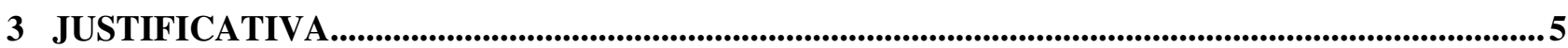

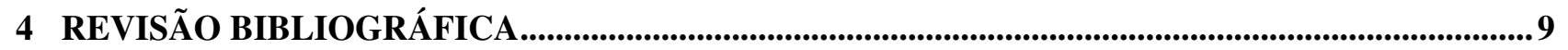

4.1 ESTUDO DAS REDES DE ESCOAMENTO SUPERFICIAL …...................................................

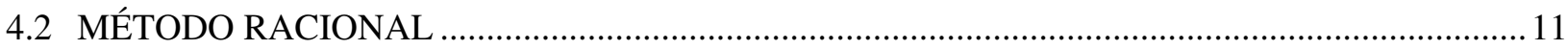

4.2.1 HIPÓTESES SIMPLIFICADORAS DO MÉTODO RACIONAL 25

4.3 MÉTODOS QUE LEVAM EM CONTA A CAPACIDADE DE ARMAZENAMENTO DO

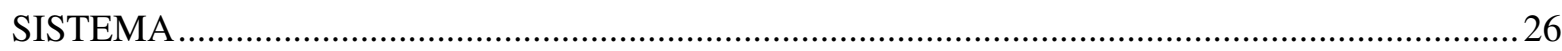

4.3.1 ESCOAMENTO NAS RUAS E SARJETAS 40

4.4 ASPECTOS TEÓRICOS DO ESCOAMENTO LIVRE.......................................................................51

4.4.1 ESCOAMENTO LIVRE E SUAS CARACTERÍSTICAS

4.4.2 A EQUAÇAO DE MANNING 58

4.5 MODELOS HIDRODINÂMICOS DE ESCOAMENTO LIVRE .................................................... 60

4.5.1 EQUAÇÕES FUNDAMENTAIS DO ESCOAMENTO NÃO-PERMANENTE

4.5.2 CLASSIFICAÇÃO DOS MODELOS DE PROPAGAÇÃO DO ESCOAMENTO 62

4.5.3 FUNDAMENTOS TEÓRICOS DOS MODELOS HIDRODINÂMICOS COMPLETOS 63

4.6 EXPERIÊNCIAS E CRITÉRIOS DE PROJETO EM REGIÕES PLANAS ...................................... 71

4.6.1 O CONCEITO DO ARMAZENAMENTO NAS RUAS 85

4.6.2 ELEMENTOS CONSTRUTIVOS DO SISTEMA 90 


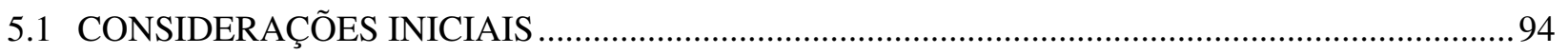

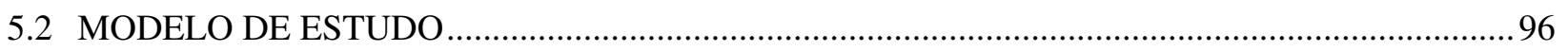

5.2.1 REGIME DE ESCOAMENTO NAS SEÇÕES DAS VIAS 103

5.2.2 EQUAÇÃO PROPOSTA PARA O MODELO DE AVALIAÇÃO DE ESCOAMENTO 108

5.2.3 PARAMETROS INTERVENIENTES 110

5.3 SIMULAÇÕES DE ESCOAMENTO - APLICAÇÃO DO MODELO ……................................... 112

5.3.1 RESULTADOS OBTIDOS 116

5.3.2 EQUACIONAMENTO OBTIDO 123

5.3.3 EXEMPLO DEMONSTRATIVO 124

5.3.4 VERIFICAÇÃO DO EFEITO DE SOBREPOSIÇÃO DE EVENTOS DE CHUVA 129

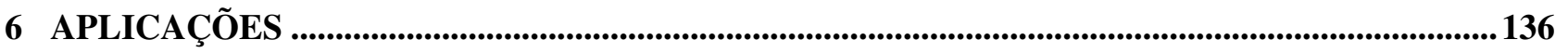

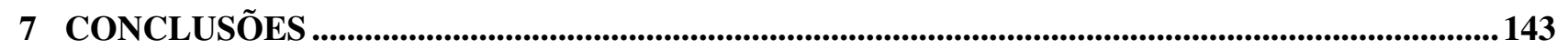

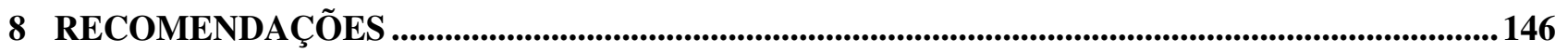

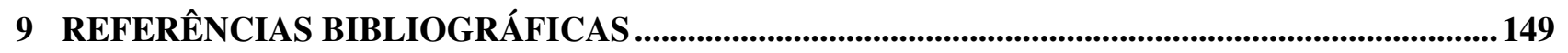




\section{LISTA DE FIGURAS}

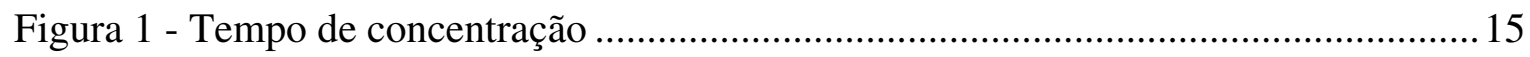

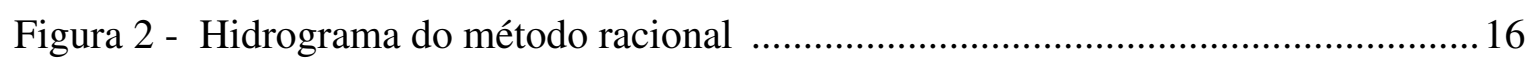

Figura 3 - Hidrograma do método racional para uma chuva de duração qualquer

Figura 4: Cunha de amortecimento do método de Muskingum ......................................2 29

Figura 5: Normograma de dimensionamento de seções triangulares de Izzard .................. 31

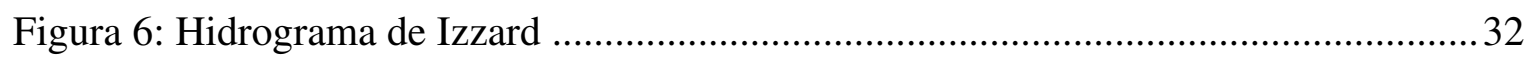

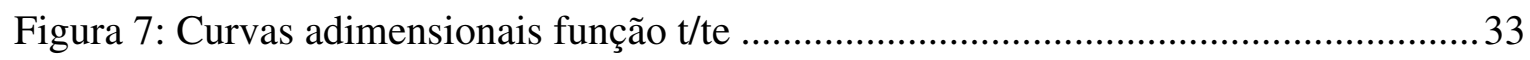

Figura 8: Alturas de água ao longo da sarjeta de 60 metros ............................................ 37

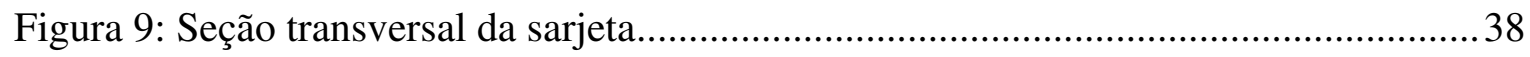

Figura 10: Comportamento típico do escoamento superficial numa seção de via urbana. 41

Figura 11: Geometria de uma sarjeta típica................................................................... 45

Figura 12: Fator de redução de vazão na sarjeta em função da declividade longitudinal .48

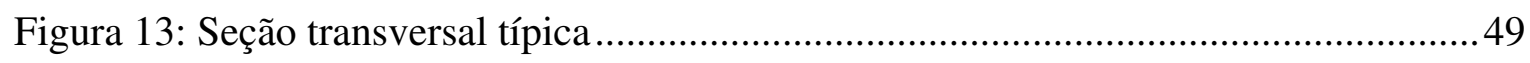

Figura 14: Geometria de sarjeta e leito carroçável - seção composta............................... 49

Figura 15: Vários tipos de canais abertos com a representação de diferentes escoamentos

Figura 16: Escoamento Laminar, transição e turbulento. Visualização com corante em

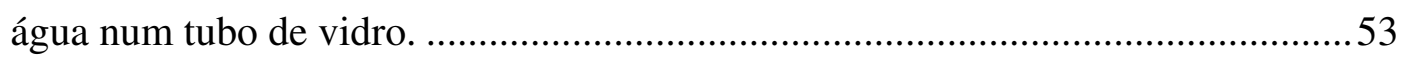

Figura 17: Relação f-Re para canais de seção retangular e triangular ...............................56

Figura 18: Configuração do plano de discretização de Preissmann ...................................66

Figura 19: Canal e áreas de várzea e sua discretização ......................................................67

Figura 20: Situação antes da ação antrópica .................................................................. 74

Figura 21: Situações após a ação antrópica ……........................................................... 75

Figura 22: Planta esquemática da solução adotada ....................................................... 82

Figura 23: Seção transversal típica do sistema de drenagem local.................................... 83

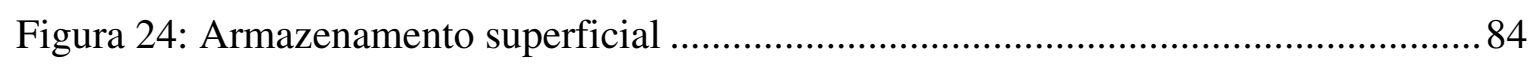

Figura 25: Rua típica do distrito de Skokie ……........................................................ 85

Figura 26: Discretização das seções transversais típicas de Skokie .................................... 86 
Figura 27: Discretização da rua Easy, para avaliação preliminar

Figura 28: Vazão x Lâmina d'água da seção em estudo em pés x cfs

Figura 29: Delimitação da bacia de contribuição do trecho da rua em estudo ..................... 88

Figura 30: Curva Profundidade x Volume Armazenado ................................................. 89

Figura 31: Alagamento descontrolado nas vias ............................................................

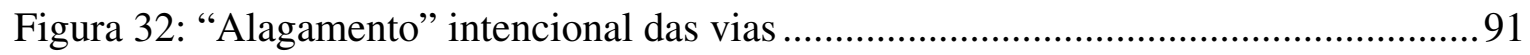

Figura 33: Posicionamento de bermas para controle de alagamento e armazenamento na via 92

Figura 34: Imagem das vias servindo como áreas de armazenamento 92

Figura 35: Imagem e esquema das grandes seções pré-moldadas que servirão como reservatórios de amortecimento de vazão

Figura 36: Perfil longitudinal típica em ruas de planícies urbanas, com a imposição de declividade mínima. 95

Figura 37: Gradiente de Vazão 97

Figura 38: Seção Transversal da sarjeta considerada no modelo 100

Figura 39: Diversas seções características consideradas, mantidas as inclinações transversais 100

Figura 40: Tela de lançamento de seções transversais do software HEC-RAS ................ 101

Figura 41: Gráfico da relação altura da Lâmina d'água x Vazão ....................................... 102

Figura 42: Gráfico relacionando Re e o fator de atrito f .................................................. 106

Figura 43: Comportamento de fator de atrito f para a declividade $0,0005 \mathrm{~m} / \mathrm{m}$ com a transição de regime 107

Figura 44: Gráfico Vazão de entrada e vazão de saída amortecida. 109

Figura 45: Tela do software HEC-RAS, para edição de seções transversais .................... 113

Figura 46: Discretização de seções ao longo da extensão da rua estudada ....................... 114

Figura 47: Entrada de dados, hidrograma de montante nulo ............................................ 114

Figura 48: Entrada de dados, declividade de fundo para determinação da altura normal 115 Figura 49: Hidrograma de Qo, a ser distribuído uniformemente ao longo do trecho....... 115 Figura 50: Tela do software para definição do passo de tempo de cálculo

Figura 51: Superfície de alagamento máxima resultante da simulação com HEC-RAS, para declividade $0,0015 \mathrm{~m} / \mathrm{m}$ e vazão de $0,25 \mathrm{~m}^{3} / \mathrm{s}$

Figura 52: Relação entre Amortecimento calculado e Adimensional proposto 118

Figura 53: Curva de amortecimento em função do adimensional proposto para diferentes durações de precipitação 
Figura 54: Relação proposta para o amortecimento em função do parâmetro adimensional

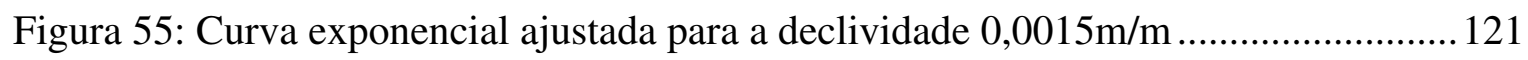

Figura 56: Curva ajustada para o Fator Multiplicador Y ............................................... 122

Figura 57: Curva ajustada para o Expoente X ............................................................. 123

Figura 58: Gráfico obtido pelo processamento dos dados no HEC-RAS......................... 128

Figura 59: Discretização de lâmina de água pré-existente .............................................. 130

Figura 60: Gráfico com o comportamento exponencial do fator de correção ................... 133

Figura 61: Gráfico com todas as simulações propostas indicando o comportamento

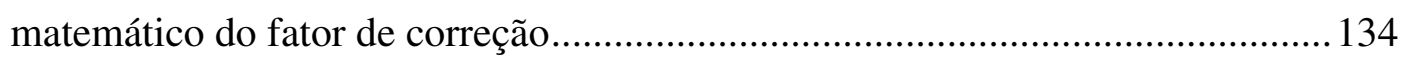

Figura 62: Gráfico com a curva teórica do fator de correção do amortecimento .............. 135

Figura 63:Indicação dos sistemas de emergência e normal ............................................ 137

Figura 64: Curva envoltória da tendência de amortecimento de vazão da rua modelo.... 138

Figura 65: Trecho do Bairro Mirim com indicação das bacias de contribuição................ 139

Figura 66: Indicação das sub-bacias das ruas objeto do estudo ....................................... 140

Figura 67: Curva característica do fator de amortecimento para a seção do modelo........ 143 


\section{LISTA DE TABELAS}

Tabela 1- Metodologias de Cálculo em função das áreas de bacias.................................... 11

Tabela 2- Tempo de recorrência em função do tipo de obra .............................................. 14

Tabela 3 - Tempo de recorrência em função do tipo de obra............................................ 15

Tabela 4 - Coeficiente de escoamento em superfícies e calhas rasas ................................. 18

Tabela 5: Coeficientes de rugosidade de Manning .............................................................2

Tabela 6: Coeficiente de escoamento superficial direto ( $T R=10$ anos) adotado pela PMSP

TABELA 7 - Coeficientes de escoamento superficial (C) em função da superfície ...........24

TABELA 8 - Coeficientes de escoamento superficial (C) em função da ocupação ...........24

TABELA 9- Limites do coeficiente de escoamento superficial, (C) ................................25

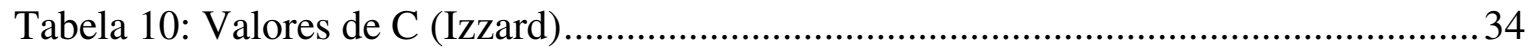

Tabela 11: Faixas de alagamento permitidas .................................................................. 42

Tabela 12: Declividades longitudinais mínimas exigidas ................................................. 44

Tabela 13: Comparação de capacidade de condução - Manning X Izzard ..........................46

Tabela 14: Comparação de capacidade de condução para baixas declividades ..................47

Tabela 15: Fatores de redução de escoamento das sarjetas ................................................48

Tabela 16: Aproximação por diferenças finitas dos termos da equação da continuidade..68

Tabela 17: Aproximação por diferenças finitas dos termos da equação do momento .......68

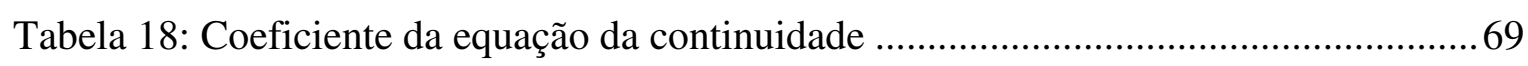

Tabela 19: Coeficientes da equação do momento ......................................................... 70

Tabela 20: Fases do desenvolvimento das águas urbanas ................................................ 72

Tabela 21: Formas de redução e retenção em diferentes áreas urbanas ............................76

Tabela 22: Vantagens e desvantagens no emprego das diferentes formas de redução e

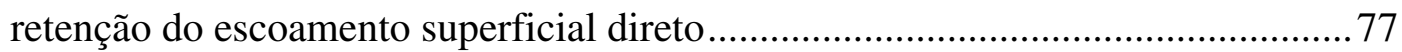

Tabela 23: Volume precipitado acumulado - EASY STREET ........................................ 89

Tabela 24: Intensidade e profundidade armazenada para EASY STREET........................90

Tabela 25: Tabela resumo dos cálculos para verificação do Regime de Escoamento ..... 104

Tabela 26: Tabela resumo dos cálculos para verificação do Regime de Escoamento ..... 107

Tabela 27: Tabela vazões de pico, em m³/s, simuladas no modelo .................................112

Tabela 28: Tabela resumo dos índices das equações observadas no modelo .................... 122

Tabela 29: Simulação de sobreposição de eventos para via com $0,0015 \mathrm{~m} / \mathrm{m}$.................. 133 
Tabela 30: Dados hidrológicos da área de aplicação do modelo, Vazão para TR 5 anos:140 Tabela 31: Dados hidrológicos da área de aplicação do modelo, Vazão para TR 10 anos:

Tabela 32: Resultados de amortecimento de vazão nas ruas estudadas - TR 5anos........ 141

Tabela 33: Resultados de amortecimento de vazão nas ruas estudadas - TR 10anos...... 141 


\section{LISTA DE SIGLAS E ABREVIATURAS}

ASCE

ASSHTO

BMP

CETESB

DAEE

DER/SP

EPA

FAA

FCTH

FHWA

HEC

HU

IDF

PMSP

RAS

SCS

USA

US-ARMY
American Society of Civil Engineers

American Association of State Highway and Transportation Officials

Best Management Practice

Companhia de Tecnologia de Saneamento Ambiental

Departamento de Águas e Energia Elétrica

Departamento de Estradas de Rodagem do estado de São Paulo

Environmental Protection Agency

Federal Aviation Agency

Fundação Centro Tecnológico de Hidráulica

Federal Highway Administration

Hydrologic Engineering Center

Hidrograma Unitário

Intensidade- Duração-Freqüência

Prefeitura Municipal de São Paulo

River Analysis System

Soil Conservation Service

Estados Unidos da América

Corpo do Exército dos Estados Unidos da América 


\section{LISTA DE SÍMBOLOS}

SÍMBOLO

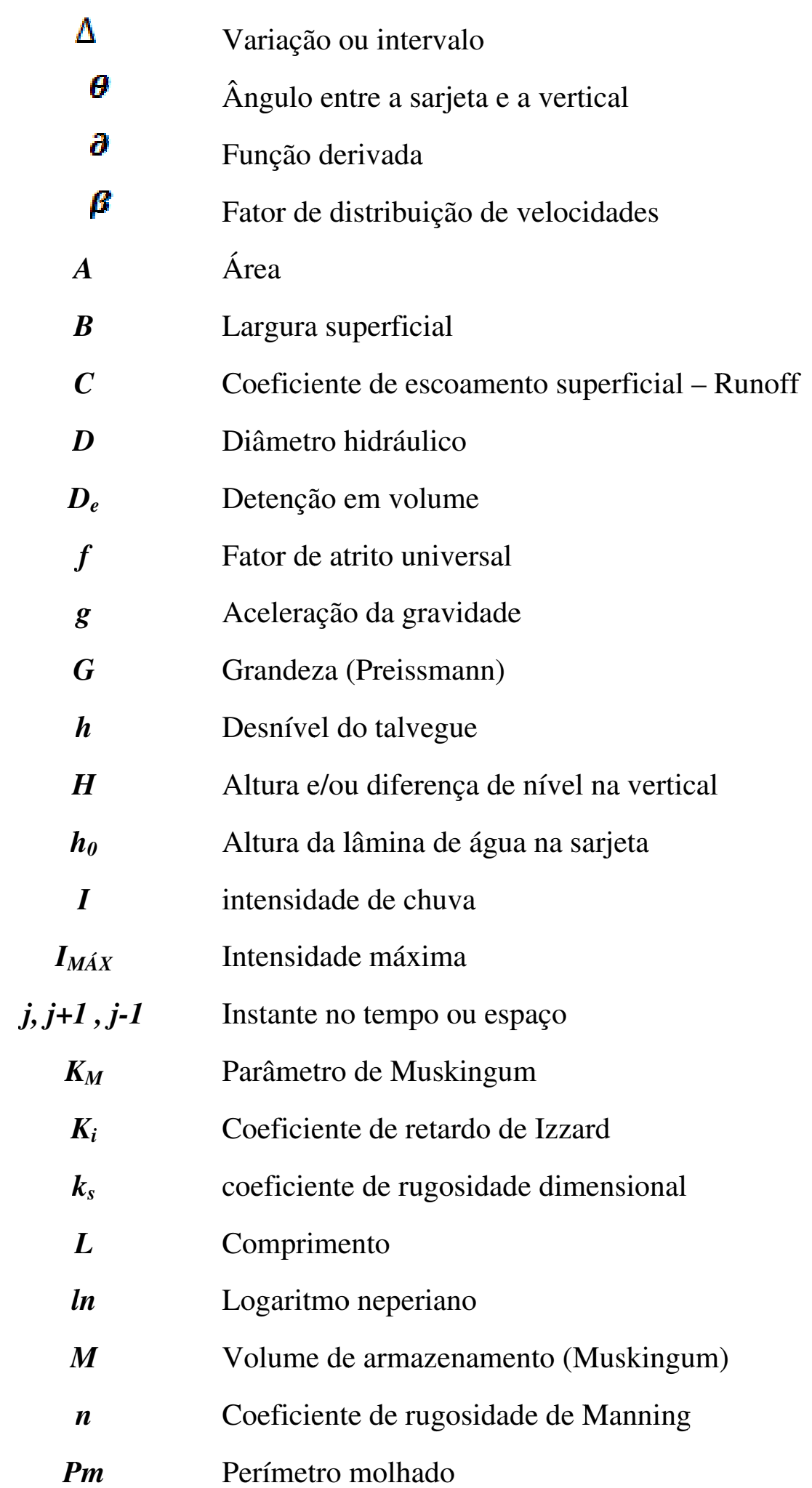




$\begin{array}{ll}\boldsymbol{P r} & \text { Função probabilidade } \\ \boldsymbol{Q} & \text { Vazão } \\ \boldsymbol{Q}_{\boldsymbol{o}} & \text { Vazão de entrada } \\ \boldsymbol{Q}_{\boldsymbol{b}} & \text { Vazão de Base } \\ \boldsymbol{q}_{\boldsymbol{e}} & \text { Vazão de equilíbrio } \\ \boldsymbol{R}_{\boldsymbol{H}} & \text { Raio hidráulico } \\ \boldsymbol{S}_{\boldsymbol{⿰}} & \text { Declividade longitudinal } \\ \boldsymbol{S}_{\boldsymbol{f}} & \text { Declividade da Linha de Energia } \\ \boldsymbol{t} & \text { Tempo } \\ \boldsymbol{t}_{\boldsymbol{c}} & \text { Tempo de concentração } \\ \boldsymbol{t}_{\boldsymbol{d}} & \text { Tempo de duração } \\ \boldsymbol{T} \boldsymbol{R} & \text { Período de retorno ou de recorrência } \\ \boldsymbol{V} & \text { Velocidade } \\ \boldsymbol{V}_{\boldsymbol{o}} & \text { Velocidade de escoamento na sarjeta } \\ \boldsymbol{x} & \text { Parâmetro adimensional de Muskingum } \\ \boldsymbol{x} & \text { Extensão na direção do escoamento } \\ \boldsymbol{y} & \text { Altura da lamina de água } \\ \boldsymbol{z} & \text { Tangente do ângulo de inclinação da sarjeta } \\ \boldsymbol{v} & \text { Viscosidade cinemática do fluido } \\ & \end{array}$




\section{INTRODUÇÃO}

Neste trabalho discutem-se os parâmetros de projeto de drenagem urbana, considerando a peculiaridade de locais, cuja declividade média, muitas vezes não atende aos critérios mínimos de projeto amplamente difundidos no meio acadêmico e técnico, seja através dos manuais ou critérios de projeto. A questão aqui abordada torna-se ainda mais relevante, se tomarmos como parâmetro localidades, como a do estudo de caso aqui tratado, onde as declividades médias de vias urbanas projetadas variam entre $0,30 \%$ e $0,15 \%$ e a comparamos com aqueles citados manuais de projeto de drenagem. Tem-se, por exemplo, o "Hydrologic Criteria and Drainage Design Manual” da cidade de Denver-USA que especifica $0.4 \%$ como declividade mínima longitudinal de vias. Muitas publicações nacionais, também preconizam declividades longitudinais mínimas no projeto das vias urbanas com essa mesma ordem de grandeza.

Poucos são os trabalhos que discutem tecnicamente a questão da falta de declividade superficial mínima, que se faz presente em diversas cidades implantadas em planícies litorâneas. Pretende-se com este trabalho propor um modelo para o aproveitamento dessa característica topográfica, no sentido de se aperfeiçoar e discutir novos critérios de projeto aplicáveis a tais situações.

PALMA (2000) cita que drenar é a arte de conduzir e controlar o fluxo ou percolação de água pelas vias ou obras de terra. Drenar é o próprio ato de prover a via com equipamentos que facilitem o movimento de água para fora de seu corpo, ou facilitem o controle de teor de umidade ou movimento da água infiltrada no solo ou outros componentes. Nas cidades, no entanto, nem sempre as obras de drenagem cumprem esses objetivos de proteger a área urbana com a devida eficiência. Tal fato vem se fazendo muito mais presente com o aumento exagerado da urbanização e a aplicação de técnicas que não primam pela sustentabilidade.

Prejuízos e transtornos causados pelas enchentes são, desde o início da civilização, um dos grandes entraves ao desenvolvimento contínuo da sociedade. Deste modo a consequência das cheias, e em particular, das cheias em ambientes urbanos, tem levado inúmeros pesquisadores a buscar uma solução efetiva para o seu controle. O controle de cheias é entendido como o conjunto de medidas que visa reduzir os seus impactos ou neutralizar as 
conseqüências da ação antrópica que tende em geral a agravar e aumentar a freqüência de tais eventos.

Quando se fala em sustentabilidade em drenagem urbana, fala-se de medidas que busquem o equilíbrio entre o desenvolvimento e o meio ambiente. No entanto, as soluções de drenagem, de modo geral buscam a solução pontual em ênfase na economia no processo construtivo.

A avaliação do escoamento e o dimensionamento de elementos que o garantam, constituem as principais medidas de proteção e controle de enchentes. A escolha desses elementos e os critérios de dimensionamento dos mesmos é que se baseiam no equilíbrio entre o custo de construção e a grandeza dos prejuízos causados pelas enchentes. Os custos de construção, de maneira geral sempre têm maior ênfase nessa decisão.

Esta visão, em países mais desenvolvidos, vem mudando, pouco a pouco, no sentido de propiciar soluções ambientais globais. Existem várias soluções técnicas para o controle de cheias urbanas. Estas podem ser do tipo estrutural ou não-estrutural. Dentre as estruturais, que são as aquelas diretamente relacionadas ao problema na forma de obras, podem ser citados os reservatórios ou bacias de detenção, a retificação e canalização de rios, a construção de diques e polders. Com a evolução do conceito de sustentabilidade, mais e mais se pensa nas soluções de controle direto na fonte, no intuito de reduzir os picos de vazão, numa forma de reverter os impactos gerados pela urbanização, notadamente a impermeabilização.

$\mathrm{O}$ princípio higienista vigente até o final do século XX que direcionava a ações estruturais dimensionadas com o preceito básico de "drenar o mais rápido possível", o que se nota é que tal política não se sustenta em longo. O que ocorre na realidade é a realocação do problema para outro ponto mais "a jusante" daquele inicial, já que a água precipitada irá concentrar-se naquele ponto em menor tempo do que o faria caso não houvesse nenhuma intervenção inicial. Para TUCCI (2008), o princípio usado de drenar a água o mais rápido possível é errado. STUART G. WALESH e CAROLYN SPOSYTO (2004) em seu trabalho "Street Storage for Control for Combined Sewer Surcharge", com vistas para essa problemática, citam dois enfoques ao problema da drenagem urbana. São os chamados "Conveyance-oriented" e "Storage oriented", que respectivamente poderíamos tratar como "Enfoque na capacidade de vazão" e "Enfoque na capacidade de armazenamento". 
A outra abordagem para o controle de cheias urbanas consiste nas chamadas soluções não estruturais (ações indiretas) que são ferramentas de modo geral, institucionais, como o zoneamento urbano. Visam propor medidas que, indiretamente contribuem com a redução das vazões a serem drenadas. Fazem parte também, medidas de alerta e que ajudem a população a conviver com cheias.

É nesse contexto de sustentabilidade que, a tentativa de simular o que a natureza faz com a precipitação sobre as bacias em estado natural, vem pouco a pouco, mostrando-se a mais eficiente política de gerenciamento da drenagem urbana nas grandes cidades. Cada vez mais, faz-se necessária a aplicação de políticas e métodos de dimensionamento que priorizem o retardamento do pico das vazões, alteradas pela impermeabilização da bacia. Todos os elementos de drenagem usados para compor o sistema de condução das águas pluviais podem e devem ter suas capacidades de armazenamento exploradas ao máximo. Ao se considerar drenagem como a arte de gerenciar espaços, principalmente naqueles locais onde a existência de áreas abertas e livres é rara, a necessidade do aproveitamento de todas as possibilidades de armazenamento das águas, faz-se premente e com certeza é grande contribuinte junto às medidas de sustentabilidade dos sistemas de drenagem urbana. 


\section{OBJETIVO GERAL}

O objetivo geral deste trabalho é discutir outra possibilidade ou outro método que busque fundir os conceitos de armazenamento e detenção/retenção na fonte, de modo a criar mais uma ferramenta sob um novo ponto de vista de ação estrutural que irá colaborar na minimização dos problemas de drenagem urbana.

\subsection{OBJETIVOS ESPECÍFICOS}

O objetivo específico e principal deste trabalho é a avaliação quantitativa dos efeitos das declividades abaixo de $0,5 \%$ no escoamento superficial em vias urbanas.

Como conseqüência desta pesquisa é possível também discutir e articular proposições que agreguem idéias ao enfoque de redução dos picos de vazão, que é a grande tendência em drenagem urbana atualmente.

Como objetivos secundários, podemos citar:

- A formulação de modelo matemático para a determinação do amortecimento de vazões de pico escoadas por superfícies com geometria padrão;

- A proposição de modo de aproveitamento do amortecimento no escoamento superficial;

- Justificar a eliminação dos pontos baixos em greides de ruas com sacrifício da declividade longitudinal mínima. 


\section{JUSTIFICATIVA}

A chuva que cai sobre uma bacia qualquer inicia seu percurso por esta, pelos elementos de drenagem localizados na superfície, que são as guias, sarjetas e a própria "caixa da rua", que servem como "canal condutor", até atingir as galerias. Esse escoamento deve ocorrer evitando-se transbordamento para as moradias lindeiras e ainda respeitando os critérios de trafegabilidade. Essa capacidade de transporte e condução das águas de chuva é condicionada à geometria da sarjeta, ao tipo de pavimento e sua rugosidade, mas principalmente, ao gradiente vertical em que tais elementos drenantes estão construídos no terreno. É sabido que, nas localidades de serra, a principal preocupação é relativa à erosão, causada pelo escoamento superficial das águas de chuva, que ocorre em altas velocidades. No caso de planícies urbanas, o mesmo ocorre, porém no sentido inverso: é a falta de velocidade nos escoamentos e que propicia acúmulo de sedimentos, tendo com conseqüência grande custo de manutenção para que se tenha sempre o sistema em condições de uso.

Quando se trata de drenagem urbana, dois grandes aspectos podem ser mencionados: aqueles relacionados à bacia e seus corpos hídricos principais, sendo discutido sob o ponto de vista de Macro-Drenagem e aqueles mais pontuais, sendo tarefa relacionada à MicroDrenagem. A Micro-Drenagem é a especialidade da engenharia que cuida da drenagem de "lotes e vias urbanos", e deste modo deve relacionar-se intimamente aos aspectos acima mencionados, como seções típicas para escoamento das águas, velocidades de escoamento, sedimentos acumulados. Tais aspectos parecem ter menos importância, quando comparados com os aspectos da Macro-Drenagem, no entanto, são eles que mais se fazem presentes no dia a dia de moradores e mantenedores dos sistemas de drenagem urbana.

A declividade longitudinal das vias urbanas é então, por esse motivo, fator determinante no aumento ou diminuição da capacidade de escoamento das vias e condicionante do tipo de solução técnica de drenagem a ser adotada. É conhecido e citado em vários manuais e padrões de projeto, o limite inferior para vias urbanas com ordem de grandeza em torno de $0.4 \%$. Este limite inferior é justificado pela redução do acúmulo de sedimentos na rede. No entanto, pouco estudo existe no sentido de se comprovar tecnicamente tal limite inferior. Trata-se de um limite imposto empiricamente. É justamente esta falta de embasamento teórico para justificar essa imposição de limite inferior, que norteia o objeto de estudo deste trabalho. 
A cidade de Praia Grande, no litoral de São Paulo, que ocupa cerca de $145 \mathrm{~km}^{2}$ da planície litorânea do Estado de São Paulo, apresenta em diversos locais de sua área urbana, vias com declividade média da ordem de $0.15 \%$. Tal declividade, como sabido, não atende à grande maioria dos manuais de projeto consagrados no meio técnico. Ainda assim, o que se nota é que nas vias cujas declividades acham-se com essa ordem de grandeza e não têm em nenhum ponto baixo ao longo de sua extensão, locais que propiciem acumulo de água, não se tem relatos de alagamentos, mesmo nos eventos mais intensos.

Por tratar-se de vias, cujas obras de infra-estrutura foram executadas mais recentemente, o critério de projeto adotado estabeleceu que seria mais útil sacrificar a declividade mínima em detrimento do estabelecimento da não existência de pontos de acúmulo de água ou chamados pontos baixos ao longa das vias. Na prática, o que se nota com a execução dessas declividades é o aumento na altura d'água durante escoamento que, em certos casos, chega a impossibilitar o trafego de veículos, momentaneamente, mas que, com o término do deflúvio, reduz-se rapidamente, restabelecendo as condições normais de uso. Ainda com o término do evento de precipitação, e findo o período de escoamento, pouco resta acumulado na superfície das vias, já que é premissa principal a não construção de pontos ou bacias que permitam o acúmulo de água.

A idéia adotada teve como conceito, a eliminação dos pontos baixos, elaborando-se greides cujas declividades direcionassem as águas sempre para um único ponto, neste caso canais de macro-drenagem ou galerias a serem implantados no ponto mais a jusante possível. Tal prerrogativa objetivava em tese, um escoamento constante, de modo independente da existência das galerias, e que, numa situação problema garantisse o escoamento na via. Este objetivo foi alcançado e as vias que foram pavimentadas e receberam tal tratamento, hoje são as que menos recebem reclamações de munícipes no que concerne a ocorrência de alagamentos.

A construção dessas ruas com declividade longitudinal de greide inferior a $0,005 \mathrm{~m} / \mathrm{m}$ levou à confirmação em campo do que se havia previsto em projeto. A elevação dos níveis de água na sarjeta é mais rápida, no entanto, quando do término do evento de chuva, o escoamento segue até o ponto de captação, independentemente da distância a jusante do ponto de captação.

Empiricamente, qualificou-se a experiência como válida, passando-se a adotar a técnica em outros locais da cidade. Os principais resultados alcançados foram: 
- Redução/eliminação de pontos de alagamentos intermediários (esquinas, meios de quadra, etc.);

- Eliminação da dependência do escoamento exclusivo das águas pelas galerias pluviais;

- Ampliação dos trechos de escoamento superficial;

- Redução da extensão de galerias, com conseqüente possibilidade de aumento da declividade das mesmas;

- Aumento da declividade longitudinal das galerias, com provável redução dos problemas de assoreamento desta rede.

Trata-se, portanto, de solução de drenagem que merece uma avaliação crítica e ao mesmo tempo um enfoque mais teórico sobre seus reais efeitos, para consideração principalmente na etapa de dimensionamento dos elementos de drenagem.

A avaliação dos efeitos desse pequeno gradiente de declividade superficial e o seu efeito no escoamento, como forma de complementar a análise e fornecer melhores recursos na adoção dos critérios de projeto de drenagem é o objetivo principal deste trabalho, já que poucos são os estudos encontrados nesse âmbito.

A discussão proposta então é a verificação teórica desta experiência, que está demonstrando ser bastante eficaz na minimização de ocorrência de cheias e alagamentos. Essa verificação teórica nos conduz à necessidade da avaliação do efeito hidrodinâmico num escoamento em declividades inferiores às mínimas estabelecidas em manuais de projeto.

A utilização do conceito da não imposição do limite mínimo de declividade longitudinal no projeto de vias, possibilitando a redução do uso de galerias, merece estudo teoricamente embasado, visto que pouco tem se falado sobre o referido problema.

Empiricamente, podemos dizer que um escoamento em baixa declividade conduzirá a uma redução no pico das vazões, sendo esta redução maior à medida que o ponto de controle se afasta do ponto de montante. Isto posto, a conclusão mais imediata é que poder-se-á reduzir em extensão e tamanho as galerias, já que o escoamento pelas superfície das ruas, sendo melhor avaliado poderá ser melhor aproveitado. A quantificação desse amortecimento na superfície das vias será então mais uma ferramenta para o controle dos picos vazão. 
A idéia de reter o excedente das chuvas na tentativa de simular as condições naturais préurbanização é conceito novo. FENDRICH (2002) cita que a primeira menção ao conceito de detenção distribuída das águas pluviais é apresentada em ASCE (1985) - storage detention approach - contrapondo aos modelos tradicionais de "máxima eficiência hidráulica" conveyance approach - até então usados, pois existem relatos de bacias de detenção desde o tempo da Babilônia até as bacias de detenção dos tempos modernos, que começaram a ser usadas no Rio Roanne, na França, em 1711.

A retenção com o objetivo de redução dos picos de vazão, no Brasil, teve início prático com a construção dos primeiros reservatórios de retenção em 1953, em Belo Horizonte, no Estado de Minas Gerais, sendo os da Pampulha e Santa Lúcia e até hoje funcionais (NASCIMENTO e BAPTISTA, 1997). Recentemente, a implantação de bacias de detenção, popularmente chamadas de "piscinões", tem se destacado na Cidade de São Paulo (CANHOLI, 1994). Outros estudos nos Estados Unidos também tem se mostrado bem eficazes na redução dos picos de vazão, reduzindo por consequência os custos de implantação de galerias pluviais.

A idéia dos reservatórios para a redução dos picos de vazão pode ser adaptada para diversas outras superfícies ou elementos. No caso dos elementos com pequeno desnível ou mesmo zero, há possibilidade de armazenamento, mesmo que temporário. Com vistas a se aproveitar a possibilidade de se usar novos elementos como reservatórios temporários ou elementos de amortecimento é que se propõe a avaliação da capacidade de amortecimento das ruas. Tais elementos, além de já ocuparem áreas consideráveis, no ambiente urbano, de modo geral, são dimensionados apenas com vistas ao trafego. Não se pretende, no entanto, esquecer de tal uso, já que realmente esta é a função principal dos leitos de vias, mas sim, estabelecerse uma relação que respeita todas as suas possibilidades de uso que possam ser alcançadas.

A idéia de avaliar o efeito das declividades abaixo daquelas consideradas mínimas deverá então determinar qual o amortecimento de vazão propiciado. A criação de um modelo de escoamento superficial nos permitirá verificar qual a relação entre declividades longitudinais, características geométricas da calha da via e esse amortecimento.

A criação de um índice ou fator de amortecimento de vazão, função da declividade longitudinal da via, é a proposta principal deste trabalho, no intuito de prover aos projetistas e engenheiros, uma ferramenta mais concreta na indicação e aproveitamento positivo daquela característica. 


\section{REVISÃO BIBLIOGRÁFICA}

Este trabalho discutirá o efeito da declividade longitudinal no escoamento sobre as superfícies das vias urbanas, de modo a aproveitar ao máximo de sua capacidade de condução e amortecimento. Tal avaliação não pode ser tomada a efeito sem que, preliminarmente, discutam-se as bases teóricas que descrevem tais propriedades. Nesse sentido, esta revisão bibliográfica teve como premissa de pesquisa, avaliar e buscar estudos que descrevessem todos os elementos que compõem um sistema de escoamento superficial, desde os elementos formadores do escoamento até os elementos de condução. Sendo assim, nesta revisão bibliográfica apresentamos pesquisas relacionadas a:

- Estudo das redes de escoamento das águas pluviais. Considerações e métodos teóricos;

- Experiências e critérios de projeto em regiões planas;

- Modelos hidrodinâmicos de escoamento livre.

No primeiro item veremos que a tentativa de considerar-se o amortecimento do escoamento, seja nas sarjetas, seja nas galerias é objeto de estudo antigo. Já no segundo item, apresentam-se os estudos e práticas implementadas em diversas localidades planas, todas elas buscando o máximo aproveitamento da capacidade de armazenamento de vias. Com os modelos de escoamento livre, apresentam-se as bases teóricas para a análise de escoamentos, sob condições quaisquer e que serão implementadas para se avaliar o amortecimento, por meio de modelo ainda a ser proposto.

\subsection{ESTUDO DAS REDES DE ESCOAMENTO SUPERFICIAL}

Toda precipitação, seja num ambiente urbano ou não, gera um escoamento superficial, que gera uma vazão a ser transportada por um corpo d'água ou elemento drenante. A avaliação quantitativa desse escoamento é a etapa de todo estudo de drenagem. 
A primeira etapa de um dimensionamento hidrológico- hidráulico para elaboração de um projeto de drenagem passa pela escolha do método de determinação da vazão de projeto. Segundo WILKEN (1978), no manual de Drenagem Urbana da CETESB, podemos classificar esses métodos em:

- Métodos baseados em fórmulas empíricas;

- Métodos estatísticos;

- Métodos com fundamento cinemático.

Dentre eles, destaca-se este último, cuja aplicação difundiu-se bem mais, graças a sua fácil determinação de parâmetros. Os métodos de fundamento cinemático nasceram da teoria exposta pela primeira vez por EMIL KUICHLING, em 1880, denominada "teoria racional", que reconhece como axiomática a relação direta entre a chuva e o deflúvio, expressa pela equação $\boldsymbol{Q}=\boldsymbol{C} \boldsymbol{i} \boldsymbol{A}$, dita "equação racional", em que $\boldsymbol{i} . \boldsymbol{A}$ representa a quantidade de chuva precipitada na unidade de tempo $(l / s . h a x h a=l / s)$, e $\boldsymbol{Q}$ é o deflúvio. $\boldsymbol{C}$ é um coeficiente menor que a unidade que pode representar, dentre outros, o tipo de impermeabilização local e as perdas.

A equação deste método é efetivamente racional, pois considera as principais características da bacia contribuinte, tais como sua área, a permeabilidade do solo, sua forma e declividades, isto é, determina a vazão em função de fatores fisiográficos. Contém ainda o fator $\boldsymbol{i}$, intensidade da chuva, o qual, como se sabe, é variável no tempo e no espaço. $\mathrm{Na}$ evolução dos métodos com fundamento cinemático, os primeiros pesquisadores admitiam $\boldsymbol{i}$ como constante, o que induziu muitos engenheiros a projetar galerias insuficientes nas partes altas da bacia e superdimensionadas nos trechos de jusante. Em seguida, os métodos evoluíram no sentido de considerar $\boldsymbol{i}$ como variável durante o decorrer da chuva, mas admitindo $\boldsymbol{i}$ como constante em toda a área abrangida por ela. Finalmente, a experiência mostrou que $\boldsymbol{i}$ varia com duração $\boldsymbol{t}$ da chuva e com a área $\boldsymbol{A}$ da bacia receptora. Posteriormente outros métodos mais modernos procuraram corrigir ou completar a equação racional introduzindo outros fatores que levam em conta a geomorfologia e a geologia da bacia e o uso do solo. 
O número de métodos para a determinação da vazão de projeto é grande, não fazendo parte deste estudo. Mostraremos aqui, aqueles que são mais difundidos e que de certa forma tentam simular o efeito do amortecimento dos picos de vazão no sistema de drenagem.

\subsection{MÉTODO RACIONAL}

O método racional é, certamente, o mais difundido na prática para a determinação de vazões de pico em pequenas bacias, como por exemplo, no caso do dimensionamento de galerias pluviais e de bueiros (PINTO et al., 1975). A grande aceitação do método deve-se à sua simplicidade e aos seus resultados, que costumam ser satisfatórios, desde que respeitadas às condições de validade. Recebe este nome pelo simples fato de derivar-se da equação racional de Kuichling.

De forma geral, reproduzindo as recomendações atualmente aceitas na literatura (TUCCI, 2000; LINSLEY e FRANZINI, 1964; PINTO et al., 1975), limita-se a aplicação do método racional em bacias até $2 \mathrm{~km}^{2}$ e, eventualmente, $5 \mathrm{~km}^{2}$ de área. Para bacias maiores recomenda-se utilizar o hidrograma unitário (HU) e modelos mais complexos (BEVEN, 2001). Deve-se observar que esta restrição é devida principalmente ao efeito do armazenamento superficial da bacia e da intensidade variável da chuva.

A Norma DE 01/HD-002 - Projeto de Drenagem, contida no Manual de Drenagem Rodoviária do DER/SP, prescreve as seguintes recomendações: “A metodologia de cálculos hidrológicos para determinação das vazões de projeto será definida em função das áreas das bacias hidrográficas, conforme a tabela 1, a seguir:

Tabela 1- Metodologias de Cálculo em função das áreas de bacias

\begin{tabular}{cc}
\hline Método & Áreaspara aplicação \\
\hline Método Racional & Áreas $<50$ ha \\
Método Racional Modificado & 50 ha $\leq$ Áreas $\leq 100$ ha \\
Método de Ven Te Chow ou U.S. Soil Conservation Service & Áreas $>100$ há \\
\hline
\end{tabular}


O método Racional engloba o conceito básico que a vazão de pico para uma pequena bacia contribuinte ocorre quando toda esta bacia está contribuindo, e que esta vazão é igual a uma fração da precipitação média. A fórmula conhecida é:

$$
\boldsymbol{Q}=\boldsymbol{C} \cdot \boldsymbol{i} \cdot \boldsymbol{A}
$$

eq. 1

em que:

$Q=v a z$ ão do escoamento excedente que escoa sobre a superfície do solo, em $\mathrm{l} / \mathrm{s}$ ou $\mathrm{m}^{3} / \mathrm{s}$;

$\boldsymbol{C}=$ relação entre o pico da vazão por unidade de área e a intensidade média da chuva;

$\boldsymbol{i}$ = intensidade da chuva em litros ou metros cúbicos por hectare e por segundo;

$\boldsymbol{A}=$ área da bacia receptora da chuva em hectares.

A hipótese central do método sugere que, em uma bacia sujeita a uma chuva de intensidade constante e distribuição uniforme, estabelece-se o regime permanente com a vazão máxima na seção de controle para um tempo igual ao de concentração da bacia, nesta seção. Como a intensidade média máxima da chuva é uma função decrescente da sua duração, a vazão máxima corresponde a uma chuva com duração igual ao tempo de concentração.

Este procedimento para estimar a vazão máxima no exutório da bacia é válido, desde que, as seguintes particularidades sejam essencialmente verdadeiras:

a) Os efeitos do armazenamento superficial na bacia não influenciem na dinâmica da propagação da cheia, tornando-se constante a partir do tempo de concentração;

b) A intensidade da chuva permanece constante até que a duração da chuva atinja o tempo de concentração da bacia. A partir daí, com toda a área da bacia contribuindo, estabelece-se o regime permanente;

c) A intensidade de precipitação diminui com o aumento do tempo de duração da chuva. Por outro lado, para chuvas de duração menor que o tempo de concentração, a contribuição da bacia é parcial, tal que, a maior vazão ocorre para chuvas de duração igual ao tempo de concentração; há duas situações em que esta definição, no entanto pode não ser verdadeira: quando a bacia é alongada ou quando há diferentes coeficientes $\boldsymbol{C}$ na bacia. 
d) A contribuição subterrânea na vazão de pico é desprezível.

Fatores diversos relacionam-se com as características da bacia e com as chuvas de projeto. São eles:

\section{Tempo de Recorrência:}

As precipitações e, conseqüentemente, as vazões resultantes, usadas para o dimensionamento de obras hidráulicas, são definidas estatisticamente em função da probabilidade de sua ocorrência, descrita usualmente pelo chamado tempo de recorrência ou tempo de retorno.

O tempo de retorno é definido como sendo o valor esperado (média) do intervalo entre dois eventos críticos, que superem a capacidade da obra. Quando se trata de variáveis hidrológicas, relacionadas a enchentes, o evento crítico é a ocorrência de uma chuva ou vazão superior a um valor pré-estabelecido. Assim se $\tau(i)$ é o intervalo entre duas chuvas de intensidades iguais ou superiores a $\boldsymbol{i}$, o tempo de recorrência dessa intensidade vale $\boldsymbol{T R}=\boldsymbol{E}(\boldsymbol{\tau})$ (CHOW et al. 1988). Prova-se que para eventos independentes o tempo de recorrência expresso em anos, vale o inverso da probabilidade de se observar ao menos uma chuva de intensidade igual ou superior a $\boldsymbol{i}, \boldsymbol{T}$ num ano qualquer.

$$
\operatorname{TR}=\frac{1}{\operatorname{Pr}\left(I_{\max } \geq \tau_{\mathrm{T}}\right)}
$$

eq. 2

em que:

$\boldsymbol{I}_{\text {máx }}=$ intensidade máxima observada em um ano qualquer.

VILLELA e MATOS (1975), CHOW et al. (1988) e PINTO (1987), em princípio afirmam que a fixação do tempo de retorno deveria ser feita por critérios econômicos, procurando-se o mínimo entre a soma do custo de construção da obra e do valor presente esperado dos prejuízos causados pelas suas falhas futuras ao longo de sua vida útil. 
Entretanto, devido a dificuldades na avaliação objetiva do custo das falhas, principalmente custos indiretos e custos intangíveis, na prática a fixação do tempo de recorrência normalmente é feita por critérios estabelecidos em normas ou consagrados pela prática da Engenharia, e referidos na literatura em tabelas que consideram em geral:
a) Vida útil da obra;
d) Perigo de perdas de vida;
b) Tipo de estrutura;
e) Ocupação da área afetada;
c) Facilidade de reparação;
f) Incertezas hidrológicas.

Por exemplo, numa avaliação do tempo de recorrência em função do tipo de obra poderiam ser adotados como critérios de referências, aqueles listados na Tabela 2.

Tabela 2- Tempo de recorrência em função do tipo de obra

\begin{tabular}{|c|c|c|c|c|}
\hline \multirow{2}{*}{ OBRA } & \multirow{2}{*}{\multicolumn{2}{|c|}{ SEÇÃO GEOMÉTRICA }} & \multicolumn{2}{|c|}{ TR (anos) } \\
\hline & & & Área & Área \\
\hline \multirow{3}{*}{ Canalização } & \multirow{2}{*}{$\begin{array}{l}\text { A céu } \\
\text { aberto }\end{array}$} & Trapezoidal & 50 & \multirow{3}{*}{ (a) } \\
\hline & & Retangular & 100 & \\
\hline & \multicolumn{2}{|c|}{ Contorno fechado } & 100 & \\
\hline Travessias: pontes, bueiros e estruturas & \multicolumn{2}{|c|}{ Qualquer } & 100 & $100^{(\mathrm{b})}$ \\
\hline
\end{tabular}

Borda livre (f)

Canais a céu aberto: $\mathrm{f} \geq 10 \%$ da lâmina de cheia $\left(\mathrm{H}_{\mathrm{TR}}\right)$, com $\mathrm{f} \geq 0,4 \mathrm{~m}$ Canais em contorno fechado: $\mathrm{f} \geq 0,2 \mathrm{H}_{\mathrm{TR}}$

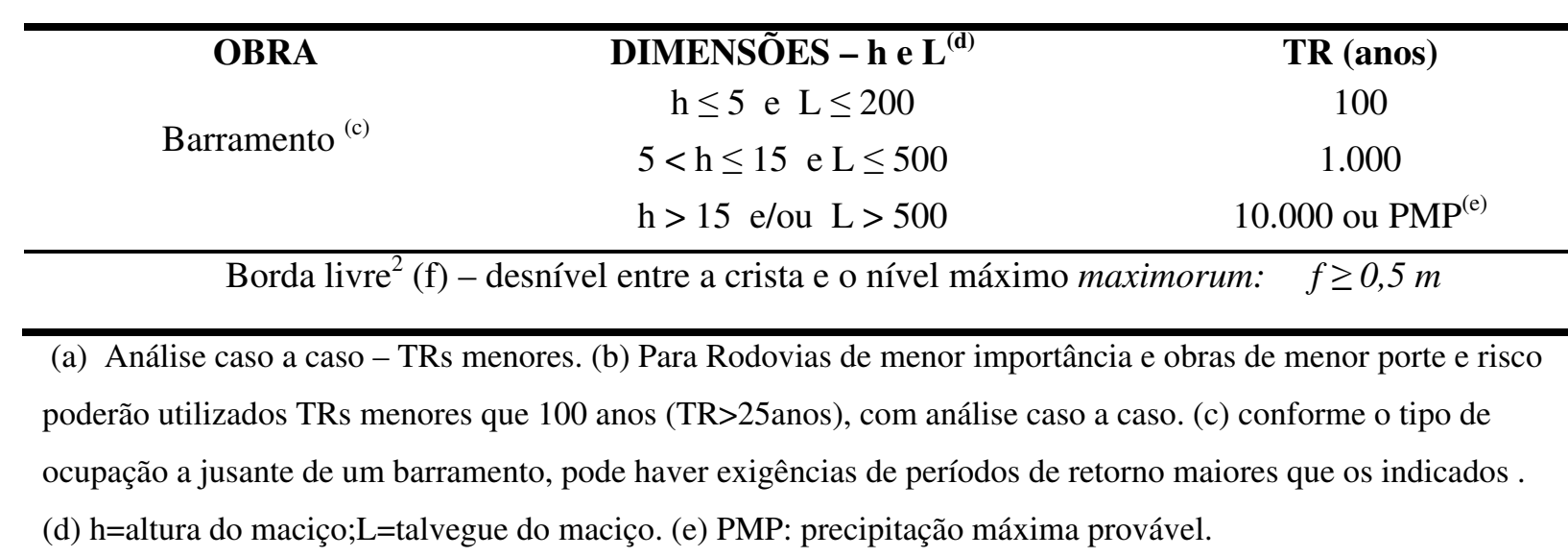


Para as obras de drenagem urbana, DAEE/ CETESB, em publicação de 1980, conforme TUCCI (1995) estabelece o uso dos tempos de recorrência, em função da ocupação da área, de acordo com as listadas na tabela 3, a seguir:

Tabela 3 - Tempo de recorrência em função do tipo de obra.

\begin{tabular}{lcc}
\hline Abrangência & Ocupação & Tempo de recorrência \\
\hline \multirow{3}{*}{ Microdrenagem } & Residencial & 2 \\
& Comercial & 5 \\
& Áreas com edifícios de serviço público & 5 \\
& Aeroportos & 2 a 5 \\
& Áreas comerciais e artérias de tráfego & 5 a 10 \\
\hline Macrodrenagem & Áreas comerciais e residenciais & 50 a 100 \\
& Áreas de importância específica & 500 \\
\hline
\end{tabular}

Fonte: Tucci (1995) apud CETESB

\section{$\underline{\text { Tempo de concentracão : }}$}

Define-se tempo de concentração como sendo o tempo necessário para que um pulso de escoamento se desloque do ponto mais afastado da bacia até o ponto de controle (RAUDKIVI, 1979). O tempo de concentração é a soma do tempo de entrada e do tempo de percurso. O primeiro, é o tempo que a citada gota de água leva pra a atingir a extremidade de montante do conduto; e o segundo, é o tempo gasto pela mesma ao percorrer o conduto desde a extremidade de montante até o ponto de concentração.
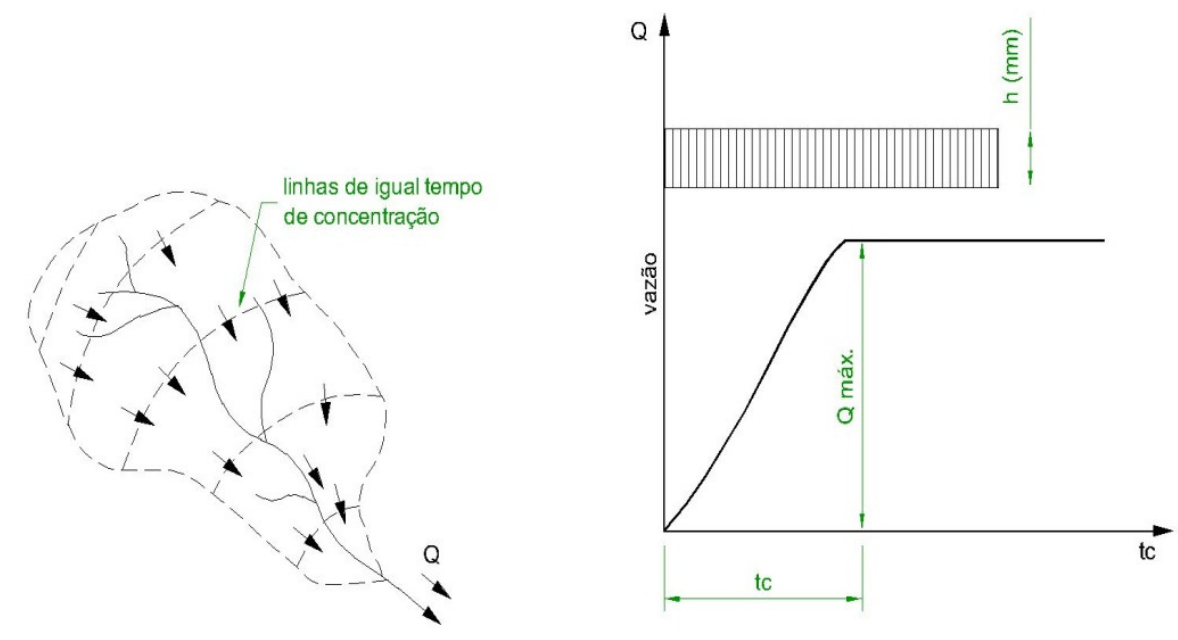

Figura 1 - Tempo de concentração (fonte: Pinto et. al, 1979) 
Considerando-se que ao se estabelecer o regime permanente $Q \boldsymbol{p}=\boldsymbol{C} \boldsymbol{i} \boldsymbol{A}$, resulta para o tempo de base do hidrograma:

$$
t b=2 t c
$$

eq. 3

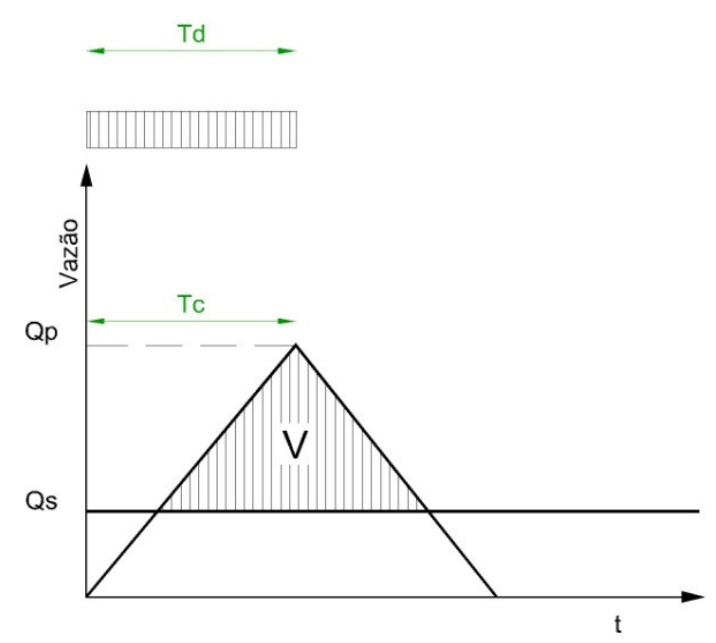

Figura 2 - Hidrograma do método racional (fonte: PORTO, 1995)

A Figura 2 ilustra o raciocínio, lembrando que nesse caso a duração total da chuva é $t c$, o que geralmente não é verdade, pois a precipitação em geral continua apesar de apresentar intensidade menor e por isso há uma redução da vazão.

Portanto, para $\boldsymbol{t} \boldsymbol{d}=\boldsymbol{t} \boldsymbol{c}$, o hidrograma de cheia do método racional (fig. 02) é representado por um triângulo isósceles. Caso os efeitos de armazenamento não fossem desprezados, o trecho descendente do hidrograma corresponderia a um tempo maior que $\boldsymbol{t} \boldsymbol{c}$, e o valor de $\boldsymbol{Q p}$ teria que ser reduzido proporcionalmente para manter o mesmo volume escoado.

Para $\boldsymbol{t} \boldsymbol{d}>\boldsymbol{t} \boldsymbol{c}$, RAUDKIVI (1979) propõe que o hidrograma de cheia do método racional seja representado por um trapézio isósceles, com base maior $\boldsymbol{t} \boldsymbol{b}$ e base menor igual a $\boldsymbol{B m}=\boldsymbol{t} \boldsymbol{d}$ - $\boldsymbol{t} \boldsymbol{c}$, admitindo-se os trechos de subida e descida iguais a $\boldsymbol{t c}$. Pode-se inferir que caso os efeitos do armazenamento não fossem desprezados, o trecho descendente do hidrograma corresponderia a um tempo maior que $\boldsymbol{t c}$, e o valor de $Q \boldsymbol{p}$ teria que ser reduzido proporcionalmente para manter o mesmo volume escoado, da mesma forma que no item anterior. 
Para $\boldsymbol{t} \boldsymbol{d}<\boldsymbol{t} \boldsymbol{c}$, ainda segundo RAUDKIVI (1979), haveria aumento do escoamento para $\boldsymbol{0}<$ $\boldsymbol{t}<\boldsymbol{t} \boldsymbol{d}$, atingindo-se uma vazão máxima $\boldsymbol{Q}=\boldsymbol{C} \boldsymbol{i A}(\boldsymbol{t} \boldsymbol{d} / \boldsymbol{t} \boldsymbol{c})$, que se mantém constante entre $\boldsymbol{t} \boldsymbol{d}<\boldsymbol{t}$ $<\boldsymbol{t c}$, decaindo logo depois, no trecho $\boldsymbol{t c}<\boldsymbol{t}<\boldsymbol{t c}+\boldsymbol{t} \boldsymbol{d}$. A proporcionalidade $(\boldsymbol{t d} / \boldsymbol{t c})$ é necessária para obedecer à equação da continuidade em relação ao volume precipitado. As relações mais importantes decorrentes desta definição são:

a) Para manter o volume de escoamento, o trapézio isósceles que representa o hidrograma tem a base menor definida por: $\boldsymbol{t} \boldsymbol{t}=\boldsymbol{t} \boldsymbol{d} \boldsymbol{- \boldsymbol { t }} \boldsymbol{c}$ e a base maior definida por: $\boldsymbol{t} \boldsymbol{b}=\mathbf{t} \boldsymbol{c} \boldsymbol{t} \boldsymbol{t}$, ou ainda, $t b=t c+t d$

b) A duração da chuva relaciona-se com a geometria do hidrograma de acordo com $\boldsymbol{t d}=$ $t c+t t$

c) Para $\boldsymbol{t} \boldsymbol{d} \geq \boldsymbol{t} \boldsymbol{c}$, o volume do hidrograma pode ser calculado como: $\boldsymbol{V}=\boldsymbol{Q} \boldsymbol{t} \boldsymbol{d}$ ou, $\boldsymbol{V}=\boldsymbol{C} \boldsymbol{i} \boldsymbol{A}$ $t d, \operatorname{com} i=f(t d, T r)$.

O hidrograma tem, então, as características apresentadas na Figura 3:

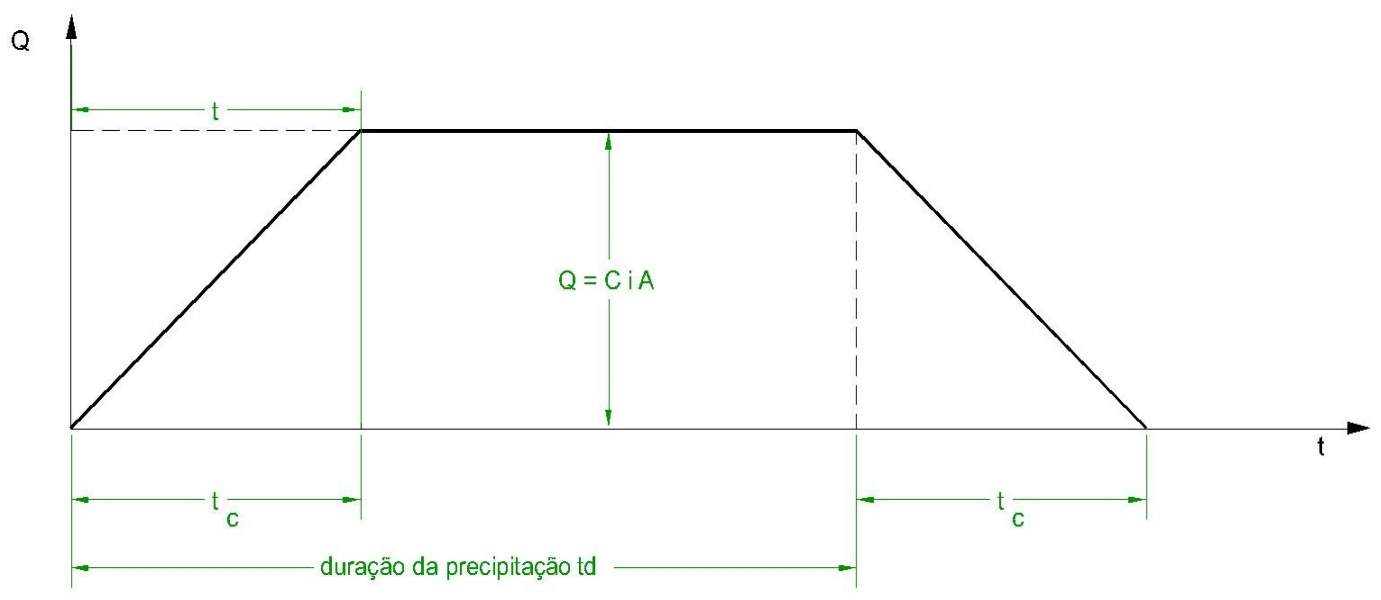

Figura 3 - Hidrograma do método racional para uma chuva de duração qualquer (fonte: RAUDIKVI, 1979)

PORTO (1995) comenta que a forma teórica mais correta de calcular o tempo de concentração é o uso do método cinemático. O uso de fórmulas empíricas deve se limitar a bacias semelhantes, devido a limitações impostas por sua obtenção. 


\section{Método Cinemático :}

O método cinemático consiste em dividir a bacia hidrográfica em trechos homogêneos e calcular a velocidade do escoamento em cada um deles. O tempo de concentração será dado pelo somatório dos tempos de percurso por todos os trechos que compõe o caminho percorrido ao longo do talvegue principal:

$$
t_{c}=\frac{1}{60} \sum L_{i} / V_{i}
$$

eq. 4

em que:

$t_{c}=$ tempo de concentração, em minutos;

$L_{i}=$ comprimento de cada trecho homogêneo, em metros;

$V_{i}=$ velocidade de escoamento no trecho " $i$ ", em $\mathrm{m} / \mathrm{s}$.

A velocidade de escoamento no trecho " $i$ " $\left(V_{i}\right)$, quando este é constituído por superfícies ou por calhas rasas, pode ser estimada pela fórmula da equação 5:

$$
V_{i}=C_{v} S_{i}^{o, 5}
$$

eq. 5

em que:

$S_{i}=$ declividade média do trecho, em porcentagem;

$V_{i}=$ velocidade de escoamento no trecho " $i$ ", em $\mathrm{m} / \mathrm{s}$;

$\boldsymbol{C v}=$ coeficiente de escoamento em superfícies e calhas.

Tabela 4 - Coeficiente de escoamento em superfícies e calhas rasas

\begin{tabular}{ll}
\hline (Cv ) Ocupação do solo & $\mathbf{C v}$ \\
\hline Florestas densas & 0,075 \\
Campos naturais pouco cultivados & 0,135 \\
Gramas ou pastos ralos & 0,210 \\
Solos quase nus & 0,300 \\
Canais gramados & 0,450 \\
Escoamento em lâmina sobre pavimentos ou em & 0,600 \\
\hline
\end{tabular}


Em bacias urbanas, com sistemas de drenagem pluvial, o tempo de concentração será composto por duas parcelas, de acordo com a Equação 6:

$$
t_{c}=t_{i}+t_{t}
$$

eq. 6

em que:

tc = tempo de concentração, em minutos;

$\boldsymbol{t} \boldsymbol{i}=$ tempo inicial, desde o início até atingir a rede de drenagem, contada na primeira boca de lobo, em minutos;

$\boldsymbol{t} \boldsymbol{t}=$ tempo de translação na rede de drenagem, calculada pelas fórmulas do escoamento em condutos, em minutos.

O método cinemático para a avaliação do tempo de concentração é mais complexo, se comparado com as fórmulas empíricas e experimentais, determinadas por diversos pesquisadores. A seguir apresentam-se algumas das mais fórmulas empíricas mais conhecidas e aplicadas:

\section{Fórmula de Kirpich:}

A fórmula de Kirpich foi apresentada em 1940, em publicação da ASCE, no artigo “Time of concentration of Small Agricultural Watershed". É uma fórmula empírica muito usada, desenvolvida em 1940, com dados de sete pequenas bacias rurais do Tenessee, com declividades de $3 \%$ a $10 \%$ e áreas de, no máximo $0,50 \mathrm{~km}^{2}$.

$$
t_{c}=3,989 L^{0,77} S^{-0,385}
$$

em que:

$\boldsymbol{t}_{c}=$ tempo de concentração, em minutos;

$\boldsymbol{L}=$ comprimento do talvegue, em $\mathrm{km}$;

$S=$ declividade do talvegue, em $\mathrm{m} / \mathrm{m}$. 
Retrata o escoamento em superfícies e canais, representados pelas variáveis L e S. Quando L é maior que $10 \mathrm{~km}$ a fórmula tende a subestimar o valor de $\mathbf{t}_{\mathbf{c}}$. Também no caso de bacias urbanas deve ser usada com cautela, pois superestima o valor de tc. Há a recomendação (CHOW et al., 1988), de se reduzir o tempo de concentração em $40 \%$ no caso de bacias urbanas, quando se utiliza a Fórmula de Kirpich.

\section{Califórnia Culverts Pratice (U.S.A):}

Apresentada em 1942, pelo Departamento de Estradas de Rodagem da Califórnia, e citada por TUCCI (1993) é a mesma fórmula de Kirpich, substituindo S por L/H, como pode ser observado na Equação (8). Aplicam-se as mesmas limitações da equação de Kirpich, ou seja, declividades de $3 \%$ a $10 \%$ e áreas de no máximo $0,50 \mathrm{~km}^{2}$, embora na prática corrente tenha sido usada para áreas maiores dentro da aplicabilidade do método racional.

$$
t_{c}=57\left(\frac{L^{3}}{H}\right)^{0,385}
$$

eq. 8

em que:

$\boldsymbol{t}_{c}=$ tempo de concentração, em minutos;

$\boldsymbol{L}=$ comprimento do talvegue, em $\mathrm{km}$;

$\boldsymbol{H}=$ desnivel total do talvegue, em metros.

\section{Federal Aviation Agency (FAA - U.S.A):}

Foi desenvolvida para drenagem de aeroportos, em 1970, publicada numa circular da FAA (Advisory Circular on Airport Drainage). Válida para escoamento em superfície de áreas muito pequenas, e pode ser expressa por:

$$
t_{c}=22,73(1,1-C) L^{0,50} S^{-0,33}
$$

eq. 9

em que:

$\boldsymbol{t}_{\boldsymbol{c}}=$ tempo de concentração, em minutos;

$\boldsymbol{C}=$ coeficiente de escoamento superficial; 
$\boldsymbol{L}=$ comprimento do talvegue, em $\mathrm{km}$;

$\boldsymbol{S}=$ declividade do talvegue, em $\mathrm{m} / \mathrm{m}$.

\section{Método da Onda Cinemática (U.S.A):}

Este método baseia-se na teoria da onda cinemática (M. Ragan apud TUCCI, 1993) considerando a superfície do escoamento como canal de grande largura e partindo-se das hipóteses de escoamento turbulento e chuva de intensidade constante. O comprimento das superfícies variava de 15 a 30 metros. É adequada para bacias muito pequenas em que o escoamento de superfícies seja predominante e, pode ser obtido pela expressão de (BEDIENT e HUBER, 1992):

$$
t_{c}=6,92 L^{0,60} n^{0,60} S^{-0,30} i^{-0,40}
$$

eq. 10

em que:

$\boldsymbol{t}_{\boldsymbol{c}}=$ tempo de concentração, em minutos;

$\boldsymbol{L}=$ comprimento do talvegue, em $\mathrm{km}$;

$\boldsymbol{S}=$ declividade do talvegue, em $\mathrm{m} / \mathrm{m}$;

$i=$ intensidade da chuva, em $\mathrm{mm} / \mathrm{h}$;

$\boldsymbol{n}=$ coeficiente de rugosidade ou de Manning em $\mathrm{m}^{1 / 6}$.

A Tabela 5 indica coeficientes de rugosidade de Manning para algumas superfícies usuais.

Tabela 5: Coeficientes de rugosidade de Manning

\begin{tabular}{lc}
\hline \multicolumn{1}{c}{ COBERTURA DA BACIA } & $\mathbf{n}\left(\mathbf{m}^{\mathbf{1 / 6}}\right)$ \\
\hline Asfalto liso & 0,012 \\
Asfalto ou concreto & 0,014 \\
Argila compactada & 0,030 \\
Pouca vegetação & 0,020 \\
Vegetação densa & 0,350 \\
Vegetação densa e floresta & 0,400 \\
\hline
\end{tabular}

Fonte: TUCCI,1993 


\section{Coeficiente de escoamento superficial :}

PINTO et al. (1975) em seu capítulo sobre o método racional, afirma que coeficiente de escoamento superficial deve ser entendido, na verdade, como um coeficiente de deflúvio, cuja função é tornar proporcional os parâmetros de entrada (área e intensidade) com a vazão no exutório da bacia.

Esse coeficiente deve refletir as condições reais da bacia. Para projetos de obras de controle de cheia devem-se estimar as condições futuras dentro da vida útil da obra e do horizonte de planejamento. Varia com o tempo e pode ser estimado em função da urbanização ou da ocupação e tipo do solo.

O coeficiente de escoamento superficial, adimensional, representa a parcela da chuva total que se transforma em escoamento superficial, podendo considerar ou não os efeitos de amortecimento na bacia. Quando o amortecimento não é considerado, o coeficiente de escoamento também é chamado coeficiente de deflúvio.

Em razão disto, o coeficiente de escoamento superficial é função de uma série de fatores, como o tipo de solo, a ocupação da bacia, a umidade antecedente, a intensidade da chuva, entre outros. Apesar disso, costuma-se, no método racional, adotar um valor constante, o que deve ser feito com muito cuidado.

PORTO (1995) apresenta uma tabela que define o coeficiente de escoamento em função do tipo de solo, para períodos de retorno de 5 a 10 anos, reproduzidos em parte na Tabela 6.

Tabela 6: Coeficiente de escoamento superficial direto $(T R=10$ anos) adotado pela PMSP

OCUPAÇÃO DO SOLO

DE EDIFICAÇÃO MUITO DENSA: partes centrais, densamente construídas de uma

cidade com rua e calçadas pavimentadas.

0,70 a 0,95

DE EDIFICAÇÃO NÃO MUITO DENSA: partes adjacentes ao centro, de menor densidade de habitações, mas com rua e calçadas pavimentadas.

0,60 a 0,70

DE EDIFICAÇÃO COM POUCAS SUPERFÍCIES LIVRES: partes residenciais com construções cerradas, ruas pavimentadas.

0,50 a 0,60 
DE EDIFICAÇÃO COM MUITAS SUPERFÍCIES LIVRES: partes residenciais com ruas macadamizadas ou pavimentadas, mas com muitas áreas verdes.

DE SUBÚRBIOS COM ALGUMA EDIFICAÇÃO: partes de arrabaldes e subúrbios com pequena densidade de construções.

DE MATAS, PARQUES E CAMPOS DE ESPORTES: partes rurais, áreas verdes, superfícies arborizadas, parques ajardinados e campos de esporte sem pavimentação.

Fonte: WILKEN,1978 appud PORTO,1995

Para períodos de retorno maiores, há necessidade de corrigir o valor do coeficiente de escoamento superficial. WILKEN (1978) propõe a seguinte expressão:

$$
C_{T}=0,8 \cdot T R^{0,1} \cdot C_{10}
$$

em que:

$\boldsymbol{C}_{\boldsymbol{T}}=$ coeficiente de escoamento superficial para o período de retorno $\boldsymbol{T} \boldsymbol{R}=$ em anos;

$\boldsymbol{C}_{\boldsymbol{1 0}}=$ coeficiente de escoamento superficial para o período de retorno $\mathbf{T R}=10$ anos;

$\boldsymbol{T R}=$ tempo de retorno, em anos.

Quando a bacia apresenta ocupação heterogênea, é recomendável calcular o valor de $C$ pela média ponderada, de acordo com a Equação 12:

$$
C=\frac{1}{A} \cdot \sum C_{i} \text { i } A_{i}
$$

em que:

$\boldsymbol{C}=$ coeficiente médio de escoamento superficial;

$\boldsymbol{A}=$ área de drenagem total da bacia hidrográfica;

$\boldsymbol{C}_{\boldsymbol{i}}=$ coeficiente de escoamento superficial correspondente à ocupação " $i$ ”;

$\boldsymbol{A}_{\boldsymbol{i}}=$ área da bacia hidrográfica correspondente à ocupação " $i$ ”.

De acordo com publicação da ASCE (1969), os coeficientes de escoamento superficial podem ser avaliados como apresentado nas Tabelas 7 e 8 . 
TABELA 7 - Coeficientes de escoamento superficial $(C)$ em função da superfície

\begin{tabular}{llc}
\hline Superfície & \multicolumn{2}{c}{ Coeficiente de Escoamento (C) } \\
& Limites & Normal \\
\hline Pavimento: & 0,70 a 0,95 & 0,83 \\
asfalto & 0,80 a 0,95 & 0,88 \\
concreto & 0,75 a 0,85 & 0,80 \\
calçadas & 0,75 a 0,95 & 0,85 \\
telhado & & \\
\hline Grama, em solo arenoso, declividade: & 0,05 a 0,10 & 0,08 \\
baixa $(\mathrm{S}<2 \%)$ & 0,10 a 0,15 & 0,13 \\
média $(2 \%<\mathrm{S}<7 \%)$ & 0,15 a 0,20 & 0,18 \\
alta $(\mathrm{S}>7 \%)$ & & \\
\hline Grama, em solo argiloso, declividade: & 0,13 a 0,17 & 0,15 \\
baixa $(\mathrm{S}<2 \%)$ & 0,18 a 0,22 & 0,20 \\
média $(2 \%<\mathrm{S}<7 \%)$ & 0,25 a 0,35 & 0,30 \\
alta $(\mathrm{S}>7 \%)$ & & \\
\hline
\end{tabular}

Fonte:ASCE, 1969

TABELA 8 - Coeficientes de escoamento superficial $(C)$ em função da ocupação

\begin{tabular}{lc}
\hline \multicolumn{1}{c}{ Ocupação } & \multicolumn{1}{c}{ Área comercial } \\
\hline \multicolumn{2}{c}{ Área residencial } \\
- central & 0,70 a 0,90 \\
- bairros & 0,50 a 0,70 \\
- residências isoladas & 0,35 a 0,50 \\
- unidades múltiplas, separadas & 0,40 a 0,60 \\
- unidades múltiplas, conjugadas & 0,60 a 0,75 \\
- lotes com área maior que $2.000 \mathrm{~m}^{2}$ & 0,30 a 0,45 \\
- áreas com apartamentos & 0,50 a 0,70 \\
\multicolumn{2}{c}{ Área industrial } \\
- indústrias leves & 0,50 a 0,80 \\
- indústrias pesadas & 0,60 a 0,90 \\
Parques e cemitérios & 0,10 a 0,25 \\
Praças & 0,20 a 0,35 \\
Pátios ferroviários & 0,20 a 0,40 \\
Áreas sem melhoramentos & 0,10 a 0,30 \\
\hline
\end{tabular}


PINTO et al. (1975) apresentam valores de $C$ em função da ocupação da bacia, proposta pelo Colorado Highway Department, de acordo com os limites dos coeficientes de escoamento superficial apresentados na Tabela 9.

TABELA 9- Limites do coeficiente de escoamento superficial, $(C)$

\begin{tabular}{cc}
\hline Ocupação do Terreno & C em \% \\
\hline Superfícies impermeáveis & $90-95$ \\
Terreno estéril montanhoso & $80-90$ \\
Terreno estéril ondulado & $60-80$ \\
Terreno estéril plano & $50-70$ \\
Prados, Campinas, terreno & $40-65$ \\
Matas decíduas, folhagem caduca & $35-60$ \\
Matas coníferas, folhagem & $25-50$ \\
Pomares & $15-40$ \\
Terrenos cultivados, zonas altas & $15-40$ \\
Terrenos cultivados, vales & $10-30$ \\
\hline
\end{tabular}

Fonte:Pinto et al., 1975

\subsubsection{HIPÓTESES SIMPLIFICADORAS DO MÉTODO RACIONAL}

Tendo em vista que neste trabalho, o emprego do método racional excede a simples determinação de vazões, é importante fazer uma análise das suas limitações para determinar sua aplicabilidade na determinação do volume de detenção.

Em princípio o método racional é aplicável apenas em bacias pequenas, com tempo de concentração suficientemente curto para que se estabeleça o regime permanente. Portanto, as propriedades que definem uma bacia como hidrologicamente pequena devem ser claramente definidas, destacando-se:

a) A chuva é considerada de intensidade uniforme;

b) A chuva é considerada uniformemente distribuída no espaço; 
c) A duração da chuva deve ao menos igualar o tempo de concentração da bacia;

d) O escoamento superficial é do tipo hortoniano, produzido por intensidade de chuva superior a capacidade de infiltração;

e) O escoamento subterrâneo é desprezível;

f) O processo de amortecimento em função do armazenamento superficial é desprezível;

g) Chuvas anteriores não afetam a vazão máxima no exutório.

Em termos práticos, a literatura classifica como bacias hidrográficas pequenas as que apresentam área menor que $5 \mathrm{~km}^{2}$ e tempo de concentração menor que 1 hora. No entanto, é importante entender o que acontece quando estas condições são relaxadas. PINTO et al. (1975) aplicam o método racional no projeto de bueiros de estrada utilizando-o implicitamente para áreas até $25 \mathrm{~km}^{2}$. Outro fator preponderante no que diz respeito ao método é que basicamente este leva em conta apenas a capacidade de transporte dos condutos, não considerando a capacidade de armazenamento existente nessas estruturas. Por esse motivo, a utilização do método racional será complementada por estudos específicos que promovam a avaliação deste armazenamento.

\subsection{MÉTOdos QUE LEVAM EM CONTA A CAPACIDADE DE ARMAZENAMENTO DO SISTEMA}

Os métodos cinemáticos consideram basicamente a vazão nos condutos e cursos de água naturais dependendo do seu enchimento durante a chuva. Todavia, o método racional leva em conta somente a capacidade de condução. Todavia, aquelas canalizações têm capacidade de acumular temporariamente as águas das chuvas. Desta observação decorre a possibilidade de redução da vazão máxima de cheia, pois durante o tempo gasto de enchimento dos condutos até atingir plena seção, a velocidade da água é consideravelmente menor, redundando em aumento no tempo de percurso e, conseqüentemente, aumento do tempo de concentração. A 
consideração desse fato levou alguns pesquisadores, como os italianos Fantoli, Poggi, Massari e outros, à criação de um método de calculo de vazões de projeto cuja maior vantagem é a determinação da atenuação do pico de vazão, produzida pela detenção dos volumes pluviais no interior e superfícies dos condutos.

Wilken (1978) apresenta em seu livro, alguns métodos que consideraram tal amortecimento, podendo ser citados:

- Método Italiano: Os pesquisadores italianos Paladini e Fantoli criaram o método por meio de observações das redes de galerias e canais de cidade de Milão. Tal método se aplica, portanto a canais e galerias, que funcionam como conduto livre. É citado também que a mesma metodologia pode ser aplicada a condutos forçados.

- Método do Eng. ${ }^{\circ}$ W. R Mathews: engenheiro da cidade de Chicago expôs o seu engenhoso método em 1929. Fundamenta-se no principio da consideração da capacidade de armazenamento do sistema pluvial e passou despercebido quando de sua publicação.

- Métodos gráficos alemães: tais métodos baseados na equação racional e têm por objetivo atenuação da vazão máxima. No entanto, tais métodos já estão ultrapassados, apesar de recentes melhorias introduzidas pelo Prof. Mueller Neuhaus.

- Método do hidrograma unitário: "O hidrograma de um curso d'água é a representação gráfica de suas variações de vazão dispostas em ordem cronológica”. A descrição do hidrograma que represente o escoamento superficial, ou seja, aquele para as quais as estruturas de drenagem devam ser dimensionadas é o principal foco de estudo de diversos pesquisadores. Diversos métodos e estudos sobre a forma dos hidrograma foram propostos. São citados:

- hidrograma de Commons;

- hidrograma de Snyder;

- hidrograma Unitário triangular;

- hidrograma do Soil Conservation Service;

- hidrograma de Reda. 
Os aperfeiçoamentos dos métodos do hidrograma unitário fornecem meios para a previsão da distribuição do escoamento em relação ao tempo, durante um período de cheias em pontos do curso de água para os quais é calculado. Em certos casos, levando em consideração o armazenamento na seção, gerando, portanto o chamado abatimento da vazão de cheia ou da vazão máxima de entrada. O traçado desses hidrogramas a partir de um hidrograma unitário base, é determinado por um processo de iteração ou como os norte americanos o chamam "stream-flow routing". Nos casos de armazenamento na própria calha do curso de água, a tarefa de iteração torna-se um pouco mais complexa do que naqueles casos em que o armazenamento se dá em bacias de acumulação ou lagos. Não há uma relação simples entre a vazão de saída e o armazenamento, como no citado caso do lago, onde sabe-se o volume máximo que pode ser acumulado.

O método Muskingum, para o caso de armazenamento em trechos de curso de água é facilmente aplicável e oferece resultados suficientemente exatos. Este método emprega o conceito de armazenamento no prisma e na cunha formada pela diferença de altura gerada pelas diferentes vazões do hidrograma de entrada.

O volume de armazenamento chamado $\boldsymbol{M}$ pode ser relacionado com a vazão de saída $(Q s)$ por uma função linear, somente quando $Q \boldsymbol{e}$ (vazão de entrada) e $Q \boldsymbol{s}$ forem iguais, isto é, se o movimento for permanente. Todavia, no trecho de um curso de água, durante o avanço de uma onda de cheia, $\boldsymbol{Q} \boldsymbol{e}$ sempre excede o $\boldsymbol{Q s}$, produzindo-se assim o armazenamento em forma de cunha. Reciprocamente, durante a recessão $Q \boldsymbol{s}$ excede $\boldsymbol{Q} \boldsymbol{e}$, resultando uma cunha negativa de armazenamento.

Pela figura 4, a seguir, verificamos que o volume da cunha pode ser relacionado com os valores instantâneos de $Q \boldsymbol{e}$ e de $\boldsymbol{Q s}$, por $\boldsymbol{K} \boldsymbol{x}(\boldsymbol{Q} \boldsymbol{e}-\boldsymbol{Q s})$. Além da cunha, há o volume do prisma representado por: $\boldsymbol{K} \boldsymbol{Q}$. Em linhas gerais o parâmetro $\boldsymbol{K}$ é associado ao armazenamento em prisma, enquanto o parâmetro $\boldsymbol{x}$ refere-se ao armazenamento em cunha.

Na primeira expressão $\boldsymbol{x}$ é um parâmetro adimensional que indica a importância relativa de $\boldsymbol{Q} \boldsymbol{e}$ e de $\boldsymbol{Q} \boldsymbol{s}$, para a determinação de $\boldsymbol{M}$, cujo valor varia de 0 a 0,5 .

O parâmetro $\boldsymbol{K}$ tem dimensão de tempo e está associado à distância entre os centros de massa dos hidrogramas de montante de jusante, ou ao tempo médio de deslocamento do transiente no trecho de canal considerado. Por outro lado o parâmetro $\boldsymbol{x}$ é adimensional e está 
associado ao peso relativo ou ponderação entre a entrada e a saída do armazenamento, o que justifica as condições desses parâmetros:

$$
0 \leq x \leq \frac{1}{2}
$$

$$
2 x \leq \frac{\Delta t}{K} \leq 2(1-x)
$$

O armazenamento total é então:

$$
M=K \cdot Q_{S}+K \cdot x \cdot\left(Q_{e}-Q_{s}\right)
$$

ou:

$$
M=K \cdot\left[x \cdot Q_{e}+(1-X) \cdot Q_{s}\right]
$$

eq. 16

Esta é a chamada "equação básica de Muskingum”, que pode ser escrita na forma:

$$
M_{2}-M_{1}=K \cdot\left[x\left(Q_{e}-Q_{s}\right)+(1-x) \cdot\left(Q_{s 2}-Q_{s 1}\right)\right]
$$

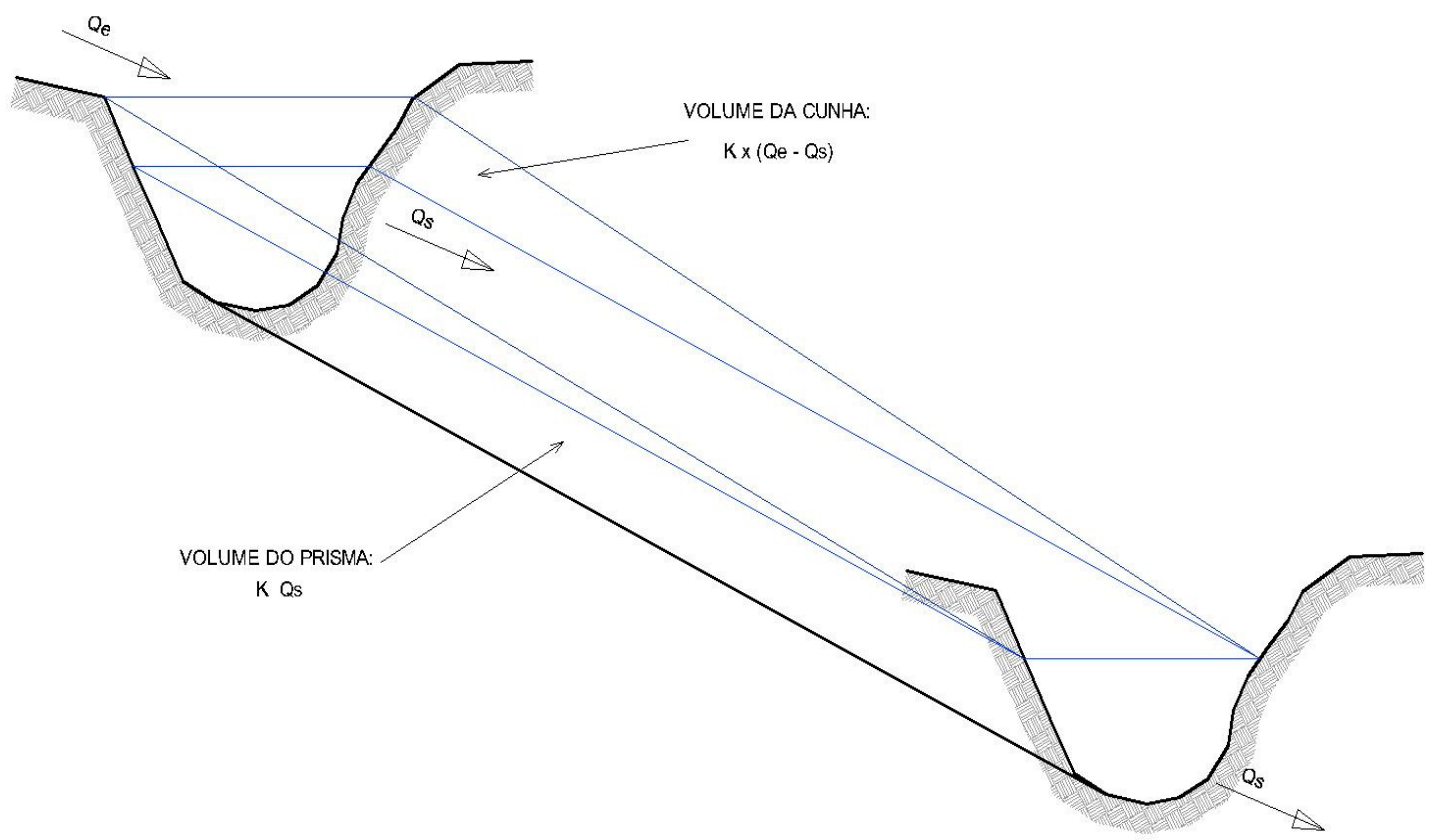

Figura 4: Cunha de amortecimento do método de Muskingum (fonte: WILKEN, 1978) 
- Método de Chicago: Método desenvolvido pelos engenheiros A. L Tholin e C. J. Keifer da municipalidade de Chicago em 1957. Também, efetua a redução do pico de vazão considerando a iteração na sarjeta.

- Método de Izzard: Dentre todos os métodos citados por WILKEN em seu livro, este é o que mais diretamente avalia as características do escoamento sobre leitos de vias urbanas (sarjetas, mais especificamente).

Izzard foi pesquisador do Bureau of Public Rodas, Washington, USA e levou a efeito uma série de experiências de laboratório com chuvas simuladas sobre superfícies revestidas e nuas, empregando dispositivos e equipamentos que possibilitam variar as declividades longitudinais e transversais. As intensidades de chuva simulada atingiram $100 \mathrm{~mm} / \mathrm{hora}$ e as declividades variaram de 0.1 a $4 \%$ para superfícies revestidas e de 1 a $4 \%$ para superfícies nuas. Os comprimentos dos escoamentos superficiais variaram de $3,66 \mathrm{~m}$ a $220 \mathrm{~m}$.

Como resultado das suas experiências, Izzard conseguiu calcular o hidrograma de deflúvio de uma superfície plana, tal como uma via pavimentada ou uma pista de aeroporto, resultante de chuvas de uma ou várias intensidades.

Izzard estudou ainda o escoamento em sarjetas, deduzindo uma fórmula de cálculo de vazão baseada na fórmula de Manning; um normograma para o emprego da formula de Izzard foi construído por WILKEN (1978) e adaptado ao sistema métrico, como visto na figura 5.

Os princípios gerais das experiências já haviam sido empregados por outros pesquisadores anteriormente, mas Izzard realizou-as em maior profundidade e extensão. Uma das principais ferramentas criadas e observadas por Izzard foi o hidrograma elementar que leva em conta o armazenamento superficial. Podemos dizer que se uma superfície impermeável de pequena extensão e exposta a uma chuva de intensidade constante, o hidrograma será semelhante ao mostrada na figura 6. 


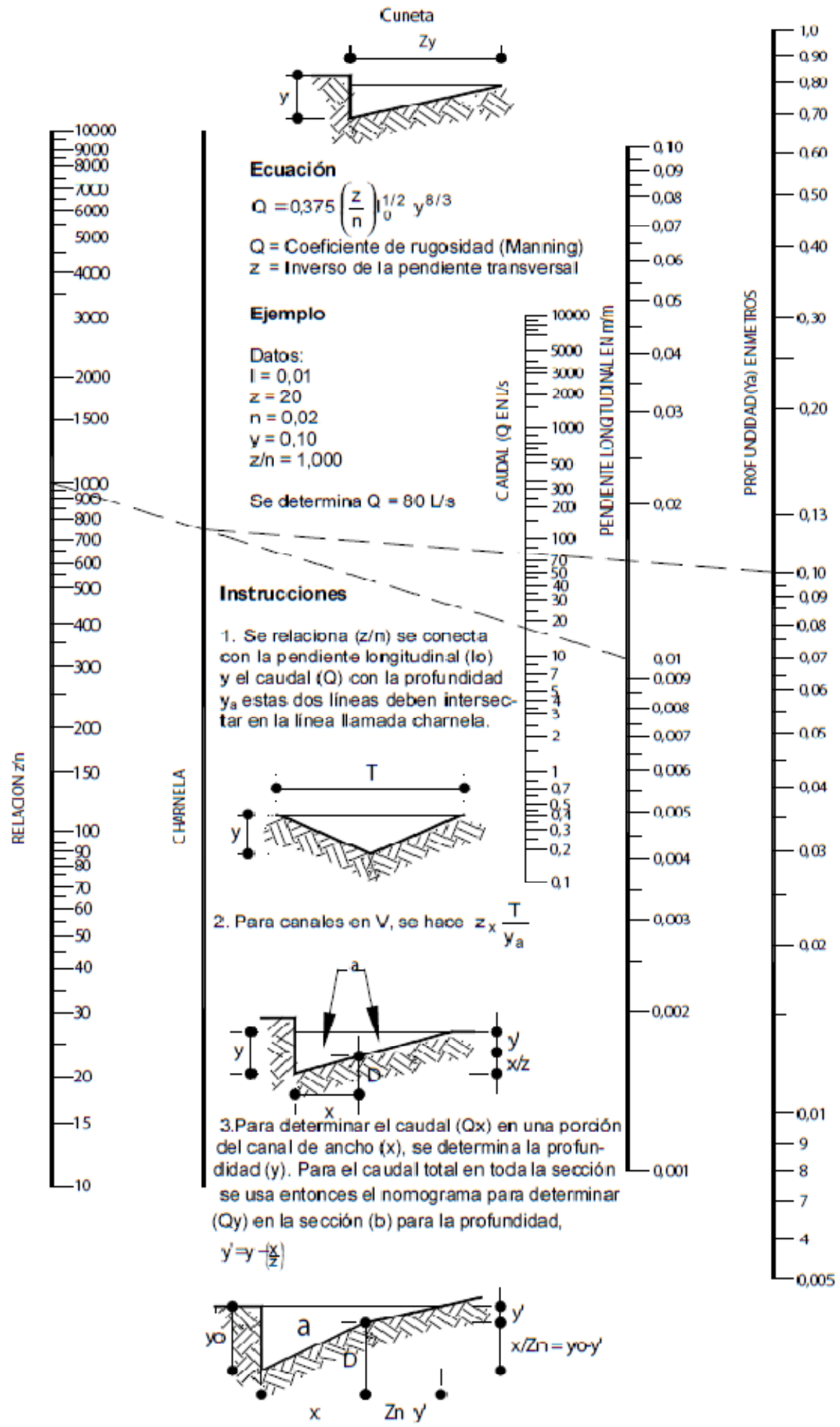

Figura 5: Normograma de dimensionamento de seções triangulares de Izzard (fonte: WILKEN, 1978) 


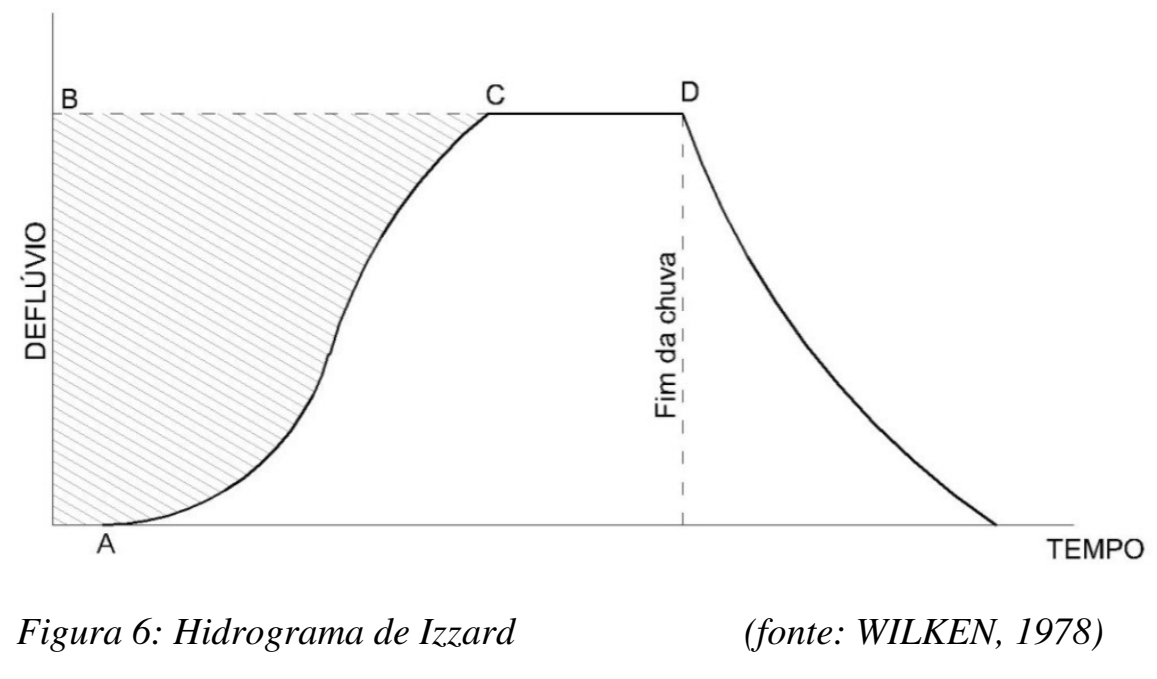

O deflúvio é $\boldsymbol{C} \boldsymbol{i} \boldsymbol{A}$, em que $\boldsymbol{C}=\mathbf{1}$. Como o deflúvio não pode ocorrer sem uma altura finita de água sobre a superfície impermeável, uma parte da chuva é armazenada temporariamente; é a detenção superficial.

A quantidade de água detida desse modo é a diferença entra a afluência total para a superfície (chuva excedente) e a afluência total da área (deflúvio direto). Depois de decorrido um período de tempo, é atingido o equilíbrio (ponto C) do hidrograma, no qual são iguais as duas vazões: o volume de água armazenada corresponde a área $\mathrm{ABC}$ do hidrograma. $\mathrm{A}$ água está em movimento constante, e um elemento de chuva pode passar pela superfície, mas a diferença de volume entre afluente e efluente permanece constante.

Quando a chuva terminar (ponto D do hidrograma), não haverá mais afluência para manter a detenção superficial; a vazão efluente e o volume armazenado na superfície decrescem. Teoricamente, é necessário um tempo infinito para a porção ascendente de o hidrograma atingir o equilíbrio e para a recessão voltar à zero. Na pratica, no entanto, ambas as curvas atingem os seus limites rapidamente. Izzard, experimentalmente, chegou a essa conclusão.

As análises de hidrogramas resultantes de chuvas simuladas, de intensidade constante, indicaram qual a forma do ramo ascendente do hidrograma que pode ser representado por um hidrograma adimensional mostrado na figura 7: 


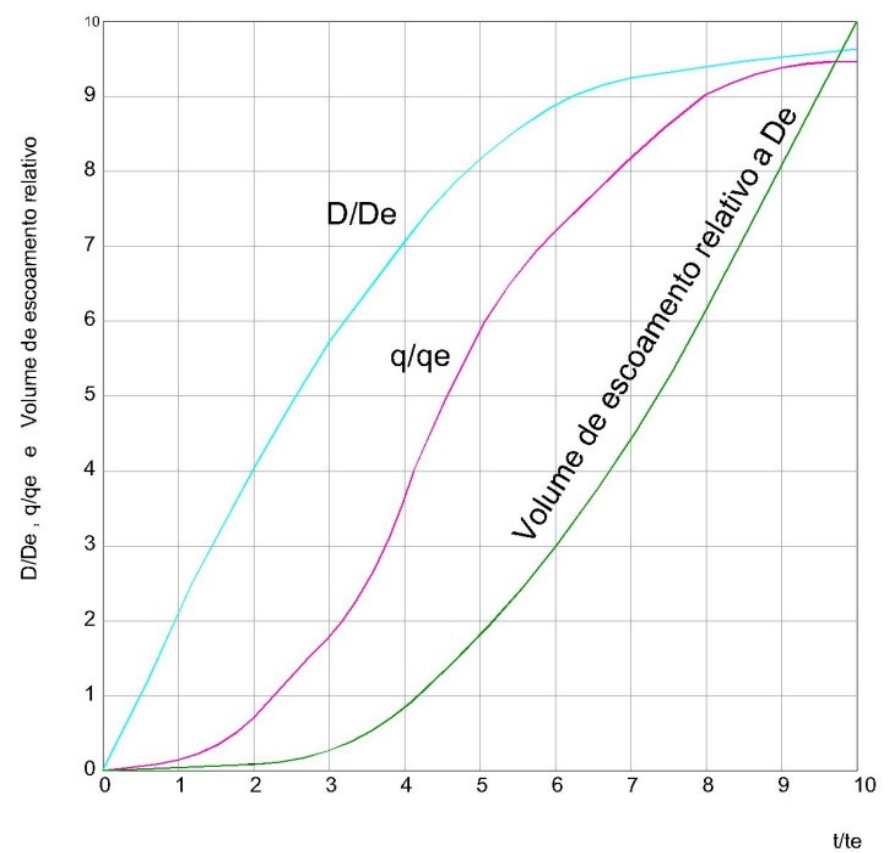

Figura 7: Curvas adimensionais função t/te (adaptado de WILKEN, 1978)

A altura do quadrado representa a intensidade da chuva e sua largura representa o tempo de fato necessário para atingir o equilíbrio.

O tempo de equilíbrio é dado pela expressão:

$$
t_{e}=\frac{2}{60} \cdot \frac{D_{e}}{q_{e}}
$$

em que:

$\boldsymbol{D}_{e}$ : detenção ou volume de água do escoamento superficial em uma faixa de largura unitária;

$\boldsymbol{q}_{e}:$ vazão no equilíbrio;

$\boldsymbol{t}_{e}:$ tempo de equilíbrio em minutos.

O significado geométrico desta equação é simplesmente que o volume de água em detenção no equilíbrio (área acima da curva) é realmente igual ao volume de água que se escoou no tempo requerido para atingir o equilíbrio (área abaixo da curva). 
Sendo " $i$ " a intensidade da chuva em $\mathrm{mm} /$ hora e $L$ o comprimento do escoamento superficial em metros, temos a vazão no equilíbrio por metro de largura de faixa:

$$
q_{e}=\frac{i \cdot L}{1000 \cdot 3600}=2,78 \cdot i \cdot L \cdot 10^{-7}
$$

O volume de detenção De, obtido por Izzard, é representado pela seguinte expressão:

$$
D_{e}=k \cdot L \cdot\left(q_{e}\right)^{\frac{1}{3}}
$$

Substituindo $\boldsymbol{q}_{\boldsymbol{e}}$, pelo seu valor dado pela equação (19), temos:

$$
D_{e}=\frac{k \cdot L^{\frac{4}{3}} \cdot i^{\frac{1}{3}}}{153,3}
$$

$\mathrm{Na}$ qual k é um coeficiente de proporcionalidade empírico, que Izzard denominou “coeficiente de retardo", expresso por:

$$
k=\frac{0,0000186 \cdot i+C}{S_{0}^{\frac{1}{3}}}
$$

em que:

$\boldsymbol{S}_{\boldsymbol{0}}:$ declividade em $\mathrm{m} / \mathrm{m}$

$\boldsymbol{i}$ : intensidade da chuva em $\mathrm{mm} / \mathrm{hora}$

C : termo que se refere a rugosidade dos revestimentos e indicados na tabela 10:

Tabela 10: Valores de C (Izzard)

\begin{tabular}{cc}
\hline CONDIÇÃO DA SUPERFÍCIE & Valores de C \\
\hline Superfície de asfalto lisa & 0,005 \\
Pavimento de concreto & 0,008 \\
Macadame betuminoso & 0,011 \\
Terra batida & 0,031 \\
Terreno turfoso denso & 0,04 \\
\hline
\end{tabular}


Existe limitação, no entanto ao uso das equações de Izzard. Tal limite refere-se ao produto $i L$ menor que 3780 ( $\mathrm{mm} /$ hora x metro). Além desse limite, segundo sua experiência, o escoamento é mais turbulento que laminar; não obstante observa que, no caso de emprego das fórmulas além daquele limite, os resultados estarão a favor da segurança, uma vez que a detenção calculada pela fórmula será menor que a verdadeira. No caso de declividade superior a $4 \%$ o escoamento, muitas vezes, torna-se pulsante.

O volume de detenção $\boldsymbol{D} \boldsymbol{e}$ indicado pela fórmula aumenta com a potência de $1 / 3$ da vazão; na realidade, a potência varia entre $67 \%$ a $133 \%$ da indicada, todavia, essa variação não invalida a fórmula. A determinação de volume de detenção D para um tempo dado no ramo ascendente do hidrograma é feita multiplicando a ordenada correspondente a $t / t_{e}$ por $\boldsymbol{D}_{\boldsymbol{e}}$.

De modo semelhante, o volume de deflúvio pode ser determinado multiplicando a ordenada da curva "volume relativo $D_{e}$ ", referente ao tempo $t / t_{e}$ por $\boldsymbol{D}_{\boldsymbol{e}}$. A vazão é determinada para qualquer tempo, por meio do hidrograma adimensional da mesma maneira empregando a curva q/qe.

Segundo verificou Izzard, experimentalmente, a detenção superficial tem grande influência no esgotamento de áreas pequenas; assim o valor $\boldsymbol{t}_{\boldsymbol{e}}$ definido acima parece que dá um valor bastante exato da duração crítica da chuva $\boldsymbol{t}$, igual ao tempo de concentração $\boldsymbol{t} \boldsymbol{c}$. Associando as equações deduzidas, obteve o tempo $\boldsymbol{t}_{\boldsymbol{e}}$ abaixo indicado, lembrando que deve ser respeitada a condição de que o escoamento seja laminar:

$$
t_{e}=\frac{783 \cdot k \cdot L^{\frac{1}{3}}}{(C \cdot i)^{\frac{2}{3}}}
$$

em que:

\section{C.i : intensidade do excesso de chuva em $\mathrm{mm} / \mathrm{hora}$}

Uma vez determinado o hidrograma de escoamento, Izzard propõe pelo estudo do escoamento na sarjeta. Assim é preciso incluir um acréscimo como tempo de percurso e armazenamento até o ponto de saída da sarjeta. 
A sarjeta armazena temporariamente um grande volume de água pluvial; assim, o tempo necessário para atingir o equilíbrio no escoamento pela sarjeta é geralmente muito maior que o tempo requerido para atingir a vazão de equilíbrio, no escoamento superficial. Por outro lado, se a sarjeta for suficientemente extensa, a duração da chuva (ou volume de água de chuva) pode não ser suficientemente grande para satisfazer as necessidades de armazenamento no equilibro e conseqüentemente, a máxima vazão do escoamento pode ser substancialmente menor que a vazão de equilíbrio. A esse respeito, Izzard relata em seu trabalho, uma experiência na qual uma sarjeta de 60 metros de comprimento e $0.5 \%$ de declividade longitudinal drenando uma área pavimentada de $12,80 \mathrm{~m}$ de largura e $2 \%$ de declividade transversal sujeita a uma chuva de intensidade $150 \mathrm{~mm} /$ hora e de 3 minutos de duração, o hidrograma mostrou pico de 25,5 1/s o qual é $77 \%$ da vazão calculada pelo método racional, ocorrendo 0,7 minutos após o fim da chuva. O cálculo da iteração pode ser feito pelo método de Muskingum, como sugestão de Izzard.

A hidrologia mostra que o volume armazenado no leito de um curso de água com uma dada vazão de deflúvio na ascensão do hidrograma é maior que o volume armazenado no mesmo curso de água com a mesma vazão na recessão do hidrograma. O mesmo fenômeno ocorre numa sarjeta. Na experiência acima relatada por Izzard, na sarjeta de 60 metros de comprimento, o armazenamento observado foi de 2,70 $\mathrm{m}^{3}$. Quando a chuva cessou depois de 3 minutos, o volume era 2,49 $\mathrm{m}^{3}$ e a vazão 18,1 1/s; aproximadamente 2 minutos depois o pico havia passado e a vazão baixou outra vez a 18,1 1/s, mas o armazenamento era somente de $1,64 \mathrm{~m}^{3}$.

A figura 8, a seguir, dá uma idéia do que aconteceu. Aos 3 minutos o perfil da superfície da água tem a mesma altura do ponto a 60 metros que aos 5 minutos, mas ele é distintamente convexo para cima ou de forma parabólica, enquanto que aos 5 minutos ele é quase uma linha reta. A altura d'água na extremidade de montante mudou muito pouco, com a inclinação caindo mais nas proximidades do meio. 


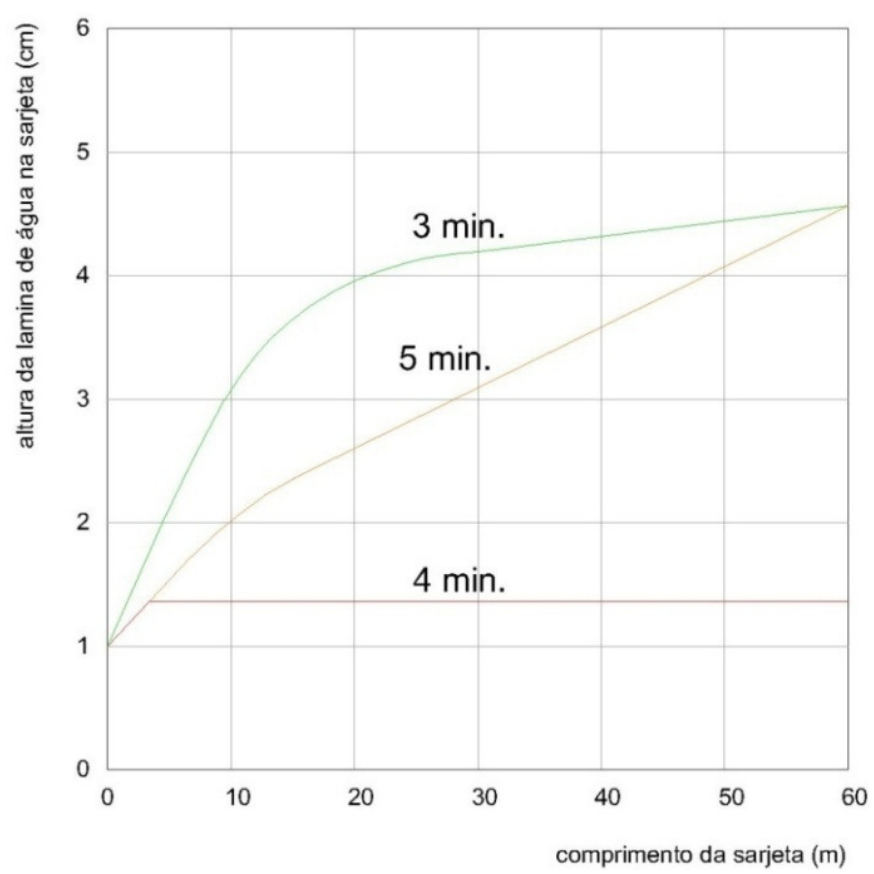

Figura 8: Alturas de água ao longo da sarjeta de 60 metros (Adaptado de WILKEN, 1978)

O tempo para atingir a vazão de equilíbrio da sarjeta $t c$, é obtido substituindo na equação (18), a detenção total mais o volume de armazenamento no equilíbrio, assim temos:

$$
t_{c}=\frac{2}{60} \cdot \frac{D_{e} \cdot L_{g}+S_{e}}{q_{e} \cdot L_{g}}
$$

O armazenamento na sarjeta no equilíbrio é estimado por Izzard em:

$$
S_{e}=\frac{2}{3} \cdot A_{e} \cdot L_{g}
$$

em que:

Ae : é a área da seção transversal da sarjeta em $\mathrm{m}^{2}$, quando a vazão for Qe;

$\boldsymbol{L g}$ : é o comprimento da sarjeta. 
Substituindo resulta:

$$
\begin{gathered}
t_{c}=t_{e}+\frac{A_{e}}{45 \cdot q_{e}} \\
z=\tan \theta
\end{gathered}
$$

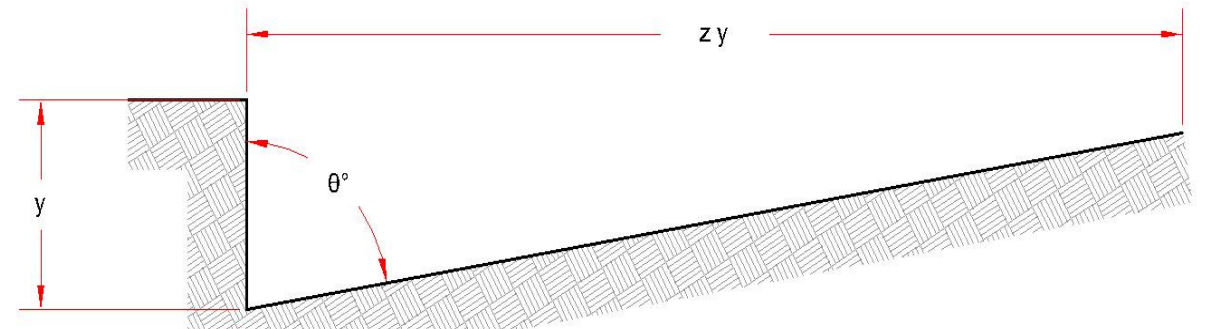

Figura 9: Seção transversal da sarjeta

Nesta equação temos:

$$
\begin{gathered}
A_{e}=\frac{z \cdot y^{2}}{2} \\
\mathrm{e} \\
Q_{o}=0,375 \cdot z \cdot \frac{S o^{1 / 2}}{n} \cdot y^{\frac{8}{3}}
\end{gathered}
$$

Fazendo:

$$
B=0,375 \cdot \frac{Z}{n} \cdot I_{g}{ }^{1 / 2}
$$

Obtemos:

$$
y_{o}=\left(\frac{Q}{B}\right)^{3 / 8}
$$

Hicks (1960), afirma que $t_{e}$ é independente da declividade longitudinal do pavimento; assim o tempo de escoamento da água na sarjeta é: 


$$
t_{g}=t_{c}-t_{e}=\frac{A_{e}}{45 \cdot q_{e}}
$$

eq. 30

Os valores de $t_{c}$ para cada intensidade são também subtraídos da duração da chuva com aquela intensidade para cada período de retorno. Num exemplo citado no trabalho de Izzard, para uma dada equação de chuva, a duração era de 6,3 minutos dando uma intensidade média de $100 \mathrm{~mm} /$ hora, para um período de retorno de um ano; para a mesma intensidade obteve-se 3,1 minutos. Temos:

$$
T_{g}=6,3-3,1=3,2 \text { minutos }
$$

Para uma seção de sarjeta, com $I_{g}=0,002, z=50, n=0,017$, obtemos:

$$
\begin{gathered}
B=0,375 \cdot \frac{50}{0,017} \cdot 0,045=49,6 \\
y_{o}=\left(\frac{Q}{49,6}\right)^{3 / 8}
\end{gathered}
$$

eq. 31

Substituindo na equação (19) $i$ e $L_{g}$ pelos seus valores, obtemos:

$$
q_{e}=\frac{0,100 \cdot 30}{1000 \cdot 3600}=8,34 \times 10^{-4} l / s \cdot m
$$

eq. 32

Substituindo os dados nas equações deduzidas, podemos verificar que uma sarjeta de 30 metros necessitaria de 3,2 minutos para atingir o equilíbrio, além do tempo de equilíbrio no escoamento superficial. 


\subsubsection{ESCOAMENTO NAS RUAS E SARJETAS}

A chuva que cai sobre o pavimento, dá origem ao escoamento superficial, que se inicia transversalmente a pista até atingir as guias e sarjetas. As guias e sarjetas funcionam como canais e precisam ser dimensionadas como tais. A profundidade do escoamento superficial deverá, de modo geral, ser zero no eixo da pista, e aumentando a medida que se aproxima da guia.

A água que flui nas guias e sarjetas, devido à chuva que cai diretamente sobre o escoamento, no pavimento e nos terrenos adjacentes escoará até alcançar um ponto de captação, normalmente uma boca de lobo. A figura 10 representa a configuração de um escoamento em guias e sarjetas. À medida que a água escoa e áreas adicionais contribuem para o aumento da vazão, sua largura aumentará e atingirá progressivamente as faixas de trânsito causando interferência no trafego de veículos.

A determinação da capacidade de escoamento da rua deve ser baseada em duas considerações:

a) Verificação da capacidade teórica de escoamento, baseada em critérios de classificação de ruas que limitem a inundação máxima do pavimento;

b) Ajuste às condições reais, baseado na aplicação de fatores de redução da capacidade de escoamento. 


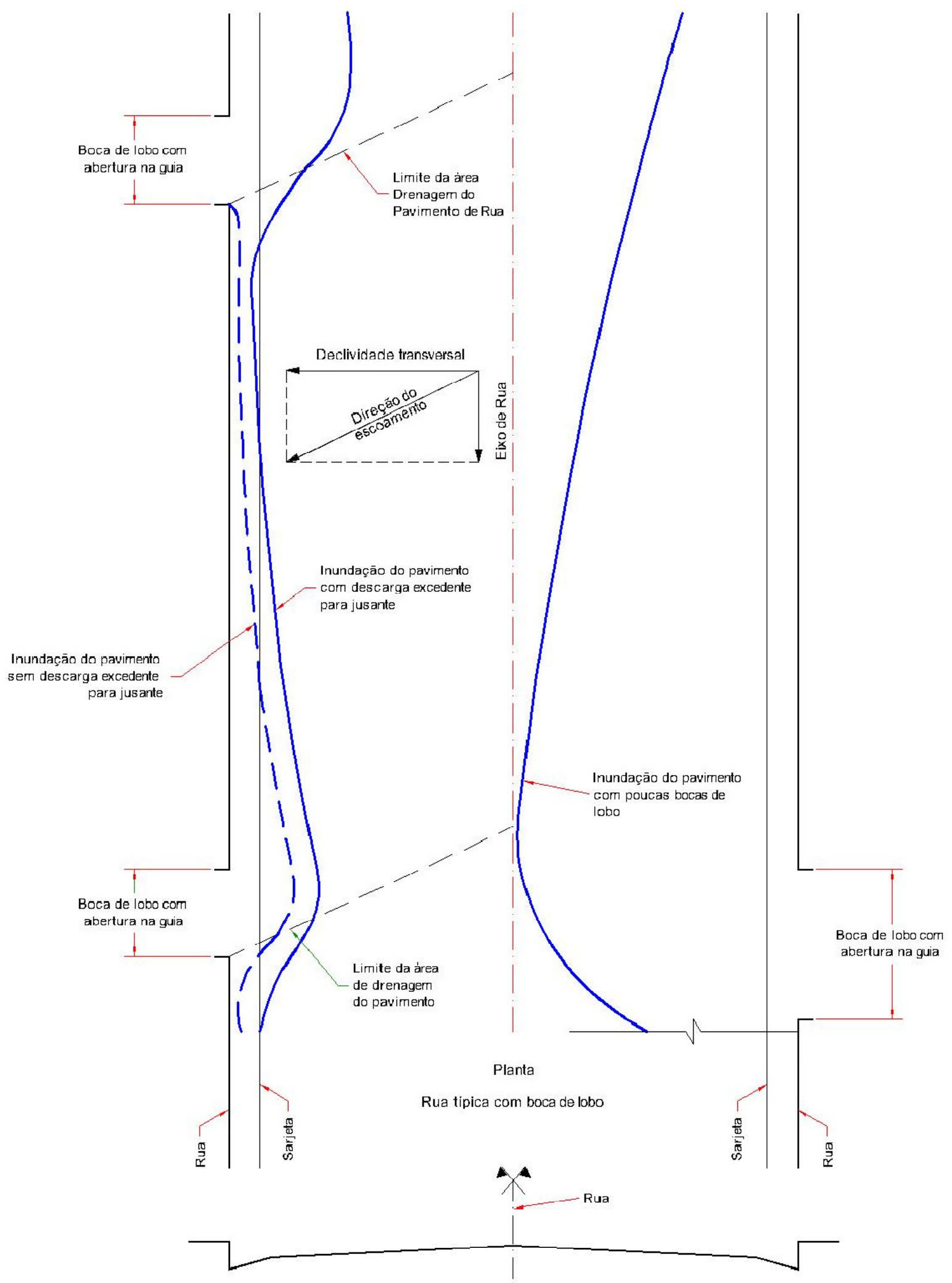

Figura 10: Comportamento típico do escoamento superficial numa seção de via urbana. Fonte: CETESB, 1986 
James C. Y. Guo (2000), pesquisador norte americano em um de seus artigos sobre capacidade de escoamento de vias, cita que a capacidade de escoamento das vias é dependente, em primeira instância, das características hidrogeométricas destas e limitadas pelas características de tráfego local. Em seu artigo "Street Storm Water Conveyance Capacity", Guo, propõe que o produto profundidade de escoamento e da velocidade do escoamento seja critério determinante na verificação da capacidade de escoamento de vias. $\mathrm{O}$ princípio de cálculo para avaliação e indicado como sendo a equação de Izzard, que é uma modificação da equação de Manning.

Na literatura técnica brasileira, as equações de Manning e Izzard são as recomendadas para cálculo da capacidade de escoamento de águas pluviais em sarjetas. Desta capacidade, sabemos, depende a localização de bocas-de-lobo, instalações que recolhem as águas de chuvas que escoam pelas sarjetas, conduzindo-as às galerias de águas pluviais e que de certa forma garantem a manutenção dos parâmetros de trafegabilidade.

Os reflexos do mal dimensionamento das sarjetas são prontamente percebidos por meio do alagamento dos passeios públicos e excesso de volume escoando, dificultando a travessia dos pedestres, além de causar um desgaste prematuro do pavimento da via. A tabela 11 exemplifica critérios adotados e recomendados, em termos de largura de inundação, conforme manual CETESB (1986):

Tabela 11: Faixas de alagamento permitidas

\begin{tabular}{cl}
\hline $\begin{array}{c}\text { Classificação } \\
\text { das ruas }\end{array}$ & \multicolumn{1}{c}{ Inundação máxima } \\
\hline Secundária & Sem transbordamento sobre a guia. O escoamento pode atingir a crista da rua. \\
Principal & $\begin{array}{l}\text { Sem transbordamento sobre a guia. O escoamento deve preservar pelo menos uma } \\
\text { faixa de tráfego. }\end{array}$ \\
Avenida & $\begin{array}{l}\text { Sem transbordamento sobre a guia. O escoamento deve preservar pelo menos uma } \\
\text { faixa de tráfego, em cada direção. }\end{array}$ \\
Expressa & Nenhuma inundação é permitida em qualquer faixa de transito.
\end{tabular}

Fonte: CETESB, 1986

Segundo a CETESB (1979), os principais tipos de interferências causados pelo escoamento superficial ao tráfego de veículos, são: 
a) Deslizamento do veículo sobre as superfícies de rolamento, provocada por redução de atrito entre os pneus e o pavimento;

b) Espirro de água, pela passagem dos veículos sobre a água retida na superfície do pavimento;

c) Acúmulo de água sobre a superfície do pavimento ou retenção de água em depressões da superfície de rolamento;

d) Alteração de posição de estacionamento de veículos, por influência de depressões para bocas de lobo, recapeamento ou excesso de declividade transversal da sarjeta;

e) Efeitos sobre os pedestres, ciclistas e motociclistas. Riscos de acidentes provocados pela geometria, localização, execução e manutenção inadequadas dos componentes da drenagem, $e$;

f) Alagamento da rua elou larguras de escoamento superficial na sarjeta maior que os limites de cálculo.

Segundo ainda a CETESB (1979), as interferências entre o escoamento superficial pela rua e o tráfego podem ser atribuídas a:

a) O escoamento superficial transversal ao pavimento, cuja direção principal é a do eixo da rua para as sarjetas;

b) Chuvas que se precipitam sobre terrenos adjacentes e são concentradas nas ruas gerando fluxos que podem invadir a pista;

c) Acúmulos de água em depressões, $e$;

d) Jatos (espirros) de água sobre os pedestres e outros.

Justamente visando que tais transtornos, acima citados sejam evitados, algumas normas de projeto padronizam a geometria das vias. Essa padronização contempla itens desde altura de guias, larguras e declividades de sarjetas, declividades transversais e longitudinais de vias.

O foco principal deste estudo é a aplicação dos conceitos, aqui discutidos, a regiões consideradas planas. Por esse motivo, no que se refere a este aspecto, foram consultadas diferentes normas e manuais de projeto com diferentes padrões de declividade longitudinal mínima, resumidas na tabela 12 . 
Tabela 12: Declividades longitudinais mínimas exigidas

\begin{tabular}{lc}
\hline Manual ou Critério & $\begin{array}{c}\text { Declividade } \\
\text { longitudinal em \% }\end{array}$ \\
\hline Clark County - USA & 0,4 \\
Denver - USA & 0,5 \\
ASSHTO, 1990 & $0,5(0,3)$ \\
Federal Highway Administration - USA & 0,3 (mínimo) \\
Manual de drenagem urbana de Porto Alegre - RS - Brasil & 0,4 \\
Manual de drenagem urbana do município de São Paulo - SP - Brasil & 0,5 \\
\hline
\end{tabular}

A FHWA (1986) afirma que "os pavimentos devem possuir declividade longitudinal razoável para favorecer a drenagem, e ao mesmo tempo, possuir declividade transversal relativamente pequena para o conforto do motorista". No que concerne aos critérios de declividade transversal, $2 \%$ tem sido valor bastante usual, tanto no Brasil quanto em países do exterior. O manual de projeto do distrito de drenagem de Denver (1999) cita $2 \%$ como sendo a declividade transversal adotada para o dimensionamento de vias urbanas.

Como dito anteriormente, Manning e Izzard são as equações citadas mais usadas na verificação da capacidade de transporte de vazão. A equação sugerida por Bidone e Tucci (1995) - eq. 33 -, é a equação de Manning enquanto que a proposta pela CETESB (1986) eq. 34 - é a modificação de Izzard. A seguir efetua-se a apresentação das referidas equações e um breve estudo comparativo, demonstrando a diferença nos resultados produzidos pelas duas equações, apesar da semelhança de bases entre elas.

$$
\begin{gathered}
Q_{o}=0,375 \cdot z \cdot \frac{S_{0}{ }^{1 / 2}}{n} \cdot y^{\frac{8}{3}} \\
z=\tan \theta
\end{gathered}
$$

$$
Q_{o}=\frac{A \cdot R_{h}{ }^{2 / 3} \cdot \sqrt{S_{0}}}{n}
$$


em que:

$Q=v a z \tilde{a} o \mathrm{em} \mathrm{m}^{3} / \mathrm{s}$

$\boldsymbol{A}=$ área em $\mathrm{m}^{2}$;

$\boldsymbol{R} \boldsymbol{h}=$ raio hidráulico;

$\boldsymbol{S}_{\boldsymbol{0}}=$ declividade longitudinal da sarjeta $(\mathrm{m} / \mathrm{m})$;

$\boldsymbol{n}$ = coeficiente de rugosidade $\left(\mathrm{m}^{1 / 6}\right)$ - considerado neste estudo o valor de 0,016;

$z$ =inverso da declividade transversal;

$\boldsymbol{Y}=$ profundidade junto a linha de fundo.

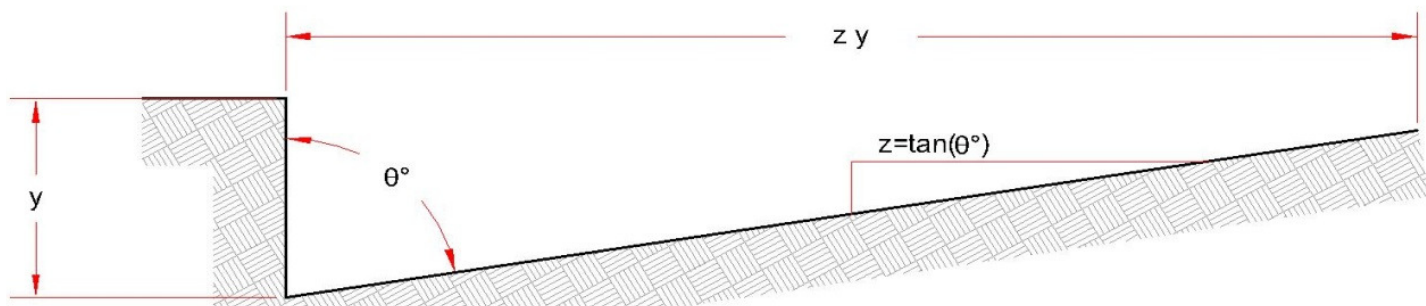

Figura 11: Geometria de uma sarjeta típica

Os pesquisadores Gerson F. Fattori e Antonio D. Benetti (ABES, $24^{\circ}$ Congresso, 2000), em seu artigo sobre o cálculo de descarga de sarjetas em sistemas de drenagem, fizeram uma comparação entre os resultados das duas formas de determinação da capacidade de escoamento em sarjetas.

A tabela 13 apresenta os resultados de simulações usando-se as Equações (33) e (34) para diferentes declividades e as condições de contorno considerando a segurança de tráfego e faixas de alagamento adotadas pelo Departamento de Esgotos Pluviais de Porto Alegre, em que fica, para o caso deste estudo, adotou-se lâmina na guia de $0,15 \mathrm{~m}$ e largura da lamina de 1,00m. A rugosidade considerada foi igual a 0,016. Observa-se que os valores das capacidades de escoamento das sarjetas calculadas pelas duas metodologias apresentam resultados que diferem em até 31,5\%. As diferenças absolutas aumentam com o incremento das declividades. 
Tabela 13: Comparação de capacidade de condução - Manning X Izzard

\begin{tabular}{ccccc}
\hline $\begin{array}{c}\text { Declividade } \\
\text { \% }\end{array}$ & $\begin{array}{c}\mathbf{Q} \\
\mathbf{l} / \mathbf{s}\end{array}$ & $\begin{array}{c}\mathbf{Q} \text { (Izzard) } \\
\mathbf{1} / \mathbf{s}\end{array}$ & $\begin{array}{c}\text { Diferença } \\
\mathbf{l} / \mathbf{s}\end{array}$ & $\begin{array}{c}\text { Diferença } \\
\text { \% }\end{array}$ \\
\hline 1 & 75,5 & 99,3 & 23,8 & 31,5 \\
2 & 106,7 & 140,4 & 33,6 & 31,5 \\
3 & 130,7 & 171,9 & 41,2 & 31,5 \\
4 & 150,1 & 198,5 & 47,6 & 31,5 \\
5 & 168,8 & 221,9 & 53,2 & 31,5 \\
6 & 184,9 & 243,1 & 58,2 & 31,5 \\
7 & 199,7 & 262,6 & 62,9 & 31,5 \\
8 & 213,5 & 280,7 & 67,3 & 31,5 \\
9 & 226,4 & 297,8 & 71,3 & 31,5 \\
10 & 238,7 & 313,9 & 75,2 & 31,5 \\
11 & 250,3 & 329,2 & 78,9 & 31,5 \\
12 & 261,4 & 343,8 & 82,4 & 31,5 \\
13 & 272,1 & 357,9 & 85,7 & 31,5 \\
14 & 282,4 & 371,4 & 89,0 & 31,5 \\
15 & 292,3 & 384,4 & 92,1 & 31,5 \\
\hline
\end{tabular}

Fonte: Fattori et. al, 2000

A conclusão dos autores foi que o emprego da equação de Izzard permite uma maior utilização da capacidade de escoamento das sarjetas do que a equação de Manning, desta forma trazendo economia no custo de implantação do sistema de drenagem urbana. Há, no entanto, que se definir qual modelo empregar na determinação da capacidade de escoamento das sarjetas, fator decisivo na definição do posicionamento das bocas-de-lobo. A escolha do modelo de cálculo tem implicação direta nos custos do sistema de micro-drenagem.

Como o objetivo de estudo é tratar daquelas declividades inferiores àquelas pesquisadas e tabuladas anteriormente, efetuou-se o mesmo estudo comparativo anteriormente apresentado, considerando a faixa de declividades abaixo a 1\%. Os resultados são apresentados na tabela 14: 
Tabela 14: Comparação de capacidade de condução para baixas declividades

\begin{tabular}{ccccc}
\hline $\begin{array}{c}\text { Declividade } \\
\mathbf{\%}\end{array}$ & $\mathbf{Q}$ & $\mathbf{Q}$ & \multicolumn{2}{c}{ Diferença } \\
$\mathbf{1 / s}$ & $\mathbf{1 / s}$ & $\mathbf{1 / s}$ & $\mathbf{\%}$ \\
\hline 0,12 & 26,1 & 34,4 & 8,2 & 31,5 \\
0,15 & 29,2 & 38,4 & 9,2 & 31,5 \\
0,2 & 33,7 & 44,4 & 10,6 & 31,5 \\
0,3 & 41,3 & 54,4 & 13,0 & 31,5 \\
0,4 & 47,7 & 62,8 & 15,0 & 31,5 \\
0,5 & 53,4 & 70,2 & 16,8 & 31,5 \\
0,6 & 58,5 & 76,9 & 18,4 & 31,5 \\
0,7 & 63,1 & 83,0 & 19,9 & 31,5 \\
0,8 & 67,5 & 88,8 & 21,3 & 31,5 \\
0,9 & 71,6 & 94,2 & 22,6 & 31,5 \\
1,0 & 75,5 & 99,2 & 23,8 & 31,5 \\
\hline
\end{tabular}

Nota-se que a diferença relativa continua, assim como ainda pode-se afirmar que quanto maior a declividade, mais acentuada é a diferença absoluta entre as duas metodologias. Conclui-se que a utilização da equação de Manning, sem a alteração proposta por Izzard, conduz a resultados mais conservadores.

Ainda assim, outro ponto a verificar-se é que a equação de Izzard simplificada, do modo como apresentada acima, computa apenas o escoamento pela sarjeta ou assume que a declividade de pavimento, é a mesma que a da sarjeta. Esta situação muitas vezes não simula perfeitamente as condições usuais nas vias urbanas. Outro ponto a ser levantado sob o ponto de vista da simulação mais real do funcionamento do escoamento em sarjetas é a existência de obstruções.

Diante das incertezas referentes a situação das guias e sarjetas no momento da ocorrências de precipitações, alguns manuais de projeto, recomendam fatores de redução de capacidade de escoamento. A tabela 15, retirada do manual DAEE/CETESB (1980), apresenta recomendações de fatores de redução de vazão em função da declividade longitudinal. É de se entender o critério declividade, visto que geralmente quão menor esta é, maior é a possibilidade de acúmulo dos sedimentos. 
Tabela 15: Fatores de redução de escoamento das sarjetas

\begin{tabular}{cc}
\hline $\begin{array}{c}\text { Declividade } \\
\text { da sarjeta }(\%)\end{array}$ & Fator de redução \\
\hline 0 a 1 & 0,90 \\
1 a 3 & 0,80 \\
5,0 & 0,50 \\
6,0 & 0,40 \\
8,0 & 0,27 \\
10 & 0,20 \\
\hline Fonte: DAEE/CETESB, 1980
\end{tabular}

A figura 12 apresenta graficamente o (FR) fator de redução de vazão na sarjeta:

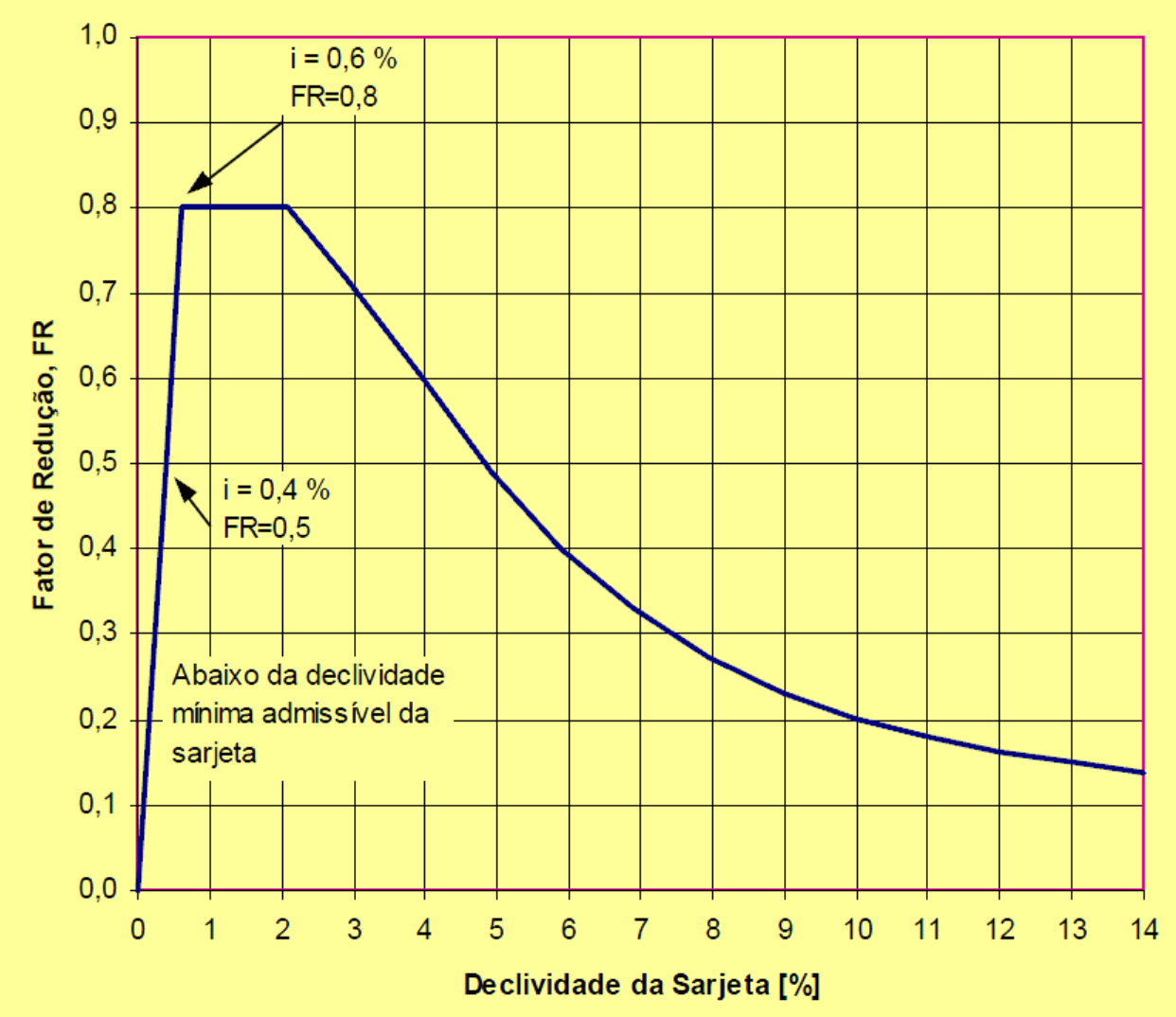

Figura 12: Fator de redução de vazão na sarjeta em função da declividade longitudinal

Para os estudos desenvolvidos neste trabalho, não foi aplicado o Fator de redução, já que limitaria muito a utilização das declividades do modelo proposto. $\mathrm{O}$ objetivo é justamente 
simular o que ocorre com tais declividades e o fator de redução não tem fundamento hidrodinâmico conhecido.

Para efeito de dimensionamento hidráulico das ruas, assim como GUO (2000) efetua seus estudos considerando a geometria de todos os componentes da drenagem de uma seção típica de rua, tal premissa passará a ser seguida em todos os estudos deste trabalho. Sabe-se então que uma seção de via urbana é composta basicamente por:

$$
\begin{aligned}
& \text { - leito carroçável; } \\
& \text { - guias; } \\
& \text { - sarjetas; } \\
& \text { - e calçadas. }
\end{aligned}
$$

A figura 13, ilustra a situação típica de posicionamento dos elementos citados anteriormente:

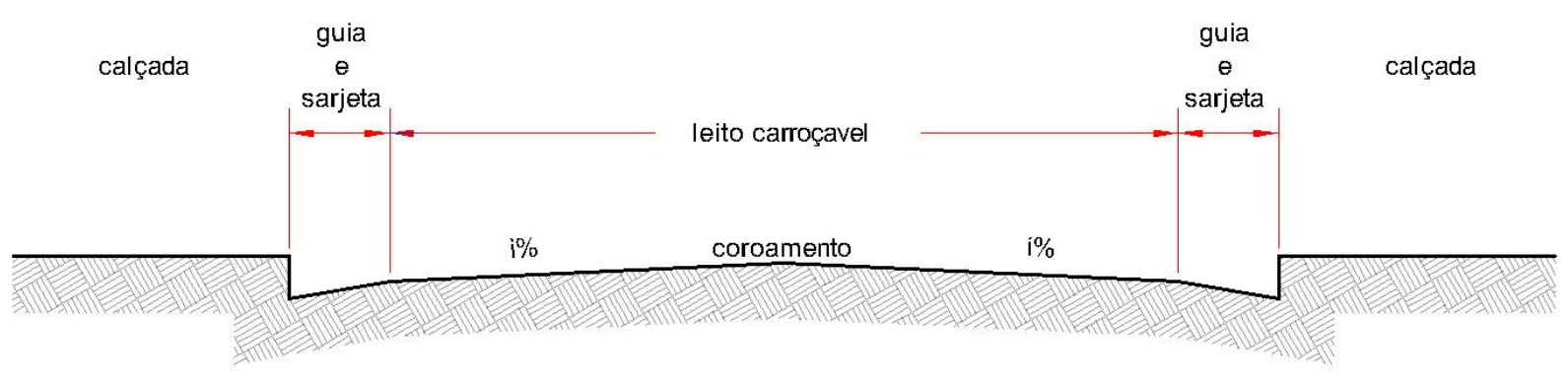

Figura 13: Seção transversal típica

Para a análise de seções do conjunto rua-sarjeta-pavimento é proposta a geometria indicada na figura 14 .

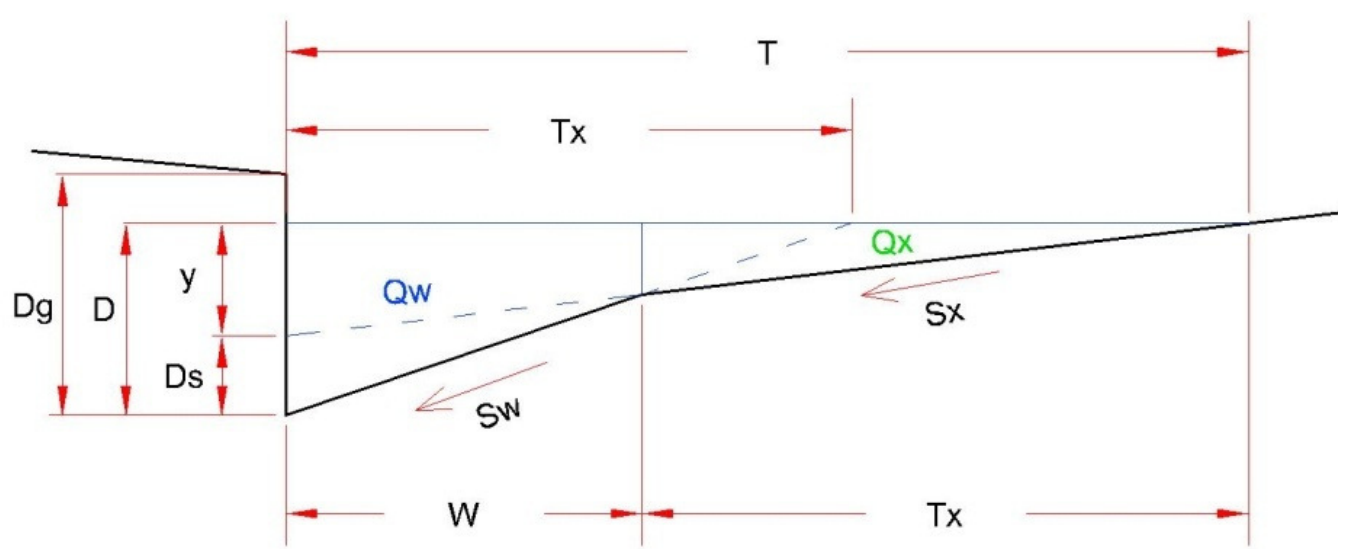

Figura 14: Geometria de sarjeta e leito carroçável - seção composta 
Podem ser considerados dois escoamentos a calcular, sendo:

- vazão da sarjeta $\left(Q_{w}\right)$;

- vazão lateral $\left(Q_{x}\right)$.

Da figura decomposta, pode-se dizer que:

$$
D=y+D_{s}
$$

eq. 35

$$
S_{w}=S_{x}+\frac{D_{s}}{W}
$$

$$
T_{X}=\frac{D}{S_{w}}
$$

$$
T=W+T_{X}
$$

eq. 38

Segundo o Manual de Drenagem de auto-estradas do Departamento de Estradas de Rodagem dos Estados Unidos (1984), a capacidade de vazão de uma seção característica depende, como sabido, da geometria da seção, sua rugosidade e declividade, podendo ser expressa por Manning modificado da forma:

$$
Q=\frac{1}{n} \cdot S_{t}^{\frac{5}{3}} \cdot T^{\frac{8}{3}} \cdot \sqrt{S_{0}}
$$

eq. 39

em que:

$Q=v a z \tilde{a} o \mathrm{em} \mathrm{m}^{3} / \mathrm{s}$

$\boldsymbol{n}=$ coeficiente de rugosidade $\left(\mathrm{m}^{1 / 6}\right)$;

$\mathbf{S t}=$ declividade transversal da seção;

$\boldsymbol{T}=$ largura molhada em $\mathrm{m}$;

$\boldsymbol{S}_{\boldsymbol{0}}=$ declividade longitudinal em $\mathrm{m} / \mathrm{m}$. 
Aplicando-se as equações deduzidas da figura decompostas à equação (39), temos:

$$
\begin{gathered}
Q_{x}=\frac{1}{n} \cdot S_{x}^{\frac{5}{3}} \cdot T_{x}^{\frac{8}{3}} \cdot \sqrt{S_{0}} \\
Q_{w}=\frac{1}{n} \cdot S_{w^{\frac{5}{3}}} \cdot\left[T_{x^{\frac{8}{3}}}-\left(T_{x}-W\right)^{\frac{8}{3}}\right] \cdot \sqrt{S_{0}}
\end{gathered}
$$

O escoamento total da seção pode ser determinado então se somando as vazões das duas seções propostas:

$$
Q=Q_{x}+Q_{w}
$$

\subsection{ASPECTOS TEÓRICOS DO ESCOAMENTO LIVRE}

\subsubsection{ESCOAMENTO LIVRE E SUAS CARACTERÍSTICAS}

O estudo do escoamento, efetuado na engenharia hidráulica conta com diversos métodos de resolução do problema, que se aplicam ou não, conforme o caso de estudo. Essa é a razão principal, pela qual se classificam os diferentes modos e formas de ocôrrencia dos escoamentos na natureza. Cada uma delas requer um diferente enfoque de estudo.

Um escoamento num conduto poder ser, preliminarmente classificado como livre ou forçado, tendo como critério, a existência ou não da superficie do fluido sujeita a pressão atmosférica. Rios e cursos d'água naturais ou artificiais, são os melhores exemplos de escoamento livre. Citado por CHOW (1959), a avaliação e o estudo do escoamento livre é tarefa bem mais complexa do que o estudo dos escoamentos em condutos fechados, dada variações de forma, rugosidade, vazão e outros fatores intervenientes.

Tratando-se dos escoamentos livres, estes podem ser classificados e descritos de diversos modos, tendo como critérios principais de classificação, tempo e espaço. Assim, a classificação fica: 


\section{a) Tempo como critério:}

- Escoamento permanente: quando não há alteraçao na profundidade do escoamento, sendo considerado constante durante o intervalo de tempo de estudo;

- Escoamento não-permanente: quando há alteração na profundidade do escoamento com o tempo; na maioria dos casos de engenharia hidráulica, a verificação para o caso do escoamento permanente é suficiente e a mais comumente feita; existem situações, no entanto, em que se faz necessária a averiguação do efeito de por exemplo, passagens de ondas de cheia em canais, que somente são possíveis considerando-se que o escoamento não é permanente.

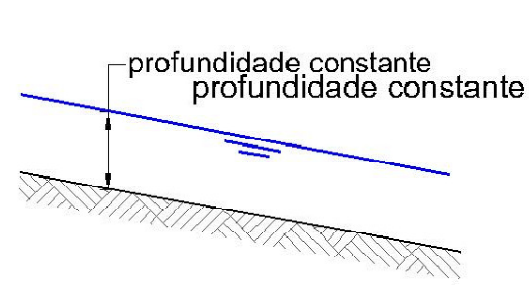

Escoamento Uniforme

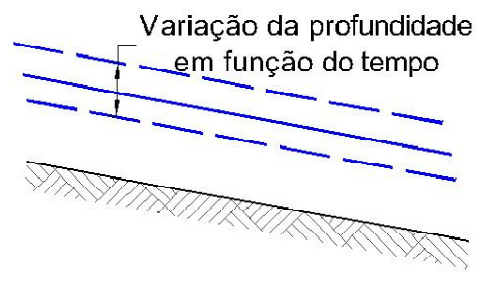

Escoamento Uniforme Não Permanente

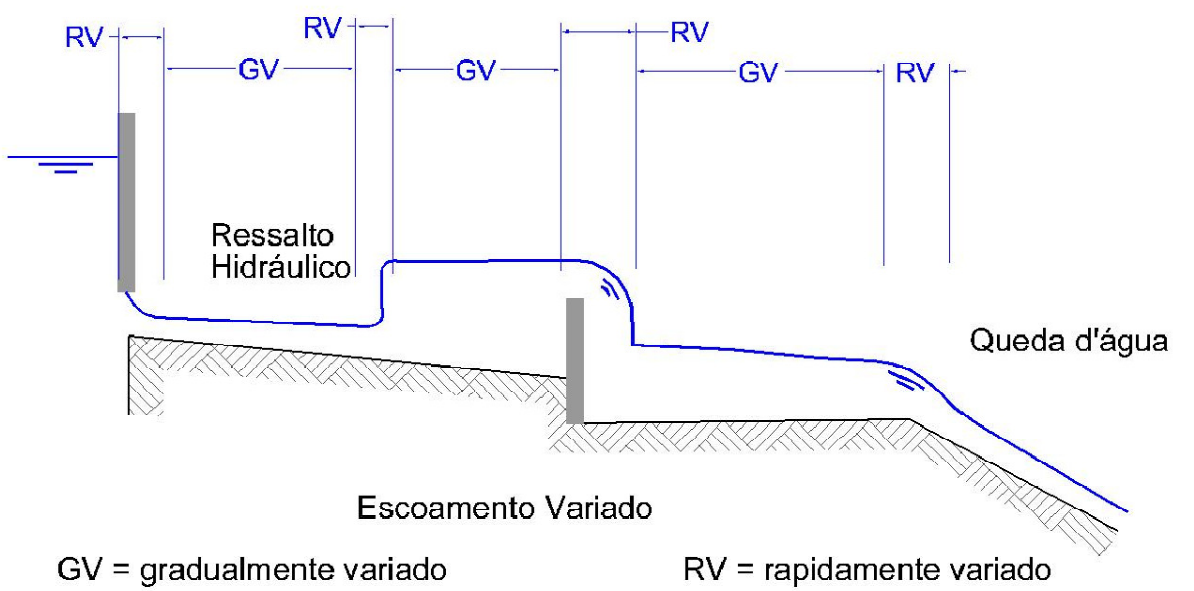

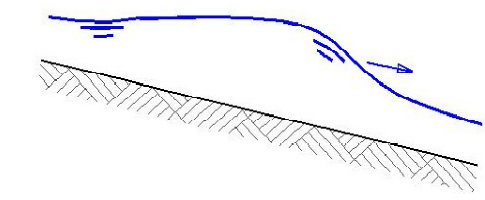

Escoamento Gradualmente Variado

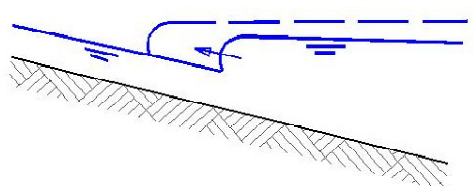

Escoamento Bruscamente Variado

Escoamcnto Não Permancnte

Figura 15: Vários tipos de canais abertos com a representação de diferentes escoamentos 


\section{b) Espaço como critério:}

- Uniforme: o escoamento é considerado uniforme, quando a profundidade do escoamento é constante ao longo de toda a extensão do canal; o escoamento em regime uniforme pode ou não ser permanente;

- Variado: escoamento em que ocorre variação da profundidade do escoamento ao longo da extensão; também pode ocorrer sob regime permanente e não-permanente.

O comportamento do escoamento livre em canais, independente do regime em que este se processa, é governado basicamente pelo efeito da viscosidade do fluido escoado e pelo efeito da gravidade e das forças de inércia na interface fluido-parede do conduto. Considerando-se tais aspectos, temos então dois tipos de escoamento:

- escoamento laminar: neste tipo de escoamento, as forças viscosas do fluido representam papel mais forte que as forças de inércia, sendo as principais responsáveis pelo comportamento do fluido escoando; No escoamento laminar, as partículas se movem em camadas de espessura infinitesimal, umas sobre as outras, de modo que não há mistura, ou intercertação entre as partículas de uma camada e de outra;

- escoamento turbulento: neste tipo de escoamento as forças viscosas, não são representativas, já que as forças inerciais, governam o comportamento do fluido; neste escoamento, as partículas do fluido, não apresentam um caminho regular, como ocorre no regime laminar;

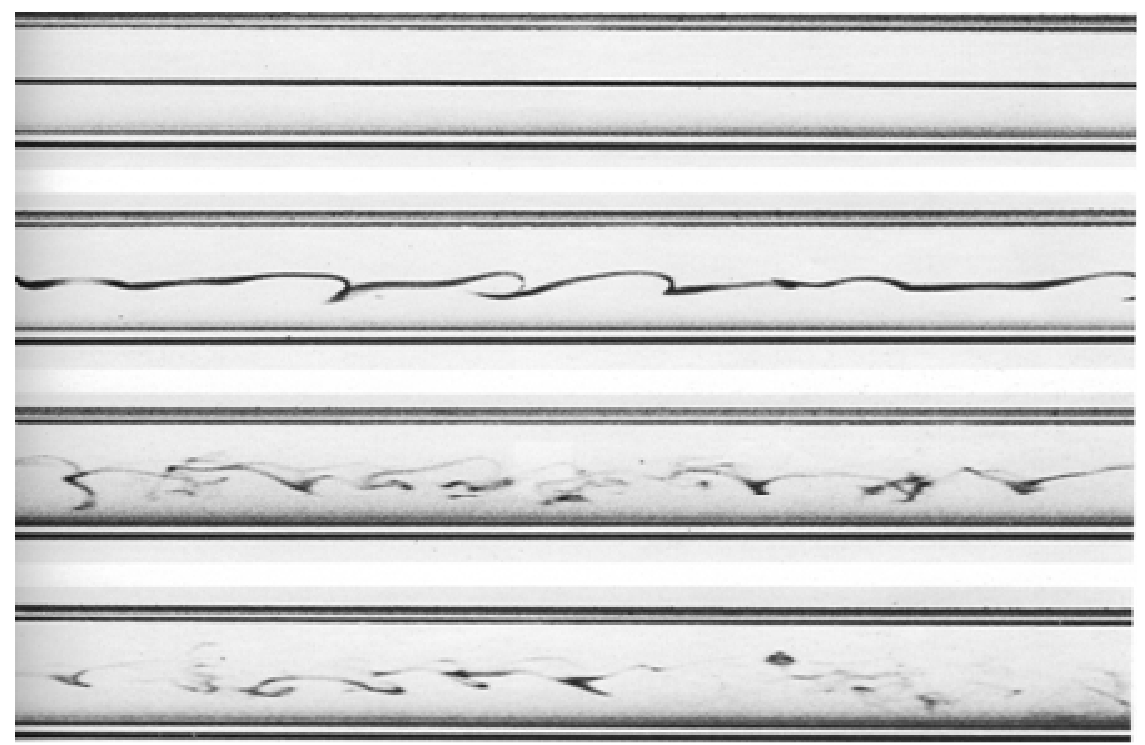

Figura 16: Escoamento Laminar, transição e turbulento. Visualização com corante em água num tubo de vidro. 
Entre os dois regimes, existe um regime crítico de transição. O efeito da viscosidade, relacionado com a inércia e que representa o tipo de regime de escoamento é dado pelo conhecido número de Reynolds, definido como:

$$
R e=\frac{V \cdot D}{v}
$$

em que:

$\boldsymbol{R} \boldsymbol{e}=$ adimensional de Reynolds;

$\boldsymbol{V}=$ velocidade do escoamento $(\mathrm{m} / \mathrm{s})$;

$\boldsymbol{D}=$ diametro hidráulico $(m)$;

$\boldsymbol{v}=$ viscosidade cinemática do fluido $\left(\mathrm{m}^{2} / \mathrm{s}\right)$;

Um escoamento livre é dito laminar quando o número de Reynolds é pequeno e turbulento quando este é grande. Diversos experimentos demonstram que escoamentos em seções tubulares tem a transição do regime laminar para o turbulento caracterizada por números de Reynolds variando entre o valor critico 2000 até 50000. Chow salienta que não há definição concreta desse limite superior.

Os diferentes regimes de escoamento (laminar, turbulento e de transição) podem ser expressos graficamente pela relação entre Reynolds e um fator $\boldsymbol{f}$, que relaciona as tensões tangenciais em sentido contrário ao escoamento. Atribuído a Darcy e Weisbach (apud Martins), desenvolvida primariamente para seções tubulares:

$$
h f=f \cdot \frac{L}{D} \cdot \frac{V^{2}}{2 g}
$$

em que:

$\boldsymbol{h f}$ = perda de carga ou declividade da linha de energia $(\mathrm{m} / \mathrm{m})$;

$\boldsymbol{f}=$ fator de atrito universal (adimensional);

$\boldsymbol{L}=$ comprimento do trecho $(m)$;

$\boldsymbol{D}=$ diametro do conduto $(m)$;

$\boldsymbol{V}=$ velocidade do escoamento $(\mathrm{m} / \mathrm{s})$;

$\boldsymbol{g}=$ viscosidade cinemática do fluido $\left(\mathrm{m}^{2} / \mathrm{s}\right)$; 
A partir dos experimentos de Nikuradse, empregando tubos com rugosidade artificial, deduziu-se que o fator de atrito $f$ e a tensão tangencial apresentam relação com o adimensional de Reynolds, sob a forma:

$$
f=\frac{2 \cdot g \cdot D \cdot S_{f}}{v^{2}}
$$

eq. 45

em que:

$\boldsymbol{f}=$ fator de atrito universal (adimensional);

$\boldsymbol{D}=$ diametro do conduto $(m)$;

$\boldsymbol{S}_{f}=$ declividade da linha de energia $(\mathrm{m} / \mathrm{m})$;

$\boldsymbol{v}=$ velocidade do escoamento $(\mathrm{m} / \mathrm{s})$;

$\boldsymbol{g}=$ viscosidade cinemática do fluido $\left(\mathrm{m}^{2} / \mathrm{s}\right)$;

O comportamento do fator de atrito $f$, da equação 45 , pode ser analisado a partir de equações que definem o perfil de velocidades nos condutos. A ocorrência dos diferentes regimes de escoamento, laminar e turbulento, condiciona qual postulado deve ser utilizado para a avaliação das condições em que o escoamento está ocorrendo. Chow (1959) descreve e apresenta dados de experimentos relacionados ao assunto, concluindo que:

a) O regime do escoamento muda nitidamente, com o incremento do número de Reynolds, também em condutos livres;

b) Os gráficos relacionando fator de atrito e número de Reynolds, para condutos circulares e seções abertas, têm características semelhantes, apresentando as mesmas regiões que representamos escoamentos em regime laminar, turbulento e de transição;

c) A região laminar é caracterizada e definida pela equação geral:

$$
f=\frac{K}{R e}
$$

em que:

$\boldsymbol{f}=$ fator de atrito universal (adimensional);

$\boldsymbol{K}$ = índice que é função da geometria do conduto;

$\boldsymbol{R} \boldsymbol{e}=$ adimensional de Reynolds; 
A relação obtida por Nikuradse, para regime laminar é dada por:

$$
f=\frac{64}{R e}
$$

eq. 47

Já a relação $\boldsymbol{f}$ - $\boldsymbol{R} \boldsymbol{e}$ proposta por Blasius para escoamento turbulento hidraulicamente liso é dada por:

$$
f=\frac{0,233}{R e^{0,25}}
$$

eq. 48

O gráfico a seguir, retirado do livro de CHOW (1959), que representa os estudos feitos na Universidade do Illinois, indicam outros dois valores para as seções estudadas, sendo aproximadamente 24, para o caso de seções retangulares e 14, considerando-se seções triangulares.

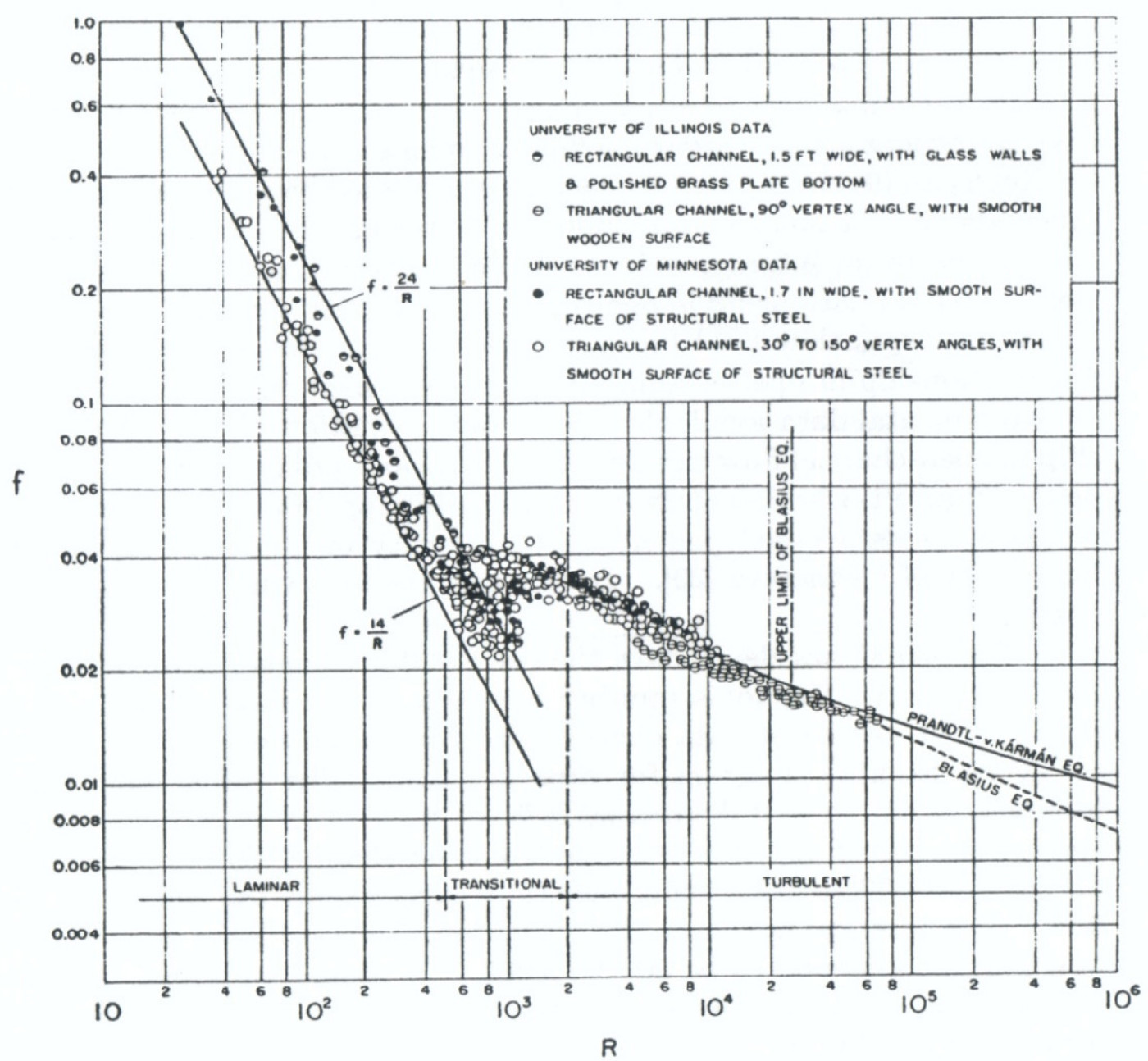

Figura 17: Relação f-Re para canais de seção retangular e triangular Fonte: CHOW (1959) 
d) A região turbulenta, observada no gráfico anterior pôde ser descrita pelas equações de Blasius-Prandt-von Kárman, indicando que estas equações apesar de terem sido propostas para seções circulares, representam também o caso do escoamento em seções de canais abertos ou de geometria similar. A equação geral desenvolvida é do tipo:

$$
\frac{1}{\sqrt{f}}=2 \log (\operatorname{Re} \sqrt{f})+0,4
$$

em que:

$\boldsymbol{f}=$ fator de atrito universal (adimensional);

$\boldsymbol{R e}=$ adimensional de Reynolds;

Para escoamentos turbulentos, então podem ser utilizadas as equações:

A) Caso de regime turbulento liso:

$$
\frac{1}{\sqrt{f}}=2,04 \log \left(\frac{\operatorname{Re} \sqrt{f}}{3,08}\right)
$$

Em que:

$f=$ fator de atrito universal (adimensional);

$\boldsymbol{R} \boldsymbol{e}=$ adimensional de Reynolds;

B) Caso de regime turbulento rugoso:

$$
\frac{1}{\sqrt{f}}=2,04 \log \left(\frac{12,2 . R e \sqrt{f}}{k_{s}}\right)
$$

em que:

$f=$ fator de atrito universal (adimensional);

$\boldsymbol{R e}=$ adimensional de Reynolds;

$\boldsymbol{k}_{\boldsymbol{s}}=$ coeficiente de atrito dimensional, função da geometria das rugosidades 
Em que $\boldsymbol{k}_{\boldsymbol{s}}$ é coeficiente de atrito dimensional e representa o tamanho e das depressões que formam a superfície rugosa das paredes do conduto. Tal coeficiente relaciona-se com a rugosidade proposta por Manning sob a forma:

$$
n=\frac{1}{8 \sqrt{g}} \cdot k_{s}^{1 / 6}
$$

em que:

$\boldsymbol{n}=$ coeficiente de rugosidade de Manning $\mathrm{em} \mathrm{m}^{1 / 6}$;

$\boldsymbol{k}_{\boldsymbol{s}}=$ coeficiente de atrito dimensional em $\mathrm{m}$.

$\boldsymbol{g}=$ aceleração da gravidade $\mathrm{m} / \mathrm{s}^{2}$;

\subsubsection{A EQUAÇAO DE MANNING}

Em 1889, o engenheiro irlandês Robert Manning, apresentou a forma que mais tarde seria modificada para a sua versão mais atual:

$$
V=\frac{R_{h}{ }^{2 / 3} \cdot \sqrt{S_{0}}}{n}
$$

em que:

$$
\begin{array}{ll}
\boldsymbol{V} & =\text { velocidade de escoamento em } \mathrm{m} / \mathrm{s} ; \\
\boldsymbol{R} \boldsymbol{h} & =\text { raio hidráulico; } \\
\boldsymbol{S}_{\boldsymbol{0}} & =\text { declividade longitudinal do canal }(\mathrm{m} / \mathrm{m}) ; \\
\boldsymbol{n} & =\text { coeficiente de rugosidade em } \mathrm{m}^{1 / 6} ;
\end{array}
$$

A equação de Manning, assim como a de Chezy, foram equações desenvolvidas para descrever o escoamento ocorrendo sob condições específicas, mas apesar dessas limitações e pela facilidade de aplicação, foram bastante difundidas e até hoje aplicadas em diversos tipos de situação em engenharia hidráulica. 
Condição básica para a aplicação e validade da equação de Manning é a de que o escoamento seja permanente, uniforme e turbulento. Nesse caso, os seguintes princípios devem ser levados em conta:

- a profundidade de escoamento é constante no tempo e no espaço; portanto área molhada, perímetro molhado e velocidade também são constantes ao longo do trecho;

- o efeito da viscosidade do fluido é desprezado;

- a declividade da linha de energia, da superfície do fluido e do fundo do canal são paralelas entre si;

O escoamento do tipo uniforme é raro de acontecer na natureza, mas apesar dessa diferença com a realidade, tal condição é freqüentemente assumida para a avaliação do escoamento em canais e condutos livres. Os resultados obtidos, próximos da realidade, são considerados satisfatórios e solucionam a maior parte dos problemas.

Para o caso do escoamento em ruas e sarjetas, aqui tratadas como canais sob escoamento livre, a condição crítica para a aplicação da equação de Manning, conhecidas suas limitações, é de que o escoamento deve ser do tipo turbulento. Tal característica é a encontrada e assumida para a grande parte dos problemas de engenharia hidráulica. $\mathrm{O}$ escoamento do tipo laminar apresenta grandes limitações no campo, no entanto pode ocorrer sob condições muito especiais, como no caso de canais com declividades muito baixas.

A verificação do tipo de escoamento que ocorre sob a condição de declividade longitudinal deve ser feita, uma vez que resultados equivocados podem ser obtidos no caso da aplicação da equação de Manning para a condição laminar. A verificação do regime de escoamento é condição a ser verificada sempre que a aplicação de declividades menores que aquelas estabelecidas por norma, sejam adotadas. Neste trabalho, foram feitas as verificações de ocorrência de regime laminar para todas as geometrias de via estudadas, não tendo sido detectada a ocorrência de regime laminar em nenhuma das situações de estudo. 


\subsection{MODELOS HIDRODINÂMICOS DE ESCOAMENTO LIVRE}

Todo escoamento superficial, seja ele nos elementos de micro ou macro-drenagem é intencionalmente dimensionado de modo a se processar sob os parâmetros de escoamento livre. O escoamento em guias, sarjetas e outros elementos de micro-drenagem também ocorre em condições de escoamento livre. O que diferencia um elemento de micro daqueles de macro drenagem, sob o ponto de vista de dimensionamento hidráulico é, de modo geral, o tratamento e a sofisticação dos métodos hidrodinâmicos que são aplicadas a estas estruturas. O escoamento em canais se processa sob as mesmas condições que se processa nas sarjetas e vias urbanas. O que ocorre, quase que na sua totalidade, é que não se efetua a aplicação de qualquer avaliação hidrodinâmica desse escoamento nas sarjetas e elementos de microdrenagem, dada a complexidade desta tarefa.

O escoamento na rede de drenagem pluvial do ponto de vista da mecânica dos fluidos é um dos mais complexos problemas hidráulicos (Yen, 1978). O escoamento é inevitavelmente não-permanente, usualmente não uniforme e turbulento, algumas vezes se processando a superfície livre, outras sob pressão. Esse conjunto de características contrasta com as simplificações utilizadas normalmente pelos métodos de análise e dimensionamento da rede, resultando em alguns casos sistemas ineficientes e de alto custo.

O critério usual de dimensionamento é adequar a capacidade hidráulica dos elementos da rede considerando o escoamento uniforme, em regime permanente e à superfície livre, a uma vazão correspondente a uma chuva de projeto normalmente com tempo de retorno entre 2 e 10 anos. Quando a precipitação supera a chuva de projeto, as características do escoamento mudam, e as premissas básicas do dimensionamento não são mais válidas. Villanueva (1990) cita que embora os modelos utilizados para o dimensionamento de redes de drenagem possam fornecer diretrizes que remetam a um dimensionamento correto, somente a utilização de um modelo de fluxo não-permanente pode identificar a segurança e economia do projeto sob situações críticas. O conceito de economia citado aqui, diz respeito justamente ao efeito de amortecimento que ocorre durante o processo de escoamento sobre o conduto, seja ele livre ou forçado.

A modelação dos escoamentos não permanentes tem grande interesse na drenagem urbana, para os estudos de translação de ondas de enchente em canais e galerias. No caso 
específico deste trabalho, tal modelação será feita para os elementos de micro-drenagem superficial, de modo a caracterizar como se processa a translação dessas ondas de cheia. A verificação das características deste escoamento tem como objetivo principal, contribuir para a falta de elementos que justifiquem a adoção de declividades abaixo daquelas consideradas como mínimas.

Estes fenômenos são descritos e estudados pelas equações genéricas de Saint-Venant, e a solução pode ser alcançada pela aplicação de métodos numéricos diversos.

\subsubsection{Equações fundamentais do escoamento não-permanente}

As equações fundamentais utilizadas para descrever o escoamento unidimensional a superfície livre baseiam-se nas leis da conservação da massa (equação da continuidade) e da quantidade do movimento (equação do momento) baseada na $2^{\mathrm{a}}$ Lei de Newton; as chamadas equações de Saint Venant. A dedução dessas equações pode ser encontrada em Tucci (1998), Henderson (1966) e Cunge et al (1980). As equações de Saint Venant são a base dos modelos de propagação do escoamento em canais e redes de condutos. A equação da continuidade descreve o balanço da massa no escoamento e a equação do momento descreve o balanço das forças sob condições dinâmicas (Ji, 1998). A aplicação destas equações em canais ou redes de condutos supõe a adoção de algumas simplificações, sendo as principais descritas abaixo:

- O escoamento é considerado incompressível e homogêneo, ou seja, são desprezadas variações na densidade do fluido;

- A declividade do fundo é pequena, dessa forma o seno do ângulo tomado com a horizontal pode ser considerado igual à tangente;

- O comprimento das ondas é grande se comparado com a profundidade do escoamento. Isto assegura que o escoamento em qualquer posição pode ser tomado como tendo direção paralela ao fundo do canal. Desta forma as acelerações verticais podem ser desprezadas e pode ser considerada uma variação hidrostática da pressão ao longo da vertical;

- O escoamento é subcrítico; 
- A declividade da linha de energia é obtida pela utilização de equações de movimento uniforme, como por exemplo, a de Manning ou Chezy.

As equações da continuidade e do momento unidimensionais na forma não conservativa são apresentadas a seguir pelas equações 54 e 55 respectivamente, embora outras formas particulares de apresentação sejam possíveis em função das variáveis dependentes.

$$
\begin{gathered}
\frac{\partial Q}{\partial x}+\frac{\partial A}{\partial t}=0 \\
\frac{\partial Q}{\partial t}+\frac{\partial \frac{Q^{2}}{A}}{\partial x}+g A \frac{\partial y}{\partial x}=g A\left(S_{o}-S_{f}\right)
\end{gathered}
$$

em que:

$\boldsymbol{Q}=\operatorname{Vaz} \tilde{a} o(\mathrm{~m} / \mathrm{s} 3)$

$\boldsymbol{A}=$ Área molhada (m2);

$\boldsymbol{y}=$ profundidade $(m)$;

$\boldsymbol{g}=$ aceleração da gravidade $\left(\mathrm{m} / \mathrm{s}^{2}\right)$;

$\boldsymbol{x}=$ distância na direção do escoamento $(m)$;

$\boldsymbol{t}=$ tempo $(s)$

$\boldsymbol{S}_{\boldsymbol{o}}=$ declividade do leito $e$

$\boldsymbol{S}_{f}=$ declividade da linha de energia.

Os primeiros dois termos do lado esquerdo da igualdade na equação do momento representam as forças de inércia, enquanto que o terceiro termo representa as forças de pressão. O termo do lado direito na equação representa as forças gravitacionais e de atrito.

\subsubsection{Classificação dos modelos de propagação do escoamento}

Os modelos de propagação do escoamento podem ser classificados em modelos de armazenamento (hidrológicos) e hidrodinâmicos (hidráulicos) (Cirilo et al, 2003). Os modelos 
de armazenamento, como o próprio nome indica, consideram somente os efeitos do armazenamento na atenuação e deslocamento da onda de cheia, desprezando os efeitos de atrito levados em conta pela equação do momento.

Os modelos que utilizam as equações de Saint Venant são chamados de hidrodinâmicos, e podem ser classificados em simplificados ou completos, de acordo com a consideração ou não dos termos da equação do momento. Se forem desprezados os termos de inércia e pressão, tem-se o modelo da onda cinemática, em que se tem a desvantagem da impossibilidade de simular fenômenos tais como efeitos de jusante sobre o escoamento. Nestas situações pode ser utilizado um modelo de difusão, negligenciando somente os termos de inércia na equação da continuidade. Este modelo, porém, segundo Tucci (2001), não deve ser utilizado quando há grande variação espacial e temporal da velocidade no sistema. Os modelos anteriores também são chamados de hidrodinâmicos simplificados.

Os modelos que resolvem as equações em sua forma completa são chamados de hidrodinâmicos completos, podendo representar com precisão os fenômenos mais importantes do escoamento em canais. Vieira da Silva et al (2003) citam que a comparação entre os modelos simplificados e completos é importante no processo de escolha e envolve propriedades como precisão, facilidade de aplicação, uso e objetivo dos resultados, base de dados existentes, economia e outros fatores. Entretanto, quaisquer que sejam os critérios na decisão sobre qual modelo utilizar, o uso de modelos baseados na solução das equações completas de Saint Venant sempre fornecerá resultados mais confiáveis.

\subsubsection{Fundamentos teóricos dos modelos hidrodinâmicos completos}

Os modelos hidrodinâmicos constituem um sistema de equações de derivadas parciais de primeira ordem, quase-linear e do tipo hiperbólico, não existindo solução analítica para o mesmo (Cirilo et al, 2003). Assim se faz necessário a utilização de soluções aproximadas, geralmente realizadas por meio de métodos numéricos. Não sendo o objetivo da pesquisa o desenvolvimento de um modelo hidrodinâmico de redes de condutos e sim sua utilização na avaliação de um sistema de drenagem, o conteúdo deste item trata somente sobre os fundamentos principais dos métodos de resolução das equações de Saint Venant, de forma simplificada e informativa. 
A forma mais utilizada para solução das equações de Saint Venant é por meio de métodos numéricos baseados nas aproximações por diferenças finitas, que podem ser explícitos ou implícitos. Para que a representação do sistema por um esquema de diferenças finitas seja adequada, certas propriedades no esquema numérico são fundamentais. A estabilidade, segundo Wrobel (1989), é uma propriedade fundamental relacionada com o esquema de integração no tempo. Quando um método numérico é instável, qualquer perturbação como erros de truncamento da série de Taylor ou erros de arredondamento podem crescer levando a solução das equações diferenciais a valores absurdos. Na prática, considerando que as equações diferenciais do escoamento envolvem duas variáveis independentes $t$ (tempo) e $\mathrm{x}$ (espaço), são utilizadas condições de estabilidade que impõem um limite superior no espaçamento $(\Delta \mathrm{x})$ dos valores de $\mathrm{x}$ e no incremento de tempo $(\Delta \mathrm{t})$ utilizados no cálculo. $\mathrm{A}$ condição de estabilidade para os esquemas explícitos é geralmente definida pelo critério de Courant, definido como:

$$
\frac{\Delta x}{\Delta t} \geq V+(g \cdot h)^{0,5}
$$

em que:

$\boldsymbol{V}=$ velocidade do escoamento $(\mathrm{m} / \mathrm{s})$;

$\boldsymbol{g}=$ aceleração da gravidade $\left(\mathrm{m} / \mathrm{s}^{2}\right)$;

$\boldsymbol{h}=$ profundidade do escoamento $(\mathrm{m})$.

Schmitt (1986) apresenta um esquema explícito em que as variáveis desconhecidas no intervalo de tempo atual são derivadas das variáveis no intervalo de tempo anterior. Dessa forma, a aproximação conduz a soluções algébricas mais simples, porém incondicionalmente instáveis do ponto de vista numérico (Cirilo et al, 2003). Ji (1998) afirma ainda, que estes esquemas requerem um pequeno intervalo de tempo e um comprimento mínimo, tornando o processo exaustivo em alguns casos. Nos esquemas implícitos, as variáveis desconhecidas no intervalo de tempo atual e anterior devem ser resolvidas simultaneamente. Desta forma as variáveis não podem ser escritas em função exclusivamente dos valores conhecidos. A solução é então obtida para todas as variáveis do sistema por meio de equações algébricas. 
Várias são as vantagens dos esquemas implícitos, a principal segundo Vieira da Silva et al (2003), seria que as equações resultantes praticamente não apresentam problemas de estabilidade numérica, permitindo quando necessário a utilização de intervalos de tempo maiores que os esquemas explícitos. Ji (1998) afirma que as pesquisas realizadas envolvendo diferentes esquemas mostram que os esquemas implícitos são os mais sofisticados, sendo o esquema implícito de quatro pontos de Preissmann o geralmente adotado em modelos de escoamento não permanente.

Existem ainda muitos modelos desenvolvidos utilizando-se esquemas implícitos alternativos, como os esquemas de seis pontos de Abbott e Ionescu (Cunge, 1980) e um esquema semelhante desenvolvido pelo Delft Hydraulics Laboratory (Cunge, 1980). A solução dos sistemas de equações resultantes da aplicação dos esquemas implícitos de diferenças finitas recai geralmente em uma matriz do tipo banda, podendo ser resolvida pelo método generalizado de Newton-Raphson ou pelo processo de dupla varredura. Entretanto, Villanueva (1990) cita que para redes complexas as matrizes resultantes não são banda como nos trechos mais simples e sim esparsas, necessitando métodos específicos de solução.

Por fim, as equações de Saint Venant, como equações diferenciais parciais, necessitam ainda de valores iniciais e valores de contorno para garantia e unicidade da solução. As condições iniciais podem ser representadas, por exemplo, por condições de escoamento uniforme. Atualmente muitos modelos de drenagem urbana têm utilizado como condição inicial a introdução artificial de uma lâmina de água mínima, com profundidade variando entre 0,5 e $5 \%$ da dimensão característica do canal, podendo ser ou não subtraída do hidrograma final para não afetar o balanço do volume da simulação. As condições de contorno, por sua vez, são informações necessárias para solução das equações do escoamento para cada conduto ou canal entre dois nós, simultaneamente na entrada e na saída do conduto. Podem ser definidas basicamente como relações entre duas variáveis, como por exemplo, vazão em função do tempo (hidrograma), vazão em função da cota (curva-chave) ou cota em função do tempo (Limnigrama).

A viabilidade deste tipo de análise complexa dos escoamentos foi possível graças à utilização de softwares que automatizam a resolução com o uso dos métodos acima citados. Cita-se o exemplo do HEC-RAS, software livre do Corpo de Engenheiros Civis das Forças Armadas Americana (US Army, 2009). O referido software permite a resolução das equações 
de Saint-Venant para os escoamentos uniformes e não uniformes por meio de sua linearização desenvolvida por Preissman.

Descreve-se brevemente a seguir o esquema generalizado de Preissmann utilizado pelo referido software. O esquema de diferenças finitas permite explicitar o cálculo das profundidades e vazões a cada instante de tempo, considerando ainda a influencia das condições futuras (implicidade). Para o esquema da figura 34, as grandezas numa determinada posição podem ser escritas de acordo com as equações genéricas propostas pelo método:

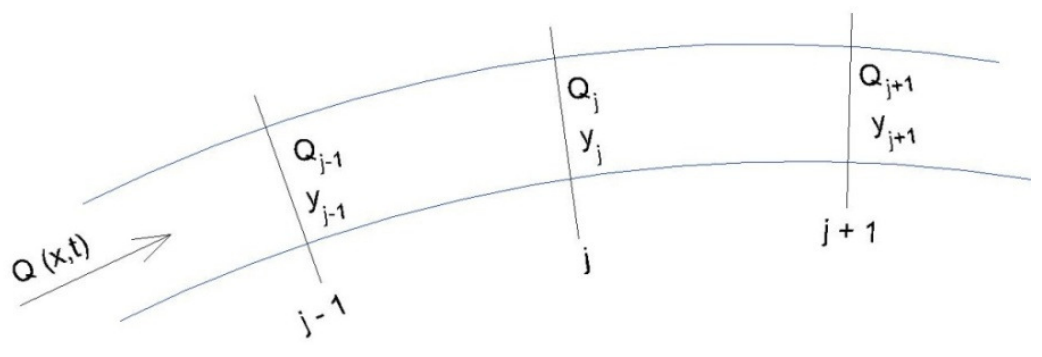

Figura 18: Configuração do plano de discretização de Preissmann

$$
\begin{gathered}
G(x, t)=\frac{\theta}{2} \cdot\left(G_{j+1}+G_{j}\right)^{t+1}+\left(\frac{1-\theta}{2}\right) \cdot\left(G_{j+1}+G_{j}\right)^{t}=\frac{\theta}{2} \cdot\left(\Delta G_{j+1}+\Delta G_{j}\right)+\frac{1}{2} \cdot\left(G_{j+1}+G_{j}\right)^{t} \\
\frac{\partial G}{\partial x}=\theta \cdot\left(\frac{G_{j+1}-G_{j}}{\Delta x}\right)^{t+1}+(1-\theta) \cdot\left(\frac{G_{j+1}+G_{j}}{\Delta x}\right)=\theta \cdot\left(\frac{\Delta G_{j+1}-\Delta G_{j}}{\Delta x}\right)+\left(\frac{G_{j+1}+G_{j}}{\Delta x}\right) \\
\frac{\partial G}{\partial t}=\left(\frac{G_{j+1}-G_{j}}{2 \Delta x}\right)^{t+1}-\left(\frac{G_{j+1}+G_{j}}{2 \Delta x}\right)^{t}=\left(\frac{\Delta G_{j+1}-\Delta G_{j}}{2 \Delta x}\right)
\end{gathered}
$$

eq. 59

Considerando que $\mathbf{0 , 5} \leq \boldsymbol{\theta} \leq \mathbf{1 , 0}$.

Aplicando-se as diferenças acima nas equações da continuidade e momento, e, assumindo que:

1) Se $f . f \gg \Delta f . \Delta f$, então $\Delta f . \Delta f \approx 0$

2) Se $\boldsymbol{g}=\boldsymbol{g}(\boldsymbol{Q}, z)$, então $\Delta \boldsymbol{g}$ pode ser aproximado pelo primeiro termo da série de Taylor.

$$
\Delta g_{j}=\left(\frac{\partial g}{\partial Q}\right) \Delta Q_{j}+\left(\frac{\partial g}{\partial z}\right) \Delta z_{j}
$$


3) Se o passo de tempo, $\Delta t$, for pequeno, algumas das variáveis podem ser tratadas explicitamente; portanto:

$$
h_{j}{ }^{n+1} \approx h_{j}^{n} \quad \text { e } \quad \Delta h_{j} \approx 0
$$

O item 2 será aplicado ao termo da declividade da linha d' água $\left(\boldsymbol{S}_{\boldsymbol{f}}\right)$ e a área molhada $(\boldsymbol{A})$. O item 3 é aplicado à velocidade $(\boldsymbol{V})$, ao fator de distribuição de velocidades $(\boldsymbol{\beta})$, ao fator de distribuição de vazão $(\boldsymbol{\varphi})$.

Com a aplicação das equações gerais de diferenças finitas, temos respectivamente o sistema linear de equações a seguir, sendo respectivamente as equações da continuidade e do momento:

$$
C Q 1_{j} \Delta Q_{j}+C Z 1_{j} \Delta z_{j}+C Q 2_{j} \Delta Q_{j+1} C Z 2_{j} \Delta z_{j+1}=C B_{j}
$$

eq. 62

$$
M Q 1_{j} \Delta Q_{j}+M Z 1_{j} \Delta z_{j}+M Q 2_{j} \Delta Q_{j+1} M Z 2_{j} \Delta z_{j+1}=M B_{j}
$$

eq. 63

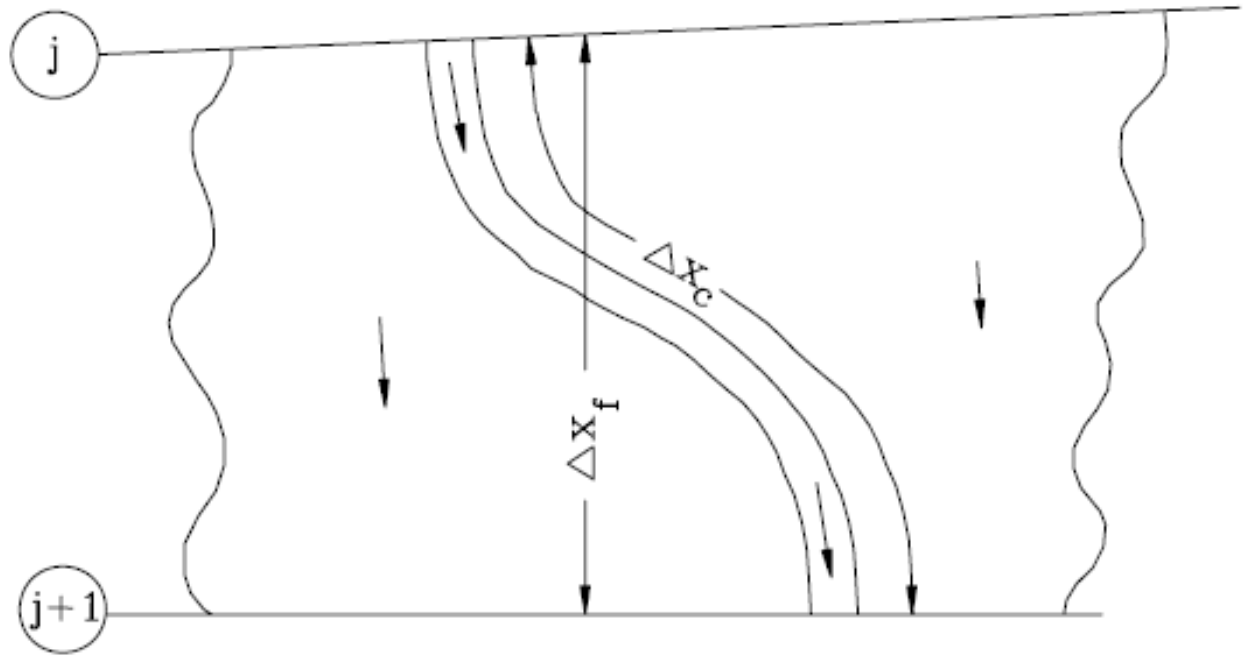

Figura 19: Canal e áreas de várzea e sua discretização

As aproximações por diferenças finitas que são utilizadas para a determinação das variáveis do sistema de equações são listada na tabela 16 e 17: 
Tabela 16: Aproximação por diferenças finitas dos termos da equação da continuidade

\begin{tabular}{cc}
\hline TERMO DA EQUAÇÂO & APROXIMAÇÂO \\
\hline$\Delta Q$ & $\left(Q_{j+1}-Q_{j}\right)+\theta\left(\Delta Q_{j+1}-\Delta Q_{j}\right)$ \\
$\frac{\partial A_{\varepsilon}}{\partial t} \Delta x_{c}$ & $0.5 \Delta x_{\mathrm{j} j} \frac{\left(\frac{d A_{c}}{d z}\right)_{j} \Delta z_{j}+\left(\frac{d A_{c}}{d z}\right)_{j+1} \Delta z_{j+1}}{\Delta t}$ \\
$\frac{\partial A_{f}}{\partial t} \Delta x_{i}$ & $0.5 \Delta x_{\mathfrak{j}} \frac{\left(\frac{d A_{f}}{d z}\right)_{j} \Delta z_{j}+\left(\frac{d A_{f}}{d z}\right)_{j+1} \Delta z_{j+1}}{\Delta t}$ \\
$\frac{\partial S}{\partial t} \Delta x_{f}$ & $0.5 \Delta x_{\mathfrak{f}} \frac{\left(\frac{d S}{d z}\right)_{j} \Delta z_{j}+\left(\frac{d S}{d z}\right)_{j+1} \Delta z_{j+1}}{\Delta t}$
\end{tabular}

Fonte: Manual HEC-RAS

Tabela 17: Aproximação por diferenças finitas dos termos da equação do momento

\begin{tabular}{|c|c|}
\hline TERMO DA EQUAÇÃO & APROXIMAÇÂO \\
\hline$\partial\left(Q_{s} \Delta\right.$ & 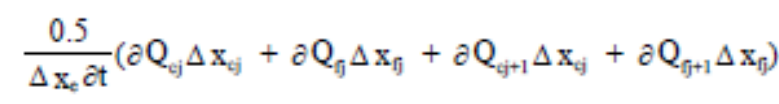 \\
\hline$\frac{\Delta \beta V Q}{\Delta x_{\mathrm{fj}}}$ & $\frac{1}{\Delta \mathrm{x}_{\mathrm{el}}}\left[(\beta \mathrm{VQ})_{j+1}-(\beta V Q)_{j}\right]+\frac{\theta}{\Delta \mathrm{x}_{\mathrm{el}}}\left[(\beta V Q)_{j+1}-(\beta V Q)_{j}\right]$ \\
\hline$g \bar{A} \frac{\Delta z}{\Delta x}$ & $g \bar{A}\left\lceil\frac{z_{j+1}-z_{j}}{\Delta x_{e j}}+\frac{\theta}{\Delta x_{e j}}\left(\Delta z_{j+1}-\Delta z_{j}\right)\right\rceil+\theta g \Delta \bar{A} \frac{\left(z_{j+1}-z_{j}\right)}{\Delta x_{e j}} \mid$ \\
\hline $\mathrm{gA}\left(\overline{\mathrm{S}}_{\mathrm{r}}\right.$ & $g \bar{A}\left(\bar{S}_{\mathrm{r}}+\bar{S}_{\mathrm{i}}\right)+0.5 \theta \mathrm{g} \bar{A}\left[\left(\Delta \mathrm{S}_{\mathrm{g}+1}+\Delta \mathrm{S}_{\mathrm{i}}\right)+\left(\Delta \mathrm{S}_{\mathrm{ig}+1}+\Delta \mathrm{S}_{\mathrm{i}}\right)\right]+0.5 \theta \mathrm{g}\left(\overline{\mathrm{S}}_{\mathrm{r}}+\overline{\mathrm{S}}_{\mathrm{i}}\right.$ \\
\hline$\overline{\mathrm{A}}$ & $0.5\left(A_{j+1}+A_{j}\right)$ \\
\hline$\overline{\mathrm{S}}_{\mathrm{r}}$ & $0.5\left(S_{f+1}+S_{f f}\right)$ \\
\hline$\partial \mathrm{A}_{j}$ & $\left(\frac{\mathrm{dA}}{\mathrm{dZ}}\right)_{j} \Delta z_{j}$ \\
\hline
\end{tabular}




$$
\begin{array}{rr}
\partial \mathrm{S}_{\mathrm{g}} & \left(\frac{-2 \mathrm{~S}_{\mathrm{r}}}{\mathrm{K}} \frac{\mathrm{dK}}{\mathrm{dz}}\right)_{i} \Delta z_{j}+\left(\frac{2 \mathrm{~S}_{\mathrm{r}}}{\mathrm{Q}}\right)_{\mathrm{i}} \Delta \mathrm{Q}_{\mathrm{j}} \\
\partial \overline{\mathrm{A}} & 0.5\left(\Delta \mathrm{A}_{j}+\Delta \mathrm{A}_{j+1}\right)
\end{array}
$$

\begin{tabular}{|c|c|}
\hline Coeficiente & Valor \\
\hline $\mathrm{CQ} 1_{\mathrm{j}}$ & $\frac{-\theta}{\Delta \mathrm{x}_{\mathrm{ej}}}$ \\
\hline $\mathrm{CZ} 1_{\mathrm{j}}$ & $\frac{0.5}{\Delta t \Delta \mathrm{x}_{\mathrm{ej}}}\left[\left(\frac{\mathrm{dA}_{\mathrm{c}}}{\mathrm{dz}}\right)_{j} \Delta \mathrm{x}_{\mathrm{cj}}+\left(\frac{\mathrm{dA}_{\mathrm{f}}}{\mathrm{dz}}+\frac{\mathrm{dS}}{\mathrm{dz}}\right)_{j} \Delta \mathrm{x}_{\mathrm{fj}}\right.$ \\
\hline $\mathrm{CQ} 2_{\mathrm{j}}$ & $\frac{\theta}{\Delta \mathrm{x}_{\mathrm{ej}}}$ \\
\hline $\mathrm{CZ}_{2}{ }_{\mathrm{j}}$ & $\frac{0.5}{\Delta t \Delta \mathrm{x}_{\mathrm{ej}}}\left[\left(\frac{\mathrm{dA}_{\mathrm{c}}}{\mathrm{dz}}\right)_{\mathrm{j}+1} \Delta \mathrm{x}_{\mathrm{cj}}+\left(\frac{\mathrm{dA}}{\mathrm{dz}}+\frac{\mathrm{dS}}{\mathrm{dz}}\right)_{j+1} \Delta \mathrm{x}_{\mathrm{f}}\right.$ \\
\hline $\mathrm{CB}_{\mathrm{j}}$ & $-\frac{Q_{j+1}-Q_{j}}{\Delta x_{e j}}+\frac{Q_{1}}{\Delta x_{e j}}$ \\
\hline
\end{tabular}

Fonte: Manual HEC-RAS

Os valores dos coeficientes das equações 62 e 63 são definidos nas tabelas 18 e 19:

Tabela 18: Coeficiente da equação da continuidade

Fonte: Manual HEC-RAS 
Tabela 19: Coeficientes da equação do momento

\begin{tabular}{|c|c|}
\hline Coeficiente & Valor \\
\hline $\mathrm{MQ} 1_{\mathrm{j}}$ & $0.5 \frac{\Delta \mathrm{x}_{\mathrm{c}} \phi_{\mathrm{j}}+\Delta \mathrm{x}_{\mathrm{f}}\left(1-\phi_{\mathrm{j}}\right)}{\Delta \mathrm{x}_{\mathrm{ej}} \Delta \mathrm{t}}-\frac{\beta_{\mathrm{j}} \mathrm{V}_{\mathrm{j}} \theta}{\Delta \mathrm{x}_{\mathrm{ej}}}+\theta \mathrm{g} \overline{\mathrm{A}} \frac{\left(\mathrm{S}_{\mathrm{f}}+\mathrm{S}_{\mathrm{hj}}\right)}{\mathrm{Q}_{\mathrm{j}}}$ \\
\hline $\mathrm{MZ}_{1_{j}}$ & $\left.\frac{-g A \theta}{\Delta x_{e j}}+0.5 g\left(z_{j+1}-z_{j}\right)\left(\frac{d A}{d z}\right)_{j}\left(\frac{\theta}{\Delta x_{e j}}\right)-g \theta \bar{A}\left(\frac{d \mathrm{~K}}{d z}\right)_{j}\left(\frac{S_{f}}{K_{j}}\right)+\left(\frac{d A}{d z}\right){ }_{j}\left(\frac{S_{i j}}{A_{j}}\right)\right]+0.5 \theta g\left(\frac{d A}{d z}\right)_{j}\left(\bar{S}_{f}+\bar{S}_{b}\right.$ \\
\hline $\mathrm{MQ} 2_{\mathrm{j}}$ & $0.5\left[\Delta \mathrm{x}_{\mathrm{cj}} \phi_{j+1}+\Delta \mathrm{x}_{\mathrm{fj}}\left(1-\phi_{j+1}\right)\right]\left(\frac{1}{\Delta \mathrm{x}_{\mathrm{ej}} \Delta \mathrm{t}}\right)+\beta_{\mathrm{j}+1} \mathrm{~V}_{\mathrm{j}+1}\left(\frac{\theta}{\Delta \mathrm{x}_{\mathrm{ej}}}\right)+\frac{\theta \mathrm{gA}}{\mathrm{Q}_{\mathrm{j}+1}}\left(\mathrm{~S}_{\mathrm{f}+1}+\mathrm{S}_{\mathrm{hj}+1}\right)$ \\
\hline $\mathrm{MZ}_{2}{ }_{\mathrm{j}}$ & $\frac{\mathrm{gA} \theta}{\Delta \mathrm{x}_{\mathrm{ej}}}+0.5 \mathrm{~g}\left(\mathrm{z}_{\mathrm{j}+1}-\mathrm{z}_{\mathrm{j}}\right)\left(\frac{\mathrm{dA}}{\mathrm{dz}}\right)_{j+1}\left(\frac{\theta}{\Delta \mathrm{x}_{\mathrm{ej}}}\right)-\theta \mathrm{gA}\left[\left(\frac{\mathrm{dK}}{\mathrm{dz}}\right)_{j+1}\left(\frac{\mathrm{S}_{\mathrm{f}+1}}{\mathrm{~K}_{\mathrm{j}+1}}\right)+\left(\frac{\mathrm{dA}}{\mathrm{dz}}\right)_{j+1}+\left(\frac{\mathrm{S}_{\mathrm{h}+1}}{\mathrm{~A}_{\mathrm{j}+1}}\right)\right]+0.5 \theta \mathrm{g}\left(\frac{\mathrm{dA}}{\mathrm{dz}}\right)_{j+1}\left(\overline{\mathrm{S}}_{\mathrm{f}}+\overline{\mathrm{S}}_{\mathrm{h}}\right)$ \\
\hline $\mathrm{MB}_{j}$ & $-\left[\left(\beta_{j+1} V_{j+1} Q_{j+1}-\beta_{j} V_{j} Q_{j}\left(\frac{1}{\Delta x_{e j}}\right)+\left(\frac{g \bar{A}}{\Delta x_{e j}}\right)\left(z_{j+1}-z_{j}\right)+g \bar{A}\left(\bar{S}_{f}+\bar{S}_{h}\right)\right]\right.$ \\
\hline
\end{tabular}

Fonte: Manual HEC-RAS

Tal sistema de equações é processado pelo software, tendo como parâmetros:

$\boldsymbol{Q}_{c}=\operatorname{Vaz} \tilde{a} o\left(\mathrm{~m} / \mathrm{s}^{3}\right) ;$

$\boldsymbol{x}=$ distância de discretização;

$\boldsymbol{t}=$ tempo de cálculo;

$\boldsymbol{A}=$ área molhada;

$\boldsymbol{S}=$ áreas de armazenamento da seção transversal;

$\boldsymbol{q}_{1}=$ contribuição lateral;

$\boldsymbol{g}=$ aceleração da gravidade;

$\boldsymbol{S}_{\boldsymbol{O}}=$ declividade de fundo;

$\boldsymbol{S}_{f}=$ declividade da linha de energia;

$v=$ velocidade do escoamento;

$\boldsymbol{Z}=$ ângulo do fundo do escoamento em relação a horizontal;

$\boldsymbol{\beta}=$ fator de distribuição de velocidades 
O tempo de processamento dessas equações por meio de software específico tornou viável a quantidade de simulações necessárias ao estabelecimento de uma relação entre vazão de entrada e saída, e sua relação com a declividade. Apesar da aparente facilidade no processamento, a base teórica aqui explicitada, não pode ser relegada, já que em determinadas situações de instabilidade de resolução podem ser evidenciadas pelo programa, necessitando assim conhecimentos teóricos para a determinação e correção da causa da instabilidade.

\subsection{EXPERIÊNCIAS E CRITÉRIOS DE PROJETO EM REGIÕES PLANAS}

O caminho percorrido pela água da chuva sobre uma superfície pode ser topograficamente bem definido, ou não. Após a implantação de uma cidade, o percurso caótico das enxurradas passa a ser determinado pelo traçado das ruas e acaba se comportando, tanto quantitativa como qualitativamente, de maneira bem diferente de seu comportamento original. De maneira geral, as águas decorrentes da chuva (coletadas nas vias públicas por meio de bocas-de-lobo e descarregadas em condutos subterrâneos) são lançadas em cursos d'água naturais, no oceano, em lagos ou, no caso de solos bastante permeáveis, esparramadas sobre o terreno por onde infiltram no subsolo. Parece desnecessário dizer que a escolha do destino da água pluvial deve ser feita segundo critérios éticos e econômicos, após análise cuidadosa e criteriosa das opções existentes. É recomendável que o sistema de drenagem seja tal que o percurso da água entre sua origem e seu destino seja o mínimo possível. Além disso, é conveniente que esta água seja escoada por gravidade. Existem então os entraves políticos relacionados ao uso e ocupação de áreas para a construção dos elementos de drenagem. Como vemos o problema da drenagem urbana não é assunto que se restringe apenas aos alagamentos, transbordamento de calhas de rios, etc. Existem aspectos globais, como qualquer atividade antrópica afeta o equilíbrio da natureza.

A gestão deste processo atualmente é fragmentada, o que tem levado à falta de sustentabilidade com impactos em doenças e epidemias, inundações, falta de água, contaminação e deterioração de forma geral no ambiente e perda de importante biodiversidade. Tucci (2008) afirma que a gestão urbana tem quatro componentes fundamentais: Econômico-Administrativo, Planejamento do Uso do Solo, Infraestrutura (transporte, águas urbanas, energia e comunicação); e Gestão Sócioambiental. A gestão das 
águas urbanas como um dos principais componentes da infraestrutura urbana tem sido um dos setores mais fragmentados da gestão urbana e esquecido no planejamento do uso do solo, apesar da urbanização ser o principal fator de impacto sobre os recursos hídricos urbanos.

Os principais impactos sobre as águas urbanas são: contaminação das áreas de mananciais, comprometimento da água distribuída, perda de água nas redes de abastecimento de água; falta de coleta e tratamento de esgoto de forma geral do país e mesmo quando existe a eficiência do tratamento é muito baixa; ocupação das áreas de risco de inundação, inundação devido a impermeabilização e canalização dos rios urbanos; erosão das áreas urbanas com criação de áreas degradadas; deterioração da qualidade da água pela poluição das águas pluviais; despejo de resíduos sólidos em rios urbanos; e o baixo nível dos projetos de engenharia sobre águas urbanas nas cidades, por falta de conhecimento, além de problemas de concepção desatualizada dos projetos relacionados com todos os componentes das águas urbanas. Cabe aqui também acrescentar como um dos impactos, a redução da recarga dos aqüíferos por diminuição da permeabilidade dos terrenos.

Os países desenvolvidos passaram por várias fases como mostra a tabela 20 abaixo:

Tabela 20: Fases do desenvolvimento das águas urbanas

\begin{tabular}{ccc}
\hline Fase & Característica & Consequências \\
\hline $\begin{array}{c}\text { Pré-higienista: } \\
\text { Até o início do } \\
\text { século XX }\end{array}$ & $\begin{array}{c}\text { Esgoto em fossas ou na drenagem, } \\
\text { sem coleta ou tratamento e água da fonte } \\
\text { mais próxima, poço ou rio. }\end{array}$ & $\begin{array}{c}\text { Doenças e epidemias, grande } \\
\text { mortalidade e inundações. }\end{array}$ \\
Higienista: & Transporte de esgoto distante das & Redução das doenças, mas \\
antes de 1970 & pessoas e canalizações do escoamento. & rios contaminados, impactos nas \\
fontes de água e inundações.
\end{tabular}


A sociedade agrícola era formada por pequenos grupos ou núcleos que convergiram para as cidades. Devido à falta da higiene, o esgoto corria pelas ruas, varias epidemias ocorreram. A mais famosa foi a da peste negra do século 13 que dizimou 1/3 a população da Europa. No início do século vinte o desafio era evitar estas doenças, como a cólera, entregando água de fontes seguras para a população. O esgoto continuava seguindo para jusante sem nenhum cuidado, escoando pela drenagem, juntamente com a chuva (sistema combinado). Esta foi à fase higienista.

Com o crescimento das cidades a poluição dos rios urbanos tornou-se um grande problema (que ainda existem nos países em desenvolvimento) e, em 1970 o Clean Water Act (lei de água limpa) dos Estados Unidos e outras medidas em outros países desenvolvidos, levando ao tratamento de efluentes das cidades destes países que levou cerca de uma década para uma cobertura quase total. Neste mesmo período, verificou-se que não era mais possível continuar canalizando os rios e transferindo os impactos para jusante, pois este processo é economicamente e ambientalmente insustentável. Buscou-se corrigir este problema utilizando-se do amortecimento, que armazena temporariamente a água evitando a sua aceleração, que produzia inundações e erosão (áreas degradadas). Esta foi chamada da fase corretiva. Este processo melhorou as condições ambientais, mas verificou-se que ainda faltava o controle das cargas difusas da agricultura e das águas pluviais urbanas. Estas cargas trazem nutrientes que produzem eutrofização e contaminação. Além disso, verificou-se que era necessário mudar a forma de planejar o espaço. Era necessário desenvolver o uso do solo, implementando as novas construções preservando as condições ambientais e os caminhos naturais do escoamento e recuperar a infiltração. Esta foi chamada da fase sustentável.

O Brasil, infelizmente está, na grande maioria das cidades, na fase higienista. Isto se deve a vários fatores como a má formação profissional, falta de investimentos e planejamento de grande prazo, falta de foco das empresas de saneamento, entre outros. O resultado então é a falta de tratamento de esgoto, transferência de inundação na drenagem e falta de controle dos resíduos sólidos. Como dito anteriormente, os países mais desenvolvidos já estão em etapas bem mais avançadas que o Brasil. A percepção da necessidade de redução das vazões de pico, com a utilização de estruturas de retenção e amortecimento já está em processo de divulgação e aplicação. Sua implementação, no entanto não tem a mesma intensidade, seja por falta de qualificação técnica, seja por falta de planejamento de espaços para que isso possa ser concretizado. Por essa razão técnicas de amortecimento sempre são úteis e se agregam às diversas possibilidades de soluções em drenagem urbana. 
Podem ser identificadas em diversos artigos da ASCE, as BMPs (Best Management Practices), que são recomendações ou práticas de gerenciamento/projeto que apresentaram bons resultados em determinadas situações e merecem ser aplicadas em outras situações. Por tais razões, são divulgadas e conforme possibilidade de aplicação a casos semelhantes são novamente aplicadas e/ou adaptadas.

Stuart G. Walesh a Carolyn Esposito (2004) indicam que, dentre as diversas soluções propostas para o problema da drenagem em ambientes urbanos, existem duas grandes vertentes de pensamento. Esses dois enfoques são:

- Conveyance-Oriented Approach: enfoque na capacidade de escoamento; enfoque mais tradicional, em que os sistemas de drenagem são projetados de acordo com sua capacidade de condução de vazão, tendo como objetivo transportar as águas pluviais o mais rápido possível para um ponto a jusante o mais distante possível. Como descrito anteriormente, tal "approach" não se sustenta ao longo dos anos, já que numa análise mais racional da situação, notamos que o problema é simplesmente transferido de um local a outro.

- Storage-Oriented Approach: enfoque mais novo em que a idéia principal é a tentativa da "imitação" das condições naturais, antes da interferência antrópica. Provendo armazenamento temporário seguido do lançamento controlado das águas pluviais retidas. Tal conceito preserva e evita os cada vez mais freqüentes eventos de alagamentos e enchentes dos pontos de lançamento. Estes pontos, muito comumente encontrados aqui no Brasil, canalizados e com importantes vias de tráfego em suas laterais.

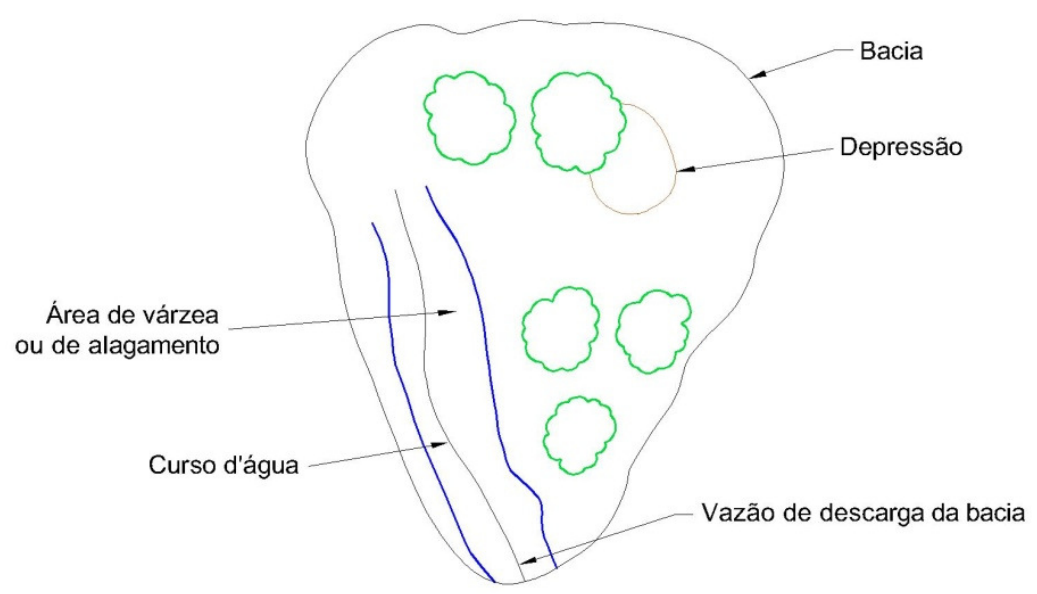

Figura 20: Situação antes da ação antrópica

(fonte: EPA, 2004) 


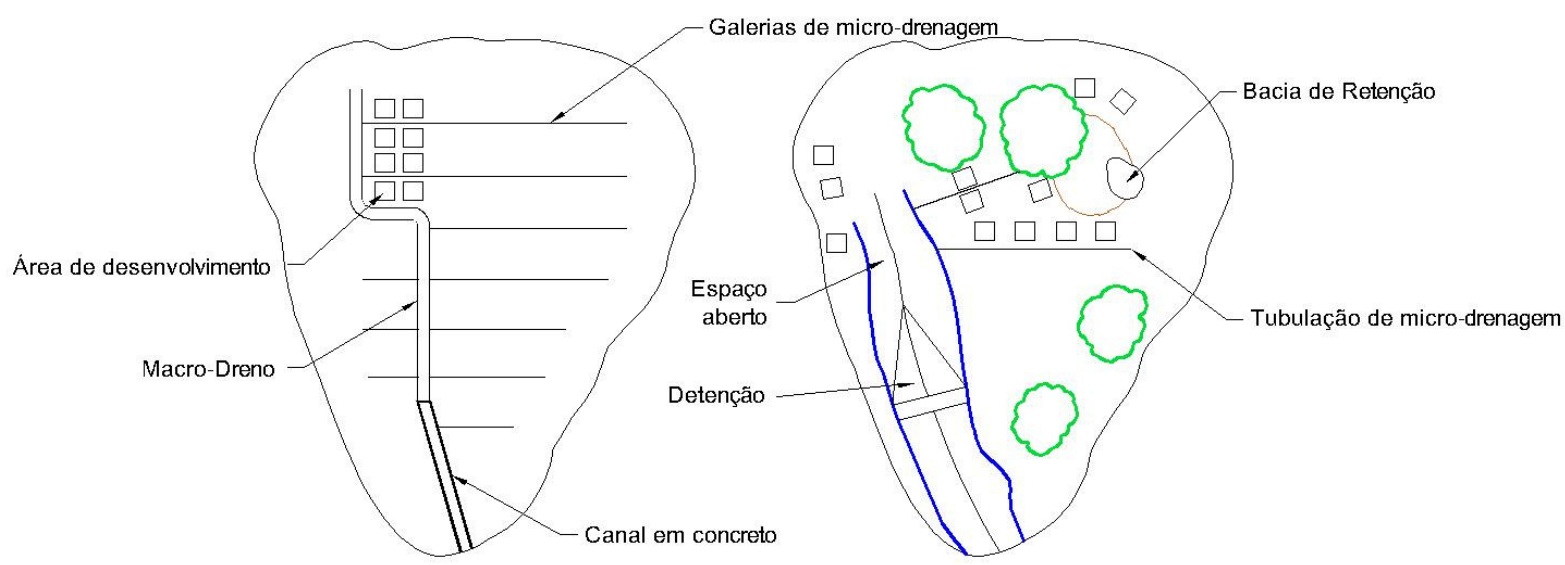

Figura 21: Situações após a ação antrópica （fonte: EPA, 2004)

Apesar da aparente maior vantagem do segundo enfoque, o primeiro enfoque é o mais difundido, por apresentar grande facilidade de aplicação seja em regiões já urbanizadas, seja naquelas ainda a urbanizar. Áreas de armazenamento são difíceis de encontrar em locais já urbanizados e mais difíceis ainda de serem deixados para esses fins numa época em que o custo de lotes urbanos cresce. Outra vantagem do enfoque tradicional de capacidade de transporte de vazão é a rapidez de remoção das águas de chuva, quando o sistema funciona eficientemente. Além disso, tais sistemas são os mais consagrados, com os seus procedimentos de projeto e dimensionamento, além de apresentarem menores custos de manutenção durante operação.

Em contrapartida, sistemas desenvolvidos com o novo enfoque de armazenamento apresentam custos menores de implantação se comparados com os custos de grandes galerias e peças usadas nos projetos tradicionais. É necessário frisar, no entanto, que nenhum dos dois enfoques, são excludente. Os dois sistemas podem ser combinados de modo a se obter melhores resultados tanto do aspecto de implantação quanto do ponto de vista de manutenção do sistema. $\mathrm{O}$ uso de estruturas de armazenamento é crescente, não somente pelos resultados positivos na redução de picos de vazão, mas como também na redução dos efeitos de poluição difusa das águas oriundas de chuvas. Países desenvolvidos, como dito por TUCCI (2008), encontram-se na fase do desenvolvimento sustentável, onde preocupações com a qualidade da água a ser lançadas em rios, lagos e no mar passa a ter importância no meio técnico.

O manual de drenagem urbana da cidade de São Paulo (FCTH,1999) apresenta uma análise comparativa dos dois enfoques e comenta que a utilização do conceito de 
armazenamento, apesar de ser moderno, ainda não é muito comum em sistemas de drenagem urbana. Segundo o manual é mais adequado para áreas em fase de desenvolvimento urbano, mas pode ser utilizado em áreas já urbanizadas se existirem locais adequados para a implantação de armazenamentos superficiais ou subterrâneos. Nas tabelas 21 e 22 apresentam-se, respectivamente, algumas medidas para redução ou retardamento do escoamento superficial direto e as vantagens e desvantagens dessas medidas.

Tabela 21: Formas de redução e retenção em diferentes áreas urbanas

\begin{tabular}{|c|c|c|}
\hline Área & Redução & Retardamento do deflúvio \\
\hline \multirow{4}{*}{$\begin{array}{l}\text { Telhado plano de } \\
\text { grandes dimensões }\end{array}$} & 1. armazenamento em cisterna & $\begin{array}{l}\text { 1. armazenamento no telhado, } \\
\text { empregando tubos condutores verticais } \\
\text { estreitos }\end{array}$ \\
\hline & \multirow{3}{*}{$\begin{array}{l}\text { 2. jardim suspenso } \\
\text { 3. armazenamento em tanque ou } \\
\text { chafariz }\end{array}$} & 2. aumentando a rugosidade do telhado; \\
\hline & & 3. cobertura ondulada \\
\hline & & 4. cobertura em cascalho \\
\hline \multirow{6}{*}{ Estacionamento } & 1. pavimento permeável & 1. faixas gramadas no estacionamento \\
\hline & 2. cascalho & $\begin{array}{l}\text { 2. canal gramado drenando o } \\
\text { estacionamento }\end{array}$ \\
\hline & \multirow[t]{4}{*}{$\begin{array}{l}\text { 3. furos no pavimento } \\
\text { impermeável }\end{array}$} & $\begin{array}{l}\text { 3. armazenamento e detenção para áreas } \\
\text { impermeáveis }\end{array}$ \\
\hline & & 4. pavimento ondulado \\
\hline & & 5. depressões \\
\hline & & 6. bacias \\
\hline \multirow{10}{*}{ Residencial } & 1. cisternas para casas individuais, & 1. reservatórios de detenção \\
\hline & 2. passeios com cascalho & $\begin{array}{l}\text { 2. utilizando gramas espessas (alta } \\
\text { rugosidade) }\end{array}$ \\
\hline & 3. áreas ajardinadas em redor & 3. passeios com cascalhos \\
\hline & 4. recarga de lençol subterrâneo: & 4. sarjetas ou canais gramados \\
\hline & a) tubos perfurados; & \multirow{6}{*}{$\begin{array}{l}\text { 5. aumentando o percursso da água por } \\
\text { meio da sarjeta, desvios, etc. }\end{array}$} \\
\hline & b) cascalhos & \\
\hline & c) valeta & \\
\hline & d) cano poroso & \\
\hline & e) poços secos & \\
\hline & f) depressões gramadas & \\
\hline \multirow{3}{*}{ Geral } & 1. vielas com cascalhos & \multirow{3}{*}{ 1. vielas com cascalhos } \\
\hline & 2. calçadas permeáveis & \\
\hline & $\begin{array}{l}\text { 3. canteiros cobertos com palhas } \\
\text { ou folhas }\end{array}$ & \\
\hline
\end{tabular}


Tabela 22: Vantagens e desvantagens no emprego das diferentes formas de redução e retenção do escoamento superficial direto

\begin{tabular}{|c|c|c|}
\hline Medidas & Vantagens & Desvantagens \\
\hline Cisterna & $\begin{array}{l}\text { 1. Água pode ser utilizada para: } \\
\text { a) proteção contra fogo } \\
\text { b) rega de terras } \\
\text { c) processos industriais } \\
\text { d) refrigeração } \\
\text { 2. Reduz o deflúvio superficial direto, ocupando } \\
\text { pequenas áreas } \\
\text { 3. O terreno ou espaço, acima da cisterna, pode } \\
\text { ser utilizado para outros fins }\end{array}$ & $\begin{array}{l}\text { 1. Custos relativamente altos } \\
\text { de instalação }\end{array}$ \\
\hline Jardim suspenso & $\begin{array}{l}\text { 1.Esteticamente agradável } \\
\text { 2. Redução do deflúvio superficial direto } \\
\text { 3. Redução dos níveis de ruído } \\
\text { 4. Valorização da vida animal } \\
\text { 5.Diminuição da temperatura } \\
\text { 6.Aumento da umidade do ar }\end{array}$ & $\begin{array}{l}\text { 1. Elevadas cargas nas } \\
\text { estruturas de cobertura e de } \\
\text { construção, exceto no caso de } \\
\text { alguns tipos especiais de } \\
\text { plantas que são mais leves; } \\
\text { 2. Instalação e manutenção de } \\
\text { alto custo }\end{array}$ \\
\hline $\begin{array}{l}\text { Reservatório com } \\
\text { espelho d'água } \\
\text { permanente } \\
\text { (geralmente em } \\
\text { áreas residências) }\end{array}$ & $\begin{array}{l}\text { 1. Controla grandes áreas de drenagem, } \\
\text { liberando pequenas descargas } \\
\text { 2. Esteticamente agradável } \\
\text { 3. Possíveis benefícios à recreação : } \\
\text { a) uso de barcos de recreação } \\
\text { b) pesca } \\
\text { c) natação } \\
\text { 4. Habitat para a vida aquática } \\
\text { 5. Aumentar o valor dos terrenos adjacentes }\end{array}$ & $\begin{array}{l}\text { 1. Requer grandes áreas } \\
\text { 2. Possível poluição pelas } \\
\text { enxurradas e sedimentação } \\
\text { 3. Possível haver crescimento } \\
\text { intenso de algas, como } \\
\text { resultado da eutrofização } \\
\text { 4. Acúmulo de lixo }\end{array}$ \\
\hline
\end{tabular}


1. Carga estrutural elevada

1. Retardo do deflúvio superficial direto

Armazenamento em telhado, empregando tubos condutores verticais estreitos
2. Efeito de isolamento térmico do edifício

a) água no telhado

b) através de circulação

3. Pode facilitar o combate a incêndios
2. A tomada de água dos tubos condutores requer manutenção

3. Formação de ondas e cargas devidas as mesmas

4. Infiltração de água do telhado para o edifício

5. Possíveis entupimentos devido às folhas das árvores

\begin{tabular}{ll}
\hline $\begin{array}{l}\text { Telhado com } \\
\text { rugosidade }\end{array}$ & $\begin{array}{l}\text { 1. Retardamento de deflúvio superficial direto e } \\
\text { alguma redução do mesmo (detenção das } \\
\text { ondulaçôes ou no cascalho) }\end{array}$ \\
\hline
\end{tabular}

1. Carga estrutural elevada

1. Entupimento dos furos ou poros

2. Compactação de terra abaixo do pavimento ou diminuição da permeabilidade do solo

Pavimento permeável (estacionamento e vielas)
1. Redução do deflúvio superficial direto

2. Recarga do lençol freático

3. Pavimento de cascalho pode ser mais barato do que asfalto ou concreto devido ao cascalho

3. Dificuldade de manutenção

4. Gramas e ervas daninhas podem crescer no pavimento

5. Lançamento de pedras com o deslocamento dos automóveis

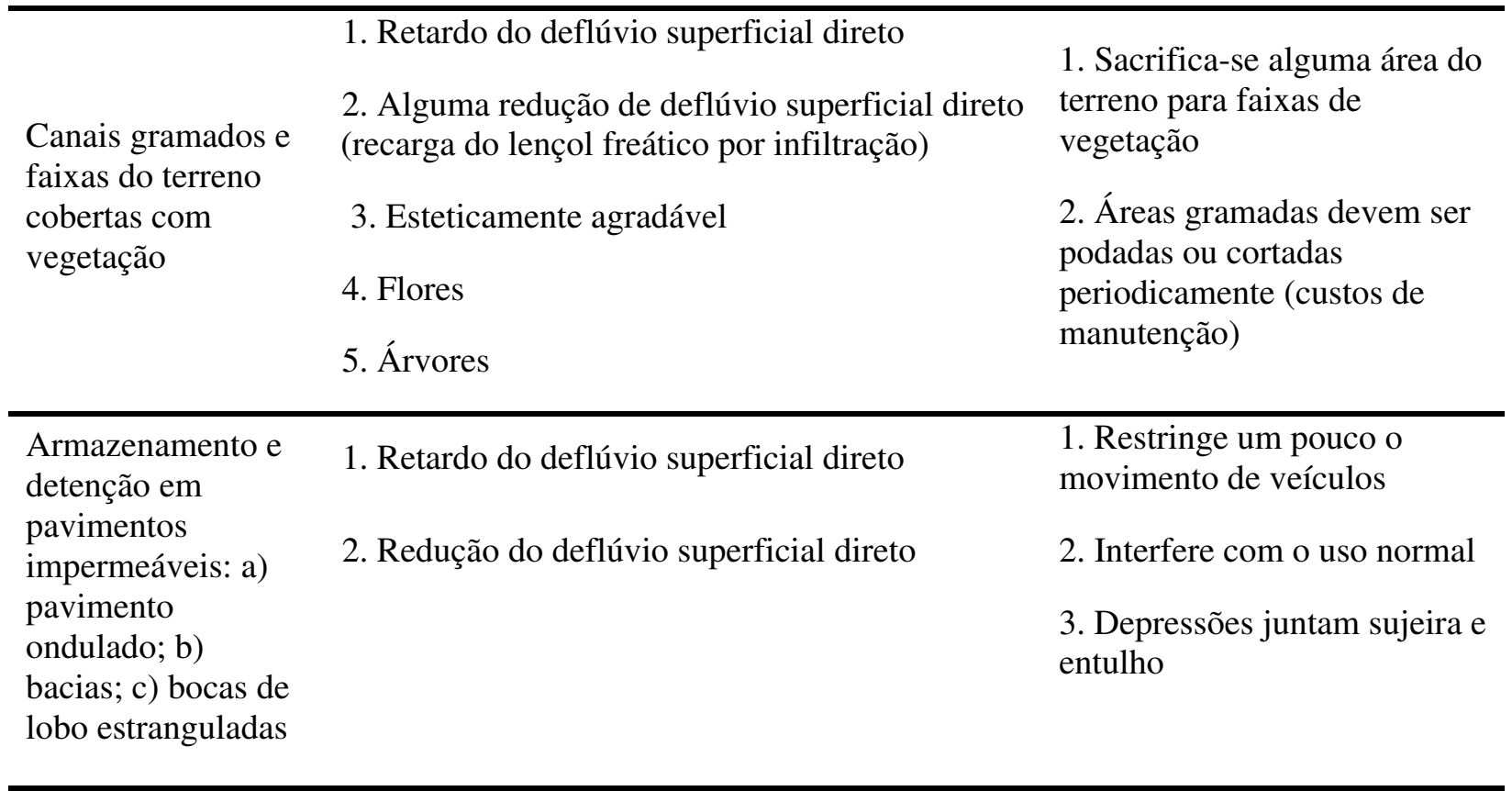




\begin{tabular}{|c|c|c|}
\hline \multirow{5}{*}{$\begin{array}{l}\text { Reservatório ou } \\
\text { bacias de detenção }\end{array}$} & 1. Retardo do deflúvio superficial direto & 1. Requer grandes áreas \\
\hline & 2. Benefício recreativo & 2. Custos de manutenção: \\
\hline & $\begin{array}{l}\text { 3. Quadras poliesportivas se o terreno for } \\
\text { propício }\end{array}$ & a) poda da gama \\
\hline & 4. Esteticamente agradável & c) limpeza periódica \\
\hline & $\begin{array}{l}\text { 5. Pode controlar extensas áreas de drenagem, } \\
\text { liberando descargas relativamente pequenas }\end{array}$ & $\begin{array}{l}\text { 3. Área de proliferação de } \\
\text { pernilongos }\end{array}$ \\
\hline \multirow{2}{*}{$\begin{array}{l}\text { Tanque séptico } \\
\text { transformado para } \\
\text { armazenamento e } \\
\text { recarga de lençol } \\
\text { freático }\end{array}$} & $\begin{array}{l}\text { 2. Redução de deflúvio superficial direto } \\
\text { (infiltração e armazenamento) }\end{array}$ & $\begin{array}{l}\text { 1. Requer manutenção } \\
\text { periódica para remoção de } \\
\text { sedimentos }\end{array}$ \\
\hline & $\begin{array}{l}\text { 3. A água pode ser usada para proteção contra } \\
\text { incendio, rega de gramados, etc. }\end{array}$ & $\begin{array}{l}\text { 2. Possíveis danos a saúde } \\
\text { 3. Algumas vezes requer um } \\
\text { bombeamento para o } \\
\text { esvaziamento apos a tormenta }\end{array}$ \\
\hline \multirow{2}{*}{$\begin{array}{l}\text { Recarga do lençol } \\
\text { freático: }\end{array}$} & 1. Retardo do deflúvio superficial direto & \multirow{2}{*}{$\begin{array}{l}\text { 1. Dificuldade de poda de } \\
\text { grama }\end{array}$} \\
\hline & 2. Aumento de infiltração & \\
\hline \multirow{2}{*}{$\begin{array}{l}\text { Escoamento } \\
\text { dirigido sobre } \\
\text { terrenos e } \\
\text { gramados }\end{array}$} & 1. Retardo do deflúvio superficial direto & 1. Possibilidade de erosão \\
\hline & 2. Aumento de infiltração & $\begin{array}{l}\text { 2. Água parada em depressões } \\
\text { no gramado }\end{array}$ \\
\hline
\end{tabular}

Fonte: Manual de Drenagem PMSP, FCTH, 1999

Dentre as diversas práticas e diferentes enfoques em drenagem urbana, algumas foram usadas e revisadas para se adaptarem às mais variadas situações. Apresentam-se a seguir alguns estudos de casos, na sua grande maioria em regiões topograficamente planas, e cujas soluções de drenagem tiveram, de certa forma, como base o conceito de armazenamento temporário. O estudo implementado nos distritos de Skokie e Wilmette, no estado de Illinois, Estados Unidos, tem uma descrição bem mais completa desses conceitos de armazenamento, já que é o objeto principal de estudo publicado pela EPA (2004). Tais estudos e soluções adotadas fazem parte do projeto elaborado por Stuart G. Walesh e Carolyn Sposito (2004) no artigo que resume e justifica as soluções adotadas naquelas comunidades. 


\section{Cleveland, OH: Puritas Avenue - Rock River Drive Area}

O principal problema da região era a ocorrência de alagamentos nos porões das residencias da localidade. Tal fato era gerado pela ocorrência cada vez mais freqüente e rápida de sobrecarga das galerias de águas pluviais. O conceito usado foi a redução dos picos de vazão conduzidos as galerias por meio da construção de tanques intermediários. Eram três diferentes bacias e cada uma delas recebeu um dos tanques, que foram implantados sob as guias e sarjetas e sobre as galerias pluviais. Construídos com tubos de metal corrugado, os tanques variavam seus diâmetros entre $1200 \mathrm{~mm}$ e $1700 \mathrm{~mm}$, com diferentes extensões, totalizando cerca de $165 \mathrm{~m}^{3}$ de capacidade de armazenamento. Estruturas de entrada e saída de vazão controlavam as taxas de entrada e saída do sistema. Este controle era efetuado por peça hidráulica denominada Hydro-Brake. Este é um mecanismo auto-ativado, que controla e atenua a vazão em função da uma vazão de entrada.

Com o experimento implantado pode-se concluir que:

- redução dos picos de vazão pode ser alcançada pelas estruturas de amortecimento mais próximas da captação e saída do sistema, mesmo sem grandes volumes de armazenamento;

- houve redução da quantidade de poluição difusa conduzida para as galerias, já que decantavam nos tanques de amortecimento;

- para um efetivo e melhor aproveitamento do Hydro-Brake, o projeto deve perfeitamente avaliar as características da região a ser drenada e a tubulação e galerias de drenagem que irão compor o sistema;

- para o caso de armazenamento na calha das vias, o sistema mostrou-se mais efetivo do que quando somente pode ter como estruturas de armazenamento aquelas localizadas subsuperficialmente.

\section{Parma, OH: Ridge Road Area}

Ridge Road é uma região, segundo WALESH e SPOSITO topograficamente muito plana, com área de cerca de 12 hectares localizada na porção mais baixa da bacia principal com 117 hectares. Sendo a porção mais baixa do conjunto de montanhas, a região enfrentava constantes problemas de alagamentos, tanto dos porões das residências, quanto das vias urbanas do local. Era sabido que o sistema de tubos e galerias de drenagem estavam 
construídos e localizados na mesma trincheira em que se localizava o sistema de esgotamento sanitário. Era comum, como resultado, então que a cada evento de cheia ocasionado por chuvas houvesse também problemas com o sistema de esgotamento sanitário, que, por ser antigo, apresentava vazamentos e infiltração.

Duas soluções foram propostas, tendo sido o fator decisivo o custo. A alternativa implementada considerou o armazenamento temporário nas ruas, o que requereu serviços como reconstrução de guias, construção de reguladores de vazão, tanques de armazenamento subsuperficial.

\section{Chicago, IL: Jeffery Manor Neighborhood}

Jeffery Manor é uma área na parte sudeste da cidade de Chicago, de características residenciais, tendo pequena porção de sua área total dedicada a uso industrial e comercial. As ruas em sua maioria são pavimentadas e tem seção transversal onde se fazem presentes guias, sarjetas, pavimento asfáltico e na maioria dos casos faixas para estacionamento. $\mathrm{O}$ sistema de drenagem era composto por tubos de drenagem com diâmetros que variavam de $250 \mathrm{~mm}$ a $1000 \mathrm{~mm}$. A principal característica topográfica, no entanto era tratar-se de área extremamente plana. Era sabido que o sistema de galerias não estava dimensionado e não teriam capacidade de coletar e conduzir vazões geradas por chuvas mais intensas.

Dos estudos que foram propostos e aquele implementado permitiu concluir que:

- O armazenamento temporário nas ruas aliviaria o sistema de galerias, evitando sua sobrecarga e conseqüente alagamento desordenado de vias e porões;

- A análise de um evento de chuva de período de retorno de 5 anos, mostrou que a área necessária para o armazenamento do volume necessário a evitar a sobrecarga da rede, usaria cerca de 74 quadras do local. Por esse motivo, as áreas de armazenamento adotadas foram às próprias ruas, que receberam bermas, com o objetivo de ordenar e controlar os locais onde haveria os “alagamentos” propositais.

A figura 22 demonstra melhor o que fora acima descrito: 


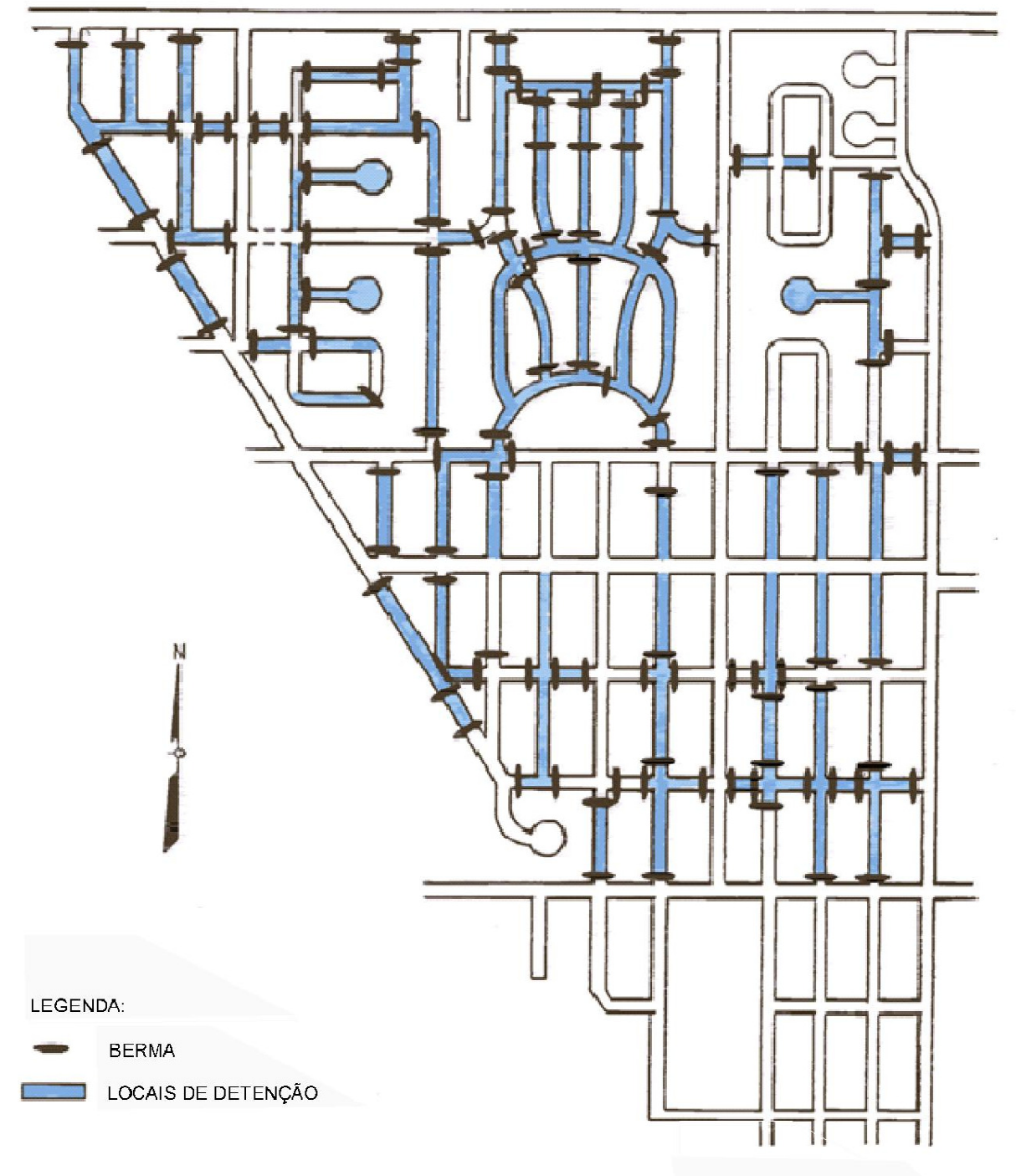

Figura 22: Planta esquemática da solução adotada (Fonte: EPA, 2004)

\section{Skokie e Wilmette, IL}

Os casos destas duas comunidades do estado do Illinois são os dois principais casos de sucesso da aplicação da tecnologia de armazenamento temporário na caixa da rua, em artigo publicado pela EPA, como uma de suas BMPs. Além de ser o maior campo de aplicação, é também o mais antigo em operação, tendo sido implantado em 1983 e desde então em operação. Estas duas comunidades estão localizadas imediatamente ao norte da cidade de Chicago, sendo constituída basicamente de áreas residenciais, caracterizadas por uma planície ampla com declividades variando entre 0.1 a $1 \%$, tendo, no entanto muitas áreas cuja declividade característica é de $0.2 \%$. 
Os sistemas de drenagem e esgotamento sanitário funcionam combinados e são compostas basicamente como indicadas na figura 23 :

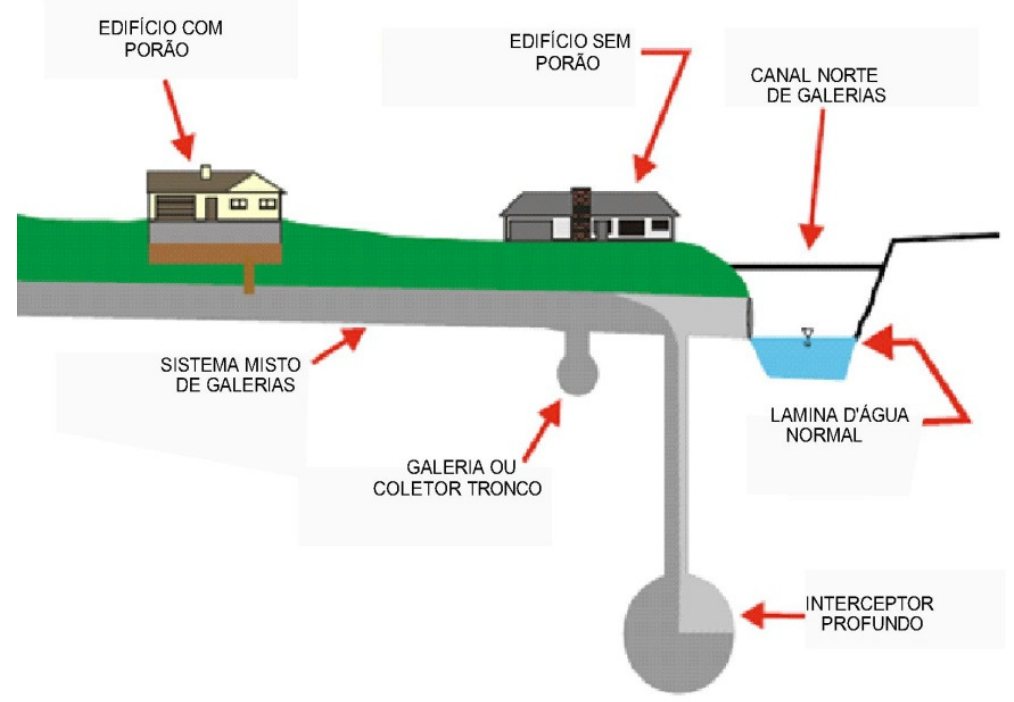

Figura 23: Seção transversal típica do sistema de drenagem local $\quad$ Fonte: EPA, 2004

Com a constante impermeabilização dos terrenos do local, problemas de alagamento e sobrecarga dos sistemas combinados de drenagem e esgotamento sanitário começaram a surgir. Durante um período de 15 anos, de estudos, tais localidades receberam diversos projetos com diferentes soluções. Todas elas, no entanto, tendo como linha de raciocínio principal a retirada rápida das águas que estavam ocasionando o problema. Nenhuma delas fora aprovada, certamente por questão de custos de implantação.

- 1967: estudo recomendando tubulações de alívio, que segundo o artigo, sua implementação em 1999 custaria US\$123 milhões. A idéia era construir galerias em várias ruas das vilas, de modo que combinadas teria a capacidade de absorver um evento de chuva com tempo de recorrência de 15 anos;

- 1973: estudo recomendando galerias profundas (deep and shallow tunnels), cujo objetivo era interceptar e coletar os efluentes advindos de todas as galerias principais de diversas localidades do município de Chicago. Novamente, segundo o artigo, os custos de implantação desta galeria em 1999, seria da ordem de US\$ 111 milhões;

- 1974: estudo que já se iniciou tendo outra linha de pensamento. Neste caso as soluções consideradas e propostas foram a colocação de redutores e controladores de vazão junto as entradas de galerias, controlando a vazão de entrada das águas de chuva; foi proposto e aprovado pela população por meio de pesquisa a desconexão dos sistema de pluvial 
residencial da rede de coleta. $\mathrm{O}$ objetivo era reduzir a vazão de entrada da rede combinada. Com essas medidas, iniciou-se ai a idéia de aproveitar-se do armazenamento nas ruas. A desconexão das águas pluviais de $98 \%$ das residências foi feita e com isso uma avaliação da capacidade de armazenamento das ruas para eventos de 5 e 10 anos de período de retorno foi procedida;

- 1981: esse estudo propôs combinação entre velha e nova tecnologia, onde um conjunto de obras foram propostas: galerias de alívio, redes de captação de água pluviais separadas daquelas existentes, que eram do tipo combinada (esgoto e drenagem juntos) e controladores de vazão de entrada (inlet controlers);

- 1982: Street Storage System foi nome dado a nova tecnologia proposta na tentativa de solução dos problemas de alagamentos e sobrecargas das redes de coleta de efluentes. Foi a primeira vez que se propôs pela utilização do armazenamento temporário nas ruas como única solução dos problemas daquelas comunidades. A idéia era explorar maneiras de intencionalmente armazenar água na superfície das ruas, de maneira controlada e de modo a esvaziá-la quando do termino do evento de chuva. O projeto em sua totalidade propôs 1200 reguladores de vazão de entrada, 24 tanques de armazenamento subterrâneo e algumas redes de ligação ao sistema principal. Os tanques de armazenamento foram usados para os casos daquelas ruas em que não se podia contar ou não existia o volume de armazenamento necessário para determinado evento de chuva. O custo de implantação foi bem inferior aquele previsto pelos projetos anteriores com enfoques mais tradicionalistas (da ordem de US\$ 11.220.000).

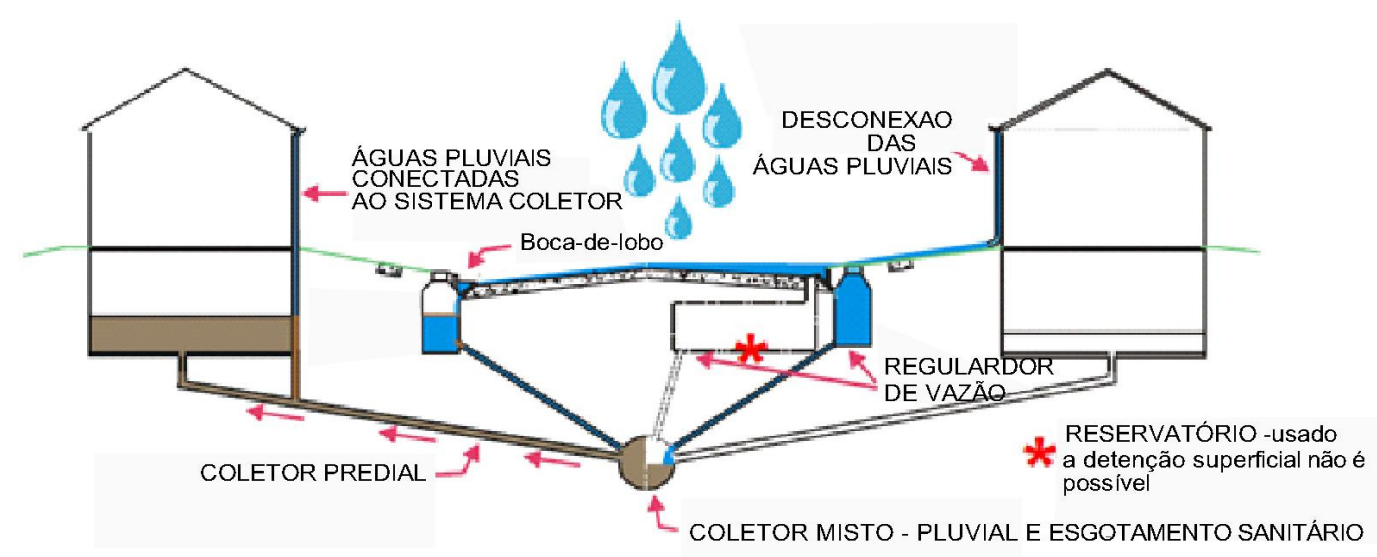

CONDIÇÃO EXISTENTE

ARMAZENAMENTO SUPERFICIAL

Figura 24: Armazenamento superficial

(Fonte: EPA, 2004) 


\subsubsection{O CONCEITO DO ARMAZENAMENTO NAS RUAS}

Para o entendimento do conceito por trás do armazenamento em ruas, é fundamental a caracterização completa dos conceitos de escoamento nas vias a capacidades de armazenamento. O exemplo aqui abordado refere-se a ruas típicas das comunidades de Skokie e Wilmete, cujas fotos abaixo oferecem boa visualização da tipologia e dos elementos que compõem a seção transversal típica de suas ruas:

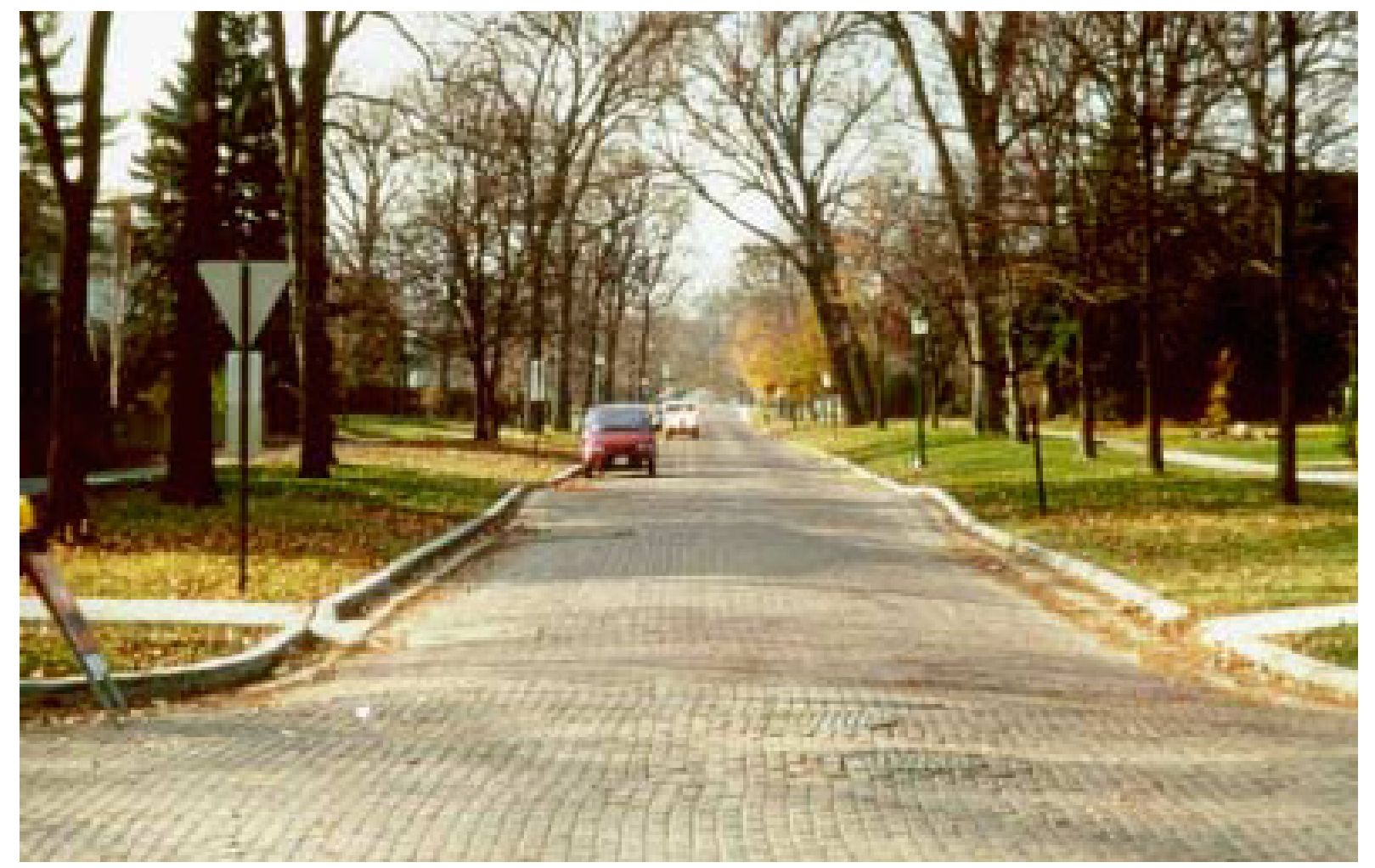

Figura 25: Rua típica do distrito de Skokie

(Fonte: EPA, 2004)

Como já explicado anteriormente na seção que tratou sobre a capacidade de escoamento de sarjetas, Manning ou Izzard podem ser usados para a averiguação das curvas de capacidade de descargas das vias. No caso específico, Manning é a equação mais adequada, já que avalia a calha total da rua, não apenas a sarjeta, como é o caso da equação de Izzard. Para isso, seção ou seções típicas de vias devem ser detalhadas hidrogeométricamente: 


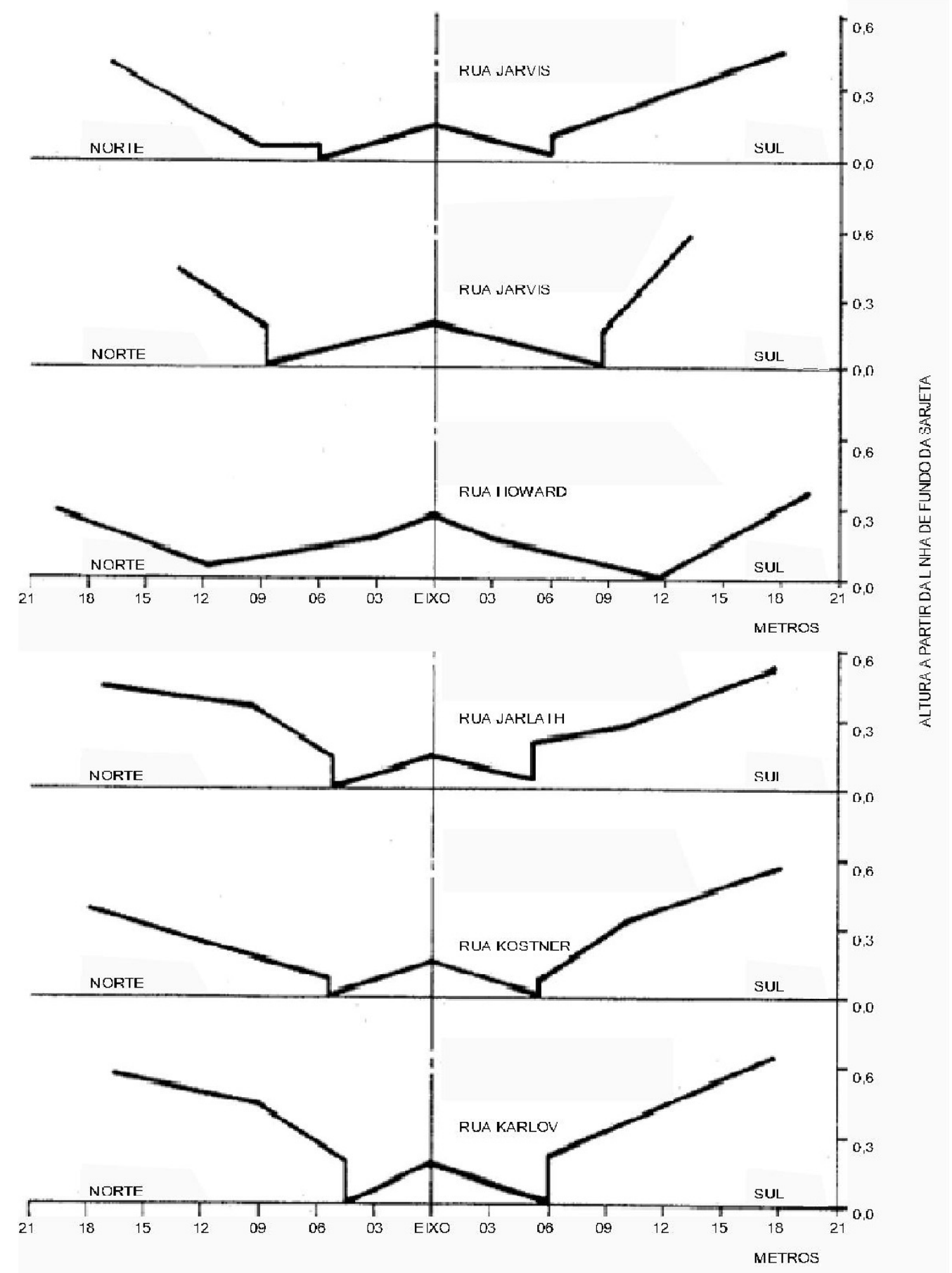

Figura 26: Discretização das seções transversais típicas de Skokie (Fonte: EPA, 2004)

O procedimento de análise consiste na aplicação da equação de Manning para diferentes alturas de água na seção a rua, considerando diferentes declividades. Isto por que, estas serão as únicas variáveis dentre os elementos da equação. 


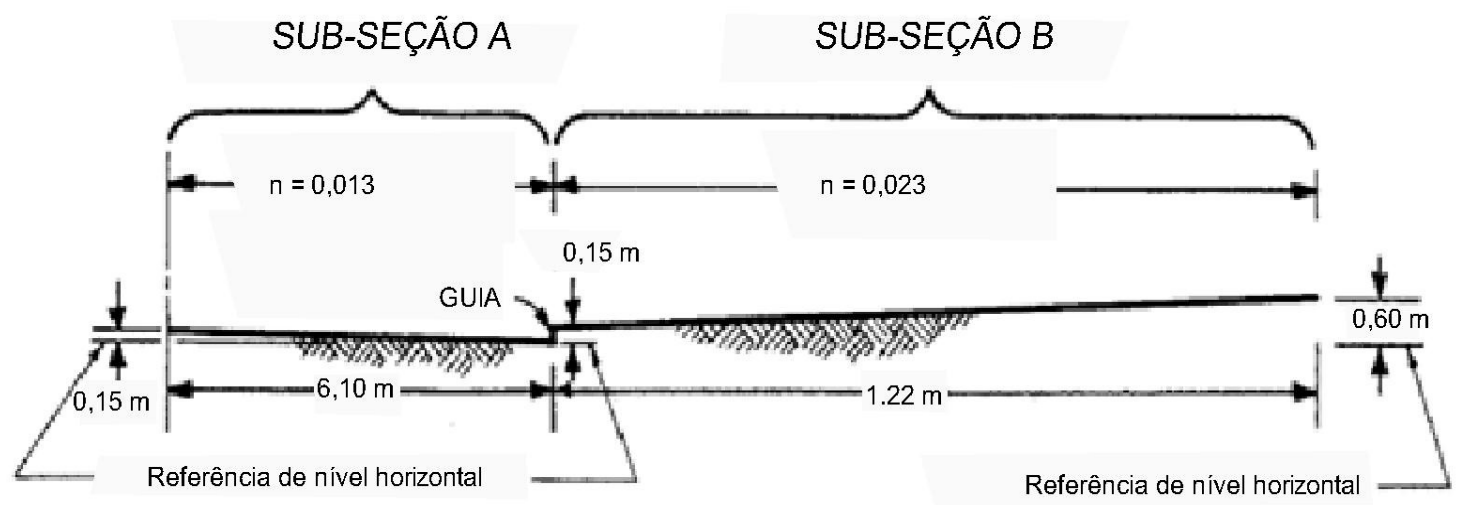

Figura 27: Discretização da rua Easy, para avaliação preliminar $\quad$ (Fonte: EPA, 2004)

$$
Q=Q_{A}+Q_{B}=S_{o}^{0,5} \cdot\left(\frac{A_{A} R_{h A}{ }^{2 / 3}}{n_{A}}+\frac{A_{B} R_{h B}{ }^{2 / 3}}{n_{B}}\right)
$$

eq. 64

em que:

$\boldsymbol{Q}_{A}=$ vazão na seção $A$;

$Q_{B}=$ vazão na seção $B$;

$\boldsymbol{S}_{\mathbf{0}}=$ declividade longitudinal;

$\boldsymbol{A}_{\boldsymbol{A}}=$ Área molhada da seção A;

$\boldsymbol{R}_{\boldsymbol{A}}=$ raio hidráulico da seção $A$;

$\boldsymbol{n}_{\boldsymbol{A}}=$ rugosidade de Manning na seção A;

$A_{B}=$ Área molhada da seção $B$

$\boldsymbol{R}_{\boldsymbol{B}}=$ raio hidráulico da seção $B$;

$\boldsymbol{n}_{\boldsymbol{B}}=$ rugosidade de Manning na seção B;

O gráfico da figura 28 a seguir demonstra as diferentes capacidades de condução de vazão em função da declividade longitudinal da via e de sua variação de nível d'água junto a guia. 


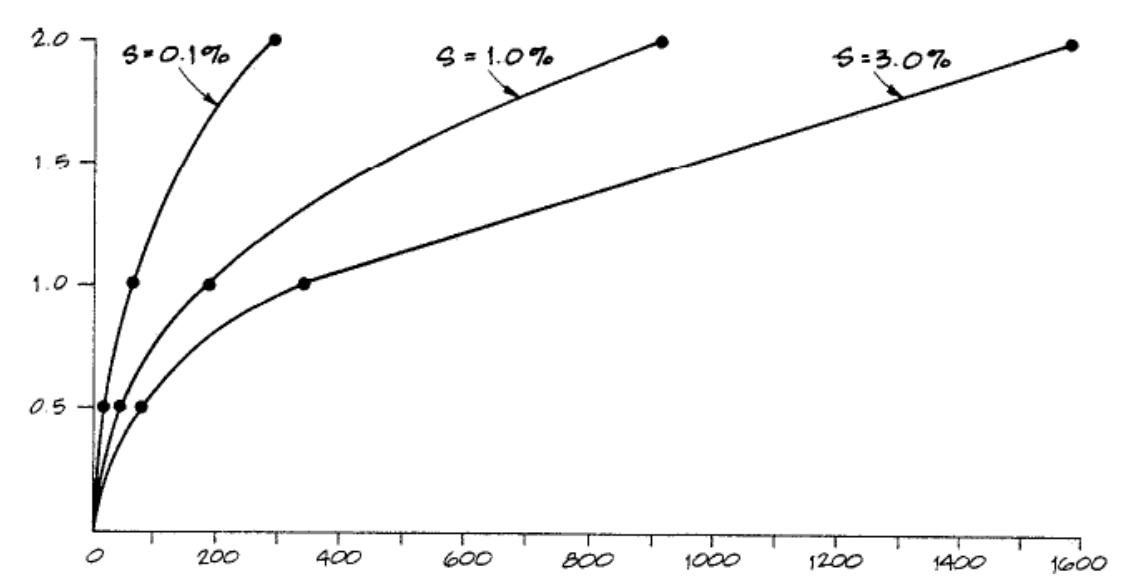

Figura 28: Vazão x Lâmina d'água da seção em estudo em pés x cfs (Fonte: EPA, 2004)

A análise indica que a seção típica da via pode carregar vazões consideráveis, quando comparada com aquelas do sistema de galerias subterrâneas, chegando a certos casos ser maior (casos de seção completamente alagada).

No que concerne o armazenamento, análise similar pode ser feita. Se for considerada novamente a mesma seção transversal típica apresentada na figura 29 e tomado como exemplo a área de contribuição abaixo desenhada:

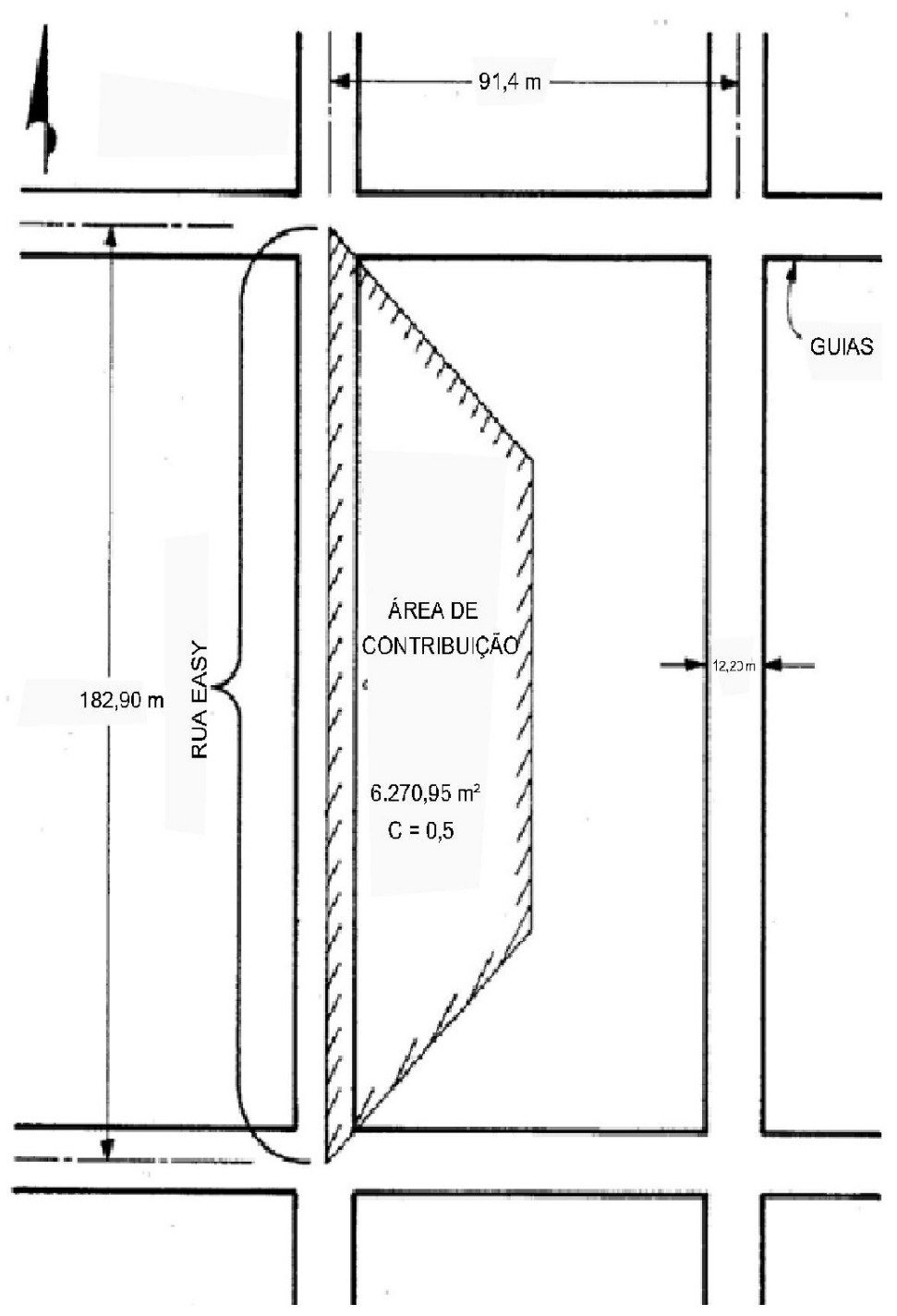

Figura 29: Delimitação da bacia de contribuição do trecho da rua em estudo (Fonte: EPA, 2004) 
Assumindo que a declividade longitudinal da via é muito próxima de zero, efetuam-se os cálculos fazendo igual a este valor. Obtêm-se uma curva de capacidade de amortecimento, muito semelhante a aquelas curvas do tipo cota $\boldsymbol{x}$ volume.

Tabela 23: Volume precipitado acumulado - EASY STREET

\begin{tabular}{cccccc}
\hline \multicolumn{2}{c}{$\begin{array}{c}\text { Profundidade } \\
\mathbf{f t}\end{array}$} & $\mathbf{m}$ & \multicolumn{2}{c}{ Área da seção } & \multicolumn{2}{c}{ Volume } \\
$\mathbf{f t}^{\mathbf{2}}$ & $\mathbf{m}^{\mathbf{2}}$ & $\mathbf{f t}^{\mathbf{3}}$ & $\mathbf{m}^{\mathbf{3}}$ \\
\hline 0 & 0.00 & 0.00 & 0.00 & 0 & 0.00 \\
0.5 & 0.15 & 5.00 & 0.46 & 3000 & 84.95 \\
1 & 0.30 & 18.33 & 1.70 & 11000 & 311.48 \\
2 & 0.61 & 65.00 & 6.04 & 39000 & 1104.35 \\
\hline \multicolumn{3}{r}{} & & \multicolumn{3}{c}{ Fonte: EPA, 2004 }
\end{tabular}

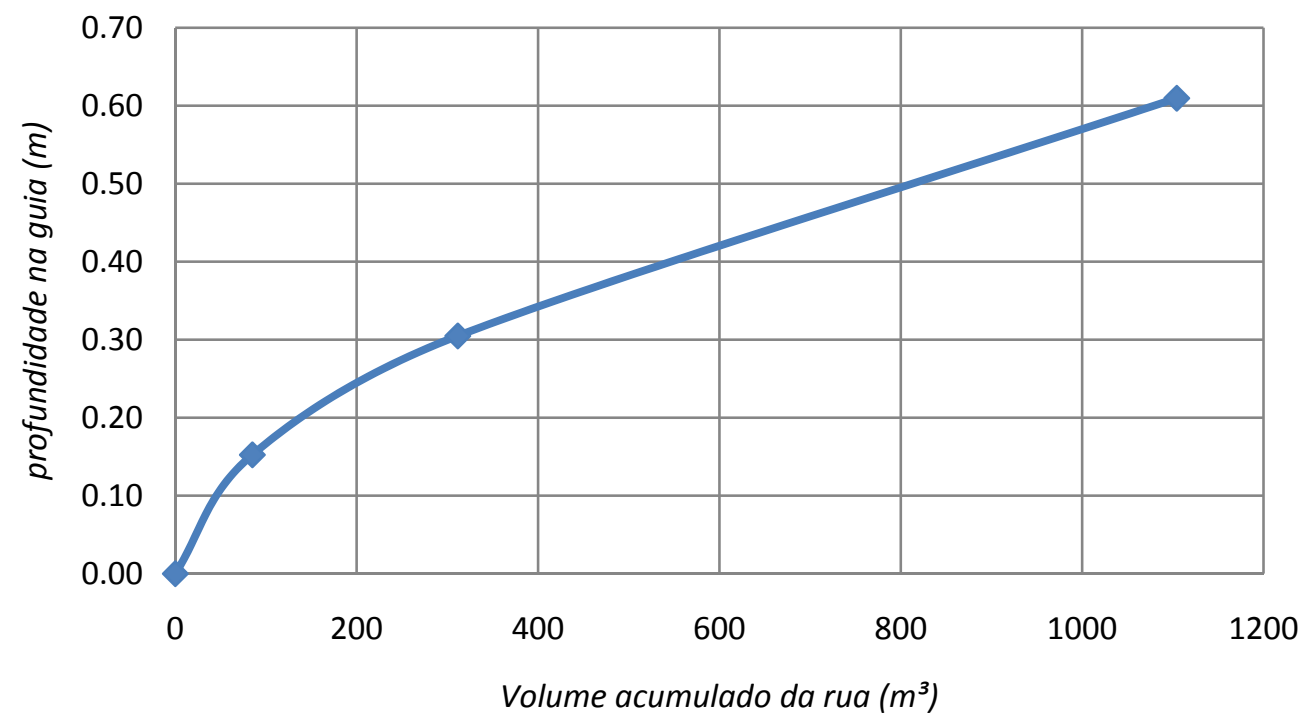

Figura 30: Curva Profundidade x Volume Armazenado (Fonte: EPA, 2004)

Fazendo a averiguação de capacidade de armazenamento da via, considerando eventos de chuva variados, temos: 
Tabela 24: Intensidade e profundidade armazenada para EASY STREET

\begin{tabular}{cc|cccc|cc}
\hline \multicolumn{2}{c|}{ Intensidade } & \multicolumn{3}{c|}{ Runoff } & \multicolumn{2}{c}{ Profundidade acumulada } \\
\hline in & $\mathrm{m}$ & in & $\mathrm{m}$ & $\mathrm{ft}^{3}$ & $\mathrm{~m}^{3}$ & $\mathrm{ft}$ & $\mathrm{m}$ \\
0.50 & 0.013 & 0.25 & 0.00635 & 1410 & 39.93 & 0.30 & 0.091 \\
1.00 & 0.025 & 0.50 & 0.0127 & 2810 & 79.57 & 0.45 & 0.137 \\
2.00 & 0.051 & 1.00 & 0.0254 & 5625 & 159.2 & 0.75 & 0.229 \\
4.00 & 0.102 & 2.00 & 0.0508 & 11250 & 318.5 & 1.00 & 0.305 \\
\hline
\end{tabular}

Fonte: EPA, 2004

Como se pode notar pelos cálculos efetuados por WALESH e ESPOSITO (2004), mesmo com um evento com altura de 0,102m (4ft) como evento de chuva, para um coeficiente de escoamento superficial igual a $0,5(\mathrm{C}=0,5)$, o nível máximo de água na via foi de $0,305 \mathrm{~m}$ (considerando as unidades do S.I). A rua teve sua seção coberta por água, mas não permitiu transbordamento para dentro das residências, nesta simulação. Esta simples análise sugere que as vias com declividades baixas têm capacidade de armazenamento de grandes volumes de água.

A combinação entre os conceitos de "capacidade de transporte de vazão" e "capacidade de armazenamento", deve conduzir, sem dúvida, a resultados positivos no sentido da redução dos picos de vazão. O conceito inovador do armazenamento temporário nas vias é justamente a redução desses picos, controlando a entrada de água no sistema a níveis por ele comportados. No caso de localidades já urbanizadas e com pouca ou nenhuma área disponível para a construção de estruturas de armazenamento, os leitos de ruas semi-planos mostraram-se muito úteis nessa tarefa.

\subsubsection{ELEMENTOS CONSTRUTIVOS DO SISTEMA}

Como dito em seções anteriores, as ruas das comunidades de Vilmete e Skokie apresentam declividades da ordem de $0.2 \%$, ou seja, diferente de zero, o que gera um escoamento superficial. Para que o conceito do armazenamento pudesse ser aproveitado da melhor maneira possível, alguns elementos construtivos foram concebidos no intuito de 
disciplinar as áreas de "alagamento". As figuras 31 e 32 ilustram o conceito de "disciplinar os alagamentos":

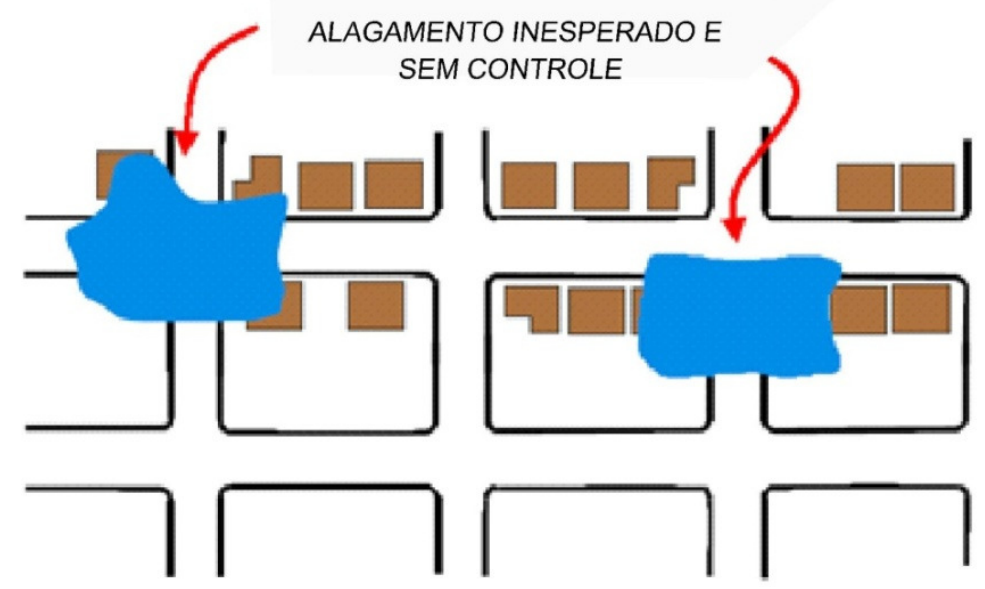

Figura 31: Alagamento descontrolado nas vias (Fonte: EPA, 2004)

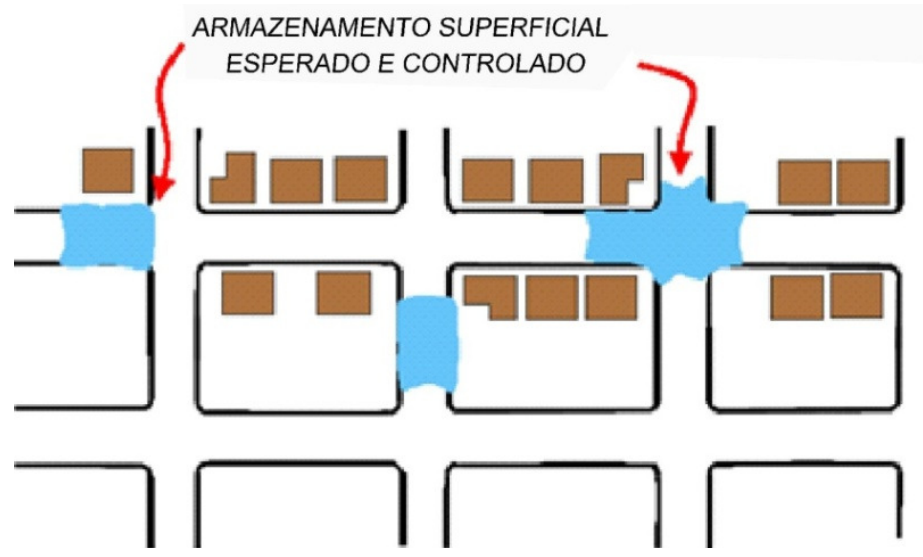

Figura 32: "Alagamento" intencional das vias (Fonte: EPA, 2004)

Bermas: uma berma é uma estrutura baixa construída transversalmente ao eixo das ruas, de guia a guia, com o objetivo intencional de impedir o escoamento das águas para a seção seguinte; funciona como um muro de barragem. Pode ser confundida com lombadas ou elemento de redução de velocidade, no entanto tem função hidráulica importante.

Reguladores de vazão: elemento passivo cuja função é regular as vazões de entrada, pela restrição geométrica nele presente. Deve ser dimensionado em conjunto ao armazenamento, já que é responsável pelo perfeito funcionamento deste. 
O funcionamento em conjunto desses dois elementos é a chave mestra deste conceito inovador de armazenamento nas ruas. Sua combinação pode ser comparada ao de um reservatório ou dos chamados "piscinões", obviamente numa escala em menores proporções.

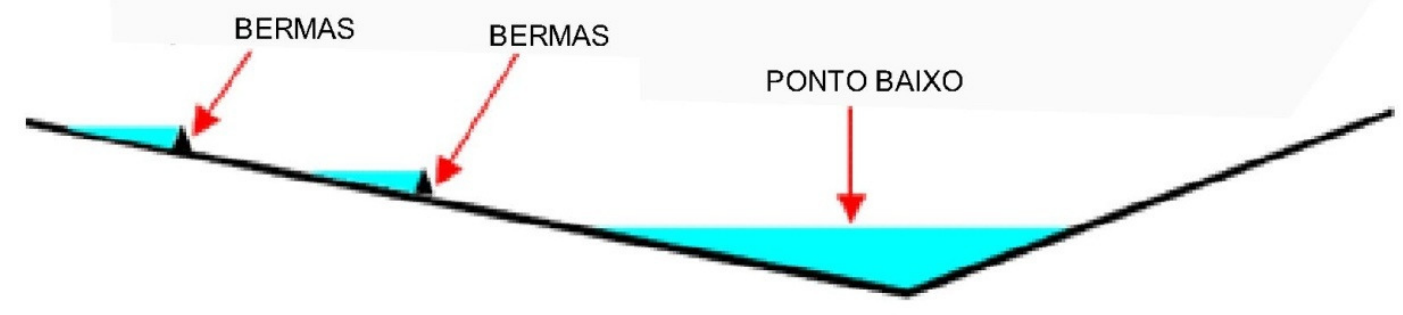

NOTA: exagero vertical

Figura 33: Posicionamento de bermas para controle de alagamento e armazenamento na via

Fonte: EPA, 2004
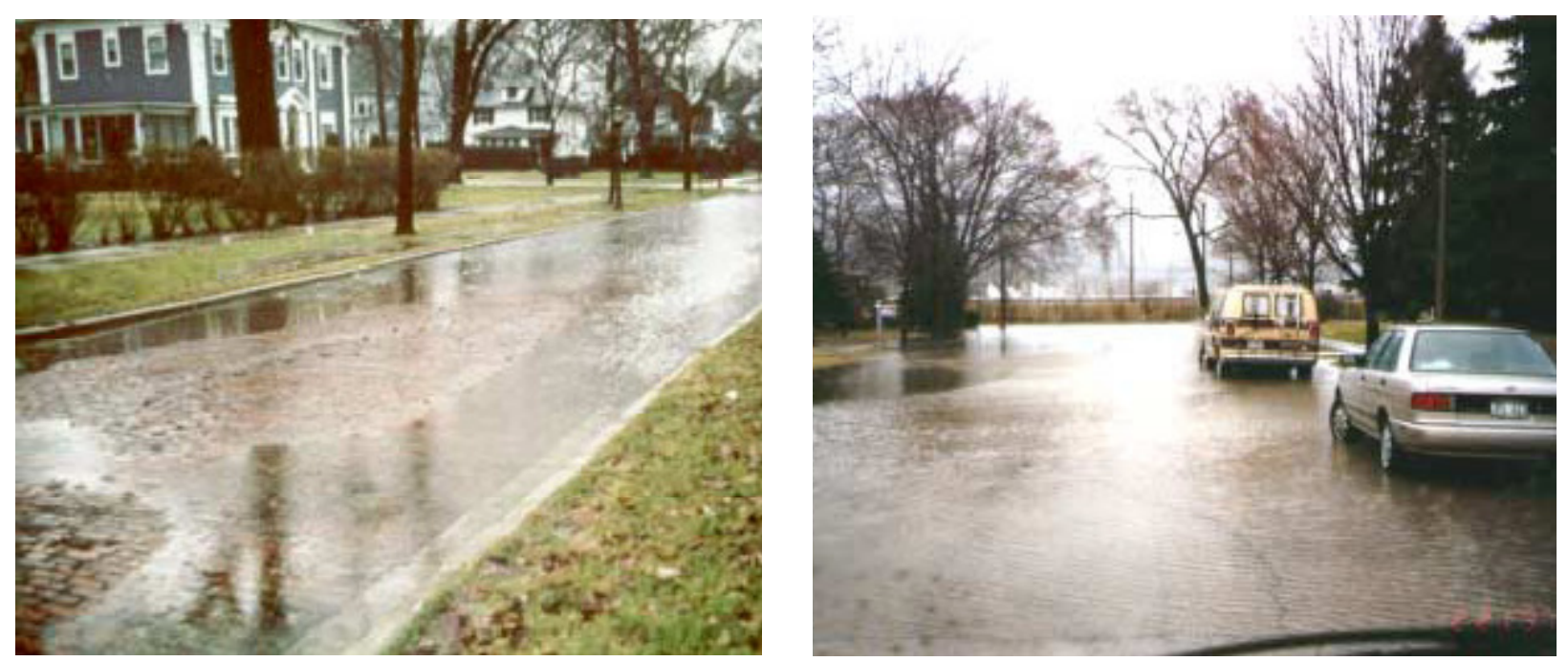

Figura 34: Imagem das vias servindo como áreas de armazenamento

(Fonte: EPA, 2004)

Estruturas de armazenamento temporário subsuperficial: há casos, onde seja pela característica da via ou mesmo pela necessidade hidráulico-hidrológica, não há volume suficiente na via e se faz necessária a construção de tanques ou galerias subterrâneas no intuito de armazenar e/ou transportar as vazões geradas. São usados onde é absolutamente necessário, por se tratar de obras de custo elevado. No estudo aqui apresentado, referente as comunidades de Skokie e Wilmete, foram construídos apenas 83 desses elementos, número pequeno se comparado com as 871 bermas e 2900 reguladores de vazão. Tais estruturas 
variam de simples caixas sob a calçada ou mesmo galerias de concreto pré-moldado, como podemos notas nas imagens a seguir:
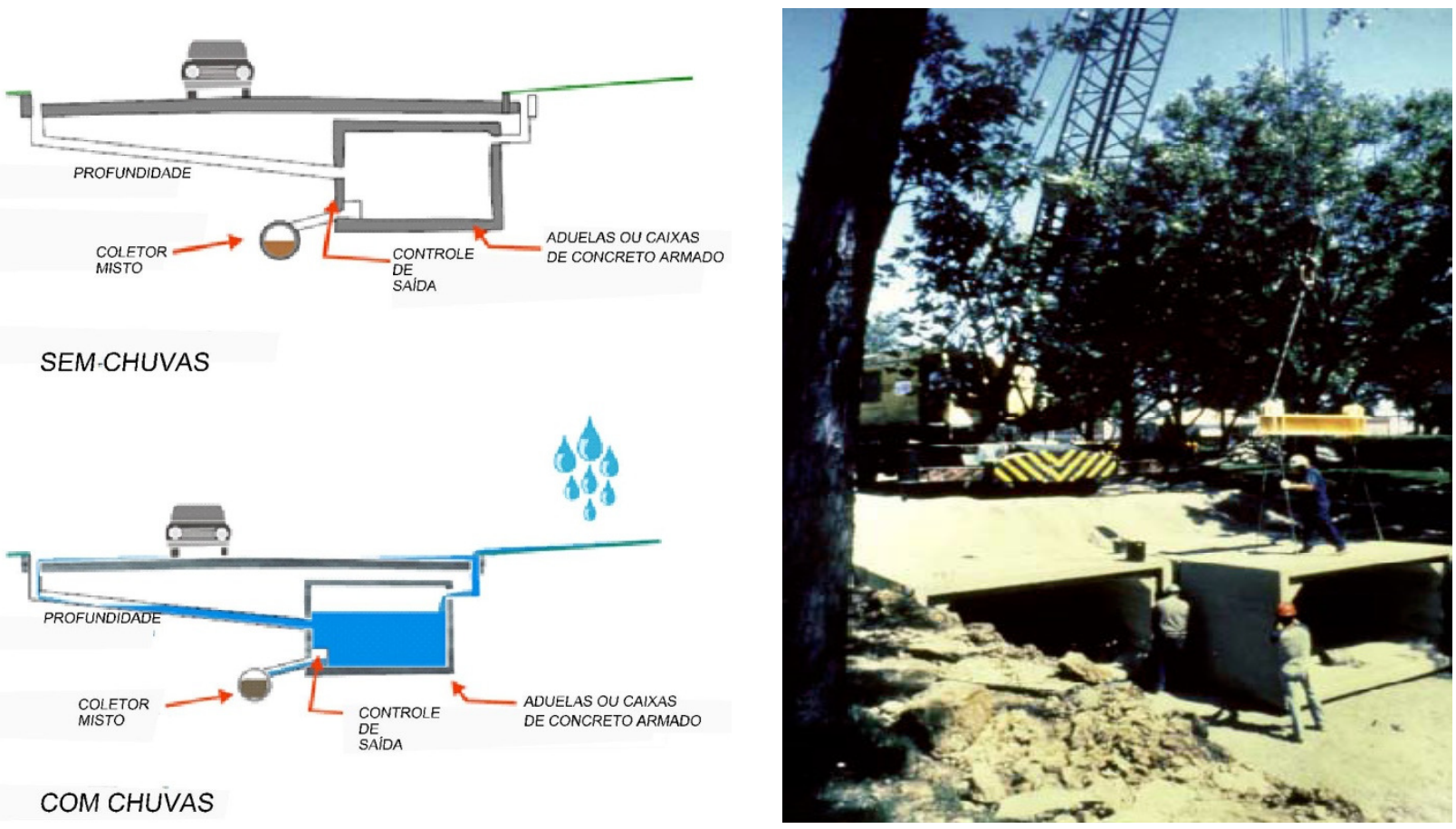

COM CHUVAS

Figura 35: Imagem e esquema das grandes seções pré-moldadas que servirão como reservatórios de amortecimento de vazão

(Fonte: EPA, 2004) 


\section{MODELO PARA CONSIDERAÇÃO DO AMORTECIMENTO NA CALHA DA RUA}

\subsection{CONSIDERAÇÕES INICIAIS}

O objetivo principal deste trabalho é a avaliação quantitativa dos efeitos das declividades abaixo de $0,5 \%$ no escoamento superficial em vias urbanas. Tal avaliação não poderia ser feita sem antes termos considerado quais os modelos atuais de escoamento em superfícies livres. Modelos estes que descrevem o fenômeno tanto sob o aspecto hidrológico quanto hidráulico, ou seja, os métodos utilizados para a determinação da vazão gerada e os cálculos e critérios de dimensionamentos dos elementos responsáveis pelo transporte de tal vazão.

Todo o trabalho para a elaboração de um projeto de drenagem, especialmente aqueles voltados para os aspectos da micro-drenagem urbana, tem como ponto de partida uma avaliação hidrológica da bacia contribuinte, para fins de determinação daquela vazão, aqui chamada vazão de projeto, que servirá como parâmetro de dimensionamento de todos os elementos drenantes do sistema. Aspectos institucionais, econômicos e de segurança de projeto permeiam esta avaliação, e, por esses motivos, alguns critérios mínimos são estabelecidos, no intuito de minimizar futuros problemas como sub-dimensionamento de estrutura de drenagem e excessiva recorrência de eventos críticos com consequiências desastrosas. O método Racional é aquele mais aplicado e usado para esta tarefa, seja pela simplicidade de aplicação, seja pela confiabilidade de resultados alcançada.

Uma vez conhecida tal vazão é feito o dimensionamento dos elementos condutores: guias, sarjetas, leito carroçável, galerias, canais e outros, por meio das conhecidas equações, de Manning e/ou Chezy. Dentre os diferentes elementos, alguns deles se destacam mais, e nesse caso são as galerias, em geral tubos de concreto, dispostos em pontos estratégicos, responsáveis pela condução rápida das águas até um curso d'água, canal ou rio, minimizando ou eliminando alagamentos daqueles locais a montante. No entanto, pouco se fala no tocante ao escoamento nas superfícies das ruas. Estas são na realidade as primeiras seções de conduto encontradas pelas águas de chuvas que caem sobre uma bacia urbana. Assim como num ambiente natural, as árvores e talvegues absorvem parte dos volumes escoados, num ambiente 
urbano, os elementos de drenagem, sejam as calhas das ruas, sejam as galerias, cumprem o mesmo papel: armazenar por determinado tempo, aqueles volumes por eles escoados. É com esse princípio de avaliação do quanto é armazenado e, portanto qual a importância desse efeito na etapa de dimensionamento hidráulico dos elementos de micro-drenagem, que um modelo de estudo deste fenômeno é aqui proposto.

Sabe-se que a capacidade de condução de um conduto livre é diretamente ligada a sua declividade e geometria. Por esta razão, em muitos manuais e diretrizes de projeto, acham-se impostas condições mínimas de declividade longitudinal, com o objetivo de garantir regularidade construtiva e a manutenção das condições de cálculo impostas. No entanto, existem determinadas situações em que tais gradientes não podem ser construídos. Esta é uma situação bastante comum nas cidades de planície, onde facilmente são encontradas vias com declividades inferiores aos $0,5 \%$ considerados como valor mínimo. Onde a "regra dos 0,5\%" não é alterada de acordo com a situação local, o que se vê são perfis de ruas, com pontos altos e baixos e a presença de inúmeras galerias e bocas-de-lobo, como exemplificadas na figura 36:

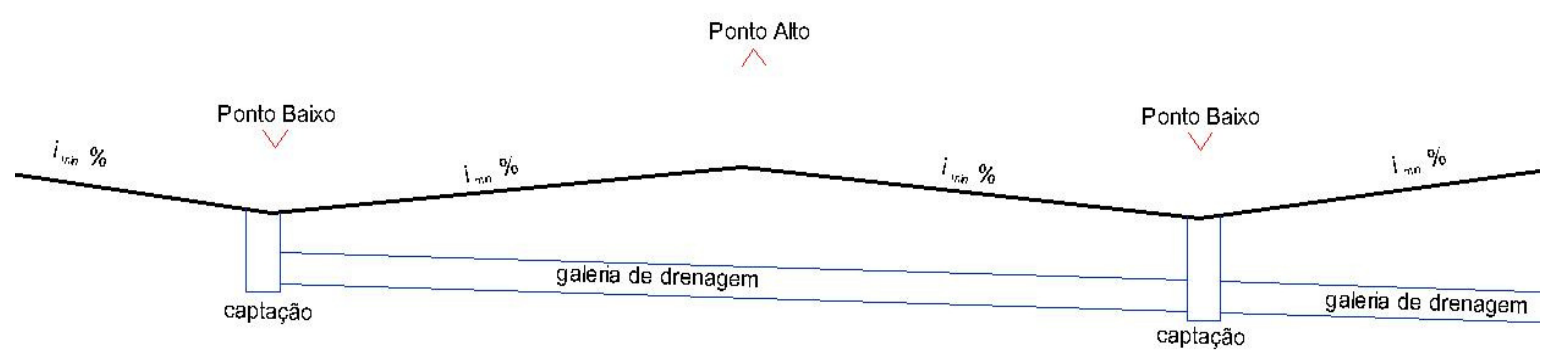

Figura 36: Perfil longitudinal típica em ruas de planícies urbanas, com a imposição de declividade mínima

A avaliação do uso de gradientes longitudinais inferiores aqueles considerados mínimos será feita, de modo a se formular uma proposta com uma maior flexibilidade nos critérios de projeto. O princípio é contribuir no sentido de se ter mais uma ferramenta cujo enfoque seja o da "capacidade de armazenamento", cuja tendência de utilização ainda é restrita pela falta de dados e estudos nesse campo.

O estudo do comportamento de uma onda de cheia, caminhando num leito de rio, canal, ou seção livre qualquer é tarefa comum da Hidráulica. Atribui-se o adjetivo comum pelo fato de já ter sido equacionada, não pela sua complexidade de resolução. Sob esse ponto de vista, 
trata-se de tarefa cujo grau de sofisticação é bastante elevado, não se tratando de atividade regularmente efetuada, principalmente para dimensionamentos de sistemas de microdrenagem. Esses estudos têm como fundamento teórico, as equações de Saint-Venant. O modelo de estudo proposto irá usar os resultados de diversas simulações do caminhamento de ondas de cheia em seções de vias urbanas com as características geométricas que melhor se adéqüem aquelas comumente encontradas em meios urbanos, com a tarefa de encontrar relações entre tais resultados e essas características geométricas.

A tabulação dos resultados será feita com o objetivo de determinar a correlação entre o amortecimento da vazão de entrada (determinada pelo método Racional) e as características hidrogeométricas da seção condutora. Esta relação de vazão amortecida e vazão calculada deverá ser chamada de índice de amortecimento. O que se procura, então é uma relação matemática entre o índice de amortecimento e a declividade longitudinal do conduto (que neste caso é a seção da via).

\subsection{MODELO DE ESTUDO}

Todo estudo para dimensionamento dos elementos de um sistema de micro drenagem é composto por duas etapas, considerados teoricamente distintas, mas que na prática estão intimamente ligados:

- Etapa de dimensionamento hidrológico, pelo Método Racional;

- Etapa de dimensionamento hidráulico, pela equação de Manning.

A aplicação do Método Racional, para a determinação das vazões afluentes, é bastante simples e segue basicamente os seguintes passos:

1) Determinação da área da bacia de contribuição do trecho;

2) Cálculo ou estimativa do tempo de concentração da bacia, junto ao ponto de controle, ou ponto mais a jusante da mesma;

3) Adoção do Período de Retorno de Projeto, que evidencia a segurança do projeto;

4) Avaliação do índice de impermeabilização da bacia, que será expresso em um fração da altura precipitada em relação a altura de lamina d'água a escoar e gerar vazão. 
Nesta etapa, como pôde ser notado, estão consideradas, basicamente todas as características do entorno da seção condutora. Incluem-se ai as características topográficas também, já que a determinação do tempo de concentração da bacia é função basicamente da declividade média local.

A segunda etapa do dimensionamento, que consiste, na determinação do tamanho e características geométricas da seção a conduzir aquela vazão determinada pelo estudo hidrológico, é feita aplicando-se esse total de vazão em toda a extensão do conduto. $\mathrm{O}$ dimensionamento é então feito considerando que a vazão de pico $(\boldsymbol{Q}=\boldsymbol{C} \boldsymbol{i} \boldsymbol{A})$ irá percorrer toda a extensão do conduto. Trata-se de uma simplificação a favor da segurança, pois tal vazão somente ocorrerá no ponto de controle, ou seja, no ponto mais a jusante do conduto. $\mathrm{O}$ modelo que melhor descreveria o que ocorre na realidade deveria considerar um gradiente de vazão, ou seja, uma "contribuição linear".

A figura 37 ilustra o modelo do gradiente de vazão, em que se propõe que ocorra um acúmulo das contribuições laterais, de valores infinitesimais ao longo da extensão da via, e que no final do trecho de estudo, esse valor acumulado de vazão seja equivalente a aquele determinado pela equação do método Racional.

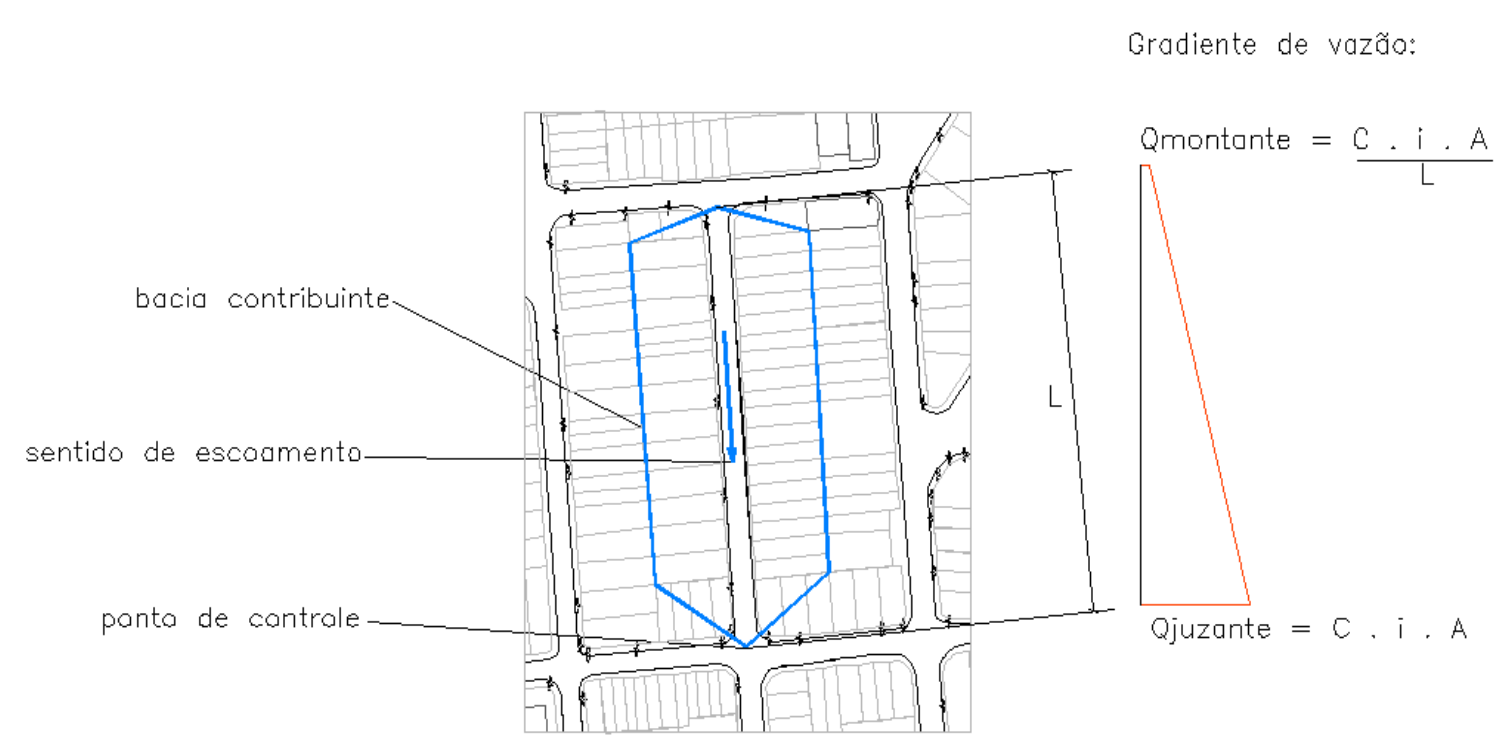

Figura 37: Gradiente de Vazão

A intensidade de chuva utilizada na avaliação hidrológica é função do tempo de duração desta, que no caso do método racional é igual ao tempo de concentração da bacia e função também do tempo de recorrência adotado para o projeto. Ambos, tempo de concentração e 
período de retorno, por meio de equação de chuvas locais, determinam a intensidade a ser utilizada. No caso do tempo de recorrência ou período de retorno, este é o responsável pela garantia de segurança da obra. Este parâmetro relaciona a intensidade com sua possibilidade de ocorrência, sendo por isso, de modo geral tabelado conforme grau de importância da estrutura em estudo. Essas tabelas foram apresentadas no capítulo de revisões bibliográficas e sabemos então que, para obras de micro-drenagem, tais valores oscilam entre 3 e 10 anos.

Tendo em vista que esses dois parâmetros influenciam a vazão final, e considerando que as características hidrogeométricas são fatores limitantes dessa vazão, estabeleceu-se um conjunto de vazões a serem estudadas neste modelo. Com a combinação de diferentes declividades, tempos de concentração, tempos de recorrência e intensidades de chuva, pode-se concluir que um conjunto de vazões variando entre $0,1 \mathrm{~m}^{3} / \mathrm{s}$ e $1 \mathrm{~m}^{3} / \mathrm{s}$ tem abrangência suficiente para uma completa avaliação dos diferentes casos de caminhamento de onda de cheia em vias urbanas. Justifica-se tal abrangência pelo fato de se tratarem das bacias de contribuição de trechos de vias urbanas, ou seja, bacias pequenas, cuja vazão gerada é proporcional a sua área. Vazões acima de $1 \mathrm{~m}^{3} / \mathrm{s}$ necessitam, de modo geral, de elementos especiais para sua condução que não apenas o conjunto de guias, sarjetas e leito carroçável. Tempo de recorrência e de concentração, neste ponto não será tratado como fator interveniente no amortecimento, uma vez que a quantidade de chuvas precipitada é valor mais representante e de maior impacto na questão.

Como dito anteriormente, dentre as possibilidades de combinação dos parâmetros de dimensionamento hidrológico, o tempo de concentração, que influencia diretamente a intensidade da chuva de projeto e por consequência a vazão, tendo grande importância no dimensionamento hidrológico e hidráulico dos elementos de drenagem. O modelo aqui proposto, deve então contar com valores de tempos de concentração que possam simular as diversas variações e possibilidades de cálculo, usualmente empregados. O tempo mínimo de concentração adotado foi de 10 minutos, valor considerado mínimo pelos diversos manuais de projeto e estabelecido também como mínimo pela maior parte das equações de chuva. Como valor superior adotou-se 60 minutos, o que cobre a totalidade dos valores de tempo de concentração mais usados no dimensionamento de micro-drenagem. Valores de tempo de concentração superiores a 60 minutos referem-se, na maioria dos casos, a casos de estudos de Macro-Drenagem. 
Já no que concerne ao principal objeto de estudo deste trabalho, ou seja, a declividade deve-se estabelecer um critério, para caracterizar "baixa declividade". De modo geral, são todos aqueles gradientes inferiores aos estabelecidos pelas normas e recomendações de projeto. Deste modo, partiu-se de $0,5 \%$, que é o valor mais comumente difundido no meio técnico como sendo a declividade mínima longitudinal a ser respeitada. Tendo o valor máximo estipulado em $0,5 \%$, o valor mínimo a ser escolhido é aquele cujas restrições construtivas ainda permitam seu controle quando da implantação. A experiência, em obras, todas elas localizados no município de Praia Grande, demonstraram que um gradiente de $0,15 \%$, ainda oferece possibilidade de controle topográfico em campo. Sendo assim, $0,15 \%$ é o valor mínimo de declividade adotado para as simulações no modelo proposto.

Em resumo, o estudo da propagação da onda de cheia no leito da via então terá, as seguintes premissas:

a) A vazão de pico do método racional não será aplicada na seção típica da via, e sim um gradiente de vazão, ou uma vazão linearmente distribuída;

b) 10, 30 e 60 minutos são os tempos de concentração (duração) a serem estudados;

c) 0,$1 ; 0,25$ e 0,50m³ são as vazões características de entrada.

Foram apresentadas então as principais características das "demandas solicitantes". Os elementos responsáveis pela devida condução dessas vazões características acima propostas, também deverão ser categorizadas. Ocorre que, de modo geral uma seção de rua típica, é composta de guias, sarjetas e leito carroçável. Materiais e dimensões destes elementos podem variar, o que conduz a um conjunto grande de possibilidades.

Procurou-se criar uma seção de estudo que abrangesse uma maior possibilidade de combinações possível entre esses elementos. Por esta razão, a primeira imposição é que seja estudada meia seção de via, o que, deixa a largura da via como variável independente. Outra imposição é a altura da guia, que quando aplicada em uma meia seção possibilita inúmeras combinações, apenas variando-se a largura de alagamento superficial. A figura 38 ilustra a seção típica a ser estudada: 


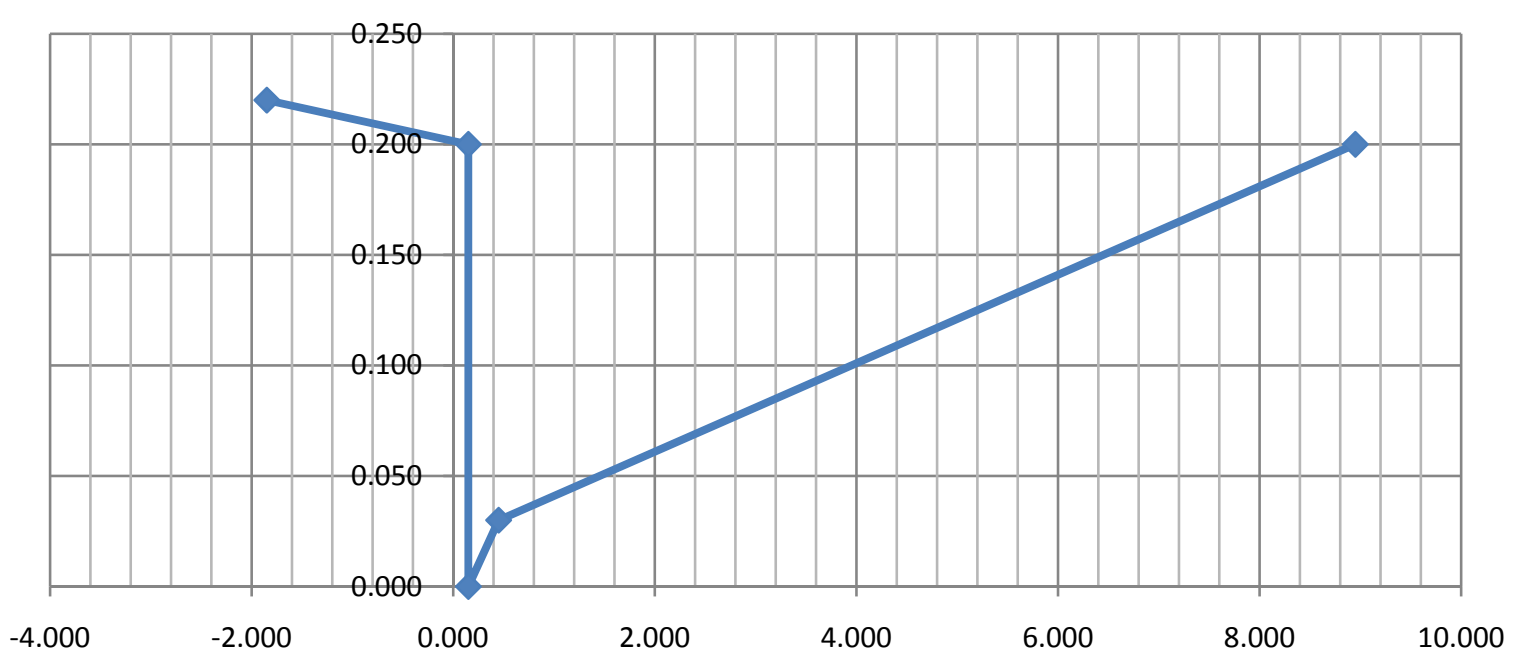

Figura 38: Seção Transversal da sarjeta considerada no modelo

Com essa seção pode-se, por exemplo, ter o resultado de uma rua de largura até 17,60 metros, assim como alturas de guia até 20 centímetros. A figura a seguir mostra que diferentes largura e alturas de guia estão inseridas na seção adotada:

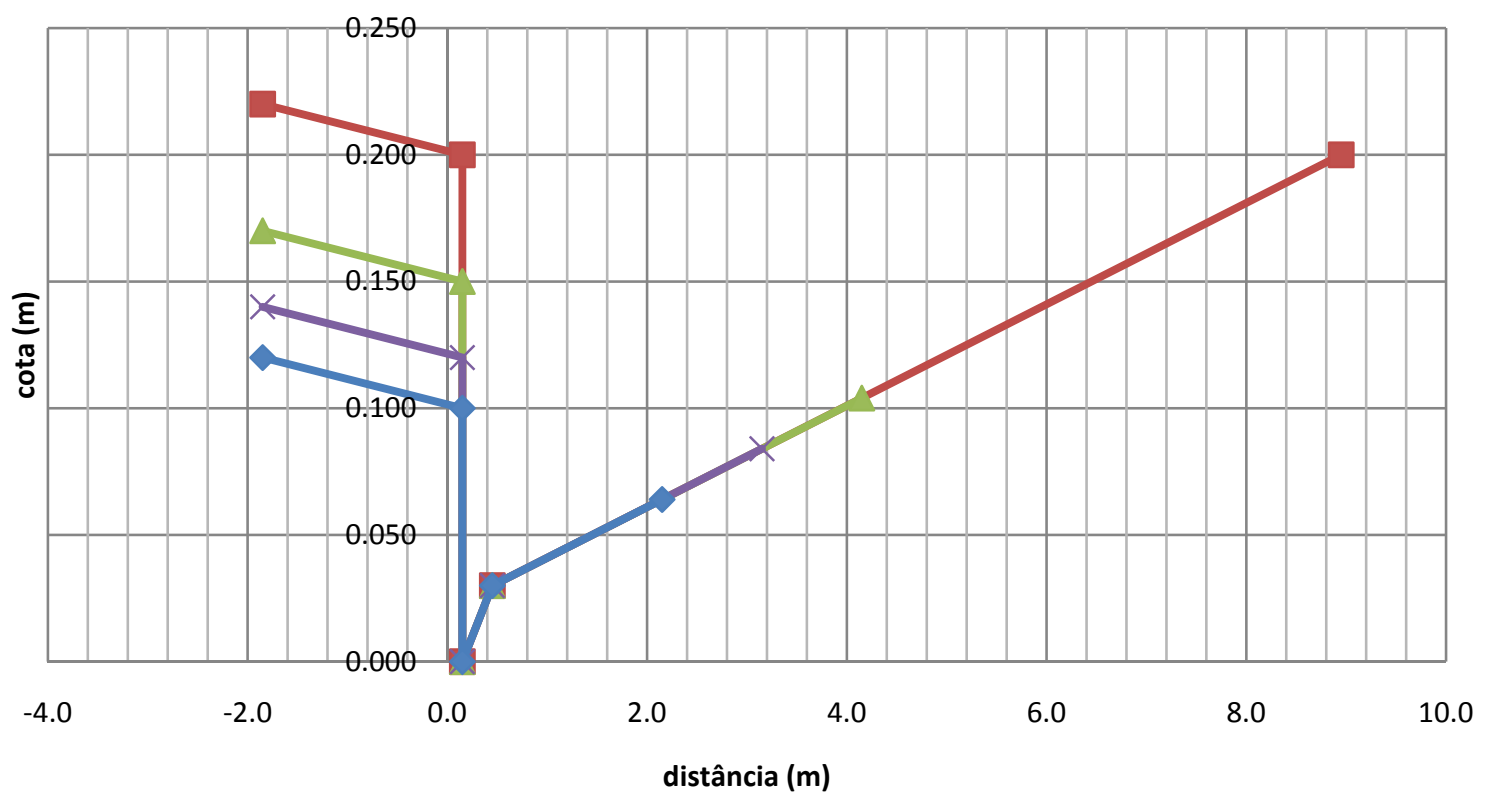

\footnotetext{
- largura da via: $10 \mathrm{~m}$ - guia de $20 \mathrm{~cm}$

$\leftarrow$ largura da via: $6 \mathrm{~m}$ - guia de $12 \mathrm{~cm}$
}

- largura da via: $8 \mathrm{~m}$ - guia de $15 \mathrm{~cm}$

- largura da via $4 \mathrm{~m}$ - guia de $10 \mathrm{~cm}$

Figura 39: Diversas seções características consideradas, mantidas as inclinações transversais 
Resumidamente, ao se duplicar a seção adotada acima, tem-se uma via com as características abaixo discriminadas:

- largura total do leito carroçável: 17,60m

- declividade transversal do leito carroçável: $2 \%$

- altura da guia: $0,20 \mathrm{~m}$

- largura da sarjeta: $0,30 \mathrm{~m}$

- declividade da sarjeta: $10 \%$

A seção típica, conforme descrita acima, e discretizada no software HEC-RAS fica como indicado na figura a seguir:

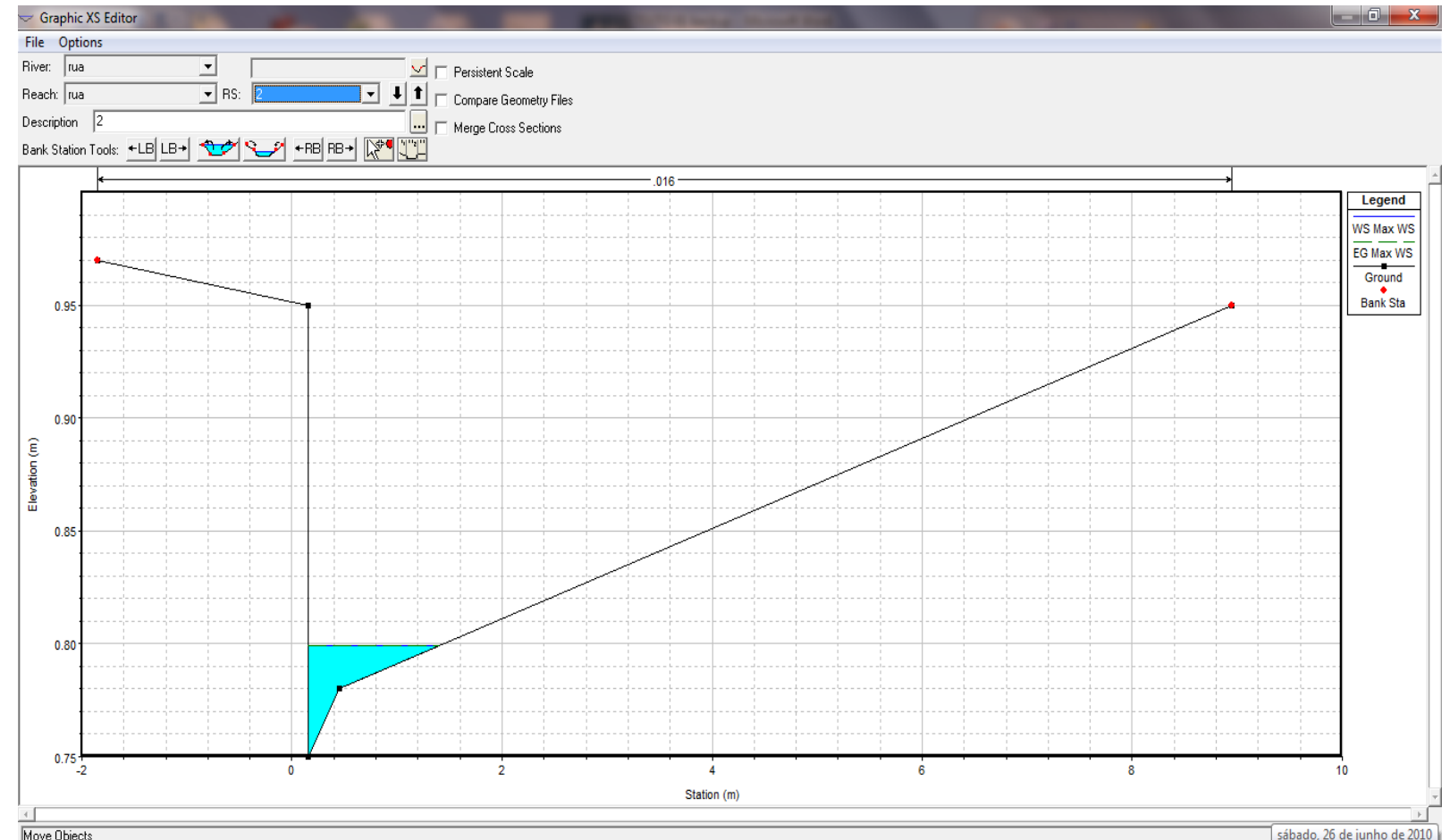

Figura 40: Tela de lançamento de seções transversais do software HEC-RAS 
As declividades adotadas, para o modelo, cobrem todos os valores inteiros inseridos na faixa daquelas declividades definidas como sendo baixas, ou seja:

- $0,0015 \mathrm{~m} / \mathrm{m}$ ou $0,15 \%$;

- $0,0020 \mathrm{~m} / \mathrm{m}$ ou $0,20 \%$

- $0,0030 \mathrm{~m} / \mathrm{m}$ ои $0,30 \%$

- $0,0040 \mathrm{~m} / \mathrm{m}$ ou $0,40 \%$

- $0,0050 \mathrm{~m} / \mathrm{m}$ ou $0,50 \%$

Avaliando-se as diferentes capacidades de vazão para a seção típica adotada, tendo como método de avaliação a equação de Manning, obtém-se as curvas definidas pela figura 41. Comprovam-se mais uma vez que o intervalo de vazões adotado no modelo de avaliação descreve bem as possibilidades de escoamento pela seção de estudo. Observa-se que não se aplica a vazão total no inicio do trecho de estudo, e sim o gradiente de vazões gerado pelas diferentes vazões consideradas, sendo descartados os resultados cuja altura da linha d'água ultrapasse a altura da guia projetada.

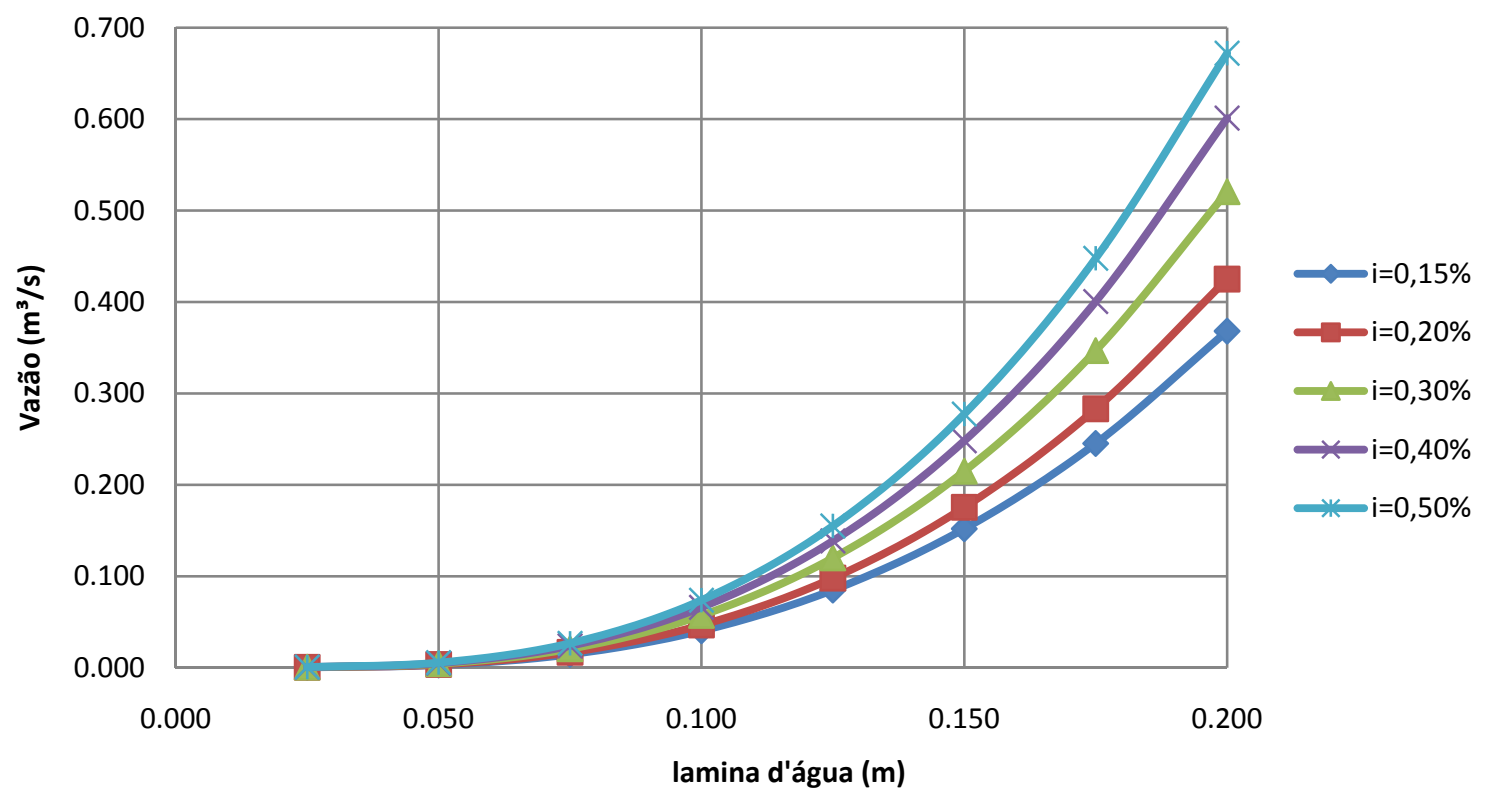

Figura 41: Gráfico da relação altura da Lâmina d'água x Vazão 
A seção típica aqui estudada tem como coeficiente de rugosidade aquele amplamente usado no meio técnico-científico, que representa uma rugosidade média, supondo:

- guias em concreto;

- pavimento asfáltico.

Por essas características, o valor médio adotado para todos os cálculos, tanto hidráulicos comuns, quanto aquele a ser feito no modelo hidrodinâmico, é de 0,016.

Como citado no capítulo que descrevia a aplicabilidade da equação de Manning, esta somente é valida sob as condições:

- regime uniforme;

- escoamento turbulento e no caso específico, turbulento rugoso;

É tarefa inicial então, validarmos a aplicação da equação de Mannning. Tal verificação poder se feita calculando o adimensional de Reynolds para os diferentes casos e diferentes declividades aqui propostos. Como num dimensionamento hidráulico, o engenheiro projetista deve verificar a condição do escoamento sob regime uniforme, o mesmo será procedido neste trabalho.

\subsubsection{REGIME DE ESCOAMENTO NAS SEÇÕES DAS VIAS}

O regime sob o qual o escoamento se processa numa seção é importante característica para a ratificação dos métodos de avaliação de vazão a estes aplicados. Neste capítulo trataremos de verificar qual tipo de escoamento se processa nas seções a serem utilizados no modelo desta dissertação.

Sabemos que o número de Reynolds é o elemento que caracteriza o tipo de escoamento, se turbulento, transicional ou rugoso. Deste modo, a tarefa desta etapa do trabalho é a verificação do número de Reynolds que caracteriza o escoamento na seção proposta alterando diferentes variáveis de condições de contorno. Essas diferentes condições de contorno são: 
- declividade longitudinal de fundo: neste caso, como comumente feito nesta etapa de dimensionamento, a declividade da linha de energia é considerada paralela a declividade de fundo do conduto;

- profundidade do escoamento: será adotada a variação da profundidade do escoamento, tendo o Maximo valor limitado à altura total da guia, $20 \mathrm{~cm}$.

A verificação e cálculo do numero de Reynolds do escoamento foi feito para todas as declividades em estudo e a variação da linha d'água ao longo de toda a altura da guia. Apresenta-se a seguir a tabela 25 em que se efetuaram os cálculos para verificação do parâmetro de Reynolds do escoamento na seção típica do modelo com declividade mínima de $0,0015 \mathrm{~m} / \mathrm{m}$ :

Tabela 25: Tabela resumo dos cálculos para verificação do Regime de Escoamento

$$
\left(S_{0}=0,0015 \mathrm{~m} / \mathrm{m}\right)
$$

\begin{tabular}{|c|c|c|c|c|c|c|c|c|c|c|c|}
\hline \multicolumn{4}{|c|}{$\begin{array}{l}\text { CARACTERISTICAS } \\
\text { GEOMÉTRICAS }\end{array}$} & \multicolumn{5}{|c|}{ REGIME LAMINAR } & \multicolumn{3}{|c|}{$\begin{array}{c}\text { REGIME } \\
\text { TURBULENTO RUGOSO }\end{array}$} \\
\hline$\underline{\mathbf{y}}$ & $\underline{\mathbf{A}}$ & $\underline{\mathbf{P}}$ & $\mathbf{R h}$ & R.f. $f_{-}^{0,5}$ & f & $\underline{\mathbf{C}}$ & $\underline{\mathbf{n}}$ & $\underline{\mathbf{R}} \underline{\mathbf{e}}$ & $\underline{\mathbf{f}}$ & $\underline{\operatorname{Re}}$ & $\underline{\mathbf{n}}$ \\
\hline$\underline{0}, \underline{0} 10$ & $\underline{0} .00005$ & $\underline{0.110}$ & 0.005 & $4 \underline{1} \underline{3} . \underline{6} 0$ & $0.023 \underline{9}$ & 57.25 & $\underline{0} .070$ & 2672.9 & $\underline{0.1} \underline{6} \underline{8} 6$ & 1007.4 & \\
\hline$\underline{0,} \underline{015}$ & $\underline{0.00} \underline{1} 1$ & $0.16 \underline{6}$ & 0.007 & $7 \underline{5} 9 \underline{9} . \underline{4}$ & 0.0071 & 105.18 & $\underline{0.004}$ & 9021.1 & $\underline{0.12} \underline{8} 0$ & 2123.7 & \\
\hline$\underline{0}, \underline{02} 0$ & $\underline{0.0020}$ & 0.221 & 0.009 & 1169.84 & $0.003 \underline{0}$ & 161.93 & $\underline{0.003}$ & $2138 \underline{3} .3$ & $\underline{0.107} \underline{0}$ & $\underline{35} \underline{6} \underline{-} \underline{8}$ & $\underline{0} .017$ \\
\hline$\underline{0}, \underline{0} 25$ & $\underline{0} .00 \underline{3} 1$ & $0.27 \underline{6}$ & 0.011 & 1634.91 & 0.0015 & 226.30 & $\underline{0.002}$ & $\underline{4} 17 \underline{6} \underline{4} . \underline{3}$ & $\underline{0.09} \underline{4} 8$ & $\underline{53} \underline{09} .3$ & $\underline{0} .016$ \\
\hline$\underline{0} . \underline{0} \underline{\underline{2}}$ & $\underline{0} .0066$ & $0.58 \underline{7}$ & 0.011 & 1631.13 & $\underline{0.0015}$ & 225.78 & $\underline{0.002}$ & $\underline{4} 1571.7$ & $0.09 \underline{4} \underline{9}$ & $\underline{52} 94.8$ & $\underline{0} .016$ \\
\hline$\underline{0.055}$ & $\underline{0.0276}$ & 1.607 & 0.017 & 3063.35 & 0.0004 & 424.03 & $\underline{0.001}$ & 146626.5 & 0.0764 & 11084.2 & $\underline{0.016}$ \\
\hline$\underline{0.070}$ & $\underline{0.0565}$ & 2.372 & 0.024 & 4995.66 & 0.0002 & 691.50 & $\underline{0.001}$ & & 0.0655 & 19519.1 & $\underline{0.015}$ \\
\hline$\underline{0.080}$ & 0.0820 & 2.882 & 0.028 & 6521.45 & 0.0001 & 902.70 & $\underline{0.001}$ & & 0.0605 & 26507.3 & 0.015 \\
\hline$\underline{0.090}$ & $\underline{0.1125}$ & 3.392 & 0.033 & 8207.11 & 0.0001 & 1136.03 & $\underline{0.001}$ & & 0.0567 & 34473.3 & $\underline{0.015}$ \\
\hline 0.100 & $\underline{0.14} \underline{8} 0$ & 3.902 & 0.038 & 10036.74 & 0.0000 & 1389.29 & $\underline{0.000}$ & & 0.0536 & 43351.5 & $\underline{0.015}$ \\
\hline$\underline{0.110}$ & $\underline{0} .18 \underline{8} 85$ & 4.412 & 0.043 & 11998.69 & $0.000 \underline{0}$ & 1660.86 & $\underline{0} . \underline{0} \underline{0}-$ & & $\underline{0.05} \underline{1} 1$ & 53091.1 & $\underline{0} .015$ \\
\hline$\underline{0.120}$ & $\underline{0} .2 \underline{3} 40$ & 4.922 & 0.048 & 14083.89 & $0.000 \underline{0}$ & $194 \underline{9} .50$ & $\underline{0.000}$ & & $\underline{0.04} \underline{90}$ & 63650.5 & $\underline{0} .015$ \\
\hline$\underline{0} .130$ & $\underline{0.2925}$ & $\underline{5.509}$ & $0.05 \underline{3}$ & $16 \underline{6} 22.51$ & 0.0000 & 2300. 89 & $\underline{0} . \underline{0} \underline{0} 0$ & & $\underline{0.04} \underline{6} 9$ & 76믐‥5 & $\underline{0} .015$ \\
\hline$\underline{0 .} \underline{140}$ & $\underline{0} . \underline{3} \underline{4} \underline{00}$ & $5.94 \underline{3}$ & 0.057 & 18595.92 & $0.000 \underline{0}$ & $257 \underline{4} .05$ & $\underline{0} .000$ & & $\underline{0.04} \underline{56}$ & 87094.5 & $\underline{0} .015$ \\
\hline$\underline{0 .} \underline{150}$ & $\underline{0 .} \underline{4} \underline{0} \underline{05}$ & $6.45 \underline{3}$ & 0.062 & 21011.44 & 0.0000 & 2908.41 & $\underline{0.000}$ & & $\underline{0.04} \underline{4} 2$ & 99923.2 & $\underline{0} .015$ \\
\hline$\underline{0 .} 160$ & $\underline{0 .}-4 \underline{6} 60$ & 6.963 & 0.067 & 23527.03 & $0.000 \underline{0}$ & $325 \underline{6} .62$ & $\underline{0} . \underline{0} \underline{0}-$ & & $\underline{0.04} \underline{3} \underline{0}$ & 113457.9 & $\underline{0} .015$ \\
\hline$\underline{0.170}$ & $\underline{0.5} \underline{3} 6 \underline{5}$ & 7.4. & 0.072 & 26138.76 & 0.0000 & $361 \underline{8} .13$ & $\underline{0.000}$ & & $\underline{0.04} \underline{19}$ & 127678.0 & $\underline{0} .015$ \\
\hline$\underline{0.180}$ & 0.6120 & 7.983 & 0.077 & 28843.10 & 0.0000 & 3992.47 & $\underline{0.000}$ & & 0.0409 & 142565.0 & 0.015 \\
\hline$\underline{0.190}$ & 0.6925 & 8.493 & 0.082 & 31636.93 & 0.0000 & 4379.19 & $\underline{0.000}$ & & 0.0400 & $15 \underline{8101.8}$ & 0.015 \\
\hline$\underline{0.200}$ & 0.7780 & 9.003 & 0.086 & 34517.40 & 0.0000 & 4777.91 & $\underline{0.000}$ & & 0.0392 & 174273.1 & $\underline{0.015}$ \\
\hline
\end{tabular}


A tabela foi determinada, efetuando-se os cálculos de acordo com o formulário a seguir:

\section{Características Geométricas:}

$\boldsymbol{y}=$ altura da lâmina de água na guia, em m: variou de 0,01 a 0,20m;

$\boldsymbol{A}=$ área da seção molhada: calculada pela geometria formada pelas diferentes lâminas de água simuladas;

$\boldsymbol{P}=$ perímetro molhado: determinado pelas diferentes lâminas estudadas;

$\boldsymbol{R} \boldsymbol{h}=$ raio hidráulico, que é a relação entre área molhada e perímetro molhado;

Regime Laminar:

$$
\begin{aligned}
\operatorname{Re} \sqrt{f} & =\frac{D_{h}}{v} \cdot \sqrt{2 g \cdot D_{h} \cdot S_{0}} \\
f & =\left(\frac{64}{\operatorname{Re} \sqrt{f}}\right)^{2}
\end{aligned}
$$

$$
C=\sqrt{\frac{8 \cdot g}{f}}
$$

$$
n=\frac{R h^{1 / 6}}{C}
$$

Regime Turbulento Rugoso:

$$
\begin{gathered}
\frac{1}{\sqrt{f}}=2,04 \cdot \log \left(\frac{12,2 \cdot R_{h}}{k_{s}}\right) \\
n=\frac{1}{8 \sqrt{g}} \cdot k_{s}^{1 / 6}
\end{gathered}
$$


Deve-se notar que não houve valores de número de Reynolds inferiores a 2000, limite do regime laminar, comprovando que para a declividade de 0,0015 , ainda não há a ocorrência deste tipo de escoamento. A figura 42 contém as curvas $\boldsymbol{f}$ - $\boldsymbol{R} \boldsymbol{e}$ (rugosidade $\mathrm{x}$ Reynolds) calculadas para todas as declividades aqui estudadas, denotando novamente que não há a ocorrência do regime laminar.

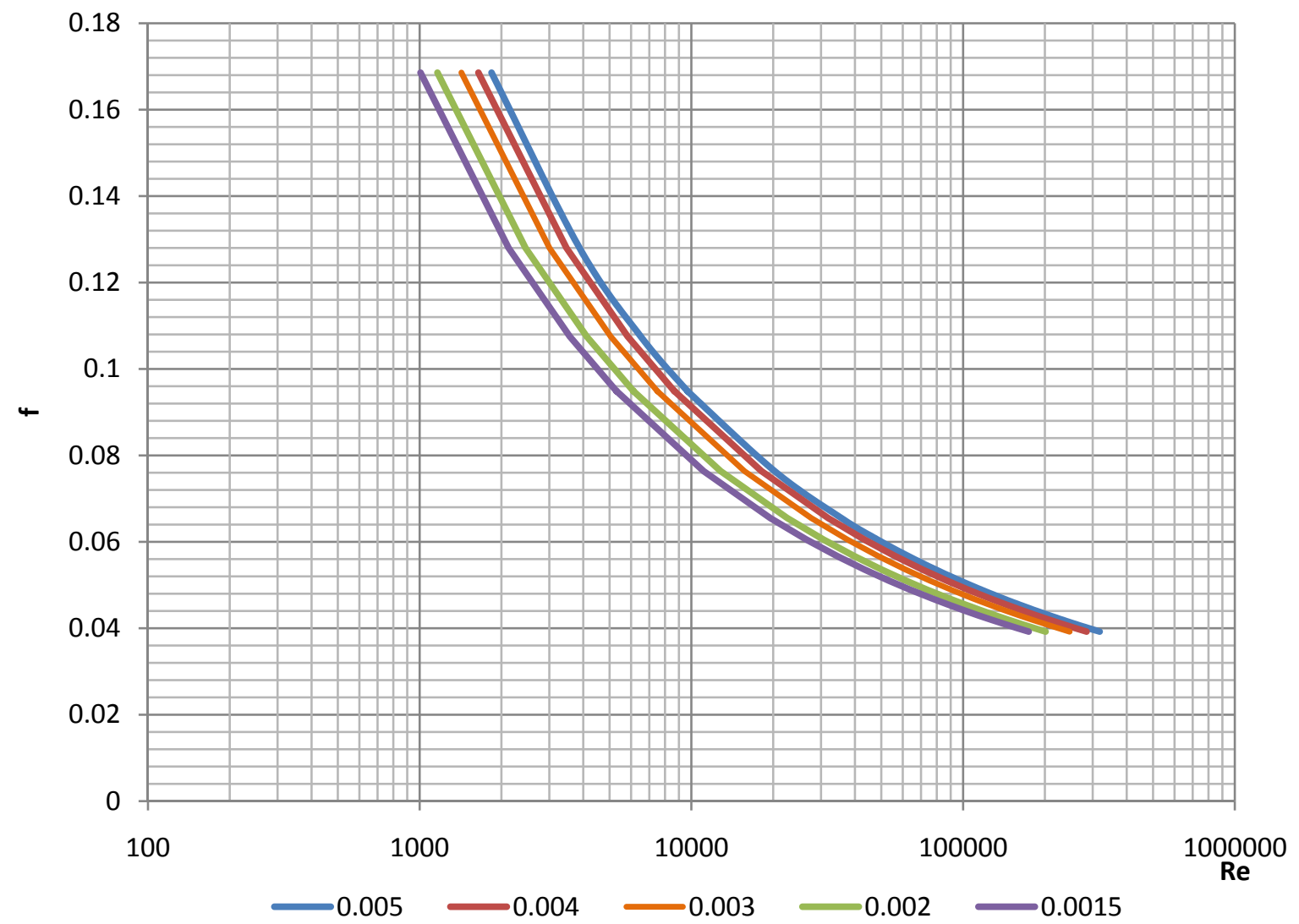

Figura 42: Gráfico relacionando Re e o fator de atrito $f$

Verificação semelhante foi feita, considerando-se que na realidade, a declividade da linha de energia não é paralela a declividade de fundo do conduto. Desse modo, podem existir declividades de linha de energia inferiores a aquelas aqui simuladas. Diversas declividades de linha de energia foram simuladas e notou-se o regime laminar passa a ocorrer em apenas trechos da via, onde a lamina d'água ou profundidade de escoamento é pequena, da ordem de até $5 \mathrm{~cm}$. Pode-se notar pelo gráfico apresentado a zona de transição do regime laminar para o turbulento, considerando o estudo feito para uma declividade de linha de energia de $0.00005 \mathrm{~m} / \mathrm{m}$. As declividades das linhas de energia somente poderão ser verificadas com o cálculo hidrodinâmico proposto. 
Tabela 26: Tabela resumo dos cálculos para verificação do Regime de Escoamento

\begin{tabular}{|c|c|c|c|c|c|c|c|c|c|c|c|}
\hline \multirow[b]{2}{*}{$\mathbf{y}$} & \multicolumn{3}{|c|}{$\begin{array}{l}\text { CARACTERISTICAS } \\
\text { GEOMÉTRICAS }\end{array}$} & \multirow[b]{2}{*}{$\mathbf{R} . ._{-}^{0,5}$} & \multicolumn{3}{|c|}{ REGIME LAMINAR } & \multirow[b]{2}{*}{$\underline{\mathbf{R e}}$} & \multicolumn{3}{|c|}{$\begin{array}{c}\text { REGIME TURBULENTO } \\
\text { RUGOSO }\end{array}$} \\
\hline & $\underline{\mathbf{A}}$ & $\mathbf{P}$ & $\underline{\mathbf{R}} \underline{\mathbf{h}}$ & & $\underline{\mathbf{f}}$ & C & $\underline{\mathbf{n}}$ & & $\mathbf{f}$ & $\mathbf{R e}$ & $\mathbf{n}$ \\
\hline$\underline{0.010}$ & $0.000 \underline{5}$ & $0.110 \underline{5}$ & $0.004 \underline{5}$ & $75.51 \underline{3}$ & $0.718 \underline{8}$ & 10.45 & $\underline{0.040}$ & 89.1 & $\underline{0} .1686$ & 183.92 & \\
\hline 0.015 & 0.0011 & 0.1657 & $0.006 \underline{8}$ & 138.726 & $\underline{0.2128}$ & 19.20 & $\underline{0.023}$ & 300.7 & $\underline{0 .} \underline{12} 8 \underline{0}$ & 387.73 & \\
\hline$\underline{0.020}$ & 0.0020 & 0.2210 & $\underline{0.0090}$ & $213.5 \underline{8} \underline{3}$ & $\underline{0} .0 \underline{8} 9 \underline{9}$ & 29.56 & $\underline{0.016}$ & $\underline{71} 2.8$ & $\underline{0.1} \underline{0} \underline{075}$ & $6 \underline{51} \underline{1.38}$ & 0.017 \\
\hline$\underline{0.025}$ & 0.0031 & 0.2762 & 0.0113 & 298.492 & $\underline{0} .0 \underline{4} 60$ & $\underline{4} 1.32$ & $\underline{0} .012$ & 1392.1 & $\underline{0} .094 \underline{8}$ & $\underline{96} 9 \underline{3} \underline{3}$ & 0.016 \\
\hline $0.03 \underline{5}$ & 0.0066 & 0.58665 & $0.011 \underline{3}$ & 297.803 & $\underline{0.0462}$ & 41.22 & $\underline{0.012}$ & 1385.7 & $\underline{0.0949}$ & 966.70 & 0.016 \\
\hline $0.05 \underline{5}$ & $0.027 \underline{6}$ & 1.6067 & $\underline{0.0172}$ & $559.2 \underline{8} 8$ & $\underline{0.0131}$ & 77.42 & $\underline{0.007}$ & 4887.6 & $\underline{0} .0764$ & 2023.70 & 0.016 \\
\hline$\underline{0.070}$ & $0.056 \underline{5}$ & 2.3719 & $0.023 \underline{8}$ & 912.079 & $\underline{0.00} 4 \underline{9}$ & 126.25 & $\underline{0} .004$ & 12998.2 & $\underline{0 .} \underline{06} \underline{65}$ & $3 \underline{5} 63.68$ & 0.015 \\
\hline$\underline{0.080}$ & 0.0820 & 2.8820 & 0.0285 & 1190.649 & 0.0029 & 164.81 & 0.003 & 22150.7 & 0.0605 & 4839.54 & 0.015 \\
\hline 0.090 & 0.1125 & 3.3921 & 0.0332 & 1498.407 & $\underline{0.0018}$ & 207.41 & $\underline{0.003}$ & & 0.0567 & 6293.93 & 0.015 \\
\hline 0.100 & $0.14 \underline{0}$ & 3.9022 & 0.0379 & 1832.450 & $\underline{0.0012}$ & 253.65 & 0.002 & & 0.0536 & 7914.87 & 0.015 \\
\hline 0.110 & 0.1885 & 4.4123 & 0.0427 & 2190.651 & 0.0009 & 303.23 & 0.002 & & 0.0511 & 9693.06 & 0.015 \\
\hline 0.120 & 0.2340 & 4.9224 & 0.0475 & 2571.355 & 0.0006 & 355.93 & 0.002 & & 0.0490 & 11620.93 & 0.015 \\
\hline $0.13 \underline{0}$ & 0.2925 & $5.508 \underline{5}$ & 0.0531 & 3034.841 & $\underline{0.0004}$ & 420.08 & $\underline{0} .001$ & & $\underline{0.0469}$ & 14012.67 & 0.015 \\
\hline$\underline{0.14} \underline{0}$ & $0.340 \underline{0}$ & 5.9426 & 0.0572 & $33 \underline{9} \underline{5} .136$ & $\underline{0.0004}$ & 469.96 & $\underline{0} .001$ & & $\underline{0} .0456$ & 15901.20 & $0.01 \underline{5}$ \\
\hline$\underline{0.15} \underline{0}$ & $0.400 \underline{5}$ & 6.4527 & 0.0621 & $38 \underline{3} 6.146$ & $\underline{0} .00003$ & $\underline{5} 31.00$ & $\underline{0} .001$ & - & $\underline{0 .} \underline{0} \underline{4} \underline{4}$ & 18243.39 & 0.015 \\
\hline$\underline{0.16} \underline{0}$ & $0.466 \underline{0}$ & 6.9628 & 0.0669 & 4295.428 & $\underline{0} .0002$ & 5994.57 & $\underline{0} . \underline{0} \underline{0} 1$ & & $\underline{0} . \underline{0} \underline{3} \underline{0}$ & 20714.48 & 0.015 \\
\hline$\underline{0.170}$ & $0.536 \underline{5}$ & 7.4729 & 0.0718 & 4772.263 & $\underline{0.0002}$ & 660.58 & $\underline{0} .001$ & & $\underline{0.0419}$ & 23310.71 & 0.015 \\
\hline$\underline{0.180}$ & $0.612 \underline{0}$ & 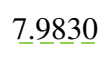 & 0.0767 & $5266 \underline{0} .006$ & $\underline{0.0001}$ & 728.92 & $\underline{0} .001$ & & $\underline{0.0409}$ & 26028.68 & 0.015 \\
\hline$\underline{0.19 \underline{0}}$ & 0.6925 & 8.4931 & 0.0815 & $577 \underline{6} .087$ & $\underline{0} .0001$ & 799.53 & $\underline{0} .001$ & & $\underline{0.04} \underline{0} 00$ & 28865.31 & 0.015 \\
\hline 0.200 & 0.7780 & 9.0032 & 0.0864 & 6301.987 & 0.0001 & 872.32 & 0.001 & & 0.0392 & 31817.78 & 0.015 \\
\hline
\end{tabular}

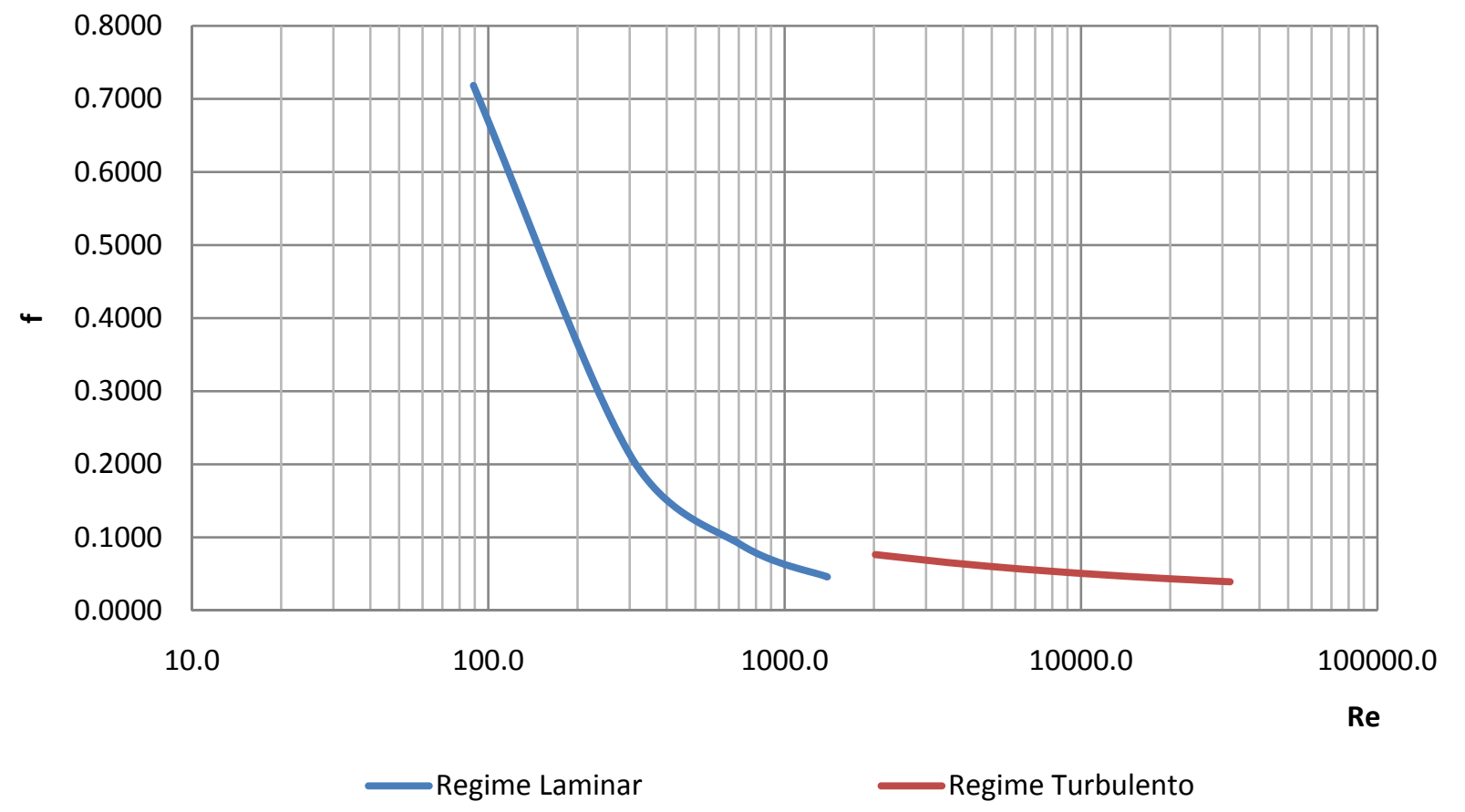

Figura 43: Comportamento de fator de atrito f para a declividade $0,0005 \mathrm{~m} / \mathrm{m}$ com a transição de regime 
É nítida a separação entre os trechos onde se identifica a ocorrência do regime laminar e o turbulento pelos dois trechos do gráfico da figura 43. Em azul temos o trecho correspondente ao regime laminar ocorrendo com uma lamina de até 8 centímetros e em vermelho o trecho turbulento rugoso. Pode-se afirmar então, pela verificação aqui feita, que a equação de Manning é válida para a avaliação da capacidade de vazão das seções transversais das vias urbanas, projetadas com declividades abaixo de $0,5 \%$, assumindo-se que a linha de energia é paralela a declividade de fundo do canal. Cabe salientar o limite inferior adotado é empírico no valor de $0,0015 \mathrm{~m} / \mathrm{m}$.

\subsubsection{EQUAÇÃO PROPOSTA PARA O MODELO DE AVALIAÇÃo DE ESCOAMENTO}

Dos estudos de Izzard, sabe-se que a vazão determinada pelo método racional, ainda que se tenha avaliado o tempo de concentração por meio de métodos cinemáticos, não considera qualquer possibilidade de amortecimento de vazão pela propagação da onda de cheia ao longo do conduto. Para que se tenha idéia desse amortecimento, Izzard propõe pela iteração da vazão na sarjeta pela aplicação do método de Muskingum. WILKEN (1978) cita uma experiência daquele autor, em que se avalia qual a taxa de amortecimento conseguida por um trecho de guia de 60 metros de extensão. Cita ainda que para declividades baixas, tal amortecimento tende a aumentar.

É com o propósito de melhor avaliar esse amortecimento e, baseando-se na sugestão de Izzard para que fosse feita a iteração na sarjeta como passo final de qualquer dimensionamento hidráulico para micro drenagem, que se pode afirmar que existe uma relação entre a vazão de entrada e o amortecimento desta nos elementos condutores superficiais.

O gráfico ilustrado na figura 44, mostra a defasagem entre hidrogramas que se pretende verificar. Uma vez determinado o hidrograma de entrada, e simulando-se o seu escoamento num trecho de via, cujas características geométricas são conhecidas, deve-se obter um diagrama de saída defasado no tempo e com a vazão de pico inferior aquela inicial. 


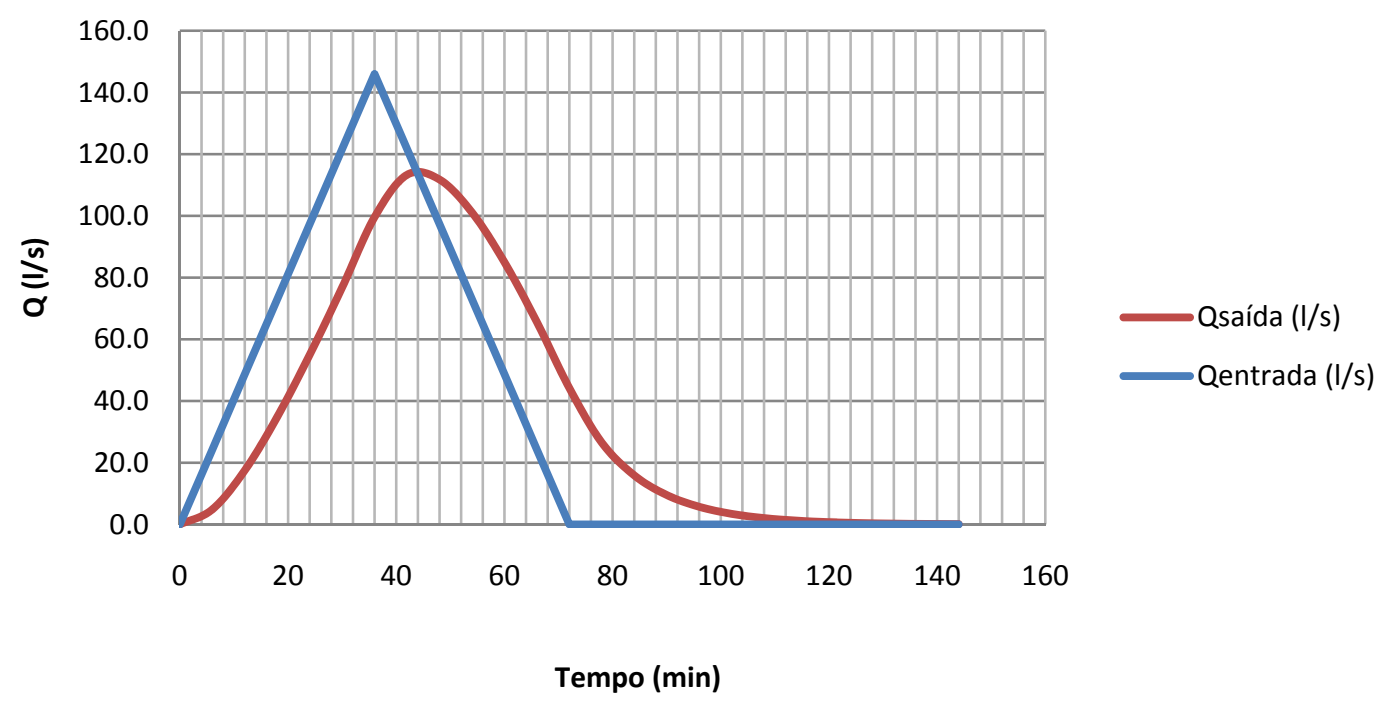

Figura 44: Gráfico Vazão de entrada e vazão de saída amortecida

A relação procurada é aquela entre a vazão de entrada, determinada pelo estudo hidrológico e calculada pela equação do Método Racional, e a vazão de saída, função das características hidrogeometricas da via e calculada pelas equações de Saint-Venant para movimento não uniforme, resolvida pelo sistema linear de diferenças finitas de Preissmann.

Temos então a equação objetivo dada por:

$$
\frac{Q}{Q_{0}}=\text { indice de amortecimento }
$$

em que:

$\boldsymbol{Q}_{\mathbf{0}}=$ vazão de entrada, do método Racional;

$\boldsymbol{Q}=$ vazão de saída; amortecida efeito da baixa declividade.

A obtenção de um índice de amortecimento função da declividade e da vazão de entrada, ou seja, aquela determinada pelo método Racional, e suas características intervenientes é a meta principal deste estudo. Sendo assim, a função característica a ser determinada é da forma

$$
\frac{Q}{Q_{0}}=F_{0}\left(S_{0}, \Delta x, h_{0}, f, B, V_{0}, t_{c}\right)
$$


em que:

$\boldsymbol{Q}=$ vazão amortecida ou vazão de saída

$\boldsymbol{Q}_{\mathbf{0}}=$ vazão de entrada ou vazão de dimensionamento do método racional

$\boldsymbol{S}_{\mathbf{0}}=$ declividade longitudinal da rua

$\Delta \boldsymbol{x}=$ extensão da rua a ser estudado, ou extensão acumulada de montante ao ponto de controle de vazão;

$\boldsymbol{h}_{\mathbf{0}}=$ altura da lâmina de água em relação a vertical, contando do ponto mais baixo da sarjeta;

$\boldsymbol{f}=$ fator de atrito universal;

$\boldsymbol{B}=$ largura da lâmina de água superficial, que é dimensão importante no que concerne avaliação do escoamento com vistas a manutenção do trafego durante os eventos de chuva;

$\boldsymbol{V}_{\mathbf{0}}=$ velocidade de escoamento da vazão na seção transversal de estudo, segundo Chezy;

$\boldsymbol{t}_{\boldsymbol{c}}=$ tempo de concentração, que no caso do método racional é o tempo de duração do evento.

\subsubsection{PARAMETROS INTERVENIENTES}

Levando-se em conta todos os parâmetros, para os quais queremos impor uma função de amortecimento, e ainda pressupor que são esses os fatores que governam as características principais do escoamento sob as condições impostas neste modelo, propõe-se pela formulação de um índice adimensional a ser chamado $\emptyset$. Assim tem-se:

$$
F_{1}=\left(\frac{Q}{Q_{0}}, S_{0}, \Delta x, h_{0}, f, B, V_{0}, t_{c}\right)=0 \quad, \quad \frac{Q}{Q_{0}}=F_{2}\left(\frac{B}{h_{0}}, \sqrt{\frac{S_{0}}{f}}, \frac{V_{0} \cdot t_{c}}{\Delta x}\right)
$$

em que:

$\boldsymbol{S}_{\mathbf{0}}=$ declividade longitudinal da rua

$\Delta \boldsymbol{x}=$ extensão da rua a ser estudado, ou extensão acumulada de montante ao ponto de controle de vazão;

$\boldsymbol{h}_{\mathbf{0}}=$ altura da lâmina de água em relação a vertical, contando do ponto mais baixo da sarjeta; 
$\boldsymbol{f}=$ fator de atrito universal, que deve representar a rugosidade das paredes do conduto;

$\boldsymbol{B}=$ largura da lâmina de água superficial, que é dimensão importante no que concerne avaliação do escoamento com vistas a manutenção do trafego durante os eventos de chuva;

$\boldsymbol{V}_{\mathbf{0}}=$ velocidade de escoamento da vazão na seção transversal de estudo, segundo Chezy;

$\boldsymbol{t}_{\boldsymbol{c}}=$ tempo de concentração, que no caso do método racional é o tempo de duração do evento.

Aplicando-se o teorema dos PI às grandezas intervenientes, temos o seguinte adimensional a ser utilizado para o entendimento do fenômeno do amortecimento na rua:

$$
\frac{Q}{Q_{0}}=F\left(\frac{B}{h_{0}} \cdot \sqrt{\frac{S_{0}}{f}} \cdot \frac{V_{0} \cdot t_{c}}{\Delta x}\right)=F(\varnothing)
$$

em que:

$\boldsymbol{S}_{\mathbf{0}}=$ declividade longitudinal da rua

$\Delta \boldsymbol{x}=$ extensão da rua a ser estudado, ou extensão acumulada de montante ao ponto de controle de vazão;

$\boldsymbol{h}_{\mathbf{0}}=$ altura da lamina de água em relação a vertical, contando do ponto mais baixo da sarjeta;

$\boldsymbol{B}=$ largura da lamina de água superficial, que é dimensão importante no que concerne avaliação do escoamento com vistas a manutenção do trafego durante os eventos de chuva; Chezy;

$\boldsymbol{V}_{\mathbf{0}}=$ velocidade de escoamento da vazão na seção transversal de estudo, segundo

$\boldsymbol{t}_{\boldsymbol{c}}=$ tempo de concentração, que no caso do método racional é o tempo de duração do evento.

$\boldsymbol{f}=$ fator de atrito universal, que se relaciona com a rugosidade determinada pelo coeficiente de Manning sob a forma de:

$$
\frac{R_{h}^{\frac{1}{6}}}{n \cdot \sqrt{g}}=\frac{C}{\sqrt{g}}=\sqrt{\frac{8}{f}}
$$

eq. 75

Resolvendo-se o sistema e isolando-se $f$, obtém-se: 


$$
f=\frac{8 \cdot g}{\left(\frac{R_{h} \frac{1}{3}}{n^{2}}\right)}
$$

em que:

$\boldsymbol{R}_{\boldsymbol{h}}=$ Raio hidráulico (relação entre Área molhada e perímetro molhado);

$\boldsymbol{n}=$ rugosidade de Manning $\left(\mathrm{m}^{1 / 6}\right)$;

$\boldsymbol{g}=$ aceleração da gravidade $\mathrm{em} \mathrm{m}^{2} / \mathrm{s}$;

\subsection{SIMULAÇÕES DE ESCOAMENTO - APLICAÇÃO DO MODELO}

O modelo de escoamento considerado foi calculado com o uso de software específico, que resolve as equações de Saint-Venant com a aplicação de modelo para linearização das mesmas. O software HEC-RAS (versão 4.0 Beta, 2006), software livre distribuído pela "U.S. Army Corps of Engineers", dos Estados Unidos, permite efetuar os mais diversos cálculos hidráulicos, considerando movimento uniforme e não uniforme, de acordo com os modelos de cálculo consagrados. Neste caso, trata-se de uma aplicação para o movimento não uniforme, onde foram simuladas as condições de escoamento de diversas vazões em uma seção transversal típica em diversas condições de declividade. O objetivo foi tabular os resultados obtidos e relacioná-los com os elementos indicados na equação 74 .

As simulações foram feitas considerando todos os tempos de concentração e vazões previamente estipuladas, para cada uma das diferentes declividades, conforme discriminado na tabela 27 , totalizando quarenta e oito diferentes situações de escoamento.

Tabela 27: Tabela vazões de pico, em $\mathrm{m}^{3} / \mathrm{s}$, simuladas no modelo

\begin{tabular}{llcc}
\hline Declividades & \multicolumn{3}{c}{ Tempo de concentração (min) } \\
& $\mathbf{1 0}$ & $\mathbf{3 0}$ & $\mathbf{6 0}$ \\
\hline \multirow{2}{*}{$0,0015 \mathrm{~m} / \mathrm{m}$} & 0,10 & 0,10 & 0,10 \\
& 0,25 & 0,25 & 0,25 \\
\multirow{2}{*}{$0,0020 \mathrm{~m} / \mathrm{m}$} & 0,50 & 0,50 & 0,50 \\
& 0,10 & 0,10 & 0,10 \\
& 0,25 & 0,25 & 0,25 \\
\hline
\end{tabular}




\begin{tabular}{cccc}
\hline & 0,50 & 0,50 & 0,50 \\
$0,0030 \mathrm{~m} / \mathrm{m}$ & 0,10 & 0,10 & 0,10 \\
& 0,25 & 0,25 & 0,25 \\
& 0,50 & 0,50 & 0,50 \\
$0,004 \mathrm{~m} / \mathrm{m}$ & 0,10 & 0,10 & 0,10 \\
& 0,25 & 0,25 & 0,25 \\
$0,0050 \mathrm{~m} / \mathrm{m}$ & 0,50 & 0,50 & 0,50 \\
& 0,10 & 0,10 & 0,10 \\
& 0,25 & 0,25 & 0,25 \\
& 0,50 & 0,50 & 0,50 \\
\hline
\end{tabular}

Todas as 45 simulações foram feitas, tendo os seus dados de entrada organizados como demonstrado a seguir:

- discretização do canal de escoamento: a seção transversal típica foi introduzida no programa na forma de coordenadas, num sistema referencial local e arbitrário, já que não seria efetuado cálculo considerando efeito de remanso.

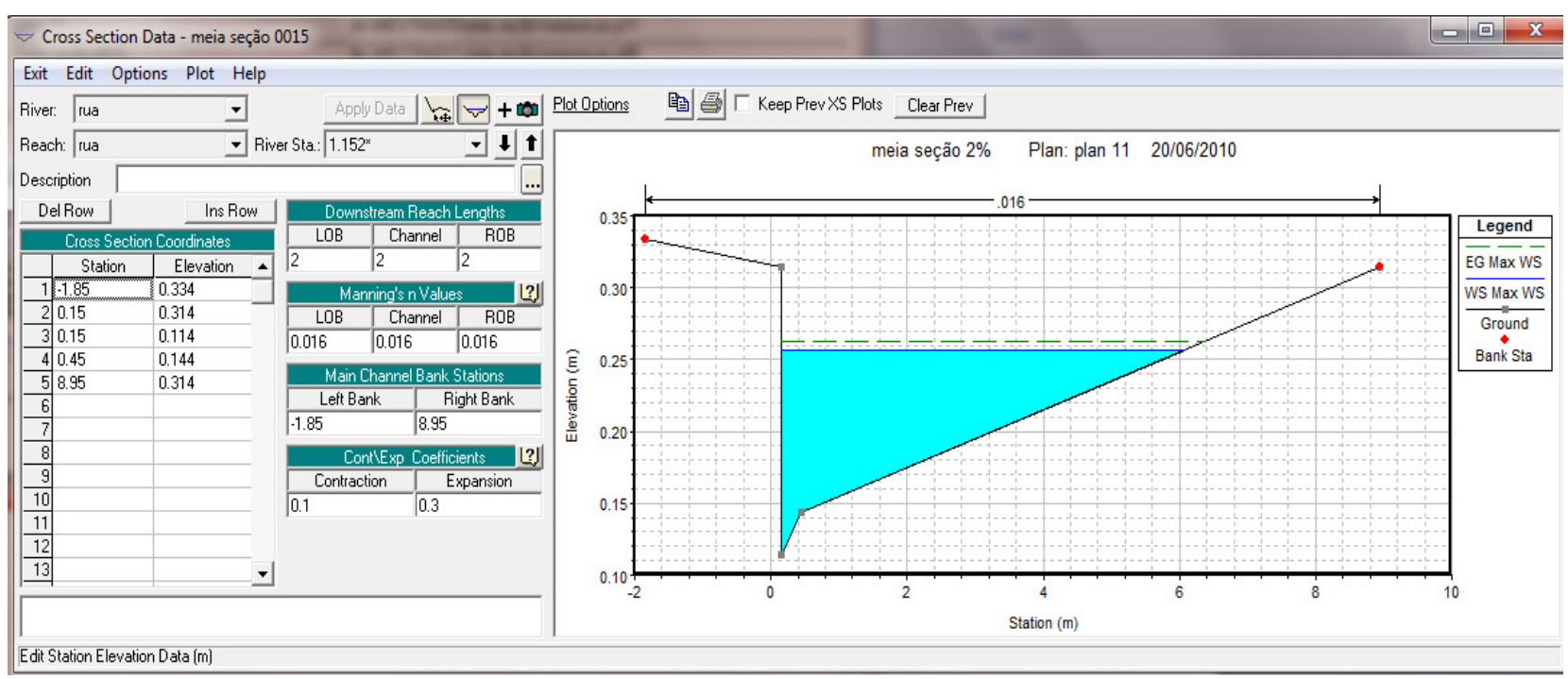

Figura 45: Tela do software HEC-RAS, para edição de seções transversais

- o espaçamento entre uma seção e outra foi estipulado como sendo de 2 metros, tendo suas cotas sido definidas por interpolação calculada pelo próprio software e o trecho de estudo uma extensão total de 500m; 


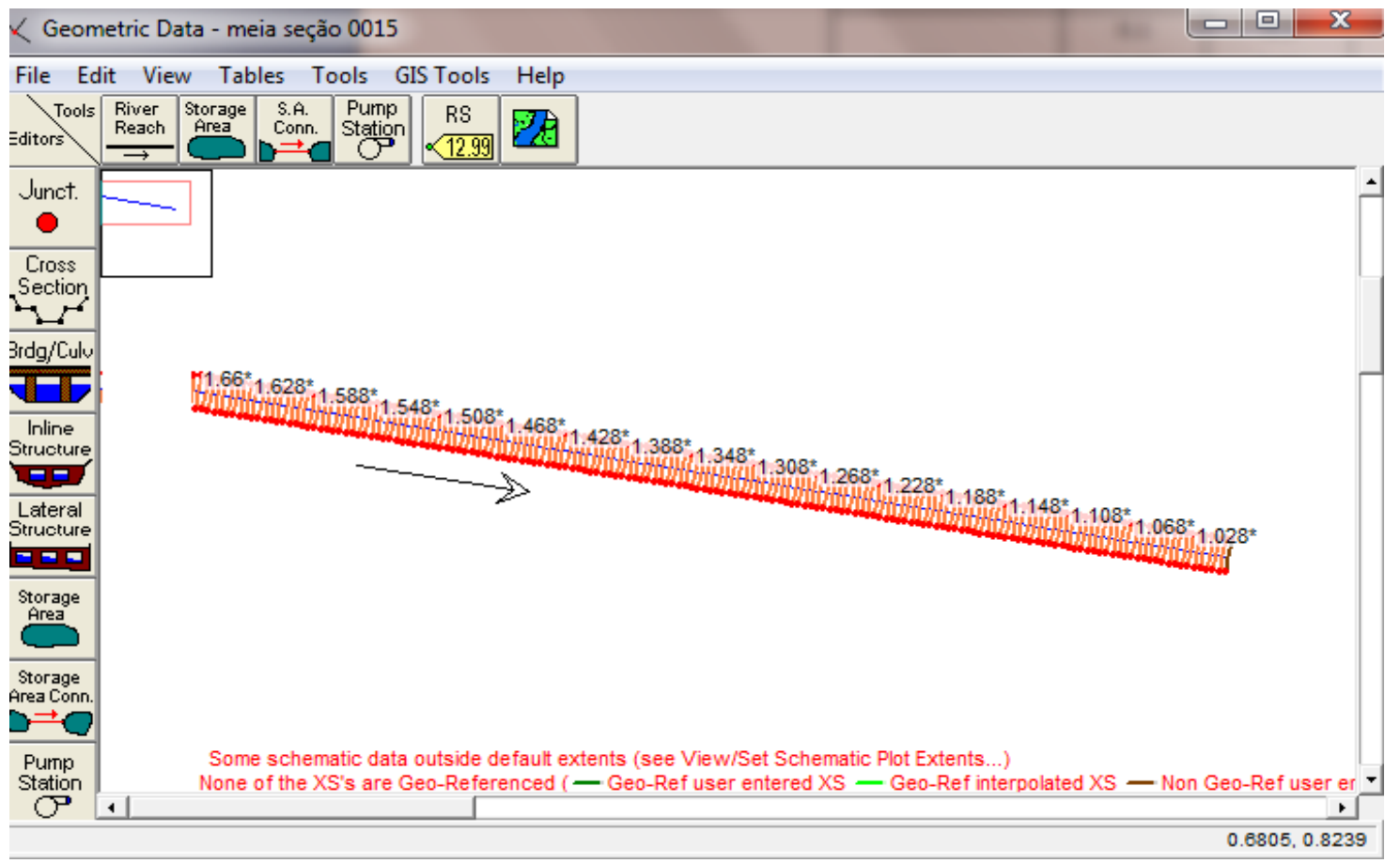

Figura 46: Discretização de seções ao longo da extensão da rua estudada

- dados de entrada são fornecidos ao modelo, na forma de hidrograma, sendo necessárias três condições de contorno a saber:

- vazão a montante: considerada nula a vazão a montante do trecho estudado

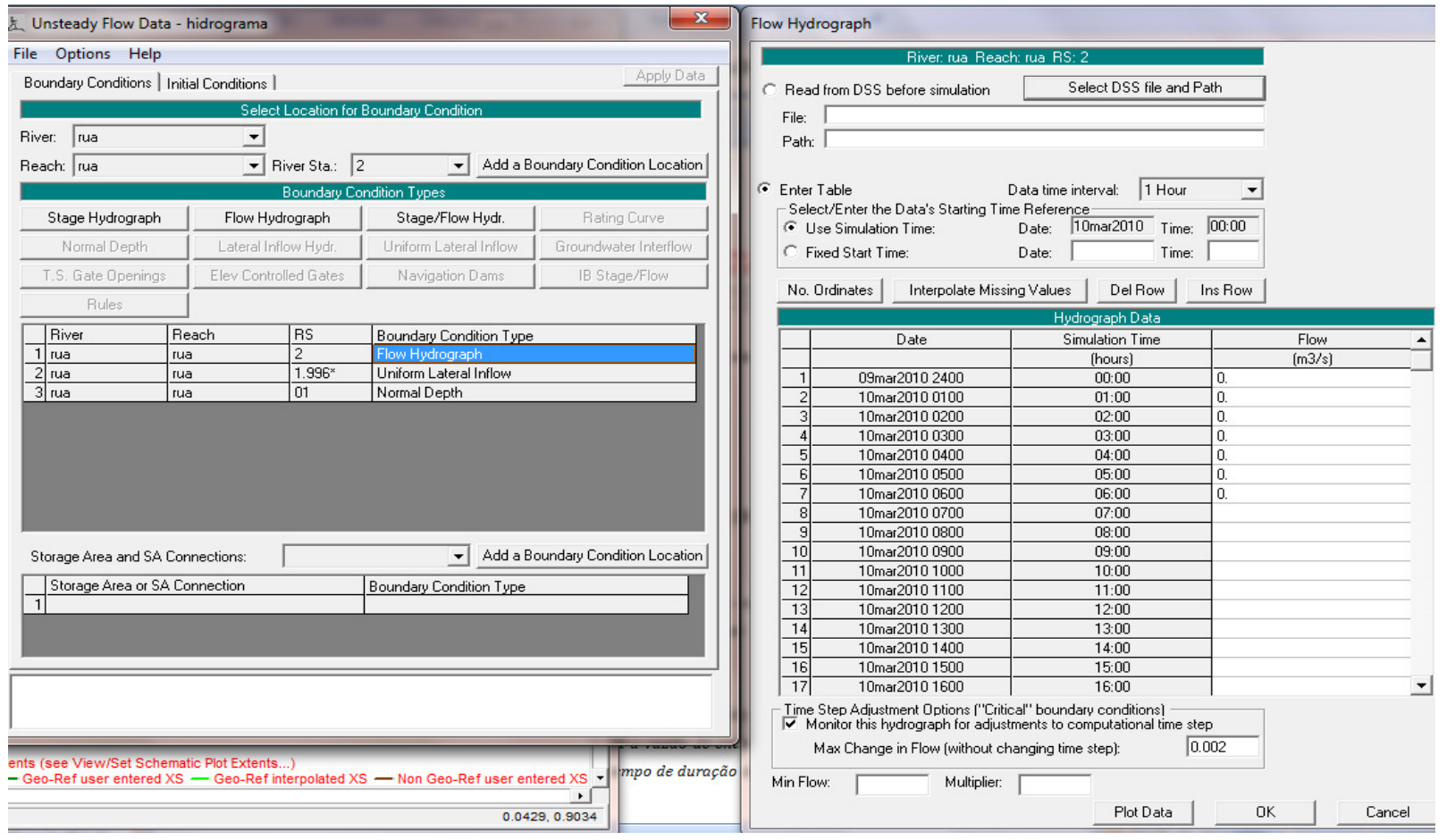

Figura 47: Entrada de dados, hidrograma de montante nulo 
- condição de contorno de jusante: foi imposta a condição de altura normal a ser determinada pela declividade de fundo;

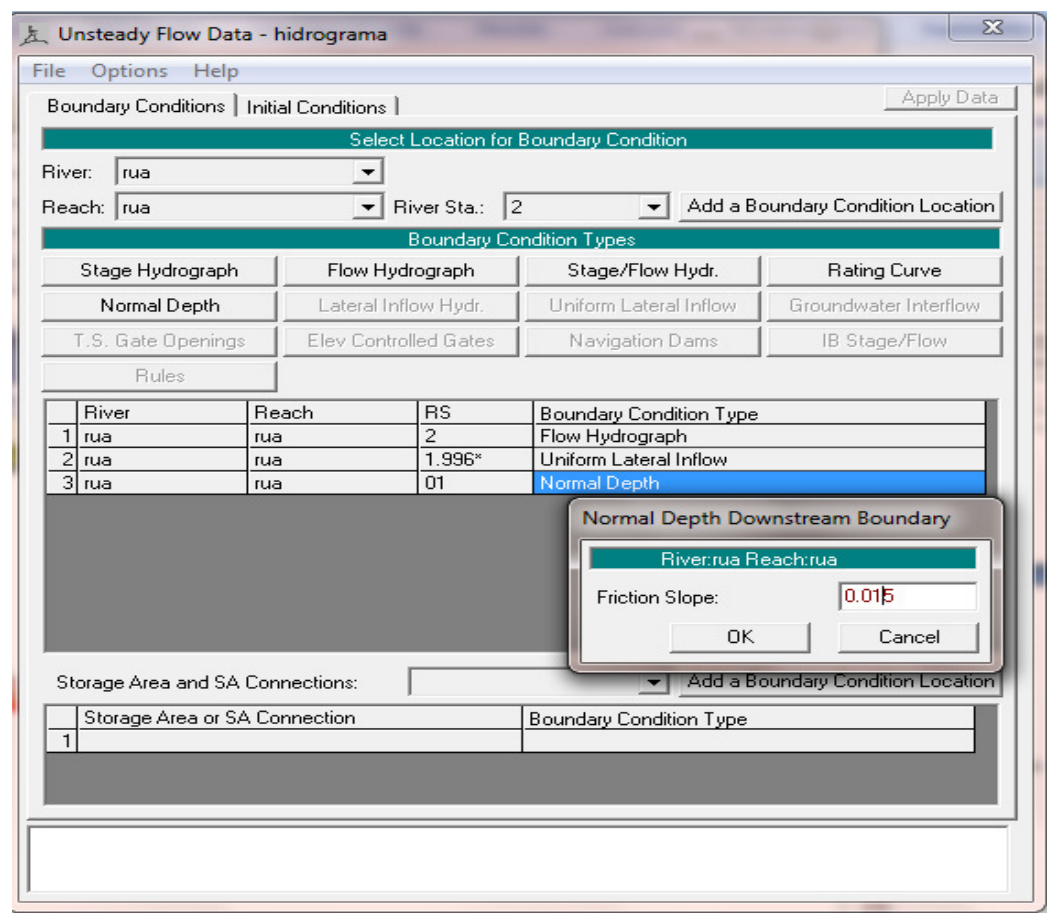

Figura 48: Entrada de dados, declividade de fundo para determinação da altura normal

- vazão distribuída ao longo do trecho de estudo: o hidrograma do método racional foi distribuído ao longo do trecho simulado, usando-se a opção "uniform lateral inflow" que simula esta distribuição.
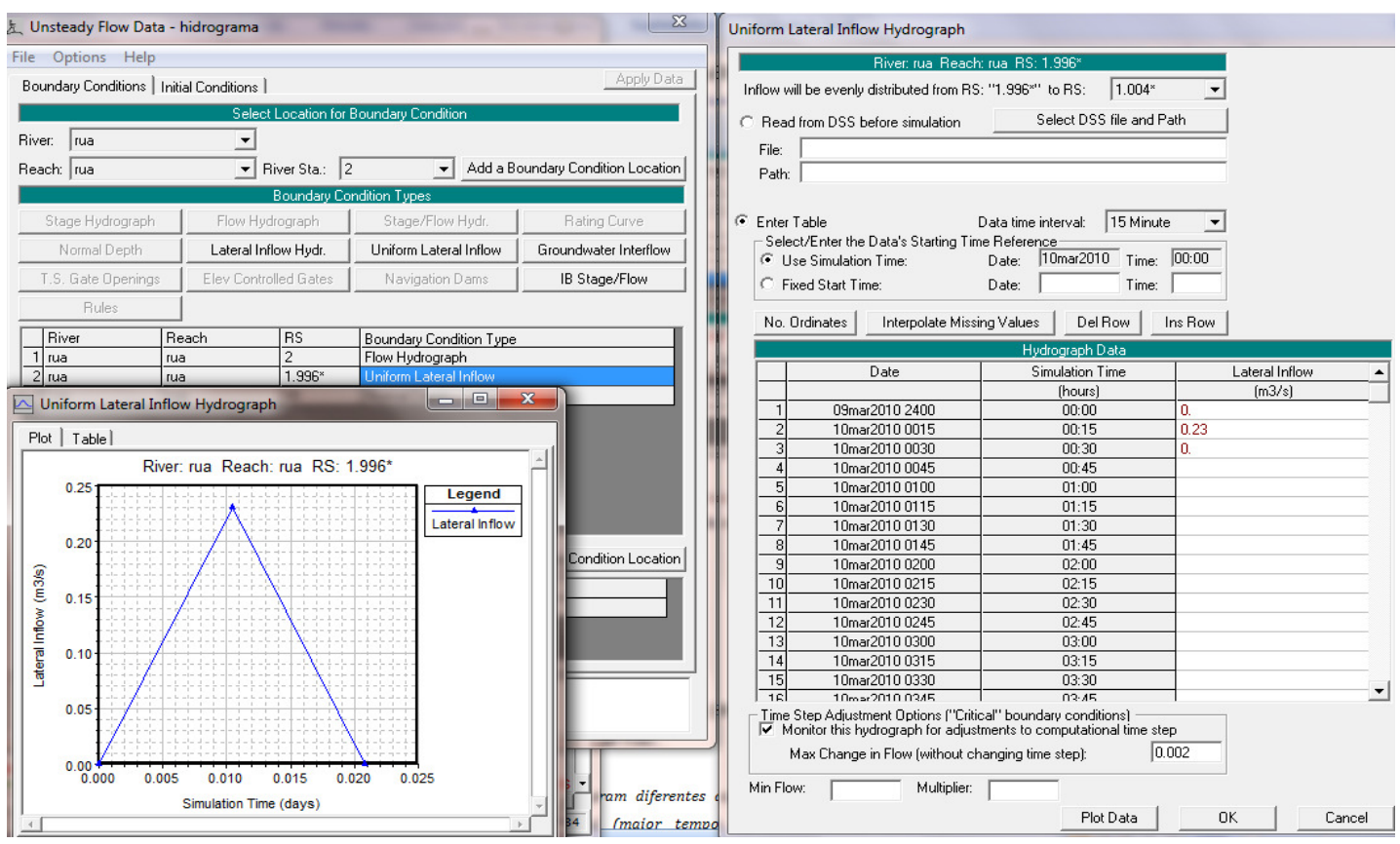

Figura 49: Hidrograma de Qo, a ser distribuído uniformemente ao longo do trecho 
- o cálculo hidrodinâmico foi feito para o intervalo de tempo de 1 segundo, o que garante a condição de estabilidade Courant. O período de simulação de escoamento foi de 4 horas, garantindo que até o hidrograma de tempo de base igual a 1 hora possa escoar pela extensão total da via estudada, considerando-se o amortecimento de vazão e retardo do escoamento.

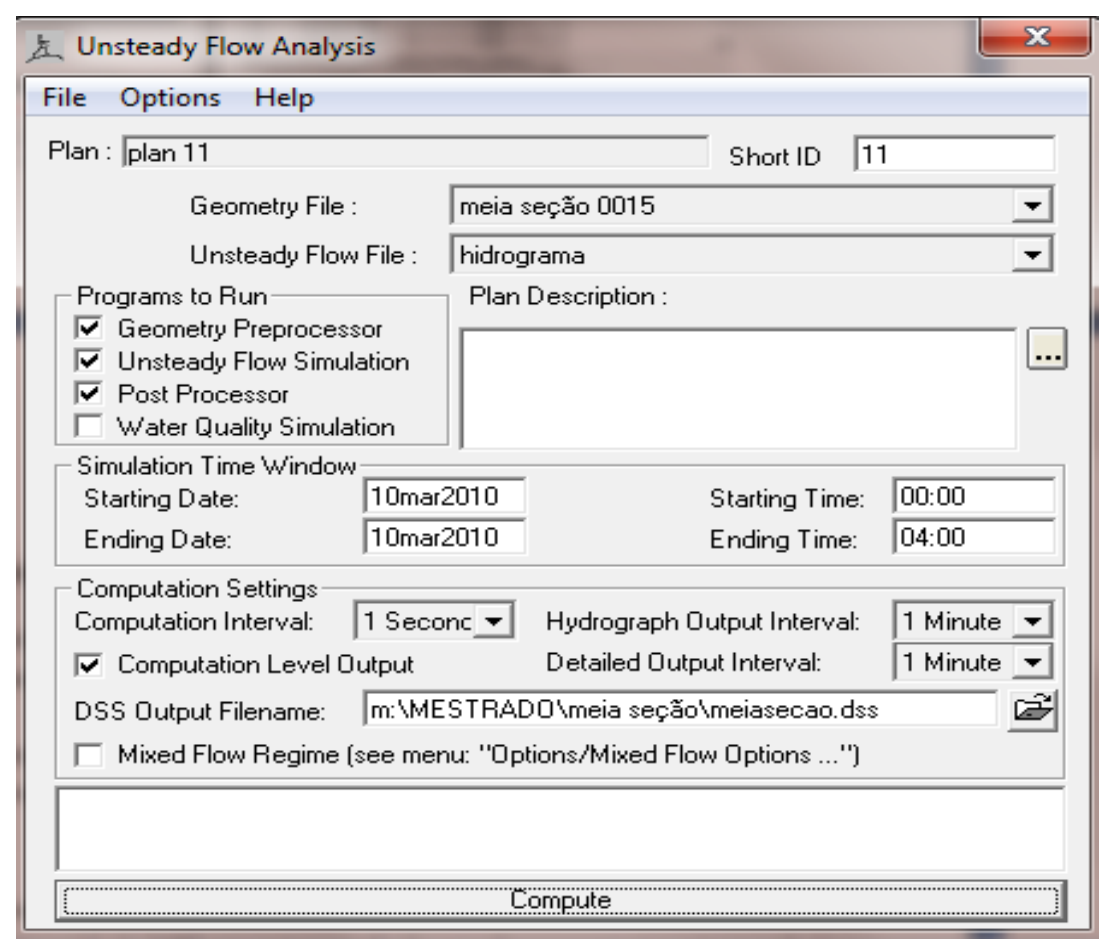

Figura 50: Tela do software para definição do passo de tempo de cálculo

\subsubsection{RESULTADOS OBTIDOS}

Das diversas simulações feitas com o uso de software específico (HEC-RAS), podemos observar as seguintes conclusões:

- diferentes tempos de concentração conduzem diferentes capacidades de amortecimento, sendo sua relação inversamente proporcional (maior tempo de concentração, menor o amortecimento);

- diferentes vazões transportadas, não modificam a capacidade de amortecimento da seção. 
O modelo de escoamento pode gerar visualização em 3D da via, apesar de ser uma simulação unidimensional, como a da figura 51, que demonstra a envoltória de máximos níveis atingidos em todos os pontos de controle do trecho estudado. Cada uma das seções, localizada a cada metro é um dos pontos de controle do trecho, sendo assim, cada uma das simulações gera uma lista de 251 resultados de cálculo.

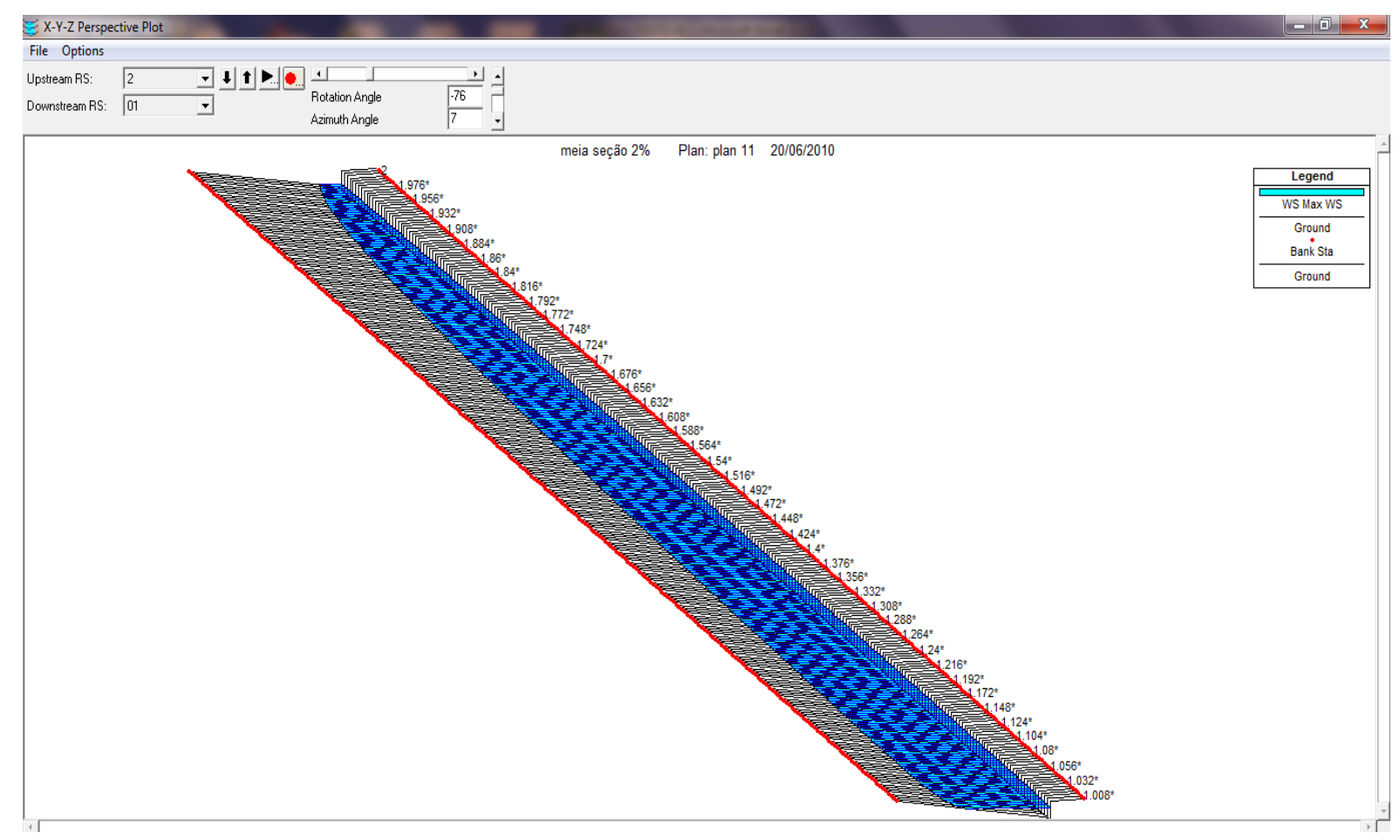

Figura 51: Superfície de alagamento máxima resultante da simulação com HEC-RAS, para declividade $0,0015 \mathrm{~m} / \mathrm{m}$ e vazão de $0,25 \mathrm{~m}^{3} / \mathrm{s}$

Para cada uma das 251 seções transversais ao longo do trecho de estudo, é obtida pelo cálculo, a envoltória de máximos de linha d'água, vazão e outras características hidrogeométricas relacionadas à vazão máxima naquela seção.

Os resultados, de modo geral ratificam a suposição inicial de que haveria um amortecimento da vazão $\boldsymbol{Q}_{\boldsymbol{o}}$, podendo-se deste modo calcular ao longo de todas as seções de controle a fator de amortecimento $Q / Q_{0}$ e então relacioná-lo com o adimensional determinado, com as grandezas intervenientes. 


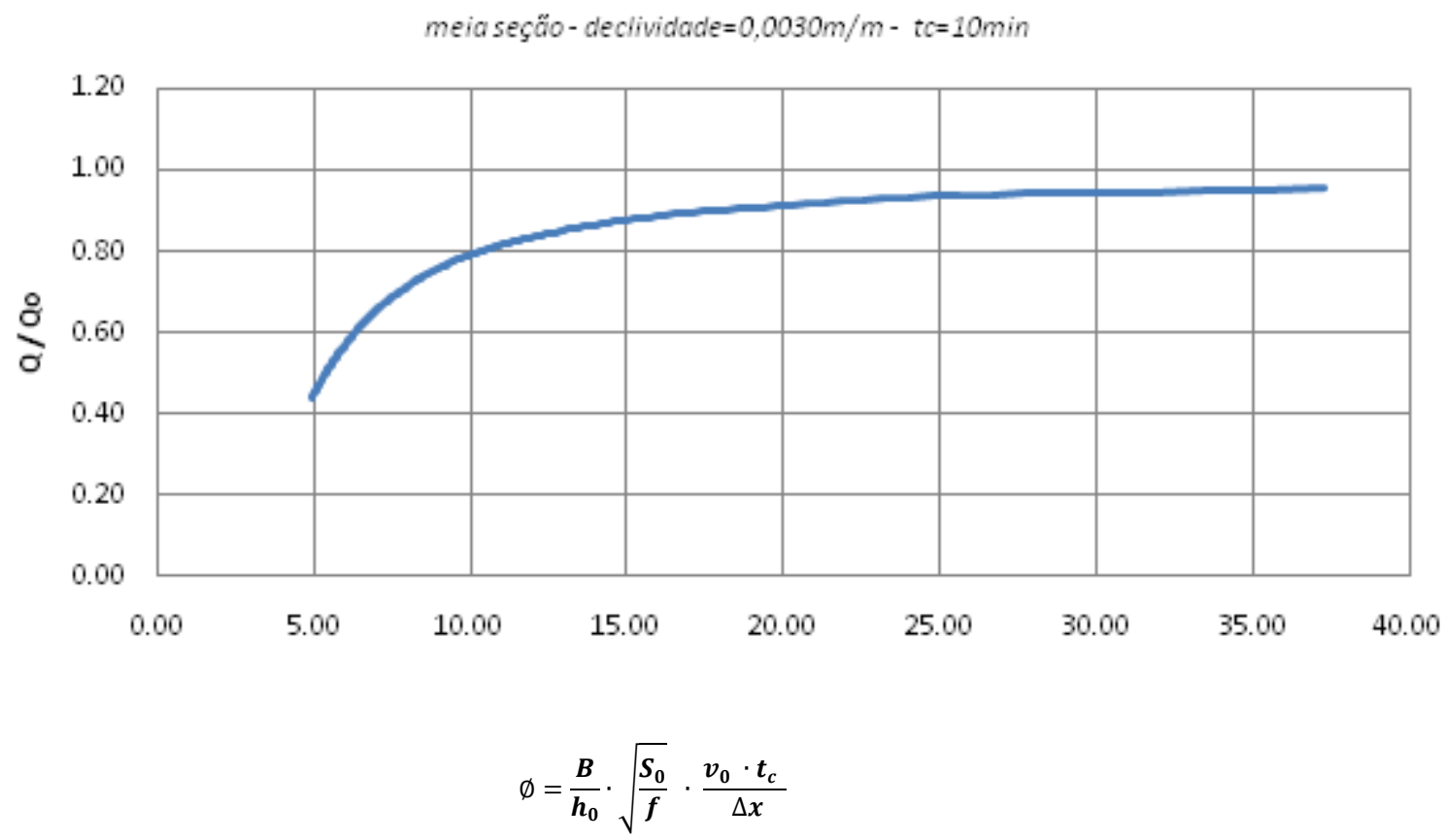

Figura 52: Relação entre Amortecimento calculado e Adimensional proposto

O gráfico ilustrado na figura 52 mostra a simulação para a meia seção padrão utilizada no modelo, para uma vazão de pico de $0,1 \mathrm{~m}^{3} / \mathrm{s}$ e tempo de duração do evento de 10 minutos. $\mathrm{O}$ gráfico da figura 53 relaciona a mesma simulação para os tempos de base de 30 e 60 minutos. A união de todos os gráficos formados pelos resultados dos três diferentes tempos de concentração forma a curva demonstrada no gráfico abaixo:

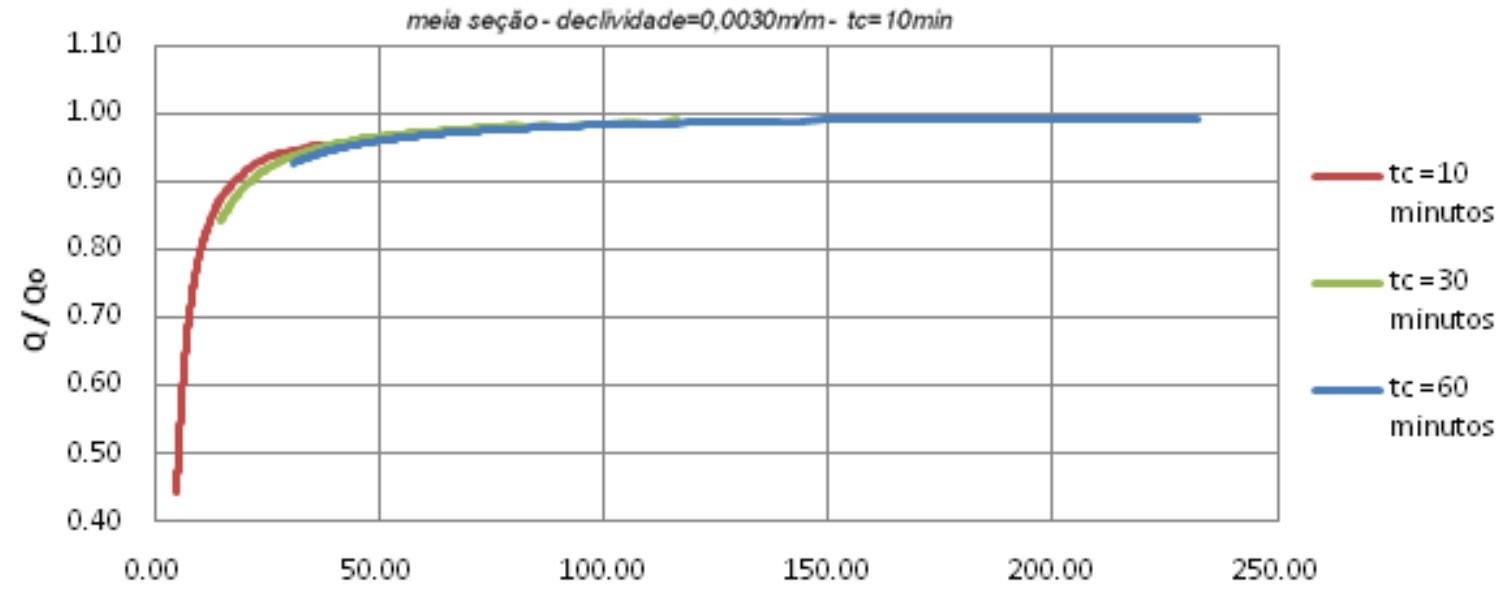

$$
\varnothing=\frac{B}{h_{0}} \cdot \sqrt{\frac{S_{0}}{f}} \cdot \frac{V_{0} \cdot t_{c}}{\Delta x}
$$

Figura 53: Curva de amortecimento em função do adimensional proposto para diferentes durações de precipitação 
Apesar de os dados de entrada terem sido simulados considerando tempos de duração de evento diferentes, para o mesmo evento de chuva e mesma declividade longitudinal, ocorreu boa aderência dos pontos formadores das três curvas resultado, levando-nos a concluir que se trata de apenas uma curva, que poderá ser matematicamente transformada de modo a facilitar a criação para a descrição do problema.

Rearranjando a equação do amortecimento proposta, para que se tenha uma equação exponencial simples, tem-se:

$$
1-\frac{Q}{Q_{0}}=\text { parcela amortecida }
$$

em que:

Qo = vazão de entrada, do método Racional;

$\boldsymbol{Q}=$ vazão amortecida, gerada pelo efeito da baixa declividade.

Relacionando-se a "parcela amortecida" com o mesmo adimensional criado $(\varnothing)$ temos a curva do tipo exponencial:

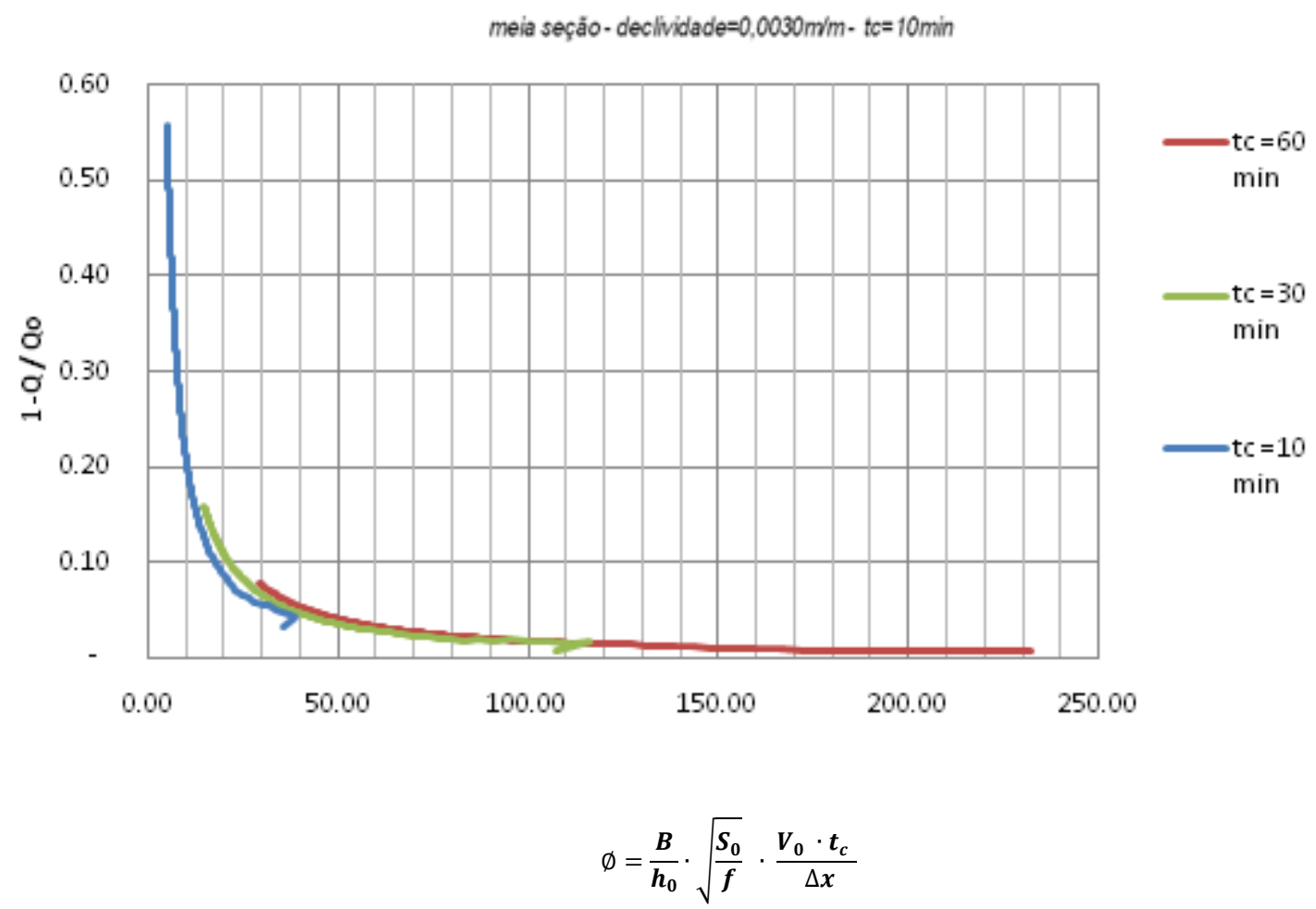

Figura 54: Relação proposta para o amortecimento em função do parâmetro adimensional 
Como proposto, buscava-se criar uma função matemática que relacionasse a parcela amortecida com o Adimensional $\emptyset$ :

$$
\begin{gathered}
1-\frac{Q}{Q_{0}}=G(\varnothing) \\
1-\frac{Q}{Q_{0}}=G\left(\frac{B}{h_{0}} \cdot \sqrt{\frac{S_{0}}{f}} \cdot \frac{V_{0} \cdot t_{c}}{\Delta x}\right)
\end{gathered}
$$

em que:

$\boldsymbol{B}=$ largura da lâmina de água superficial, em m;

$\boldsymbol{h}_{\mathbf{0}}=$ altura da lâmina de água em relação a vertical, contando do ponto mais baixo da sarjeta, em $m$.

$\boldsymbol{S}_{\mathbf{0}}=$ declividade longitudinal $\mathrm{em} \mathrm{m} / \mathrm{m}$;

$\boldsymbol{f}=$ fator de atrito universal;

$v_{0}=$ velocidade inicial de escoamento, $\mathrm{em} \mathrm{m} / \mathrm{s}$;

$\boldsymbol{t}_{\boldsymbol{c}}=$ tempo de concentração ou de duração da chuva de projeto, em segundos;

$\Delta \boldsymbol{x}=$ distancia de montante ao ponto de controle de vazão, em $\mathrm{m}$;

Observa-se então que a relação procurada é do tipo exponencial, podendo ser expressa por:

$$
1-\frac{Q}{Q_{0}}=Y \cdot(\varnothing)^{-X}
$$

$$
1-\frac{Q}{Q_{0}}=Y\left(\frac{B}{h_{0}} \cdot \sqrt{\frac{S_{0}}{f}} \cdot \frac{V_{0} \cdot t_{c}}{\Delta x}\right)^{-X}
$$


Para as equações 80 e 81 , podemos propor que a relação entre as variáveis $\mathrm{X}$ e Y seja função da declividade longitudinal. Da análise das 48 simulações efetuadas neste trabalho, 15 equações exponenciais, semelhantes a eq.80 foram determinadas, sendo cada uma delas, para cada uma das declividades consideradas no modelo e cada uma das três vazões padronizadas. A figura 54 ilustra e demonstra a aderência da equação proposta as dados obtidos nas simulações. Na seqüência apresenta-se uma tabela 28 que resume os índices X e Y e sua variação em relação as diferentes declividades das seções.

$\mathrm{i}=0,0015 \mathrm{~m} / \mathrm{m}$

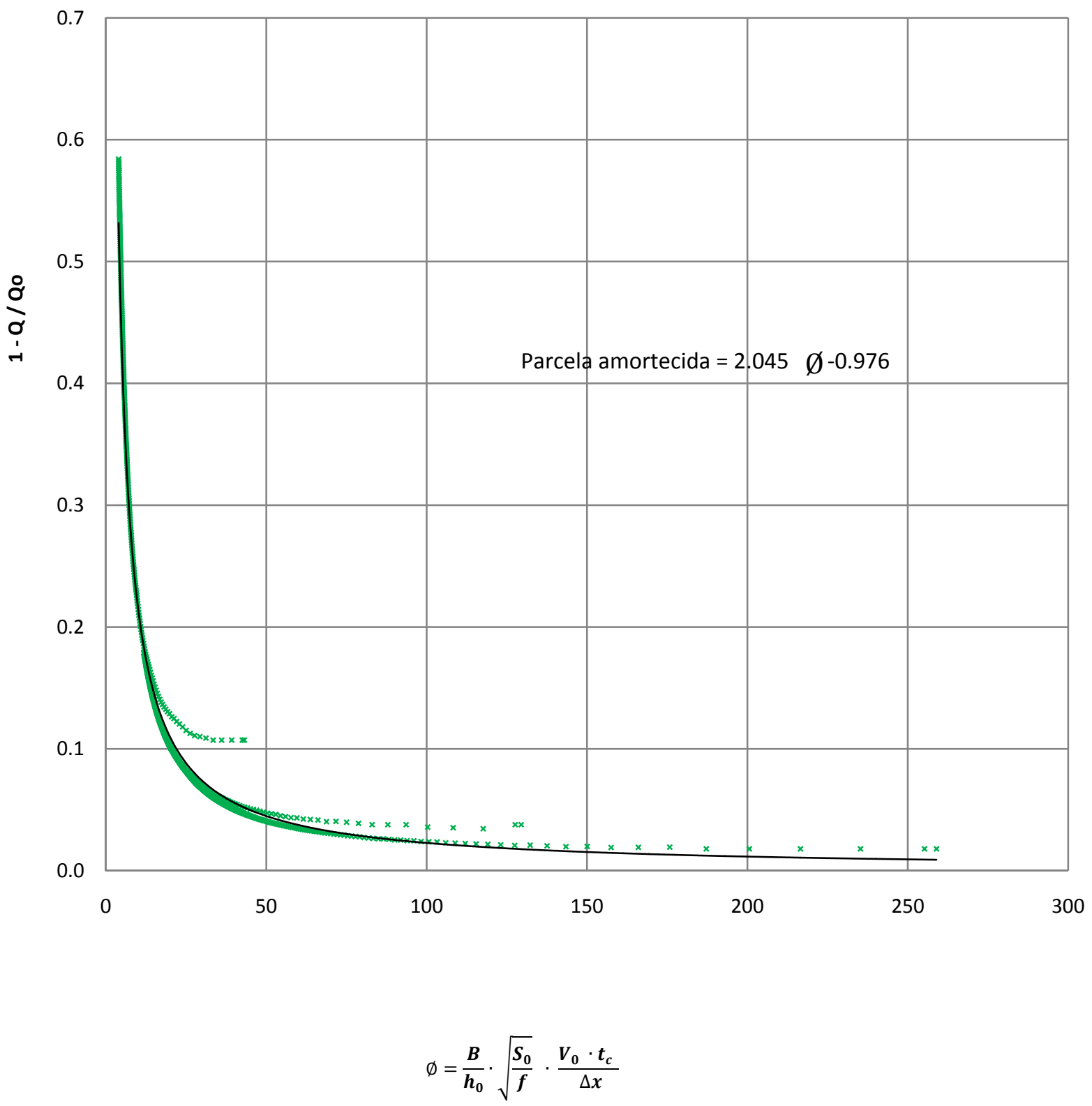

Figura 55: Curva exponencial ajustada para a declividade 0,0015m/m 
Tabela 28: Tabela resumo dos índices das equações observadas no modelo

\begin{tabular}{|c|c|c|}
\hline $\mathbf{Y}$ & $\mathbf{X}$ & Declividade \\
\hline 1.98 & 1.043 & \multirow{3}{*}{0,0015} \\
\hline 2.04 & 0.976 & \\
\hline 1.97 & 0.916 & \\
\hline 2.37 & 1.083 & \multirow{3}{*}{0,002} \\
\hline 2.45 & 1.022 & \\
\hline 2.39 & 0.968 & \\
\hline 3.08 & 1.123 & \multirow{3}{*}{0,003} \\
\hline 3.11 & 1.063 & \\
\hline 3.02 & 1.017 & \\
\hline 3.44 & 1.120 & \multirow{3}{*}{0,004} \\
\hline 3.65 & 1.082 & \\
\hline 3.60 & 1.043 & \\
\hline 3.80 & 1.122 & \multirow{3}{*}{0,005} \\
\hline 4.10 & 1.090 & \\
\hline 4.14 & 1.059 & \\
\hline
\end{tabular}

Relacionando-se o fator multiplicador $\mathrm{Y}$ e o expoente $\mathrm{X}$, com as diferentes declividades, podem ser propostas equações também do tipo exponencial para representar suas respectivas variações, como demonstradas graficamente a seguir:

\section{Índice Multiplicador Y}

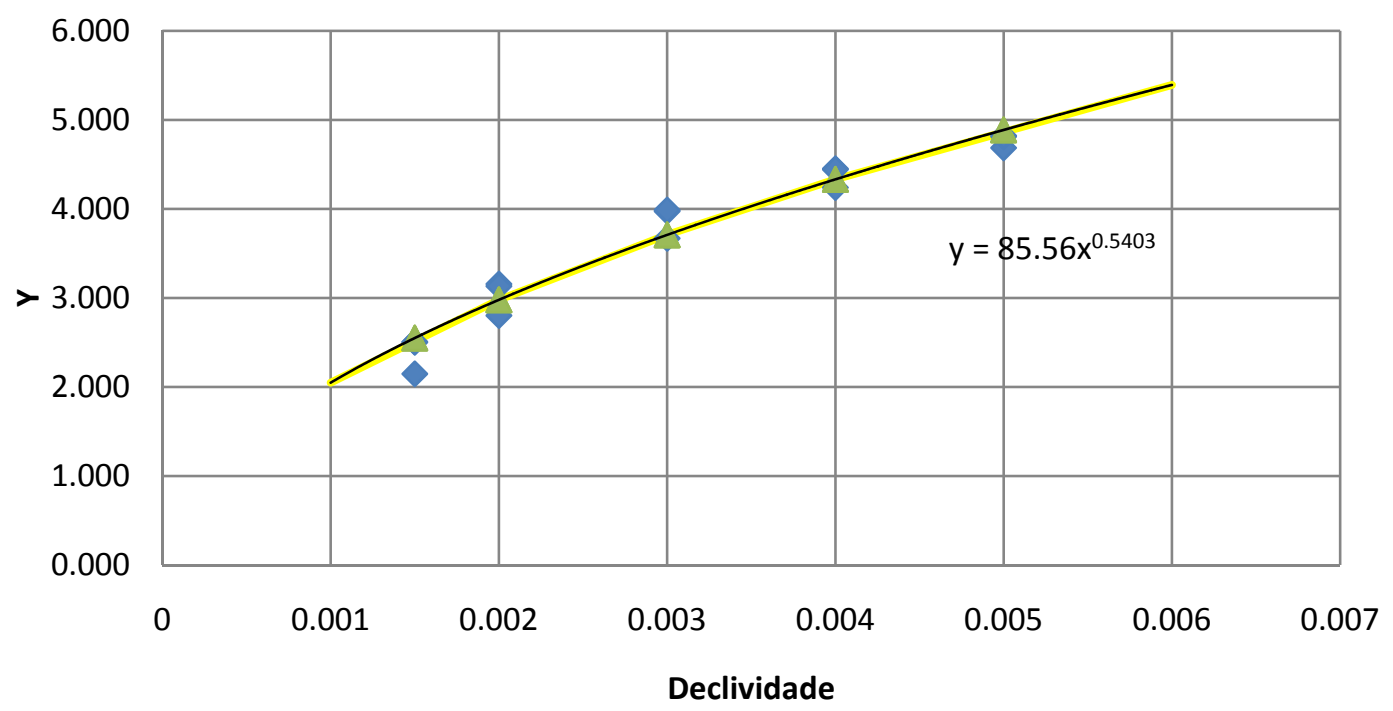

Figura 56: Curva ajustada para o Fator Multiplicador Y 


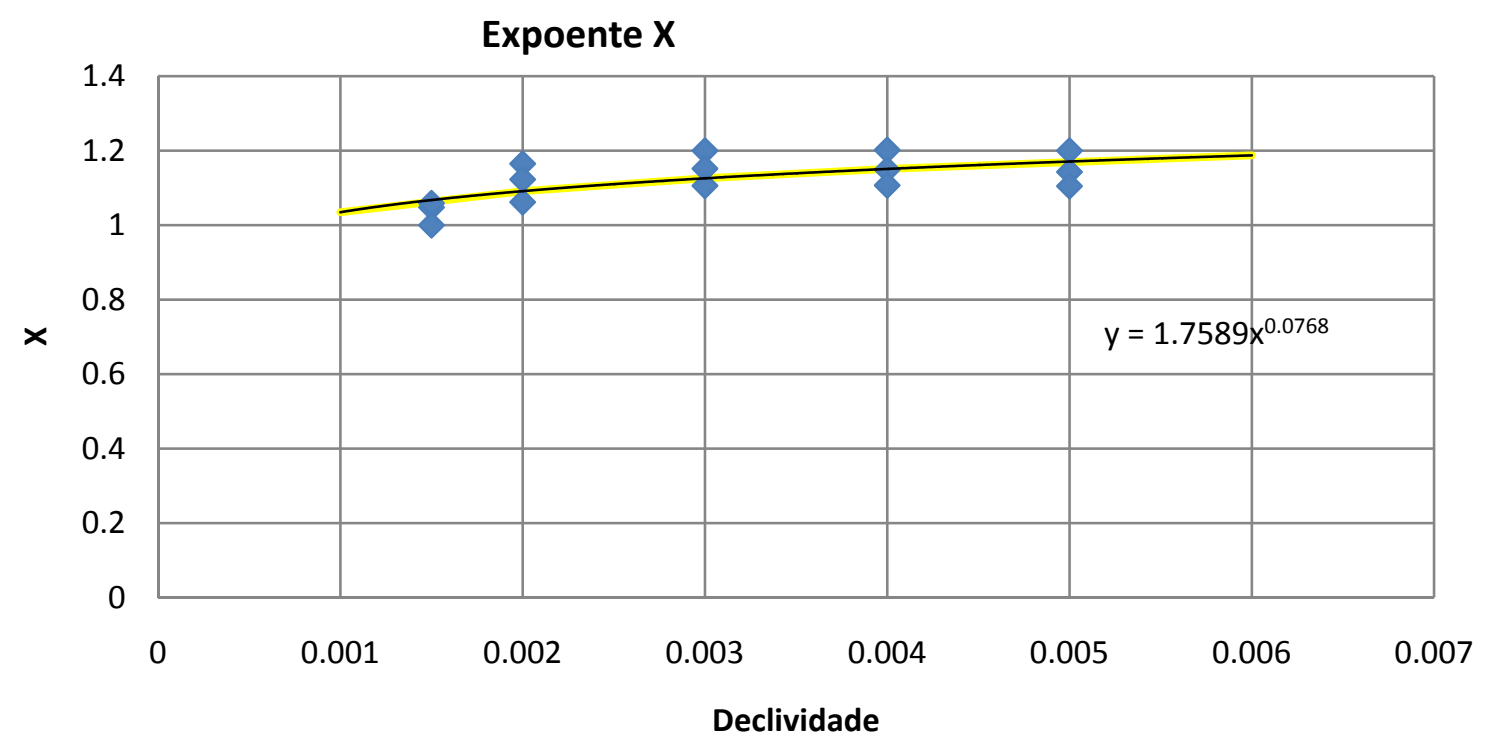

Figura 57: Curva ajustada para o Expoente X

\subsubsection{EQUACIONAMENTO OBTIDO}

Com base nos resultados anteriormente mostrados, resulta o modelo de avaliação do amortecimento, com base no Adimensional $\emptyset$ e na parcela de amortecimento dada por:

$$
1-\frac{Q}{Q_{0}}=Y\left(\frac{B}{h_{0}} \cdot \sqrt{\frac{S_{0}}{f}} \cdot \frac{V_{0} \cdot t_{c}}{\Delta x}\right)^{-X}
$$

Como já deduzido, o expoente $\mathrm{X}$ e o fator multiplicador $\mathrm{Y}$, para a seção típica deste modelo variam conforme as equações (83) e (84), obtidas pelo comportamento gráfico dessas variáveis quando da relação exponencial entre elas e declividade da via:

$$
\begin{aligned}
& Y=85,56 \cdot S_{0}^{0,54} \\
& X=1,758 \cdot S_{0}{ }^{0,077}
\end{aligned}
$$


em que:

$\boldsymbol{Y}=$ fator multiplicador da equação do amortecimento;

$\boldsymbol{X}=$ expoente da equação da equação do amortecimento;

$\boldsymbol{S}_{\mathbf{0}}=$ declividade longitudinal $\mathrm{em} \mathrm{m} / \mathrm{m}$.

\subsubsection{EXEMPLO DEMONSTRATIVO}

Tomando-se como exemplo uma via localizada no município de Praia Grande cuja equação de chuvas, proposta pelo Plano de Macro Drenagem Municipal (PMD Praia Grande, 1997) é do tipo LnLn e expressa por:

$i_{t, T}=25,1025 \cdot(t c+20)^{-0,7522}+6,4266 \cdot(t c+20)^{-0.7050} \cdot\left[-0,4772-0,9010 \ln \ln \left(\frac{T R}{T R-1}\right)\right]$ eq. 85

Para $10 \leq t \leq 1440 \mathrm{~min}$

em que:

$\boldsymbol{i}=$ intensidade da chuva de projeto, em $\mathrm{mm} / \mathrm{min}$;

$\boldsymbol{t} \boldsymbol{c}=$ tempo de concentração da chuva de projeto, em min;

$\boldsymbol{T} \boldsymbol{R}=$ período de retorno em anos.

Considerando-se uma bacia de contribuição cuja extensão é a extensão da rua (300m) e uma largura de $50 \mathrm{~m}$, temos uma área de contribuição de $0,015 \mathrm{~km}^{2}$. Pelas características da bacia e do talvegue principal, que é a rua estudada, podemos determinar o tempo de concentração médio avaliados pelos diferentes métodos de cálculo: 
CARACTERISTICAS DO CANAL

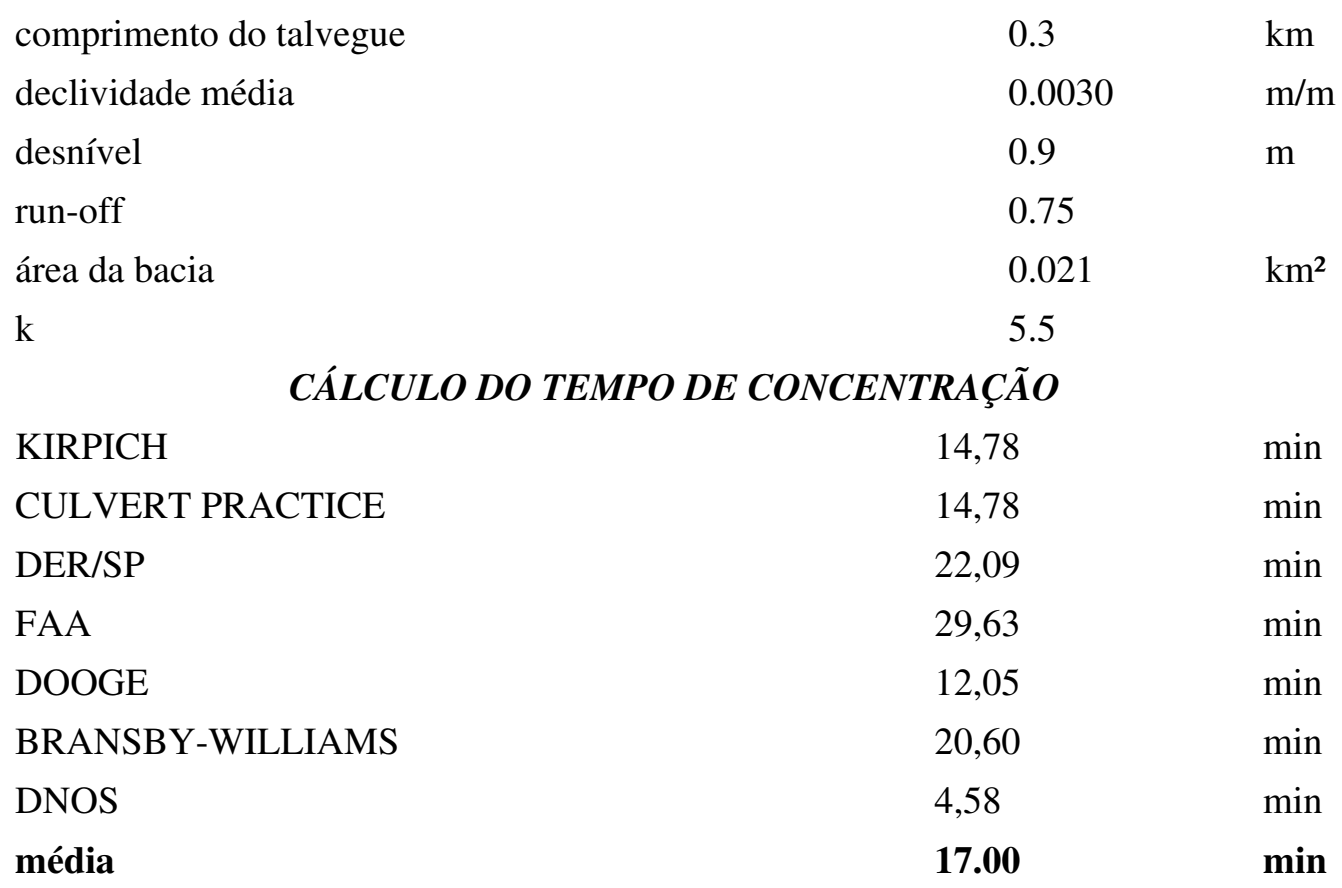

Com o tempo de concentração médio e adotado de 17 minutos, temos a intensidade e podemos calcular pelo método racional a vazão de pico do hidrograma do método racional:

$\begin{array}{lll}\text { Área da bacia } & 0.015 & \mathrm{~km}^{2} \\ \text { Tempo de concentração } & 17 & \text { minutos } \\ \text { Coeficiente C } & 0.75 & \\ \text { intensidade } & 95,16 & \mathrm{~mm} / \mathrm{h} \\ \text { TR } & 2 & \text { anos } \\ \text { VAZÃO DE PICO } & 0,297 & \mathrm{~m}^{3} / \mathrm{s}\end{array}$

Temos então o hidrograma de entrada, a ser distribuído ao longo da extensão da rua:

Hidrograma de entrada - Qo

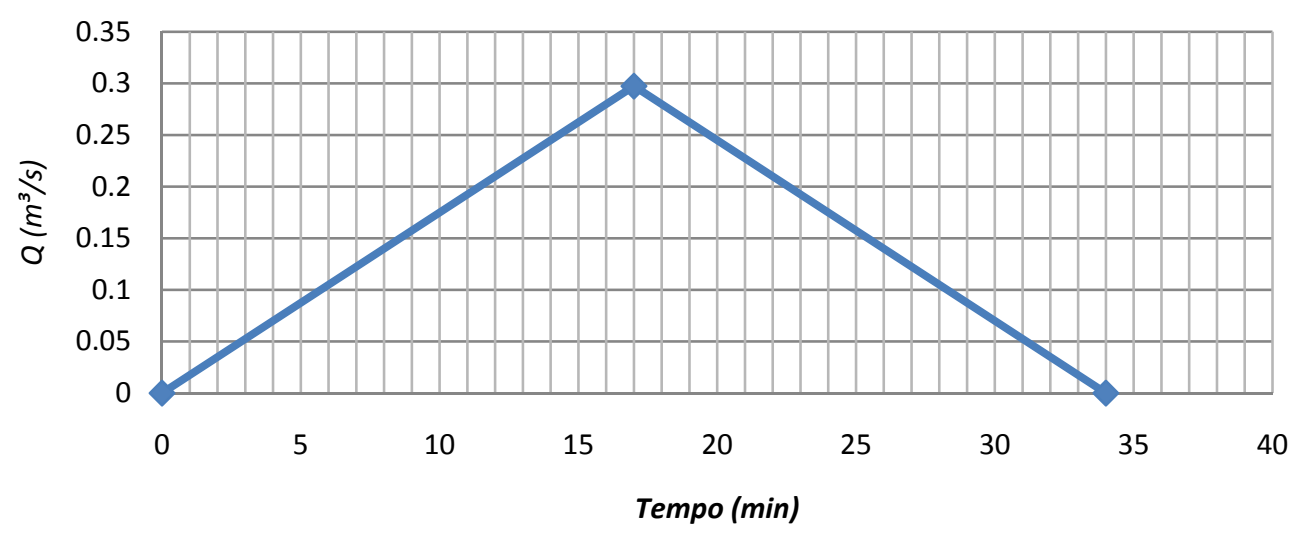


A geometria da rua, em função da vazão de entrada que nela ira passar poderá ser:

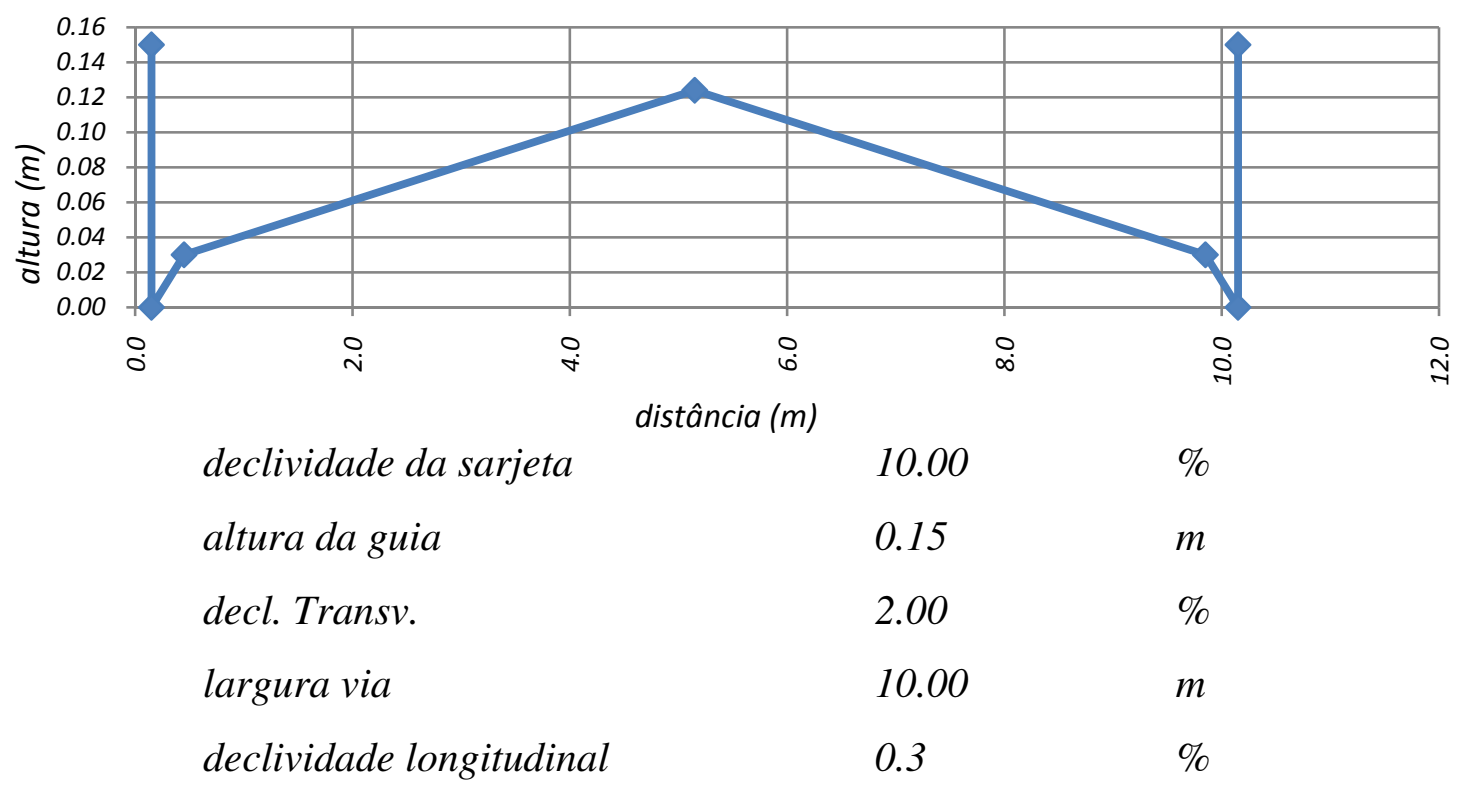

A vazão máxima, quando aplicada à seção transversal adotada, gera uma lamina d'água, de $\mathbf{0 , 1 3 4} \mathbf{m}$. Tal altura de linha d'água gera uma largura superficial de 5,48m.

Com isso pode-se verificar que a velocidade média do escoamento é de $0,489 \mathrm{~m} / \mathrm{s}$. É necessária também a determinação do fator de atrito universal, que pode ser facilmente calculado por:

$$
\frac{C}{\sqrt{g}}=\frac{8}{f}=\frac{R_{h}^{\frac{1}{6}}}{n \cdot \sqrt{g}}
$$

em que:

$\boldsymbol{C}=$ constante de Chezy;

$\boldsymbol{g}=$ aceleração da gravidade em $\mathrm{m} / \mathrm{s}^{2}$;

$\boldsymbol{R}_{\boldsymbol{h}}=$ raio hidráulico;

$\boldsymbol{n}=$ número de Manning

Pode-se calcular o coeficiente de rugosidade universal por meio de: 


$$
f=\frac{8 \cdot g}{\left(\frac{R_{h}^{\frac{1}{6}}}{n}\right)^{2}}
$$

eq. 87

Fazendo-se então:

$$
f=\frac{8 \cdot 9,81}{\left(\frac{0,05407^{\frac{1}{6}}}{0,016}\right)^{2}}
$$

Obte-se que : $\quad f=0,0531$

Uma vez determinados os dados de entrada, podemos calcular o adimensional $\emptyset$ :

$$
\varnothing=\frac{B}{S_{0}} \cdot \sqrt{\frac{S_{0}}{f}} \cdot \frac{v \cdot t_{c}}{\Delta x}=\frac{10}{0,132} \cdot \sqrt{\frac{0,003}{0,0531}} \cdot \frac{0,489 \cdot(17 \cdot 60)}{300}=16,22
$$

Conhecido o valor do Adimensional $\emptyset$, é necessário determinarmos os valores do fator multiplicador e expoente da equação de amortecimento da seção característica. Para isso faze-se:

$$
\begin{gathered}
Y=85,56 \cdot S_{0}{ }^{0,56}=85,56 \cdot 0,003^{0,54}=3,708 \\
X=1,758 \cdot S_{0}{ }^{0,076}=1.758 \cdot 0,003^{0,076}=1,126
\end{gathered}
$$

Assim a equação de amortecimento fica:

$$
\begin{gathered}
1-\frac{Q}{Q_{0}}=1,13\left(\frac{B}{S_{0}} \cdot \sqrt{\frac{S_{0}}{f}} \cdot \frac{v_{0} \cdot t_{c}}{\Delta x}\right)^{-3,708} \\
1-\frac{Q}{Q_{0}}=1,13(16,22)^{-3,708}=\mathbf{0 , 1 6 1}
\end{gathered}
$$

Com isso, pode-se estimar que a vazão final será reduzida de uma parcela correspondente a $16 \%$, sendo estimada em $0,249 \mathrm{~m}^{3} / \mathrm{s}$. Do processamento no HEC-RAS obtemos o resultado do hidrograma de saída na seção de jusante como sendo: 


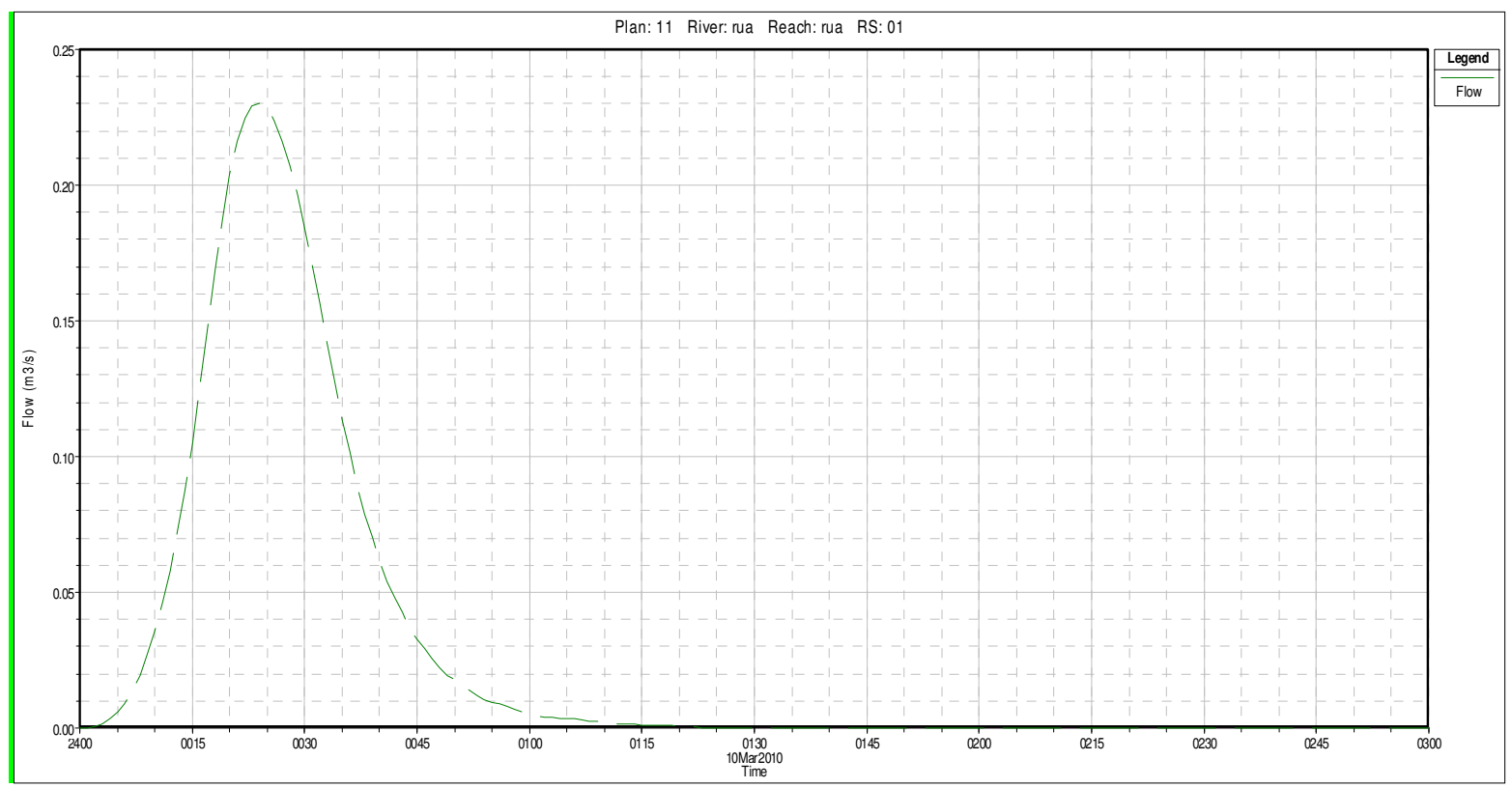

Figura 58: Gráfico obtido pelo processamento dos dados no HEC-RAS

Temos então um amortecimento calculado de:

$$
1-\frac{Q}{Q_{0}}=1-\frac{0,251}{0,297}=\mathbf{0 , 1 6}
$$

O modelo proposto estimou um amortecimento de vazão bastante próximo ao resultado da nova simulação, podendo ser considerado bastante estável para esta geometria de via.

Apresenta-se a seguir a mesma simulação que Izzard propôs em seus ensaios, onde uma sarjeta de 60 metros de extensão, declividade transversal de $2 \%$, declividade longitudinal de $0,5 \%$, transporta a vazão gerada por uma área de $12,8 \mathrm{~m}$ de largura. A vazão gerada é de 33,1 1/s, considerando um tempo de duração de 3 minutos.

- $\quad$ Altura da lâmina d'água =0,078m;

- $\quad$ Largura superficial $=2,72 \mathrm{~m}$;

- Velocidade média de escoamento $=0,405 \mathrm{~m} / \mathrm{s}$;

$$
f=\frac{8 \cdot g}{\left(\frac{R_{h}^{\frac{1}{6}}}{n}\right)^{2}}=0,0664
$$




$$
\begin{aligned}
& \varnothing=\frac{B}{h_{0}} \cdot \sqrt{\frac{S_{0}}{f}} \cdot \frac{v \cdot t_{c}}{\Delta x}=\frac{2,72}{0,078} \cdot \sqrt{\frac{0,005}{0,664}} \cdot \frac{0,051 \cdot(3 \cdot 60)}{60}=11,57 \\
& Y=85,56 \cdot S_{0}^{0,56}=85,56 \cdot 0,005^{0,56}=1,1709 \\
& X=1,758 \cdot S_{0}^{0,076}=1.758 \cdot 0,005^{0,076}=4,8868 \\
& 1-\frac{Q}{Q_{0}}=1,1709\left(\frac{B}{h_{0}} \cdot \sqrt{\frac{S_{0}}{f}} \cdot \frac{V_{0} \cdot t_{c}}{\Delta x}\right)^{-4,8868} \\
& 1-\frac{Q}{Q_{0}}=1,1709(11,57)^{-4,8868}=\mathbf{0 , 2 7 8}
\end{aligned}
$$

Aplicando-se o fator de amortecimento, obtêm-se o valor de vazão de pico reduzido em $\mathbf{7 2 , 2 \%}$, ou seja, $0,023 \mathrm{~m}^{3} / \mathrm{s}$, o que é equivalente ao encontrado por Izzard $(25,5 \mathrm{l} / \mathrm{s}) \mathrm{em}$ seu experimento, assim como, por ele, calculado pelo método de Muskingum.

\subsubsection{VERIFICAÇÃO DO EFEITO DE SOBREPOSIÇÃO DE EVENTOS DE CHUVA}

O princípio de aproveitar a baixa declividade da rua para que se tenha o efeito de amortecimento das vazões de pico, conduz a ocupação, de parte da calha das vias com o volume precipitado e amortecido. Apesar do dimensionamento dos sistemas de micro drenagem serem feitos com a imposiçao de parâmetros como Período de Recorrência e Tempo de Concentração com o intuito de simular a situação mais crítica, para um determinado padrão de segurança, a ocorrência de eventos que se seguidos ou que se sobrepõem não é comumente verificada. Casos muito especificos, como análises de efeitos de ondas de cheia em canais, problemas relacionados a macro-drenagem muito específicos, rompimento de barragens, são as situações mais comuns em que se efetua a avaliação dos efeitos desses eventos.

A proposta de amortecimento estudada, neste trabalho, tem interface direta com o aspecto dessa sopreposição de eventos, uma vez que conta com a geometria da via livre e desimpedida 
em todos as situações de cálculo propostas. Empiricamente, pode-se dizer que o amortecimento é drasticamente reduzido com a ocorrência de eventos consecutivos, já que parte da seção da via que estaria disponível para cumprir o papel de reter parcela do volume precipitado, estando ocupada, não mais desempenhará o mesmo efeito no armazenamento temporário.

Em termos práticos, a sobreposiçao de eventos pode ser entendida e então discretizada, como uma "ocupação prévia" da seção da via, da galeria ou de qualquer elemento de drenagem superficial. Em complemento a essa proposição, a ocupação prévia da via também pode ser entendida como qualquer elemento, seja ele lâmina d'água de um evento anterior ou mesmo a presença de sedimentos ao longo de uma sarjeta, que, ocupando determinada área da seção transversal reduz a capacidade de amortecimento/condução da mesma.

Isto posto, a avaliação do impacto ocorrido pela sobreposição de eventos parte do princípio de que esse fenômeno é discretizado pela presença de uma vazão prévia, ou o que chamaremos a partir de agora de uma vazão de base $\left(Q_{b}\right)$. Esta vazão de base $\left(Q_{b}\right)$ é entendida como uma ocupação inicial da seção transversal, ou seja uma lâmina d'água pré-existente $\left(h_{b}\right)$. Esta lâmina inicial $\left(h_{b}\right)$ pode ser transformada em vazão pelas equações conhecidas da hidráulica. A figura 59 a seguir ilustra o explanado acima:

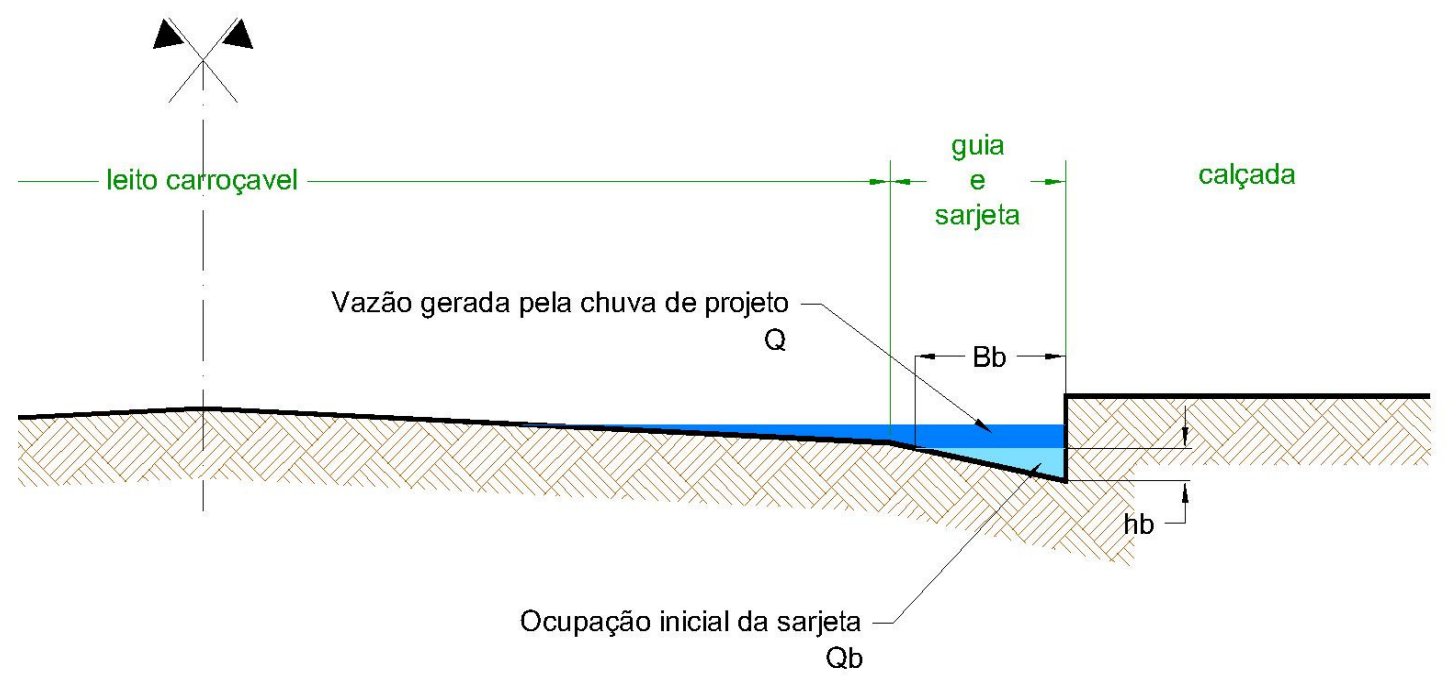

Figura 59: Discretização de lâmina de água pré-existente

Deve-se notar neste ponto que uma altura inicial $h_{b}$, pode facilmente, com a aplicação da equação de Manning ser transformada em uma vazão $Q_{b}$. O inverso também pode ser feito. 
O princípio da avaliação do efeito da sobreposição de eventos no amortecimento superficial é baseado então na relação entre Vazão de Projeto e Vazão de Base $\left(Q_{0}\right.$ e $\left.Q_{b}\right)$. É de se supor então que a relação de amortecimento proposta neste trabalho, para a situação sem vazão inicial deva agora, considerando-se que exista uma vazão prévia ocupando a seção da via, ser alterada por um fator de correção. Fator de correção este que deverá diminuir o amortecimento.

O fator de correção proposto é então, função de:

$\boldsymbol{Q b}=$ vazão de base ou vazão geradora de ocupação prévia da sarjeta e suas características:

$\boldsymbol{S}_{\mathbf{0}}=$ declividade longitudinal da rua;

$\Delta \boldsymbol{x}=$ extensão da rua;

$\boldsymbol{h}_{\boldsymbol{b}}=$ altura da lamina de água em relação à vertical, contando do ponto mais baixo da sarjeta;

$\boldsymbol{n}$ = rugosidade característica da seção transversal estudada, descrita pelo fator de atrito f;

$\boldsymbol{B}_{\boldsymbol{b}}=$ largura da lâmina de água superficial;

$\boldsymbol{V}_{\mathbf{0} \boldsymbol{b}}=$ velocidade de escoamento da vazão na seção transversal de estudo;

$\boldsymbol{t}_{\boldsymbol{c}}=$ tempo de concentração.

$\boldsymbol{Q}_{\mathbf{0}} / \boldsymbol{Q}_{\boldsymbol{b}}=$ relação entre $Q_{0}$ e $Q_{b}$;

A relação $\boldsymbol{Q}_{0}$ e $\boldsymbol{Q}_{b}$ é fundamental na avaliação do impacto no efeito de amortecimento causado por uma ocupação prévia na seção da via. $\mathrm{O}$ fator de correção do amortecimento então deve ser equacionado tomando-se como parâmetros intervenientes, aqueles listado anteriormente, porém verificados e calculados para a vazão de base $\boldsymbol{Q}_{b}$. Em complemento a essa constatação, deve-se ter mente que a vazão de base $\boldsymbol{Q}_{b}$ deve relacionar-se com a vazão de projeto $\boldsymbol{Q}_{0}$ e esta relação é que deve ser relacionada com o fator de correção.

Para que pudesse ser verificado qual o impacto ou qual a correção a ser feita no amortecimento que sofre a interferência de uma vazão prévia (ou ocupação prévia) foram feitas simulações hidrodinâmicas com vazões de base e de projeto cuja relação $\boldsymbol{Q}_{0} / \boldsymbol{Q}_{\boldsymbol{b}}$ variou entre os valores de $25 \%, 50 \%$ e $75 \%$. As mesmas condições do estudo de amortecimento inicial foram propostas nesta verificação, ou seja:

a) Três diferentes tempos de concentração foram considerados para a vazão de base e de projeto; 
b) A extensão da via estudada também foi de 500 metros;

c) O adimensional $\emptyset$ foi calculado para a vazão de base;

d) Foram simuladas as novas condições de amortecimento para três diferentes declividades, com a mesma variação do modelo principal;

e) As simulações foram feitas com duas diferentes vazões de projeto, sendo $0,1 \mathrm{~m}^{3} / \mathrm{s}$ e 0,4 $m^{3} / s$;

f) A seção transversal de estudo é a mesma adotada no modelo principal.

As simulações hidrodinâmicas foram feitas com o uso do Software HEC-RAS, e os resultados apesentados, com a envoltória de máximos, foram tabelados tendo o seu comportamento equacionado de modo a se identificar alguma tendência matemática do fator de correção do amortecimento.

Assim como no estudo principal, o adimensional $\emptyset$ é um dos elementos na equação de correção do amortecimento. Como trata-se de fator corretivo que é função direta da área de amortecimento necessária, propôs-se que o adimensional fosse corrigido pelo produto deste com a relação $Q_{0} / Q_{b}$. Desta forma, o fator de correção do amortecimento, para o caso de ocupação prévia da sarjeta, é proposto com a forma:

$$
\boldsymbol{f} \boldsymbol{c}=\boldsymbol{A} \cdot\left(\varnothing \boldsymbol{b} \cdot \frac{\boldsymbol{Q}_{\boldsymbol{o}}}{\boldsymbol{Q}_{\boldsymbol{b}}}\right)^{k}-1
$$

em que:

$f c=$ fator de correção do amortecimento, função de uma vazão pré-existente;

$Q_{0}=$ vazão de projeto;

$Q_{b}=$ vazão de base ou vazão que gera ocupação prévia da seção da rua;

$\emptyset b=$ Adimensional calculado com as características do escoamento de base, dado por:

$$
\emptyset b=\frac{B_{b}}{h_{b}} \cdot \sqrt{\frac{S_{0}}{f}} \cdot \frac{V_{b} \cdot t_{c}}{\Delta x}
$$


A equação 89 tem os mesmos parâmetros propostos para o índice $\emptyset$ do modelo principal. Da mesma forma o coeficiente de atrito $f$ é determinado tendo como dados de entrada aqueles determinados pelas características hidrogeométricas da seção ocupada pela vazão de base.

As diferentes simulações foram tabuladas como modelo de planilha semelhante a tabela 29, abaixo e o gráfico obtido confirma o comportamento exponencial do fator de correção sugerido:

Tabela 29: Simulação de sobreposição de eventos para via com 0,0015m/m

\begin{tabular}{|c|c|c|c|c|c|c|c|c|}
\hline & & $Q o=$ & 0,1 & $m^{3} / s$ & & & & \\
\hline Qb/Qo & $\begin{array}{l}Q \text { base } \\
\left(\mathbf{m}^{3} / \mathbf{s}\right)\end{array}$ & $\begin{array}{l}\text { Tc } \\
(\mathbf{m i n})\end{array}$ & $\begin{array}{l}Q_{\text {amort2 }} \\
\left(\mathbf{m}^{3} / \mathbf{s}\right)\end{array}$ & $\mathbf{Q}_{\text {amort2 }} / \mathbf{Q}_{\mathbf{0}}$ & $\mathbf{Q} \mathbf{Q}_{\mathbf{0}}$ & $\begin{array}{l}\text { Fator de } \\
\text { correção }\end{array}$ & $\emptyset b$ & $\varnothing b \cdot \frac{Q_{o}}{Q_{b}}$ \\
\hline 0,250 & 0,025 & 10 & 0,054 & 0,541 & 0,170 & 3,2 & 1,6 & 6,5 \\
\hline 0,500 & 0,050 & 10 & 0,070 & 0,700 & 0,170 & 4,1 & 2,1 & 4,3 \\
\hline 0,750 & 0,075 & 10 & 0,090 & 0,900 & 0,170 & 5,3 & 2,5 & 3,4 \\
\hline 0,250 & 0,025 & 30 & 0,083 & 0,837 & 0,763 & 1,1 & 4,8 & 19,5 \\
\hline 0,500 & 0,05 & 30 & 0,089 & 0,895 & 0,763 & 1,2 & 6,4 & 12,9 \\
\hline 0,750 & 0,075 & 30 & 0,094 & 0,948 & 0,763 & 1,2 & 7,5 & 10,1 \\
\hline 0,250 & 0,025 & 60 & 0,092 & 0,922 & 0,896 & 1,0 & 9,7 & 39,0 \\
\hline 0,500 & 0,05 & 60 & 0,094 & 0,946 & 0,896 & 1,1 & 12,9 & 25,8 \\
\hline 0,750 & 0,075 & 60 & 0,097 & 0,974 & 0,896 & 1,1 & 15,0 & 20,1 \\
\hline
\end{tabular}

Fator de correção de amortecimento (situações com vazão de base) - VIA COM 0,0015m/m

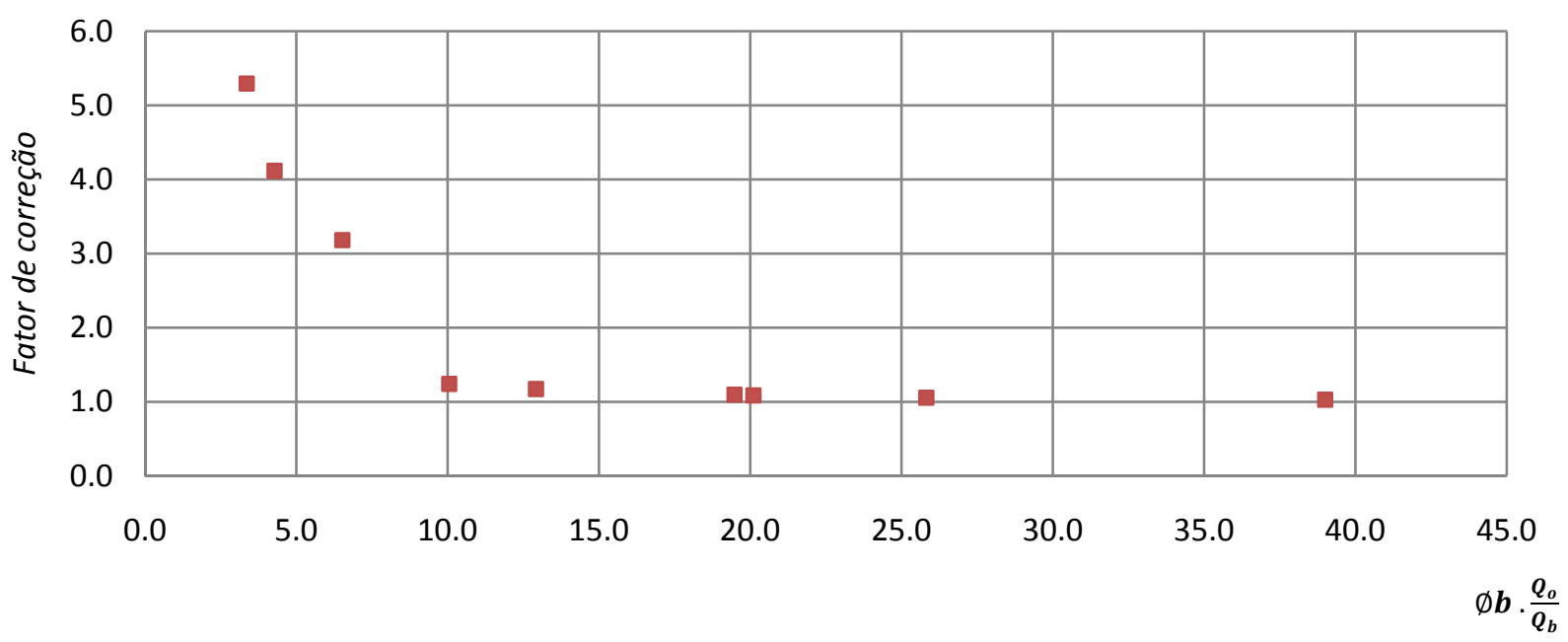

Figura 60: Gráfico com o comportamento exponencial do fator de correção 
Para cada declividade de rua e cada vazão $Q_{0}$ simulada, foi obtido um gráfico semelhante ao da figura 60, que justapostos, formam o gráfico da figura 61 que demonstra o comportamento do fator de correção para a situação geral de projeto.

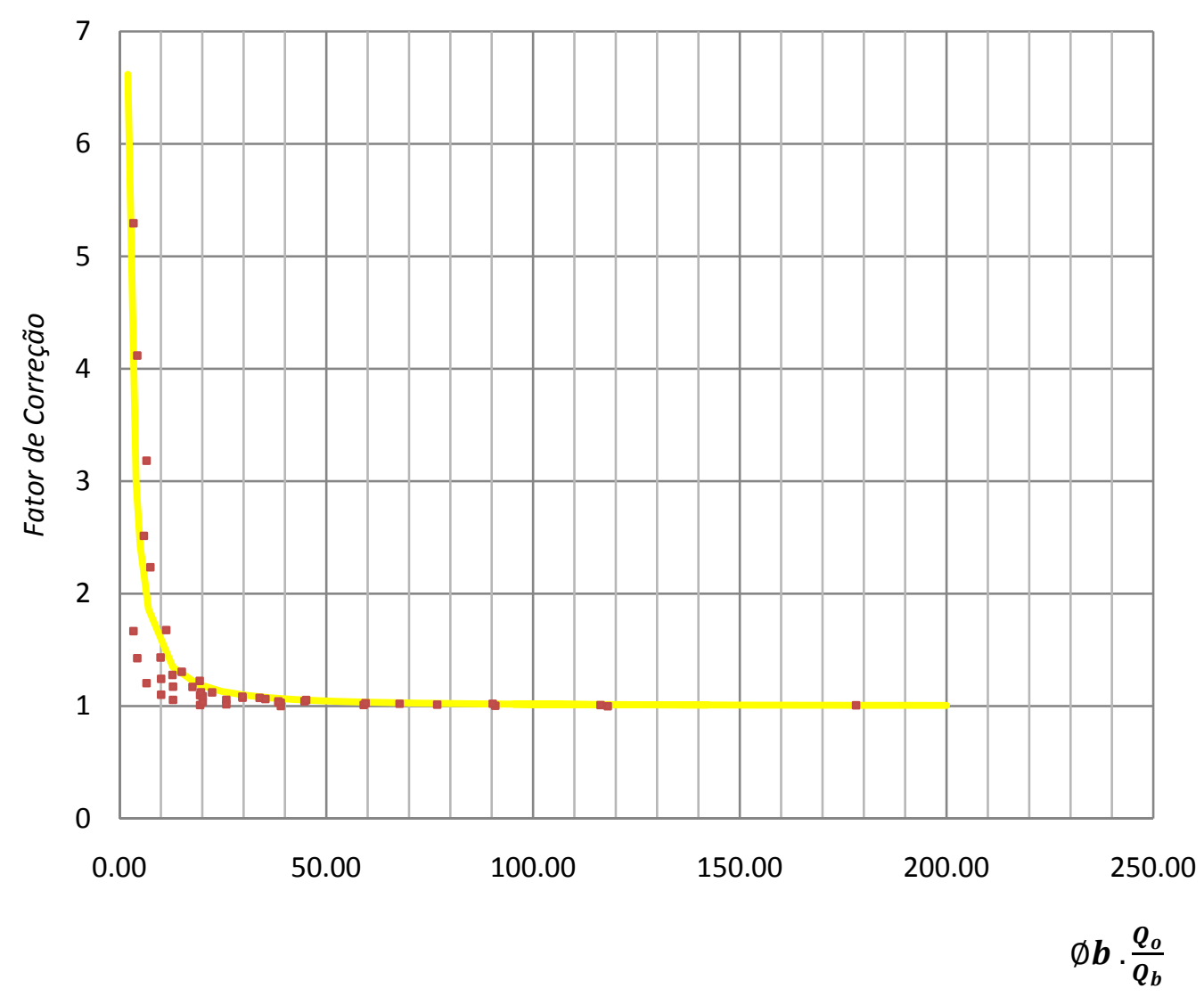

Figura 61: Gráfico com todas as simulações propostas indicando o comportamento matemático do fator de correção

O comportamento geral pode ser então descrito pela equação inicialmente proposta, ficando os índices $A$ e $k$, com a otimização dos resultados, com a forma:

$$
f c=15,842 \cdot\left(\varnothing b \cdot \frac{Q_{o}}{Q_{b}}\right)^{-1,49561}-1
$$

eq. 90

A curva teórica do Fator de correção fica como o gráfico da figura 62: 


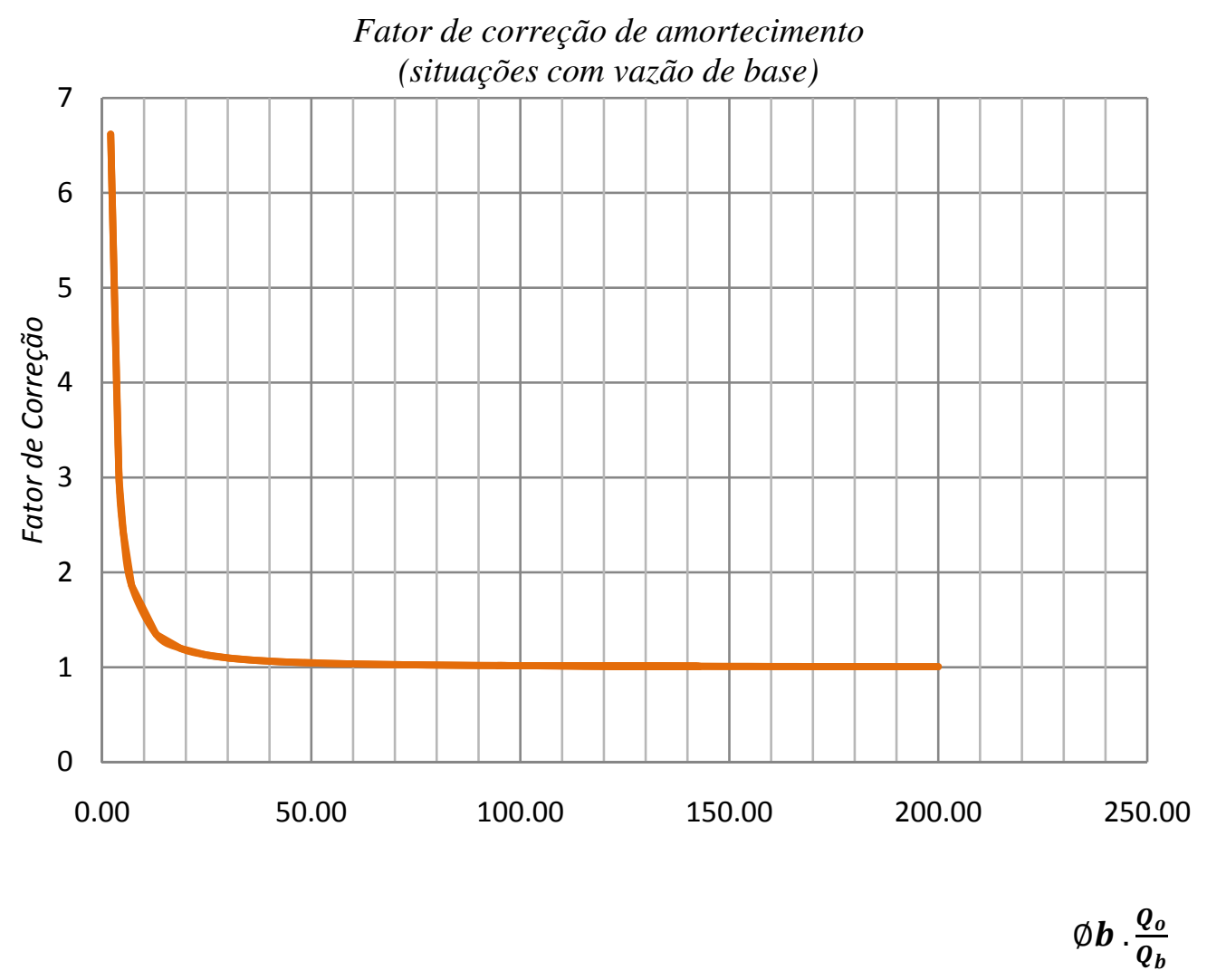

Figura 62: Gráfico com a curva teórica do fator de correção do amortecimento

O amortecimento superficial é afetado pela existência de lamina pré-existente e tal efeito pode ser avaliado, admitindo-se que:

- a lâmina pré-existente pode ser discretizada por meio de uma vazão pré-existente, onde os dados de tempo de concentração,velocidade e lâmina são mensuráveis;

- a relação entre a vazão de projeto e a vazão gerada pela lâmina d'água pré-existente é menor que 1, ou seja: $Q_{b} / Q_{0}<1$.

Os padrões e critérios para a avaliação da ocorrência de eventos que se sobrepõem, deve ser feita pelo projetista, que deve observar as peculiaridades locais, não sendo objeto deste trabalho tal indicação ou prescrição. O efeito negativo sobre o amortecimento foi alertado e de certa forma equacionado, cabendo agora que casos especiais sejam avaliados um a um. 


\section{APLICAÇÕES}

O modelo para a averiguação do amortecimento proposto foi verificado por meio de dois exemplos de aplicação simples, sendo que em um deles (experiência de Izzard), os resultados eram conhecidos. A aplicação ampla do que fora aqui discutido pode ser feita de modo teórico comprovando numericamente as vantagens deste tipo de enfoque.

Antes que se faça qualquer avaliação em estudos de casos específicos, deve-se, no entanto dissertar sobre as condições de funcionamento de um sistema de micro-drenagem superficial. Os sistemas de micro-drenagem superficial, de modo geral, são dimensionados para atender a eventos com período de retorno pequeno, usualmente até 10 anos. As ocasiões em que a verificação para os períodos de retorno maiores são, geralmente, raras ou até mesmo não existem, ficando a cargo dos estudos de Macro-Drenagem.

O que ocorre na prática é que os elementos de micro-drenagem, e em especial nas seções das vias (guias, sarjetas, galerias, etc.) ficam expostos a quaisquer eventos, de maior ou menor intensidade. Eventos com períodos de Retorno da ordem de 50 ou 100 anos, podem inevitavelmente ocorrer e desta constatação é que se pode falar da necessidade da existência de um "Sistema de emergência" que possa comportar esse evento de maior intensidade.

O chamado Sistema de Emergência, ou Major System, como citado em artigos da EPA (Environmental Protection Agency), é composto pelos elementos de drenagem superficial, responsáveis pela condução/armazenamento temporário dos volumes precipitados por ocasião da ocorrência de eventos cujo período de recorrência é superior ao daquele usado para o dimensionamento do sistema. Na prática, a existência de sistemas de emergência é possível admitindo-se algumas premissas, como:

- armazenamento temporário pode ocorrer tanto em áreas destinadas a esse propósito, quanto naquelas em que a interrupção não gera grandes danos;

- estabelecimento de soleiras das edificações em níveis mais altos que o das guias ou que os níveis d'água de projeto;

- permitindo que as seções das vias possam funcionar como canais aberto, estabelecendo critérios, conforme tipo de uso da via, de modo a otimização tal uso. 
Um sistema de drenagem superficial pode ser considerado ideal então, quando consegue conjugar os dois sistemas: o de emergência e o normal, de modo simultâneo. Neste caso, o que se considera é que o sistema normal pode controlar e transportar as vazões geradas pelos eventos de menor porte, com vistas a minimizar possíveis interrupções ou transtornos aos seus usuários quando da ocorrência dos eventos de maior intensidade. Os elementos de um sistema de emergência são então projetados, em complemento ao sistema normal, tendo-se como premissa de que temporariamente poderá haver interrupções de uso de vias, por exemplo. Deve-se ter em mente, no entanto que tais eventos, uma vez que são mais intensos, são também mais raros e tais interrupções não terão a freqüência que possa ser considerada significativa.

Os componentes dos sistemas de drenagem superficial podem ser analisados sob a perspectiva de seu funcionamento, se é adequado ou não, e da importância relativa do seu funcionamento sob cada uma das duas condições de funcionamento: a normal e a de emergência. Como exemplo prático pode ser citadas as bocas-de-lobo distribuídas ao longo de uma rua; de modo geral estas são projetadas para captar toda a vazão produzida pela precipitação de projeto, e no caso de eventos de maior intensidade, permitem que parte do volume seja detido temporariamente na rua.

As seções das vias são então os elementos chave dos sistemas de amortecimento das vazões, sejam aqueles produzidos pelos eventos normais, sejam aquelas produzidas pelos eventos de maior período de retorno e que, portanto irão utilizar os "sistemas de emergência".
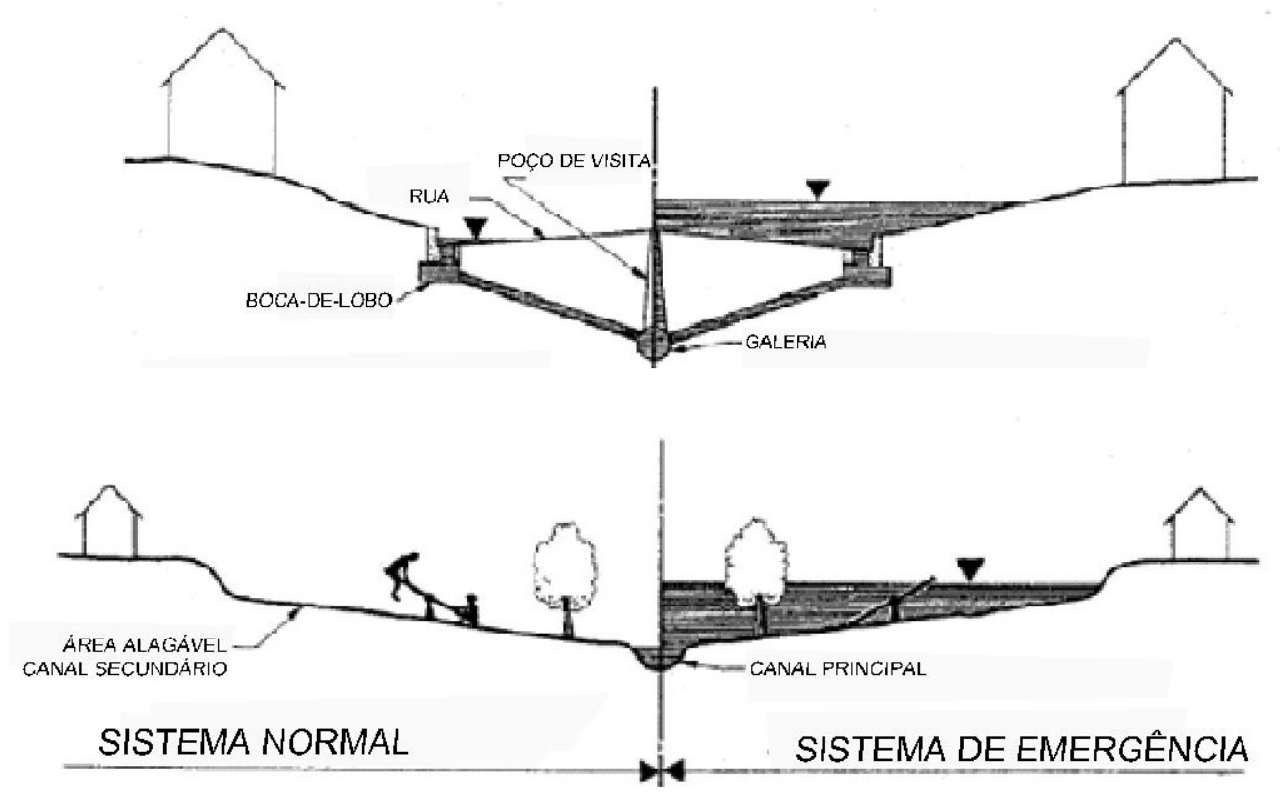

Figura 63:Indicação dos sistemas de emergência e normal - fonte: EPA,2000 
O amortecimento ocorrido pelo deslocamento da onda de cheia ao longo da seção das vias, objeto deste trabalho, produz, como consequiência, redução no período de retorno equivalente a vazão amortecida. Esse efeito pode ser entendido como parte do sistema de emergência citado pela EPA. Simulações de amortecimento, considerando o método de avaliação do amortecimento foram feitas, e os resultados tabelados de modo a verificar-se tendência de redução do período de retorno de vazões. O gráfico da figura 63 , representa a envoltória com a tendência de redução de TR:

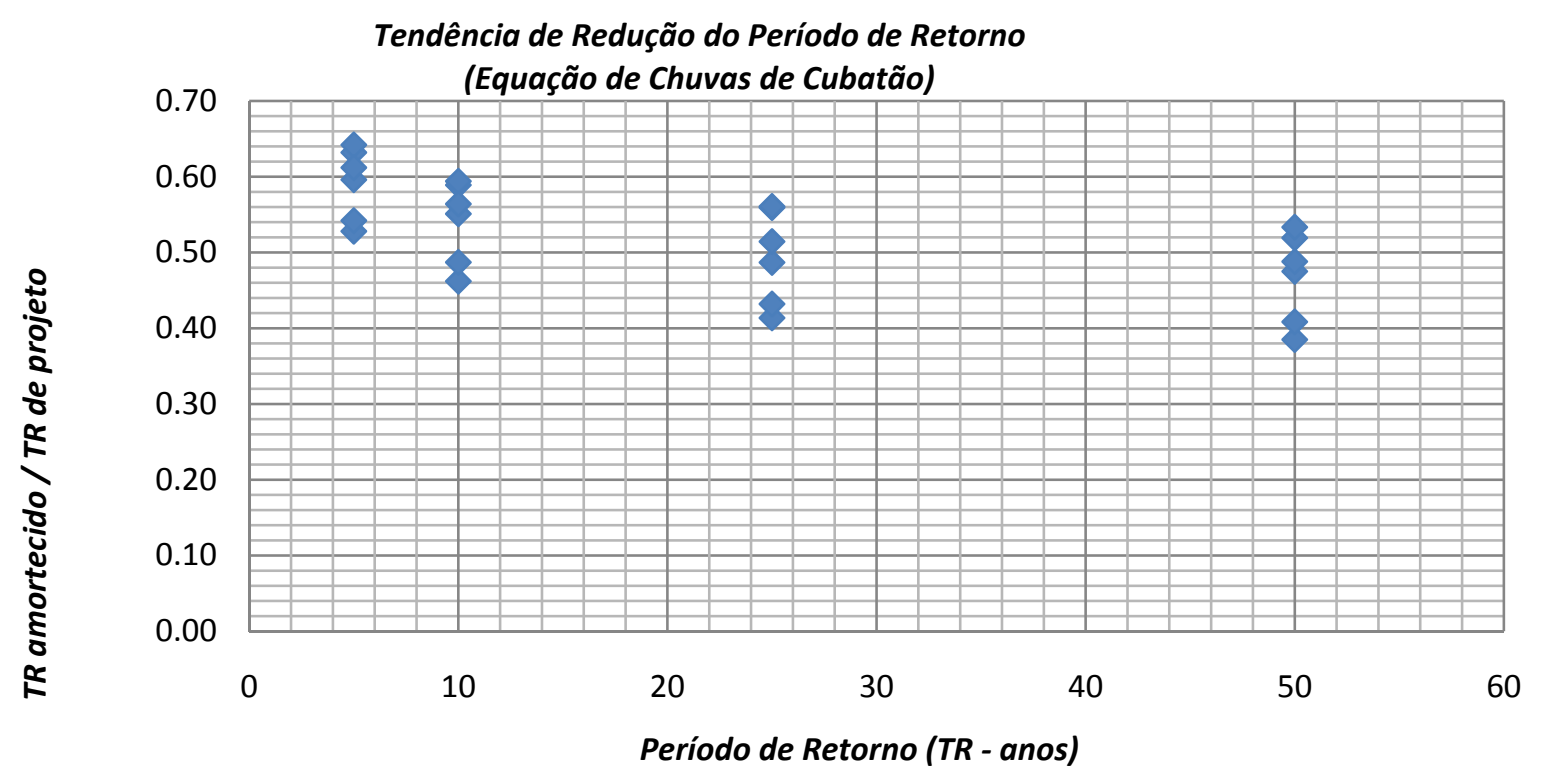

Figura 64: Curva envoltória da tendência de amortecimento de vazão da rua modelo

A disposição dos pontos do gráfico da figura 64 indica existir uma tendência de amortecimento que é função do período de retorno, sendo esta menor quanto maior o TR. A envoltória de redução do período de retorno, para o modelo aqui proposto, flutuou entre 0,385 e 0,642, o que significa dizer por exemplo, que uma vazão de período de retorno de 50 anos, amortecida, passa a ser equivalente a uma vazão de período de retorno igual a 19 anos. Assim como uma vazão de TR $=5$ anos tenha um amortecimento, reduzindo-se a uma vazão cujo período de retorno equivalente a 3 anos. Essas reduções, bastante consideráveis, viabilizam o uso do conceito do amortecimento superficial como forma de criar os sistemas emergenciais em drenagem superficial. 
Demonstra-se ,assim, a diferença de enfoques entre a experiência americana, exposta no artigo de Walesh, para os distritos de Skokie e Wilmete, e o proposto neste trabalho: o amortecimento aqui criado ocorre com a translação da onda de cheia e não com a sua detenção temporária, o que representa vantagem considerável.

Para a aplicação do estudo desenvolvido neste trabalho foram escolhidas, algumas vias do Bairro Nova Mirim, no município de Praia Grande. Foram escolhidas as vias que escoam em direção ao macro-dreno denominado Canal Acaraú-Mirim. O mapa esquemático da figura 65 indica a bacia de drenagem, que contribui para o trecho de montante do referido canal. Dentre as ruas e trechos de ruas que compreendem a bacia a ser estudada, a Avenida Julio Prestes de Albuquerque não foi dimensionada considerando amortecimento, por tratar-se de via principal de tráfego, não sendo admitida a formação de lâmina d'água que possa interromper o trânsito dos veículos.

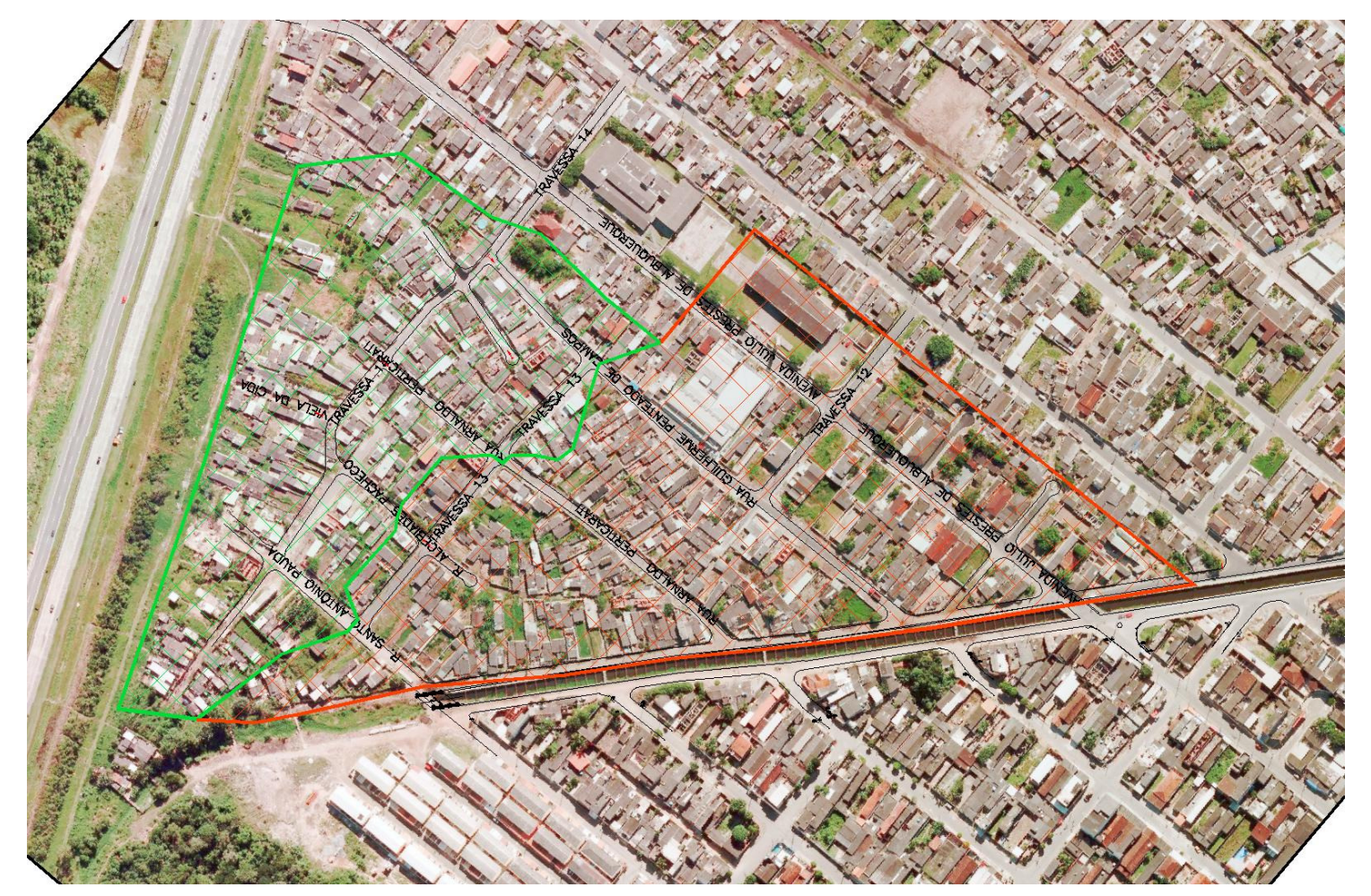

Figura 65: Trecho do Bairro Mirim com indicação das bacias de contribuição

Fonte: PMPG-Google-abr/2011

Do trecho que drena em direção ao canal Acaraú-Mirim (em vermelho), estão identificadas então as ruas e suas respectivas bacias de contribuição na figura 66. Indicadas com setas em vermelho estão os sentidos de escoamento, que equivalem aos trechos sem galeria. Em azul está traçada a galeria de concreto. 


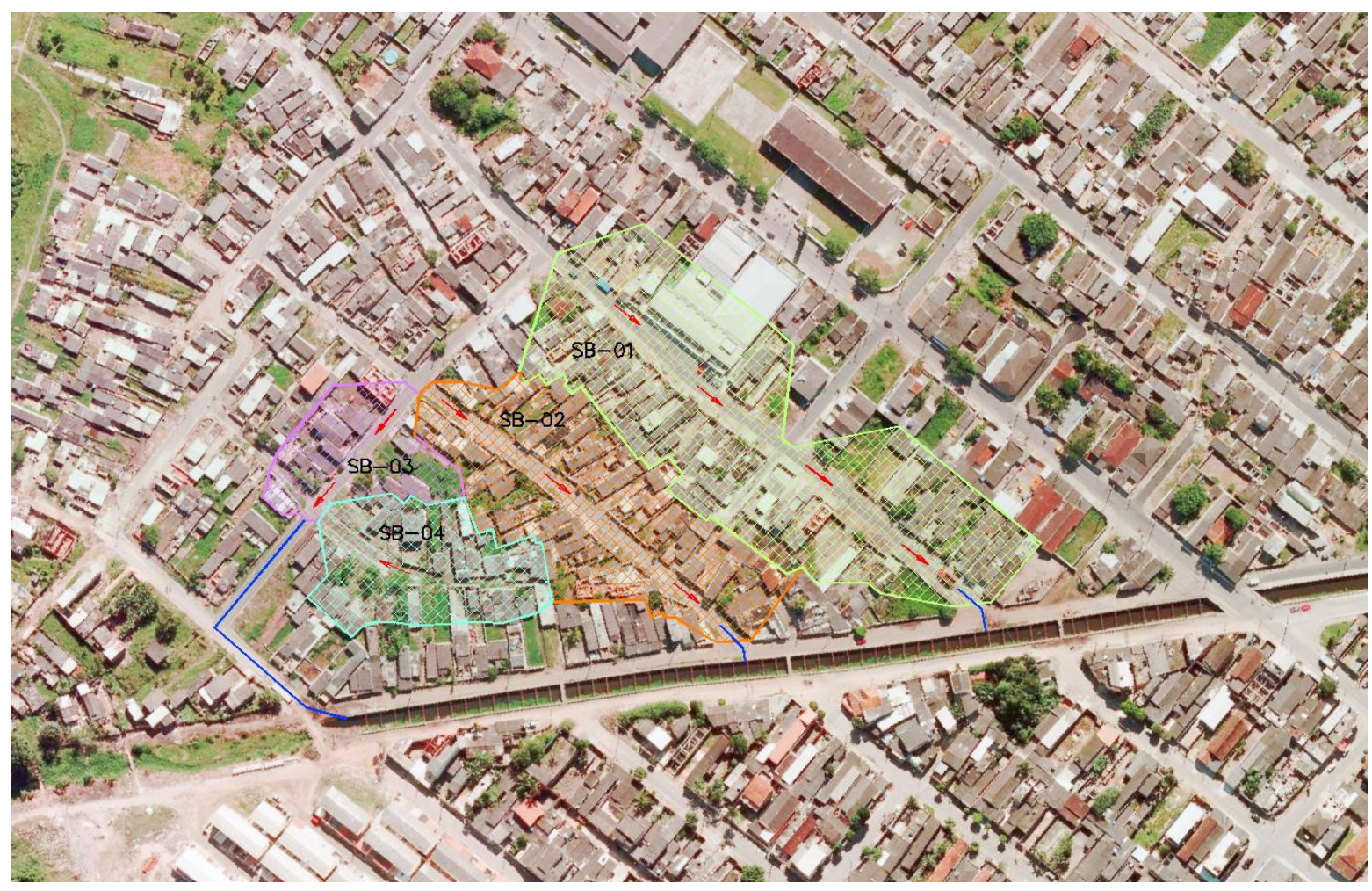

Figura 66: Indicação das sub-bacias das ruas objeto do estudo

Fonte: PMPG-Google - abr/2011

As ruas selecionadas, em número de quatro, com o dimensionamento com o método racional, considerando diferentes Períodos de Retorno. As tabelas 30 e 31 contêm os resultados dos cálculos, assim como as características das bacias:

Tabela 30: Dados hidrológicos da área de aplicação do modelo, Vazão para TR 5 anos:

\begin{tabular}{ccccccccc}
\hline Sub-bacia & $\begin{array}{c}\text { Área } \\
\text { ha }\end{array}$ & $\begin{array}{c}\text { Extensão } \\
\mathbf{m}\end{array}$ & $\begin{array}{c}\text { Declividade } \\
\mathbf{m} / \mathbf{m}\end{array}$ & $\begin{array}{c}\text { tc } \\
\mathbf{m i n}\end{array}$ & $\begin{array}{c}\text { TR } \\
\text { anos }\end{array}$ & $\begin{array}{c}\text { Intensidade } \\
\mathbf{m m} / \mathbf{h}\end{array}$ & $\begin{array}{c}\text { run-off } \\
\text { vazão } \\
\mathbf{1 / s}\end{array}$ \\
\hline 1 & 1,4519 & 225 & 0,0015 & 15,46 & 5 & 361,32 & 0,71 & 372,463 \\
2 & 0,8718 & 167 & 0,0018 & 11,46 & 5 & 394,93 & 0,71 & 244,451 \\
3 & 0,4375 & 70,5 & 0,0015 & 10,00 & 5 & 409,08 & 0,71 & 127,070 \\
4 & 0,3054 & 57 & 0,0021 & 10,00 & 5 & 409,08 & 0,71 & 88,702 \\
\hline
\end{tabular}

Tabela 31: Dados hidrológicos da área de aplicação do modelo, Vazão para TR 10 anos:

\begin{tabular}{ccccccccc}
\hline Sub-bacia & $\begin{array}{c}\text { Área } \\
\text { ha }\end{array}$ & $\begin{array}{c}\text { Extensão } \\
\mathbf{m}\end{array}$ & $\begin{array}{c}\text { Declividade } \\
\mathbf{m} / \mathbf{m}\end{array}$ & $\begin{array}{c}\text { tc } \\
\mathbf{m i n}\end{array}$ & $\begin{array}{c}\text { TR } \\
\text { anos }\end{array}$ & $\begin{array}{c}\text { Intensidade } \\
\mathbf{m m} / \mathbf{h}\end{array}$ & $\begin{array}{c}\text { Run- } \\
\text { off }\end{array}$ & $\begin{array}{c}\text { vazão } \\
\mathbf{1 / s}\end{array}$ \\
\hline 1 & 1,4519 & 225 & 0,0015 & 15,46 & 10 & 419,83 & 0,71 & 432,785 \\
2 & 0,8718 & 167 & 0,0018 & 11,46 & 10 & 458,60 & 0,71 & 283,865 \\
3 & 0,4375 & 70,5 & 0,0015 & 10,00 & 10 & 474,92 & 0,71 & 147,522 \\
4 & 0,3054 & 57 & 0,0021 & 10,00 & 10 & 474,92 & 0,71 & 102,979 \\
\hline
\end{tabular}


Com a aplicação do método para avaliação do amortecimento superficial, foram obtidos os resultados apresentados nas tabelas 32 e 33:

Tabela 32: Resultados de amortecimento de vazão nas ruas estudadas - TR 5anos

\begin{tabular}{rccccccc}
\hline $\begin{array}{c}\text { Sub- } \\
\text { bacia }\end{array}$ & $\begin{array}{c}\text { Extensão } \\
\mathbf{m}\end{array}$ & $\begin{array}{c}\text { tc } \\
\mathbf{m i n}\end{array}$ & $\begin{array}{c}\text { Vazão } \\
\mathbf{m}^{\mathbf{3} / \mathbf{s}}\end{array}$ & $\begin{array}{c}\text { Declividade } \\
\mathbf{m} / \mathbf{m}\end{array}$ & $\begin{array}{c}\text { Vazão } \\
\mathbf{m}^{\mathbf{3}} \mathbf{s}\end{array}$ & $\begin{array}{c}\text { TR } \\
\mathbf{Q}_{\mathbf{0}}\end{array}$ & $\begin{array}{c}\text { TR } \\
\text { equivalente }\end{array}$ \\
\hline 1 & 225 & 15,46 & 0,372 & 0,0015 & 0,307 & 5 & 2,52 \\
2 & 167 & 11,46 & 0,244 & 0,0018 & 0,198 & 5 & 2,40 \\
3 & 70,5 & 10,00 & 0,127 & 0,0015 & 0,111 & 5 & 3,02 \\
4 & 57 & 10,00 & 0,089 & 0,0021 & 0,082 & 5 & 3,67 \\
\hline
\end{tabular}

Tabela 33: Resultados de amortecimento de vazão nas ruas estudadas - TR 10anos

\begin{tabular}{cccccccc}
\hline $\begin{array}{c}\text { Sub- } \\
\text { bacia }\end{array}$ & $\begin{array}{c}\text { Extensão } \\
\mathbf{m}\end{array}$ & $\begin{array}{c}\text { tc } \\
\mathbf{m i n}\end{array}$ & $\begin{array}{c}\text { Vazão } \\
\mathbf{m}^{\mathbf{3}} / \mathbf{s}\end{array}$ & $\begin{array}{c}\text { Declividade } \\
\mathbf{m} / \mathbf{m}\end{array}$ & $\begin{array}{c}\text { Vazão } \\
\mathbf{m}^{3} / \mathbf{s}\end{array}$ & $\begin{array}{c}\text { TR } \\
\mathbf{Q}_{\mathbf{0}}\end{array}$ & $\begin{array}{c}\text { TR } \\
\text { equivalente }\end{array}$ \\
\hline 1 & 225 & 15,46 & 0,433 & 0,0015 & 0,360 & 10 & 4,40 \\
2 & 167 & 11,46 & 0,284 & 0,0018 & 0,234 & 10 & 4,20 \\
3 & 70,5 & 10,00 & 0,148 & 0,0015 & 0,131 & 10 & 5,60 \\
4 & 57 & 10,00 & 0,103 & 0,0021 & 0,938 & 10 & 6,40 \\
\hline
\end{tabular}

A análise dos resultados em termos de parcela de vazão reduzida é num primeiro momento de pouca significância. Por esta razão a verificação do Período de Retorno equivalente torna-se mais relevante. Notar por exemplo que a vazão de pico da sub-bacia 1 para um período de retorno de 10 anos, com o amortecimento que ocorre durante o escoamento na via, é reduzida a valor equivalente a uma vazão com período de retorno de 5 anos.

Os resultados podem ser interpretados e utilizados sob dois pontos de vista:

1) Manutenção dos critérios de dimensionamento dos elementos de drenagem, ou seja, as galerias e bocas de lobo serão dimensionados para a vazão $Q_{0}$, sem consideração do amortecimento, considerando-se que, com o efeito de amortecimento o sistema de drenagem está verificado para o Período de Retorno maior;

2) Alteração das vazões de dimensionamento dos elementos de drenagem de jusante, ou seja, galerias e bocas-de-lobo, que, por efeito do amortecimento, receberão vazões menores do que aquelas determinadas pelo método Racional. 
Ambos os casos de critério de aplicação do método, relacionam-se com os critérios de dimensionamento dos elementos de micro-drenagem urbana, desde o seu posicionamento, espaçamento, quantidade e tamanho, gerando redução dos custos de implantação desses sistemas.

A escolha de qualquer um dos critérios acima descritos fica então a cargo do projetista e de sua avaliação da situação local. No caso do presente estudo, as ruas da região foram dimensionadas então para a vazão sem o amortecimento, já que neste caso específico, a diferença no diâmetro dos tubos das galerias seria desprezível, se considerarmos redução nos custos. Outros casos em que a redução da vazão seja mais significativa podem ocorrer e cabe ao projetista efetuar esta avaliação para cada caso específico. 


\section{CONCLUSÕES}

A análise do comportamento hidrodinâmico do caminhamento de uma onda de cheia na calha de uma rua demonstrou que a parcela de vazão amortecida, principalmente naqueles casos em que o tempo de duração do evento é pequeno, representa uma significativa porcentagem de vazão que pode ser engolida pelo sistema de galerias mais lentamente. Esse amortecimento da vazão de pico, que ocorre em vias com declividades inferiores a $0,5 \%$, pode ser então usado como um efeito positivo para o dimensionamento e definição dos elementos de micro-drenagem superficial principalmente quando a técnica é aplicada em regiões planas.

De acordo com a seção típica adotada, neste trabalho, e a simulação do escoamento dos hidrogramas do método Racional, pode-se criar uma relação que representa o comportamento do amortecimento superficial daquelas condições propostas. É de se esperar, no entanto, que o efeito do amortecimento possa seguir lei semelhante mesmo com alteração de alguns dos critérios, como por exemplo, a geometria da seção e a ampliação dos valores do hidrograma. A limitação da lei proposta está na alteração da forma do hidrograma. Espera-se que o amortecimento das vazões de pico de hidrogramas triangulares do método Racional, possam ser determinados pelas curvas deduzidas neste trabalho e indicadas na figura 67.

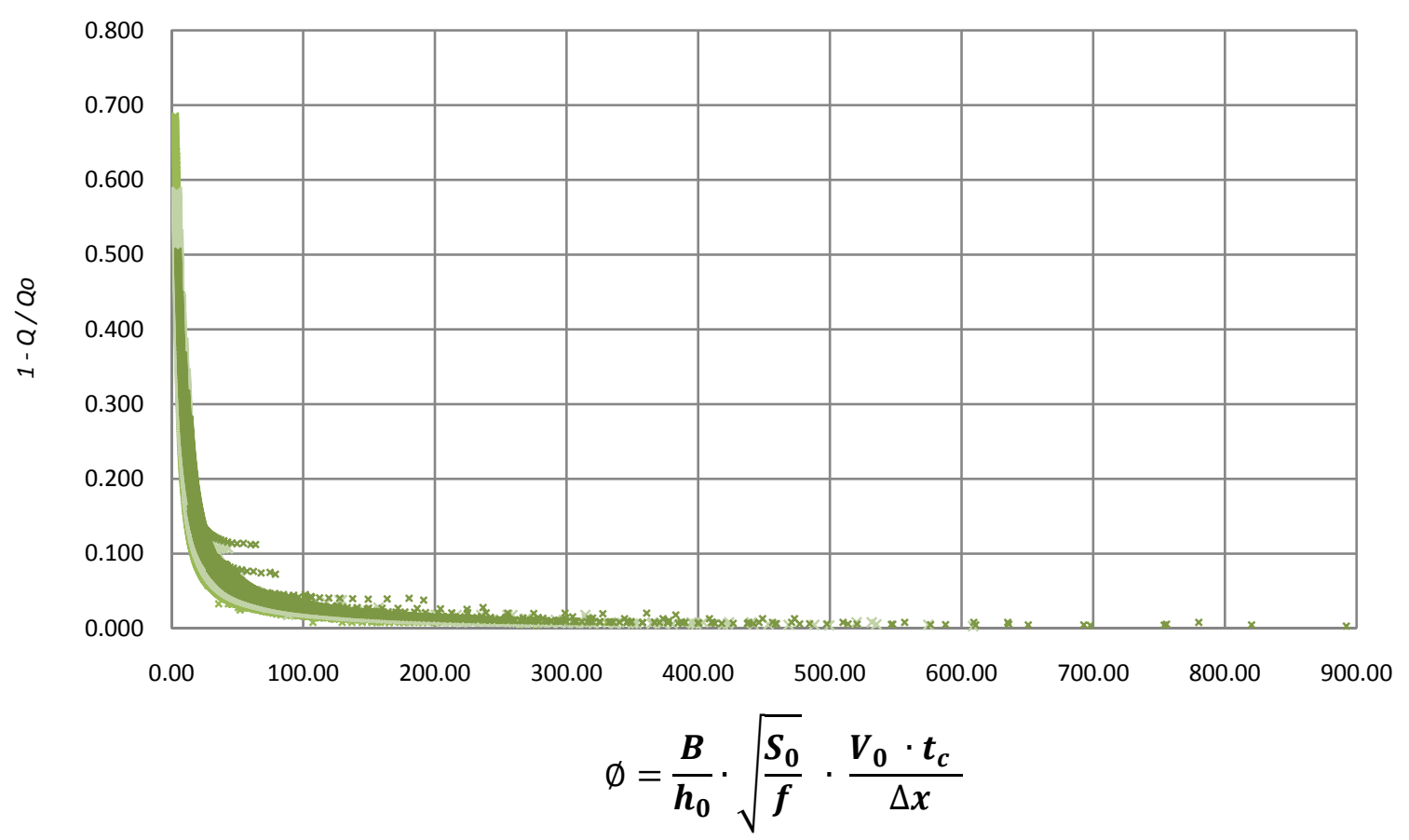

Figura 67: Curva característica do fator de amortecimento para a seção do modelo 
A defasagem observada entre as curva da figura 67 é resultado das diferentes declividades simuladas no modelo hidrodinâmico. Os índices das equação diferenciam-se, como descrito, neste trabalho, conforme a declividade longitudinal. Supõe-se também que exista relação direta com a geometria da seção. Pesquisas, no sentido de melhor determinar a variação dos índices x e y da equação aqui proposta podem então ser feitas. Para ampliar a abrangência do método proposto, cabem recomendações que poderão ser abordadas em estudos futuros:

- avaliação e determinação mais precisa da variação dos índices X e Y da equação de amortecimento; parametrização com a geometria da seção;

- verificação da validade do método para hidrogramas com outros formatos;

- readequação do método para a simulação de eventos sobrepostos, com a avaliação estatística de sua ocorrência.

- aplicação e validação do método para seções de canais de drenagem.

O estudo do escoamento que ocorre em ruas com baixa declividade denota, sob o ponto de vista de hidráulica do escoamento livre, a influência do efeito da rugosidade da parede de conduto no caso de lâminas ou profundidades de escoamento pequenas. Tais situações, geradas pelos deflúvios de curta duração foram os que produziram maior índice de amortecimento.

Ainda que o método aqui proposto não tenha abrangência total, ou seja, nem todas as tipologias de vias podem ser dimensionadas considerando-se tal equacionamento e somente hidrogramas do tipo triangular foram simulados, algumas conclusões podem ser obidas, tais como:

- o amortecimento superficial gerado pelo caminhamento de uma onda de cheia numa seção de via, e aqui cabe também ampliar o conceito para canais, é significativo, principalmente sob o ponto de vista do Período de Retorno;

- a adoção do método implica no reconhecimento de que o efeito de amortecimento tende a anular-se para eventos de chuva com durações maiores que 1 hora; salienta-se no entanto que eventos com durações maiores, de modo geral, tem menor intensidade, cabendo então ao projetista selecionar a situação de projeto que melhor represente ou que melhor se adeque a região de estudo; 
- pode ser estabalecida um relação do tipo potencial que descreve o comportamento do amortecimento superficial em função da geometria da seção e das características do hidrograma triangular do método racional;

- a experiencia tem demonstrado ser eficaz a adoção de declividades inferiores a 0,5\%, com a eliminação dos pontos baixos, naqueles casos de localidades muito planas, já que o efeito empiricamente foi positivo e teoricamente aqui também comprovou-se semelhante vantagem;

- a aplicação do método pode ser feita sob dois pontos de vista: aquele em que reduzem-se as vazões para o dimensionamento de galerias e bocas-de-lobo e aquele em que se verifica a redução do Período de Retorno, com aumento do Período de Projeto; pelo estudo de caso apresentado pode-se dizer que apesar do dimensionamento da Sub-bacia 01 ter sido feito para 5 anos, considerando-se o amortecimento, uma vazão gerada por uma chuva de intensidade equivalente a um período de retorno de até 10 anos está garantida pelo sistema;

- a aplicação do método deve ser precedida com critério e anuência pública, já que, de modo geral, implica em impedimento de uso temporário de vias e logradouros públicos. 


\section{RECOMENDAÇÕES}

A adoção de declividades inferiores aqueles valores tidos como mínimos demonstrou-se, pelo discutido neste trabalho ser de grande eficácia no que se refere à redução das vazões de pico escoadas pelos sistemas de micro-drenagem superficial, principalmente nos leitos de vias urbanas. A utilização do leito carroçável como local para amortecimento dos picos de vazão, no entanto, deve ser feita com cautela e critério. Apesar de, tecnicamente, a solução apresentar diversos pontos a favor, sua aplicação implica em, muitas vezes, conhecimento e aceitação publica.

De um modo geral, ninguém quer "água empoçada" na porta de sua residência. O grande ponto a favor de se limitar a construção de pontos baixos em detrimento da declividade é o fato da formação de lâmina d’água ocorrer apenas durante o evento de chuva. A declividade, ainda que baixa, e por conseqüência, ainda que a velocidade de escoamento seja menor, o verdadeiro "empoçamento" somente poderá ocorrer à jusante da rua, e não em locais intermediários, fato comumente visto.

A EPA em seu artigo "Street Storage System" indica uma técnica aplicada em uma localidade americana que apresentava problemas de sobrecarga da rede mista de coleta de efluentes, onde se usa a calha das vias como bacias de detenção. Os elementos de drenagem foram adaptados de modo a canalizar o volume precipitado às vias previamente dispostas para o amortecimento e detenção das cheias. No caso aqui estudado, apenas o princípio do amortecimento foi considerado. A diferença principal está no fato de que não se pretende reter o volume precipitado em nenhum local ou trecho das via e sim, aproveitar-se do amortecimento que ocorre naturalmente com a propagação da onda de cheia ao longo da seção de uma rua com declividade baixa.

As premissas básicas do armazenamento temporário na superfície é o de temporariamente reter os volumes precipitados, mais próximo da fonte, antes de sua entrada nos sistemas de galerias. Os volumes totais precipitados serão transportados pelas galerias, no entanto, com uma vazão de pico reduzida. Essa redução é maior ou menor em função do tipo de enfoque dado: se, adotada a técnica americana, em que a seção da rua torna-se um reservatório, a redução é maior do que no caso do presente estudo, em que a seção da via torna-se um canal e o amortecimento é função do escoamento. 
Apesar da diferença conceitual, algumas das vantagens destes tipos de enfoque são similares, dentre elas:

- mitigação de problemas relacionados à rede de drenagem funcionando como conduto forçado;

- mitigação dos alagamentos pontuais causados por bueiros elou galerias obstruídas;

- redução nas taxas de poluição difusa, principalmente a presença de sedimentos finos dentro das galerias pluviais, guardados os devidos cuidados de limpeza pública,uma vez que culturamente no país usam-se as bocas-de-lobo como "lixeiras";

- sensível redução das vazões de pico usadas no dimensionamento das galerias pluviais, ou aumento do período de retorno da chuva para a qual o sistema está dimensionado.

Premissas secundárias do amortecimento superficial também diferem entre as duas situações aqui comparadas. Enquanto que na experiência americana da detenção temporária no leito das vias é o de evitar a sobrecarga dos coletores mistos de efluentes, tendo como consequiência o impedimento dos constantes alagamentos dos porões das residências locais; para o caso do amortecimento aqui proposto, ou seja, aquele que ocorre em função do escoamento no leito da via, a objetivo era mitigar a ocorrência dos alagamentos que ocorrem nos pontos baixos gerados em função da necessidade de se manter uma declividade longitudinal mínima. Neste caso, com essa eliminação de pontos baixos, é grande a vantagem sob o ponto de vista dos custos de construção e funcionamento do sistema.

A aplicação do método de amortecimento superficial, seja o do modelo aqui proposto, seja aquele aplicado nas comunidades de Skokie e Wilmette, deve considerar alguns fatores, a saber:

- aceitação pública;

- avaliação dos impactos econômicos na comunidade;

- avaliação econômica e técnica dos impactos na operação e manutenção do sistema;

- avaliação de propensão ao surgimento de reclamações por parte dos usuários.

O que se verificou por meio de pesquisa com os munícipes de Skokie e Wilmette, assim como averiguado informalmente no município de Praia Grande, naqueles bairros onde se optou em sacrificar a declividade longitudinal das vias em detrimento de um escoamento até o 
ponto final de lançamento, é que o armazenamento/amortecimento superficial não é visto como a solução perfeita. De um modo geral a presença de uma lâmina d'água é vista como uma "falha de projeto". Em contrapartida, a presença de lâmina d'água nas vias, após o término do evento de chuva é muito mais criticada do que aquela que ocorre durante o evento. Essa é a principal razão pela qual este tipo de enfoque, em que se aproveita a calha da via para reduzirem-se as vazões encaminhadas ao sistema de galerias, necessita de aprovação e entendimento perante a comunidade a que este serve. 


\section{REFERÊNCIAS BIBLIOGRÁFICAS}

ASCE. (1969). "Design and construction of sanitary and storm sewers". Manuals and Reports of Engineering Pratice $N^{\circ} 37$. New York.

BEDIENT P.B., HUBER, W. C. (1992). "Hidrology and Floodplain Analysis". 2 Edição. New York: Adison Wesley, 315 p.

BEVEN, K. J. (2001). "RainFall-Runoff Modelling - the Primer". Chichesler : John Wiley \& Sons , , 360 p.

BIDONE, R. A.; TUCCI C. E. M. “Microdrenagem”. In: TUCCI, C. E. M.; PORTO, R. L. L.; BARROS, M. T. Drenagem urbana. Porto Alegre: Editora UFRGS/ABRH, (1995). cap. 3, p. 77-105.

CANHOLI, A. P. (1994). “O dimensionamento de soluções não convencionais em drenagem urbana”. In: SEMINÁRIO: HIDRÁULICA COMPUTACIONAL APLICADA A PROBLEMAS DE DRENAGEM URBANA, 1., 1994, São Paulo. 20p

CETESB, (1986). "Drenagem urbana: manual de projetos. São Paulo"; CETESB/ASCETESB.

CETESB/DAEE, (1979). "Drenagem Urbana - Manual de Projeto", CETESB/DAEE, São Paulo.

CHOW, V. T. ; (1959). “Open Channel Hydraulics", McGraw-Hill Book Company, New York

CHOW, V. T. ; MAIDMENT, D. R. ; MAYS, L. W. (1988). “Applied Hidrology” . New York : McGraw-Hill. 572 p.

CIRILO, J.A. (2003). "Hidráulica Aplicada" Coleção ABRH de Recursos Hídricos.Porto Alegre: ABRH. 2 ed., v.8, 621p. Porto Alegre. 
CIRILO, J. A. "Programação Não Linear Aplicada a Recursos Hídricos”, In: PORTO, R. L. L. et al. "Técnicas quantitativas para o gerenciamento de Recursos Hídricos". São Paulo: ABRH/EUFRGS, (1997). 1 ed. cap.6, p.305-360

CONGRESSO BRASILEIRO DE ENGENHARIA SANITÁRIA E AMBIENTAL, 24º, (2007), Belo Horizonte. "O Impacto do Modelo de Cálculo na Capacidade de Dercarga de Sarjetas em Sistemas de Drenagem Urbana”. ABES/ Minas Gerais.

CUNGE, J.A., HOLLY, F.M., VERWEY, A. (1980). “Practical Aspect of Computational River Hidraulics" Maeshfield: Pittman.

DAEE/CETESB. (1980). “Drenagem Urbana”. $2^{\mathrm{a}}$ ed., São Paulo.

DAEE/CETESB. (1986). "Drenagem Urbana: Manual de Projeto", 3a ed., São Paulo, CETESB, 477 p.

DAEE. (1980). “Armazenamento e Drenagem urbana: Manual de projeto”. São Paulo: Departamento de Águas e Energia Elétrica - DAEE / Companhia de Tecnologia de Saneamento Ambiental - CETESB, Cap. X, p. 459-468.

FATTORI, G.F. e BENETTI, A. D., (2000). “O impacto do modelo de cálculo na capacidade de descarga de sarjetas em sistema de drenagem urbana", $2^{\circ}$ Congresso Brasileiro de Engenharia Sanitária e Ambiental, ABES.

FEDERAL AVIATION ADMINISTRATION - Department of Transportation. (1970) "Airport Drainage", AC No. 150/5320-5B.

FENDRICH, R. (2002).”Coleta, armazenamento, utilização e infiltração das águas pluviais na drenagem urbana". Curitiba, 499 p. Tese ( Doutorado em Geologia Ambiental) - Setor de Ciências da Terra, Universidade Federal do Paraná.

FCTH/PMSP. (1999). "Diretrizes básicas para projetos de drenagem urbana no município de São Paulo", edição eletrônica.

FRANCO, E. José, et al.; (2004). "Dimensionamento de Bacias de detenção de águas pluviais com base no método Racional', Curitiba, Mestrado em Engenharia de Recursos Hídricos e Ambiental, Universidade Federal do Paraná. 
GODOI, A. ARTIOLI C.; (2006). "Desempenho dos equipamentos de drenagem urbana da cidade de Franca", São Carlos, Mestrado em Engenharia Civil, Modalidade Transportes, Universidade de São Paulo.

GUO,JAMES C.Y. (2000). "Inundation capacity at street intersection", University of Colorado at Denver, 2001.

GUO, JAMES. C. Y., E URBONAS B. (1996) "Maximized Detention volume determined by runoff capture ratio". Journal of Water Resources, planning and management, ASCE, 122(1), 33-39.

GUO, JAMES. C. Y (1997). "Street hydraulics and inlet sizing”. Water Resources Publication, Littleton, Colorado.

GUO, JAMES. C. Y. (2000), "Street Storm Water Conveyance Capacity". Journal of Irrigation and Drainage Engeeniring, ASC, 126, abril.

GUO, JAMES. C. Y. (2000), "Street Storm Water Storage Capacity”. Journal of Water Environmental Research, ASCE, 72,626.

HEC-RAS. Versão 4.0 Beta, (2006), software livre distribuído pela "U.S. Army Corps of Engineers", dos Estados Unidos.

HENDERSON, F.M. (1966).”Open Channel Flow” New York: Mac Millan

HYDROLOGIC ENGINEERING CENTER (HEC). (2008a). "HEC-RAS River analysis system 4.0- User's manual'. U.S. Army Corps of Engineers, Califórnia.

HYDROLOGIC ENGINEERING CENTER (HEC). (2008a). “HEC-RAS River analysis system 4.0 - Hydraulic Reference Manual". U.S. Army Corps of Engineers, Califórnia.

JI, Z. (1998). "General Hydrodynamic Model for sewer/channel networkssystems. Journal of Hydraulic Engineering”. Reston. vol.124, n³, p.307-315.

LINSLEY R K. ; FRANZINI J. B. (1964) “Water Resources Engineering”. Tokyo : Mc GrowHill

NASCIMENTO, N. O. et al.. (1997). “Estudo de caso de uma bacia de detenção em meio urbano - O caso do reservatório Santa Lúcia”. In: SIMPÓSIO BRASILEIRO 
DE RECURSOS HÍDRICOS, XII, 1997, Vitória. Anais ABRH, CD-ROM, p. $1-9$.

MARTINS, J. R. S. e FADIGA, F. M., (1989) “Rompimento de barragens. Cálculo Adimensional da Propagação da enchente efluente" In:VIII Simpósio Brasileiro de Hidrologia e Recursos Hídricos, 1989, Foz do Iguaçu. Anais do VIII Simpósio Brasileiro de Hidrologia e Recursos Hídricos, 1989.v.2.

MARTINS, J. R. S.et AL. (2003). “Hidrodinâmica das Macro-rugosidades de Fundo em Canais", São Paulo, Doutorado em Engenharia Civil, Escola Politécnica da Universidade de São Paulo.

PALMA, J. (2000). "Da Avaliação de Equipamentos para Drenar a Qualidade de Viagens por Rodovias". São Carlos, Dissertação de Mestrado, Escola de Engenharia de São Carlos, Universidade de São Paulo.

PINTO, N. L. S. "Hidráulica Aplicada" Curitiba: CEHPAR, (1987)

PINTO, N. L. S. (1975) et al..”Vazão de dimensionamento de bueiros" Rio de Janeiro: IPR, Publ. 478, 56p.

PORTO, R. L. (1995) “Escoamento superficial direto". In: TUCCI, C. E. M. et al. Drenagem Urbana. Porto Alegre : ABRH - Editora da Universidade - UFRGS, pp.107-164.

RAUDKIVI, A. J. (1979) “Hidrology” Oxford : Ed., Pergamon Press, 471p.

SCHMITT, T.G. (1986). "An Efficient Method for Dynamic Flow Routing in Storm Sewers". In: Urban Drainage Modelling: Proceedings of the International Symposium on Comparison of Urban Drainage Models with Real Catchment Data. Pergamon Press. p.159-169. Dubrovnik.

TUCCI, C.E.M.; (1993). "Hidrologia: Ciências e Aplicações". EDUSP, Editora da UFRGS, ABRH, 952p.

TUCCI, C.E.M.; (1998). “Modelos hidrológicos”. Editora Universidade/UFRGS/ABRH, Porto Alegre, 669p.

TUCCI, C. E. M.; (2000). “Coeficiente de esgotamento e vazão máxima” RBRHV5 n. 2p. 
TUCCI, C.E.M. (2001). "Hidrologia- Ciências e Aplicações". Editora ND-ABRH.

URBAN DRAINAGE and FLOOD CONTROL DISTRICT. (1992). "Urban Storm Drainage Criteria manual". Vol.3 - Best Management Practices. Urban Drainage and Flood Control District, Denver, Colorado.

URBAN DRAINAGE and FLOOD CONTROL DISTRICT. (1969). "Storm Water Drainage Design Criteria Manual" Vol.1 e 2 - Denver, Colorado.

US DEPARTMENT OF TRANSPORTATION, FEDERAL HIGHWAYS ADMINISTRATION, (1984) "Drainage of Highway Pavements", Hydraulic Engineering Circular No. 12, May.

US DEPARTMENT OF TRANSPORTATION, FEDERAL HIGHWAYS ADMINISTRATION, (1979) "Design of Urban Highway Drainage", The State of the Art, August .

VIEIRA DA SILVA, R.C.; MASCARENHAS, F.C.B.; MIGUEZ, M.G..(2003) "Hidráulica Fluvial". COPPE/UFRJ. 304p. Rio de Janeiro.

VILLANUEVA, A.O.N. (1990). "Modelo para escoamento não-permanente em uma rede de condutos". Porto Alegre: UFRGS - Programa de Pós-Graduação em Engenharia de Recursos Hídricos e Saneamento Ambiental.83 p. Dissertação (Mestrado Engenharia). Porto Alegre.

VILlELA, S. M.; MATTOS A.,(1975) “Hidrologia Aplicada" São Paulo: Ed. McGrawHill do Brasil Ltda,. 239p.

WALESH, S. G. (2000). "Street Storage System for Control of Combined Sewer Surcharge", U.S. Environmental Protection Agency, EPA/600/R-00/065.

WILKEN, P. S. (1978). "Engenharia de drenagem superficial", São Paulo, CETESB, $477 \mathrm{p}$.

WROBEL, L.C.(1989).“Métodos numéricos em recursos hídricos”. Associação Brasileira de Recursos Hídricos - ABRH. v.1, 380p. Rio de Janeiro 
YEN, B.C. (1978) "Hydraulic Instabilities of Storm Sewer Flows". In: Urban Storm Drainage: Proceedings of the International Conference held at the University of Southampton. London: Plymouth. p.282-293. London. 